Life Sciences Contribution

Royal Ontario Museum

82

Late Pleistocene Vertebrates from Archaeological Sites in the Plain of Kom Ombo, Upper Egypt

C. S. Churcher

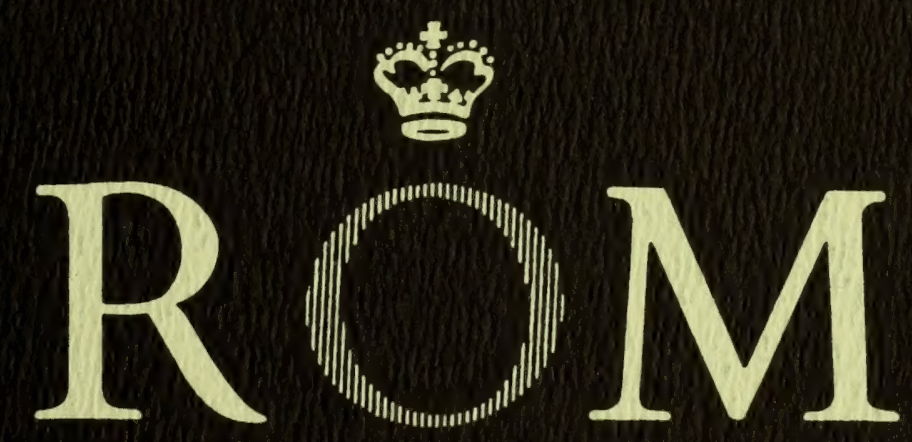





\section{ERRATA}

Late Pleistocene Vertebrates from Archaeological Sites in the Plain of Kom Ombo, Upper Egypt; C. S. Churcher; Royal Ontario Museum Life Sciences Contribution 82

Page 2, line 6:

dans les bois riverains, les savanes et prairies qui les bordent

Page 5, para 2, last line:

(Churcher and Smith, 1972).

Page 8, last two lines:

the Gebel Silsila Formation (Younger Channel Flood Plain Silts), 's' for the Shaturma formation (Upper Wadi Alluvium), and horizontal hachuring for

Page 16, following Khor el-Sil, Sites I and II:

Site III 15,050 B.C. \pm 600 (I-1297) on Shell, Halfan industry (Smith 1967).

Page 139, para. 4, line 1:

Blanc (1956)

Page 145, fifth and sixth entries:

CHURCHER, C. S. and P. E. L. SMITH

1972 Preliminary report on the fauna of Late Palaeolithic sites in Upper Egypt, Science, vol. 177, no. 4045, pp. 259-261.

CHURCHER, C. S.

In press The relationships of the late Pleistocene vertebrate fauna from Kom Ombo, Upper Egypt. In Rushdi Said and B. H. Slaughter, eds. Contributions to the paleontology of Africa. Proc. 75th Anniv. Geol. Surv. Egypt, Ann. Geol. Surv. Egypt. 
Digitized by the Internet Archive in 2011 with funding from University of Toronto 
LIFE SCIENCES CONTRIBUTIONS

ROYAL ONTARIO MUSEUM

NUMBER 82

c. s. CHURChER Late Pleistocene Vertebrates from Archaeological Sites in the Plain of Kom Ombo, Upper Egypt 


\section{ROYAL ONTARIO MUSEUM \\ PUBLICATIONS IN LIFE SCIENCES}

The Royal Ontario Museum publishes three series in the Life Sciences:

LIFE SCIENCES CONTRIBUTIONS, a numbered series of original scientific publications, including monographic works.

LIFE SCIENCES OCCASIONAL PAPERS, a numbered series of original scientific publications, primarily short and usually of taxonomic significance.

LIFE SCIENCES MISCELLANEOUS PUBLICATIONS, an unnumbered series of publications of varied subject matter and format.

All manuscripts considered for publication are subject to the scrutiny and editorial policies of the Life Sciences Editorial Board, and to review by persons outside the Museum staff who are authorities in the particular field involved.

LIFE SCIENCES EDITORIAL BOARD, 1971-1972

Chairman: P. C. SWANN

Director, Royal Ontario Museum

Editors: E. J. CROSSMAN

J. R. TAMSITT

Charles S. Churcher is a Professor in the Department of Zoology, Faculty of Arts and Sciences, and Associate in Dentistry, Division of Biological Sciences, Faculty of Dentistry, University of Toronto, and a Research Associate in the Department of Vertebrate Palaeontology, Royal Ontario Museum.

The publication of Contribution 82 was supported by funds from The Canadian Prehistoric Expedition to Nubia, and the Life Sciences and Art and Archaeology publication budgets of the Royal Ontario Museum.

PRICE : $\$ 10.00$

(C)The Royal Ontario Museum, 1972

100 Queen's Park, Toronto, Canada

PRINTED AT THE BRYANT PRESS LIMITED 


\section{Contents}

List of Figures, $v$

List of Tables, $v i$

Abstract, 1

Résumé, 2

Preface, 3

Introduction, 5

The Kom Ombo Plain, 6

Location, 6

Geology, 7

Distribution and Description of the Archaeological Sites, 8

Ages of the Archaeological Sites, 15

Materials and Methods, 17

Specimens, 17

Laboratory Preparation, 18

Cataloguing, 18

Treatment of the Samples, 18

Mensuration, 19

Systematic Treatment, 20

Pisces

Clarias anguillaris-Nile catfish, quarmouth, 20

Barbus bynni-African barbel, 24

Lates niloticus-Nile perch, 24

Reptilia

Trionyx triunguis-Nile soft-shelled turtle, 26

Aves

Phalacrocorax carbo-cormorant or shag, 27

Ardea cinerea - grey heron, 30

Platalea leucorodia-spoonbill, 30

Phoenicopterus antiquorum - greater flamingo, 31

Plectropterus gambensis-spur-winged goose, 31

Anser albifrons - white-fronted goose, 32

Anser fabalis - bean goose, 32

Branta sp., ?B. bernicla-brent, or B. ruficollis-red-breasted goose, 33

Tadorna ferruginea — ruddy sheld duck, 33

Anas platyrhynchos-mallard, 34 
Anas crecca-teal, 35

Anas penelope-widgeon, 36

Anas acuta-pintail, 37

Anas sp.—unidentified duck, 38

Aythya ferina-pochard, 38

Mergus merganser-goosander, 38

Mergus serrator-red-breasted merganser, 39

Mergus albellus-smew, 39

Milvus migrans — black kite, 40

Pandion haliaetus - osprey, 40

Aquila chrysaëtos-golden eagle, 40

Grus grus-crane, 41

Numenius?arquatus-curlew, 41

Aves indet., 42

Mammalia

Homo sapiens-man, 42

Canis sp., probably either Canis lupaster-Egyptian wolf-jackal, or C. familiaris-domestic dog, 44

Hyaena hyaena-striped hyaena, 44

Lepus capensis-Cape hare, 44

Nesokia indica-Egyptian bandicoot or pest rat, 46

Equus asinus cf. africanus-Nubian wild ass, 48

Hippopotamus amphibius_hippopotamus, 53

The Genera Homoioceras, Syncerus and Bos, 62

Alcelaphus buselaphus - bubal hartebeest, 90

Gazella dorcas-Dorcas gazelle, 113

Gazella leptoceros-rhim or white gazelle, 120

Ammotragus lervia-Barbary sheep, 121

Discussion of the Kom Ombo Faunas, 123

New Observations, 123

Comparison of the Kom Ombo Fauna with Others Reported within the Nile Valley, 127

Comparison with the Cyrenaican Faunas from Wadi Derna and the Synchronous Levels at the Caves of Haua Fteah, Hagfet et-Tera and Hagfet ed-Dabba, 137

Comparison with the Fauna from the Synchronous Levels from the Caves of Ksâr 'Akil, Lebanon, and Wady el-Mughara and Shukbah, Palestine, 140

Summary, 142

Acknowledgments, 143

Literature Cited, 144

Appendix - Catalogue of Specimens by Taxon, Site, and Level, 151 


\section{Figures}

1. Map of northeastern Africa and adjacent Asia, 5

2. Geomorphology and surficial deposits, Kom Ombo Plain, 8

3. Gebel Silsila III from approximately southeast, 11

4. Northwest wall of excavation at Gebel Silsila III, 12

5. Concentration of horncores of hartebeest (Alcelaphus buselaphus), Gebel Silsila III, 13

6. Recovery of mandible of hippopotamus (Hippopotamus amphibius) from Oasis Depression, 14

7. Clarias anguillaris, dorsal aspect of partial cranium, 22

8. Clarias anguillaris, ventral aspect of partial cranium, 23

9. Clarias anguillaris and Lates niloticus, 25

10. Avian skeletal elements, mainly from Gebel Silsila III, 28

11. Homo sapiens, Hyaena hyaena, and Lepus capensis, 43

12. Lepus capensis, aspects of fragmentary mandibles, 45

13. Nesokia indica and Equus asinus, 47

14. Equus asinus cf. africanus, occlusal aspects of cheek teeth, 48

15. Hippopotamus amphibius, damaged and partial skull, 54

16. Hippopotamus amphibius, damaged mandible, 55

17. Hippopotamus amphibius, occlusal aspects of cheek teeth, 56

18. Hippopotamus amphibius, podial elements, 57

19. Hippopotamus amphibius, femoral and tibial fragments, 58

20. Bovine upper molar patterns, 62

21. Bos primigenius, occlusal aspect of left upper $\mathrm{M}^{3}, 63$

22. Bos primigenius, occlusal aspects of upper permanent dentition, 67

23. ?Bos primigenius, occlusal aspects of upper dentition, 68

24. Bos primigenius, occlusal aspects of lower permanent cheek teeth, 69

25. Bos primigenius, frontal aspect of partial female skull, 76

26. Bos primigenius, nuchal aspect of partial female skull, 77

27. Bos primigenius, frontal aspect of partial male skull, 78

28. Bos primigenius and? Homoioceras vignardi, comparative tibial, medial, calcanear and lateral aspects of left astragali, 79

29. Homoioceras vignardi, occlusal aspect of left $\mathrm{M}^{2-3}, 80$

30. Alcelaphus buselaphus, anterior aspect of complete horncores and frontal pedicel, 91

31. Alcelaphus buselaphus, occlusal aspects of upper right cheek teeth, 92

32. Alcelaphus buselaphus, occlusal aspects of cheek teeth, 93

33. Alcelaphus buselaphus, atlas and axis vertebrae, 94

34. Alcelaphus buselaphus, cervical vertebrae ?III, ?VI and ?VIII, 97

35. Alcelaphus buselaphus, pectoral limb elements, 99

36. Alcelaphus buselaphus, lateral aspect of articulated right elbow joint, and proximal ends of ulna and radius, 100

37. Alcelaphus buselaphus, podial elements, 101

38. Alcelaphus buselaphus, metapodial elements, 102

39. Alcelaphus buselaphus, propodial elements, 103 
40. Alcelaphus buselaphus, aspects of left astragalus, 104

41. Gazella dorcas, aspect of damaged male cranium, 116

42. Gazella dorcas and Gazella ?leptoceros, horncores, 117

43. Gazella dorcas, occlusal aspects of cheek teeth, 118

44. Ammotragus lervia, frontal aspect of base of horncores, 122

\section{Tables}

1. Measurements of skulls 8827 (Sebil IV) and 8835 (Sebil va) compared with those of Bos primigenius and B. brachyceros, 75

2. Ratios of skulls 8827 (Sebil IV) and 8835 (Sebil va) compared with those of Bos primigenius, 81

3. Comparative measurements of crania of the Pleistocene Kom Ombo and Recent Gazella dorcas, 115

4. Distribution of the vertebrate taxa, arranged by locality and archaeological site, subsite or horizon, opp. 123

5. Faunal comparisons: Kom Ombo Plain, Qâu, Edfu in Egypt; Wadi Halfa, Singa, Abu Hugar in the Sudan; caves of Haua Fteah, Hagfet et-Tera, Hagfet ed-Dabba in Cyrenaican Libya; caves of Wady elMughara and Shukbah in Israel; Ksâr 'Akil in Lebanon, 132 


\title{
Late Pleistocene Vertebrates \\ from Archaeological Sites in the Plain of Kom Ombo, \\ Upper Egypt
}

\begin{abstract}
Vertebrate remains from Late Palaeolithic sites that date between 15,000 and 10,000 B.C. and that are associated with artifacts of the Sebilian, Sebekian, Silsilian, Menchian, and Halfan industries represent 40 taxa, comprising three fish, one reptile, 22 birds and 14 mammals. These taxa constitute a sample of the fauna that inhabited the Nile River, the woodlands along its banks, and the tree savannas and grasslands on either side within the Kom Ombo graben and on the hills and plains that bound the Nile Valley.

The aquatic and water-loving vertebrates (e.g., Nile catfish, Nile perch, soft-shelled turtle, pest-rat, hippopotamus, wild cattle, and water-birds) indicate the presence of many still pools, marshes, or branches of the ancestral Nile. Wholly terrestrial vertebrates (e.g., Dorcas gazelle, bubal hartebeest, Cape hare, Nubian ass, and Barbary sheep) represent elements of dry grassland or bushveld savanna environments.

Vertebrate faunas of similar age from the Sudan, Cyrenaica, and elsewhere in the Nile Valley bear a striking resemblance to that from the Kom Ombo deposits and attest to a uniform faunal province in northeast Africa during the Late Pleistocene and Early Holocene. This faunal province extended from the Central Sudan to the Gulf of Sirte and supported a fauna that had a facies similar to that now present in the Southern Sudan and parts of East Africa.

The synchronous faunas known from Palestine and Lebanon differ in the presence of many Eurasian taxa (e.g., roe deer, Mesopotamian deer, red deer, wolf, red fox, marten, and smaller northern carnivores). The presence of oryx and hartebeest in some of the Palestinian and Lebanese faunas, together with less unexpected elements such as wild cattle or ass, emphasizes the interchange of taxa across the Sinai Peninsula and Isthmus of Suez during the Late Pleistocene and Early Holocene. The presence of man in settled communities in the Nile Valley and Delta is suggested as a possible reason for the lack of interchange of mammalian taxa between Africa and Asia Minor during Middle Holocene to Historic times.
\end{abstract}




\section{Résumé}

Les ossements des sites du Paléolithique récent qui ont livré des outils du Sébilien, Sébekien, Silsilien, Menchien et Halfan, ont permis d'identifier 40 taxons de Vertébrés (Poissons 3, Reptils 1, Oiseaux 22, Mammifères 14). Ces vertébrés constituent une échantillon de la faune qui vivait dans le Nil, dans les bois riverains, les savanes et prairies qui les bordelit dans le graben de Kom Ombo de même que sur les collines et les plaines qui limitent la vallée du Nil. Cette faune peut être datée de 15,000 à 10,000 avant J.-C.

Les espèces aquatiques ou riveraines comme le poisson-chat quarmouth, la perche du Nil, le Trionyx tyrsé, le bandicoot égyptien, l'hippopotame, le bétail sauvage et certains oiseaux indiquent la présence de marais, d'étangs tranquilles ou de branches du Nil ancien. Les espèces plus exclusivement terrestres comme la gazelle Dorcas, l'antilope bubale, le lièvre du Cap, l'âne nubienne et le moufflon de Barbarie indiquent la présence de prairies sèches ou de savanes herbeuses ou boisées.

Cette faune de Kom Ombo ressemble fortement à la faune mise au jour dans divers sites synchrones du Soudan, de la Cyrenaïque et d'ailleurs dans la vallée du Nil. Cela nous permet d'affirmer la présence d'une province faunistique uniforme en Afrique du nord-est durant le Pléistocène final et le début de l'Holocène. Cette province s'étendait du Soudan central jusqu'au Golfe de Syrte et ses caractéristiques rappellent celles de la faune qui occupe aujourd'hui le Sud du Soudan et certaines régions de l'Afrique de l'Est.

Les gisements du même âge trouvés en Palestine et au Liban ont livré une faune différente qui contient plusieurs taxa eurasiatiques (chevreuil, daim mésopotamien, cerf commun, loup, renard, martre et plusieurs petits carnivores du nord). L'association de l'oryx et de l'antilope bubale en certain des faunes paléstiniennes et libanaises, ainsi que les éléments normals comme le bétail sauvage ou l'âne indique le passage de plusieurs taxa à travers la Péninsule du Sinaï et l'Isthme de Suez durant le Pléistocène supérieur et le début de l'Holocène.

La présence de communautés humaines sédentaires dans la Vallé du Nil et son Delta pourrait être une raison de l'interruption de ces échanges fauniques entre l'Afrique et le Moyen Orient depuis l'Holocène moyen. 


\section{Preface}

In 1961 the Government of Canada accepted an invitation from UNESCo to contribute to the International Nubian Salvage Campaign in which more than twenty nations eventually participated. Through the National Museum of Canada I was asked to direct a prehistoric archaeological expedition to the area of the United Arab Republic which was to be affected by construction of the new High Dam at Aswan. After a survey along the Nile from Aswan to the Sudanese border it was decided to concentrate the Canadian efforts in the area around the town of Kom Ombo in Upper Egypt. Although this zone lies just north of Nubia proper and outside the reservoir, it was already undergoing extensive archaeological damage since it was here that the U. A. R. Government had decided to resettle most of the Nubian population to be displaced by the rising waters of what is now Lake Nasser.

Most of the Kom Ombo Plain is composed of Pleistocene silts which are potentially good agricultural land, and already by 1961 those parts of the Plain which were not already under cultivation were being levelled by heavy machinery and dissected by irrigation canals. Archaeologists had known for almost forty years, since the investigations of Edmond Vignard in the 1920s (Vignard, 1923), that the Plain was very rich in prehistoric sites, but no serious work had been done there since. A rapid visit to the Plain in January, 1962 convinced me that an even greater emergency existed here than in Nubia itself and, with the generous cooperation of the UNESCO and U. A. R. authorities, the Canadian expedition was permitted to choose a concession here. We began our salvage investigations in October, 1962 and ended them in April, 1963 after six months of nearly continuous work. Much of this involved keeping just ahead of the advancing bulldozers, and by the time the season ended most of the area containing sites had been destroyed. Since similar destruction of sites had been going on in the Kom Ombo Plain since the beginning of the 20th century, those we were able to salvage undoubtedly represent only a small fraction of the sites originally present. Nevertheless even this sampling has helped to revise many of our previous ideas about the late Palaeolithic cultures of Egypt, while the faunal analysis presented here by Dr. Churcher occupies a special place in the study of the prehistory and palaeontology of the Nile Valley.

Not a great deal is known of the Pleistocene fauna of Egypt, for various reasons, and the amount found in archaeological contexts is very small. Most of what is known belongs to the final Pleistocene, but the major discoveries were made many years ago and in most cases the contexts, both archaeological and geological, were uncertain. This is especially true of the largely surface collections made by Vignard at Kom Ombo in the early 1920s. In addition the identifications of some taxa posed certain problems. The new collections made by us in 1962-63 within a more precise framework offered an excellent opportunity to re-examine these problems with profit to the palaeontological as well as the archaeological specialists.

It was originally planned to publish the complete results of the Canadian expedition, archaeological and palaeontological, simultaneously. However, 
the large quantities of archaeological material collected have required a longer time for analysis and writing-up than was anticipated, and this delay was increased by my move from Toronto to Montreal in 1966 and by subsequent moves from one laboratory to another. Up to the present time preliminary reports only have been published on the archaeological results (sec especially Smith, 1966, 1967). In addition it quickly became apparent that the unusual richness of the faunal materials collected (probably the richest yet made for the Pleistocene of the lower Nile Valley) deserved a more complete publication than is normal in an archaeological report. The decision was therefore made several years ago to publish this part separately and in advance of the archaeological section. We were fortunate in attracting the interest of Dr. C. S. Churcher who has had a long personal and professional familiarity with Africa and African palaeontology and who has often worked closely with prehistoric archaeologists in the past. The opportunity to publish the results of his study in such detail in the ROM series is an additional piece of luck. In my final archaeological report Dr. Churcher's interpretations and conclusions, particularly those relating to subsistence activities and to seasonality of occupations, will be presented in condensed form and related to the archaeological materials; but the present memoir will remain the principal reference for the prehistoric fauna of the Kom Ombo Plain and indeed a major source for all future studies in the palaeoecology of Northeastern Africa.

In this publication I must take the responsibility for the archaeological information provided and for the chronological and cultural frameworks used. Our knowledge of the Late Palaeolithic prehistory of the lower Nile Valley is changing rapidly these days. Thus some modifications in the archaeological, chronological and climatic interpretations given here in brief form may be expected by the time my own report on the prehistory of the Kom Ombo Plain appears. However, I believe that the framework presented here is an adequate reflection of our understanding at the present time.

My own thanks go to the Government of Canada for their generosity in responding to the UNESCO appeal to help in the Nubian emergency, and to the University of Toronto for some financial help as well as for granting me a leave of absence in 1962-63. I must also thank Dr. Loris S. Russell, former Director of the National Museum of Canada (now of the Royal Ontario Museum) for his interest in setting up the Expedition and for arranging with Dr. Churcher to make the present study; Dr. William Taylor, Jr., now Director of the National Museum of Man, Ottawa, for help on several occasions; my assistant in the field, Mr. Morgan Tamplin, and Dr. Robert Fulton of the Geological Survey of Canada who helped establish the geological contexts of the sites investigated; and the Antiquities Service of the United Arab Republic who encouraged our research at Kom Ombo and through whose generosity the collections were permitted to come to Canada. Finally, all prehistorians working in northern Africa will share my gratitude to Dr. Churcher for his major contribution to our understanding of the early cultures of the Nile Valley. 


\section{Introduction}

Vertebrate faunas of Late Pleistocene age from the valley of the River Nile are not well known. The fauna from Kom Ombo was first noticed by Edmond Vignard in his archaeological investigations of the area in 1919 and 1924, and later described by Claude Gaillard in 1934. Subsequent to Vignard's departure from Egypt in 1924, little or no serious archaeological or geological investigations of the area were carried out and the Kom Ombo Plain was progressively levelled and brought under irrigation from the Aswan Barrage for cotton and sugar-cane. The levelling of the surface and the construction of the irrigation ditches destroyed or obliterated many of the sites described by Vignard. In 1960 it was decided to level the remainder of the irrigable land and to settle on these reclaimed lands the people to be displaced from Egyptian Nubia to the south by the construction of the High Dam at Aswan.

UNESCO encouraged and sponsored an attempt to salvage the archaeological sites of Nubia that would be flooded by the creation of Lake Nasser or its associated works, and the survey and salvage of the archaeological sites in the Kom Ombo Plain was part of this programme. The two expeditions that were organized to carry out the Kom Ombo salvage during the winter of 1962-1963 were the Yale University Prehistoric Expedition to Nubia, under the directorship of Charles A. Reed, which excavated several sites in the Kom Ombo Plain between October 1962 and March 1963, and the Canadian Prehistoric Expedition to Nubia, under the directorship of P. E. L. Smith, supported by the Government of Canada through the National Museum of Canada and with some assistance from the University of Toronto, which excavated other sites in the Plain between October 1962 and April 1963. This paper is a description and discussion of the vertebrate remains obtained from the sites excavated by the Canadian Expedition, of which a preliminary account has already been published (Churcher, 1972).

I was not a member of the Canadian Expedition and therefore did not visit the sites or assist in the archaeological excavations or geological investigations in 1962-1963. As I have no first-hand knowledge of the geography, topography, geology, or archaeology of the Kom Ombo region, all the introductory passages are culled from the works of others or from conversations with members of the two expeditions.

C. S. C. 


\section{The Kom Ombo Plain}

\section{Location}

The widening of the valley of the Nile River that is called the Kom Ombo Plain lies mainly on the east, or right bank, of the Nile in Upper Egypt and is centred about the town of Kom Ombo (Fig. 1). Kom Ombo is located about latitude $24^{\circ} 26^{\prime}$ north and longitude $32^{\circ} 57^{\prime}$ east and about 40 kilometres north of Aswan and 50 kilometres south of Edfu. The Plain covers an area of about 400 square kilometres and is oval or trapezoidal in outline, with the long axis lying east of the present Nile River, and its western margin formed by the river's course.

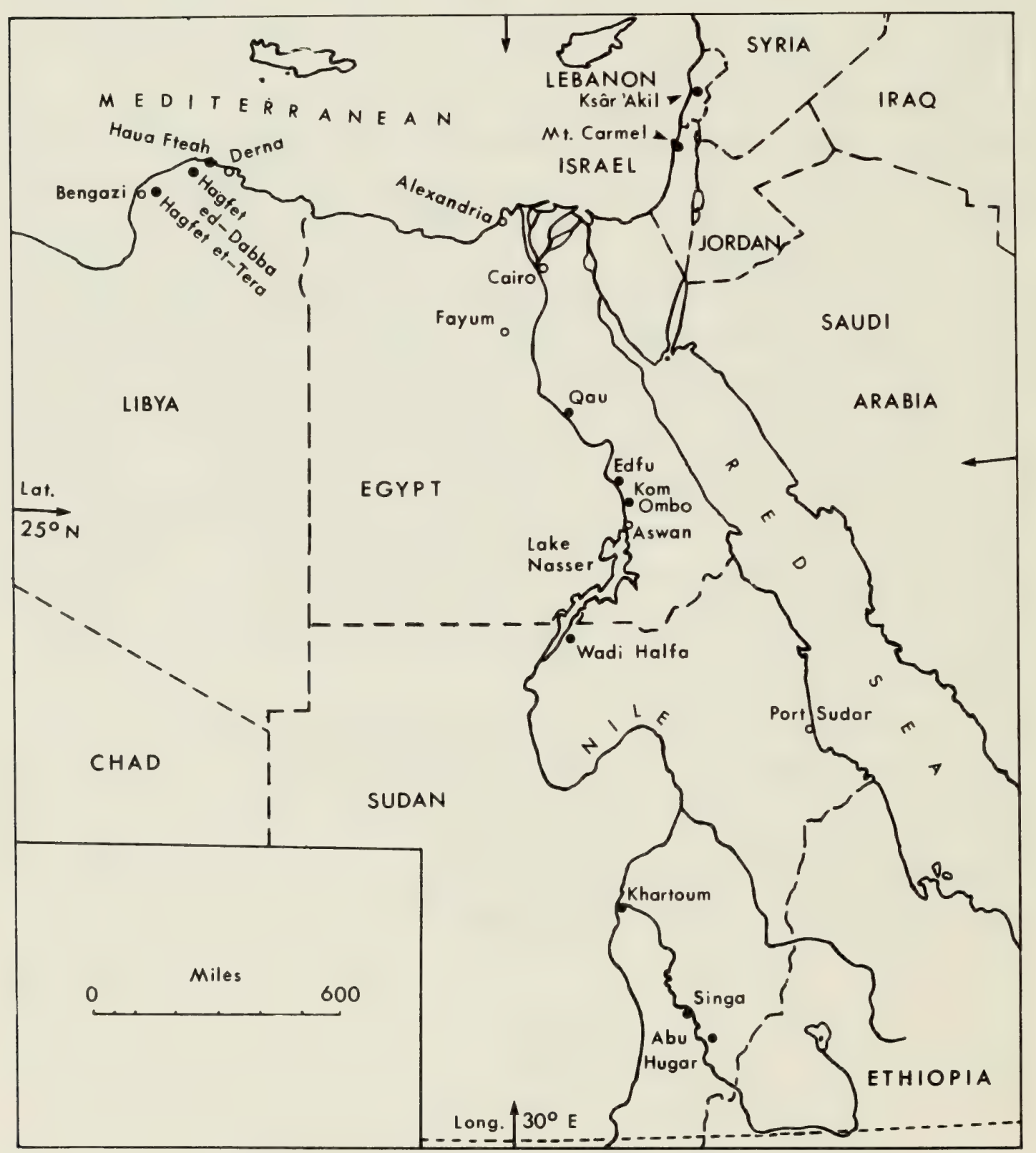

Fig. 1 Map of northeastern Africa and adjacent Asia Minor showing the location of Kom Ombo and other sites mentioned in the text from which equivalent Late Pleistocene horizons have been reported. Solid dots indicate archaeological or palaeontological sites and hollow circles other localities. 


\section{Geology}

The structure and geology of the Kom Ombo Plain were described by Sandford and Arkell (1933), Fulton (1964), and Butzer and Hansen (1965, 1968). The present account is a selected précis mainly from Butzer and Hansen (1968). The Plain occupies part of the Kom Ombo Graben, where it is crossed by the Nile River, and is bounded on the north by the Silsila Fault that strikes N. $65^{\circ} \mathrm{W}$. and on the south by a series of minor faults striking mainly N. $85^{\circ} \mathrm{W}$. (Fig. 2). The walls of the graben that form the hills bounding the plain to the north and south are formed of Nubian sandstone. On the east the wadis Kharit and Shait enter where they pass through the early Pleistocene Burg el-Makhazin gravel deposits. Across the Nile to the west occurs the extensive Darb el-Gallaba gravel plain of similar age. The depression that formed the Plain may have originated in the late Tertiary as a result of tectonic action.

The surface of the Plain is formed of interbedded silts and sands laid down by the ancestral Nile as it flowed in now-abandoned channels or by tributary drainages that now comprise the Wadi Shait and Wadi NatashWadi Kharit drainages. This surface lies at elevations of about 90 metres above sea level and more than 20 metres above the present Nile flood plain. Five formations were defined by Butzer and Hansen (1968):

Formal Designation (Informal Names)

Younger

Shaturma Formation (Upper Wadi Alluvium)

Ineiba Formation, Malki Member Only

(Lower Wadi Alluvium)

Gebel Silsila Formation. Darau Member Only (Younger Channel Silts)

Masmas Formation (Older Flood Plain Silts)

Korosko Formation (Basal Sands and Marls)
Ages and $C_{14}$ Dates - B.C.: A.D. (Radiocarbon Sample Numbers)

4,000-3,000 B.C.

$15,000-10,500$ B.C

$15,450 \pm 300(\mathrm{I}-2179)$

$10,070 \pm 205(\mathrm{Hv}-1205)$

$15,000-10,500$ B.C.

$15,050 \pm 600$ (I-1297, oldest)

$10,450 \pm 400$ (I-1300, youngest)

(Range of 11 determinations)

$22,000-16,000$ ? B.C.

$16,350 \pm 310(\mathrm{I}-2060)$

$15,150 \pm 400(\mathrm{I}-2178)$

25,000 B.C. (terminal date)

$25,250 \pm 950(\mathrm{I}-2061)$

Older

Only the silts of the Darau Member of the Gebel Silsila Formation concern us in this report, as all the middens from which vertebrate remains have been obtained are considered to lie within that unit. Two later members of the Gebel Silsila Formation (the Arminna and Kibdi Members) are apparently not found on the Kom Ombo Plain, although they occur in Nubia. 


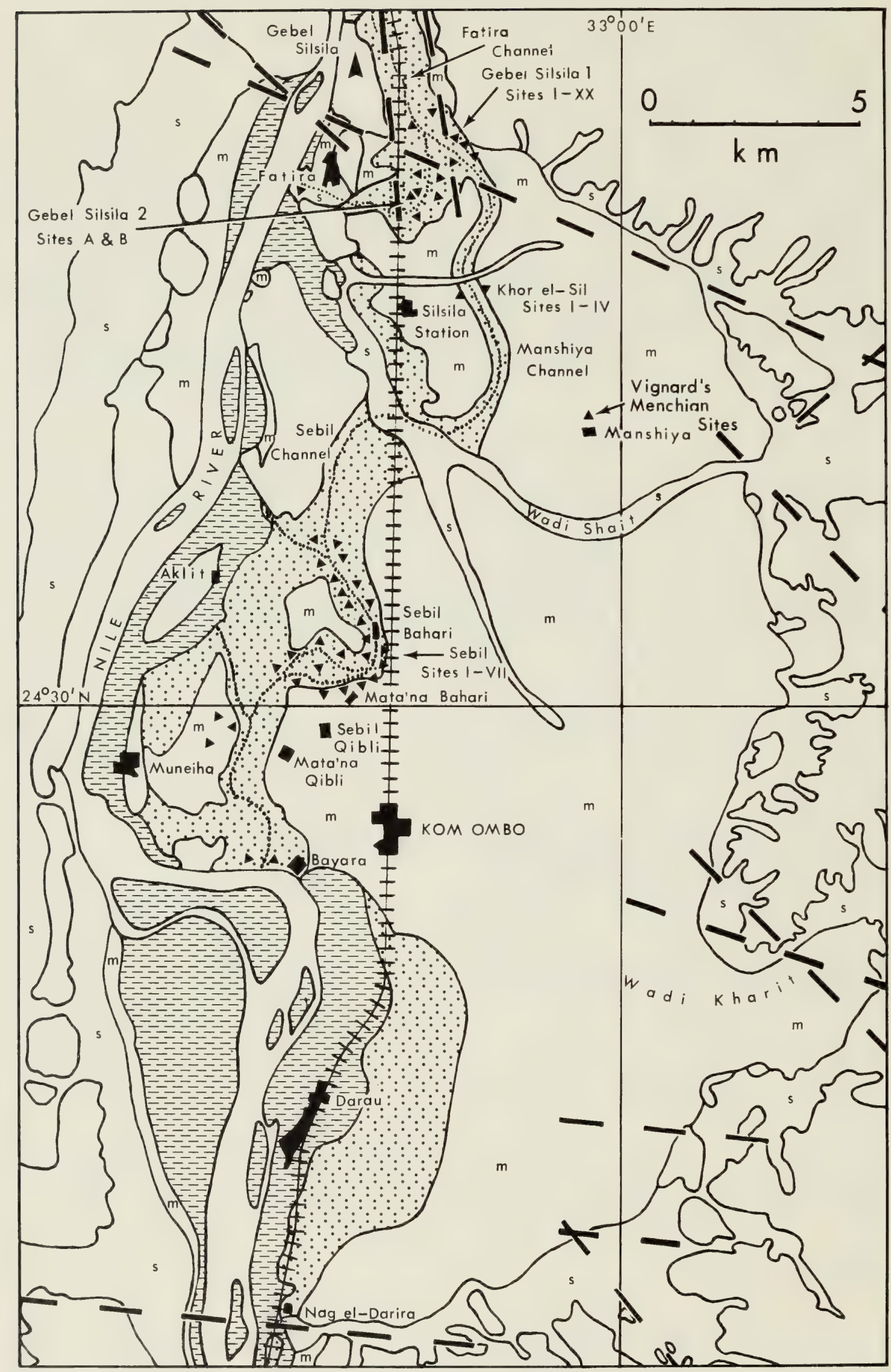

Fig. 2 Geomorphology and surficial deposits of the Kom Ombo Plain. Faults in the Nubian sandstone that bound the graben that forms the Kom Ombo Plain are indicated by heavy broken lines. The surficial deposits are indicated by ' $\mathrm{m}$ ' for the Masmas Formation (Older Channel Flood Plain Silts), stippled areas for Shaturma Formation (Upper Wadi Alluvium), and horizontal hachuring for the Gebel Silsila Formation (Younger Channel Flood Plain Silts), 's' for the 
The Gebel Silsila Formation (Darau Member) forms a band lying east of the present Nile flood plain from Nag el-Darira in the south to Silwa Qibli (Kagug village) in the north. The surface of these silts lies at an elevation just above 100 metres over an area of some 75 square kilometres and attains a maximum thickness of more than 14 metres. The formation has been dissected by three successive erosional channels, phases of the late Pleistocene Nile, which comprise:

Channel $A$ phase at 100-102 metres, 12 metres above modern flood plain, containing material $\mathrm{C}_{14}$ dated at $c$. 15,000-12,500 B.C., recorded at Gebel Silsila 2A, Sebil, Darau, and possibly Khor el-Sil;

Channel $B$ phase at 98-99 metres, 9 metres above modern flood plain, containing material $\mathrm{C}_{14}$ dated at $c .12,000-11,000$ B.C., recorded at Gebel Silsila I and 2B and at Sebil and Darau;

Channel $C$ phase at 97 metres, 7 metres above modern flood plain, containing material $\mathrm{C}_{14}$ dated at a guess date as late as 10,000 B.C., recorded between Bayara and Sebil Qibli (Butzer and Hansen, 1968, p. 146).

\section{Distribution and Description of the Archaeological Sites}

The sites from which the vertebrate materials were obtained lie along the banks of ancient Nile channels, referred to here as the Sebil and Manshiya (Menchia) Channels, with some of the latter's associated channels that pass near Fatira, and from Bayara, near Kom Ombo. All these sites except that referred to as Gebel Silsila III are on the surface or unstratified. The section in the Gebel Silsila area investigated by the Yale University Expedition is designated by them as Gebel Silsila 2, with subdivisions $2 \mathrm{~A}$ and $2 \mathrm{~B}$. The area to the north of this, investigated by the Canadian Expedition, may be considered as Gebel Silsila 1, with individual localities given Roman numerals. In this paper sites excavated by the Canadian Expedition are indicated by name and locality number, e.g., Gebel Silsila III or GS III.

The sites on the banks of the channels can be stratigraphically allocated to the Older A, Middle B and Younger C Channels, thus:

Channel A c. 15,000-12,500 B.C.

GS III (Silsilian) and Khor el-Sil II and III (supported by $\mathrm{C}_{11}$ determinations )

Channel B c. 12,000-11,000 B.C.

GS 2B, GS III (Sebekian) (supported by $\mathrm{C}_{11}$ determinations), Sebil VII? (suggested by $C_{1: 4}$ determinations), Menchian at GS XIII?

Channel C Guess age possibly as late as 10,000 B.C. Probably most of the Sebil sites.

the Recent Nile Flood Plain deposits. The distribution of the archaeological sites from which vertebrate specimens have been recovered is indicated by solid triangles and the larger areas of concentration are named. e.g.. 'Sebil Sites I-VIr'. The sites usually lie on the sides of channels of the Late Pleistocene or Holocene Nile, e.g., 'Manshiya Channel', and chiefly in or on the surface of the Gebel Silsila Formation. Geomorphological data mainly from Butzer and Hansen (1968, p. 89, Fig. 3-1). 


\section{BAYARA LOCALITIES A AND B}

These sites are located on the right bank of the Nile, west of Kom Ombo, and occur in a small area of deep deposits (Gaillard, 1934) that have produced relatively little fossil material and all from the surface.

FATIRA AREA, LOCALITIES A, B, C, D AND D1 (1962); E (1963)

These sites are located on the surface of the limestone bedrock and contained in the overlying silt remnants. Locality $\mathrm{C}$ produced bones that were given to Dr. C. A. Reed in the field.

\section{OASIS DEPRESSION LOCALITY}

This locality lies within Gebel Silsila 1 Area, between the railway and the eastern scarp and consists of a shallow, deflated depression, with surface and subsurface deposits. It was subdivided into sectors $A-G$ for collecting purposes.

\section{GEBEL SILSILA AREA}

Fulton (MS 1964) described this area as "a broad sand and silt filled pass" leading north from the Kom Ombo plain between Gebel Silsila and the sandstone escarpment to the east. The pass consists of "an elongate channel-like depression", which is defined by a 2 to 4 metre escarpment on the east and poorly defined on the west, where it merges into "sandy ridges and knolls separated by shallow depressions." "All the major occupation sites are marked by accumulations of broken exotic stones", and most sites are surface occurrences that generally lie on the higher portions of the area.

The Gebel Silsila sites are located at the northern end of the Kom Ombo Plain, near Gebel Silsila, and on the banks of the Manshiya Channel near its junction with the Fatira Channel, in the fan deposits of Wadi Shait.

The Gebel Silsila Series of Archaeological Sites, Gebel Silsila Area 1, Localities I-XX

GS I Surface occurrence, apparently Sebilian, immediately north of Oasis Depression.

GS II This site represents mixed Menchian, Sebilian, and perhaps Silsilian materials on the surface of a small depression, east of GS III, and may have been randomly mixed by stream action.

GS III A stratified occupation site that lies as high or higher than the other sites (Figs. 3 and 4). It is older than the other Gebel Silsila 1 series of archaeological sites, for if the silt that buried Gebel Silsila III had been deposited after the surface sites had been occupied, silt would have covered them all (Fulton, MS 1964). It was extensively excavated in $1962-1963$ by the Canadian Expedition and was found to contain in the upper zone Sebekian and in the lower zone Silsilian assemblages, with a mixed cultural layer separating them and some other mixed materials lying on and near the surface (Fig. 4). The site was on the sides of what had been originally a small depression, about 10 metres across, in the former flood plain east of the Manshiya Channel. The materials mainly on the edge of the 


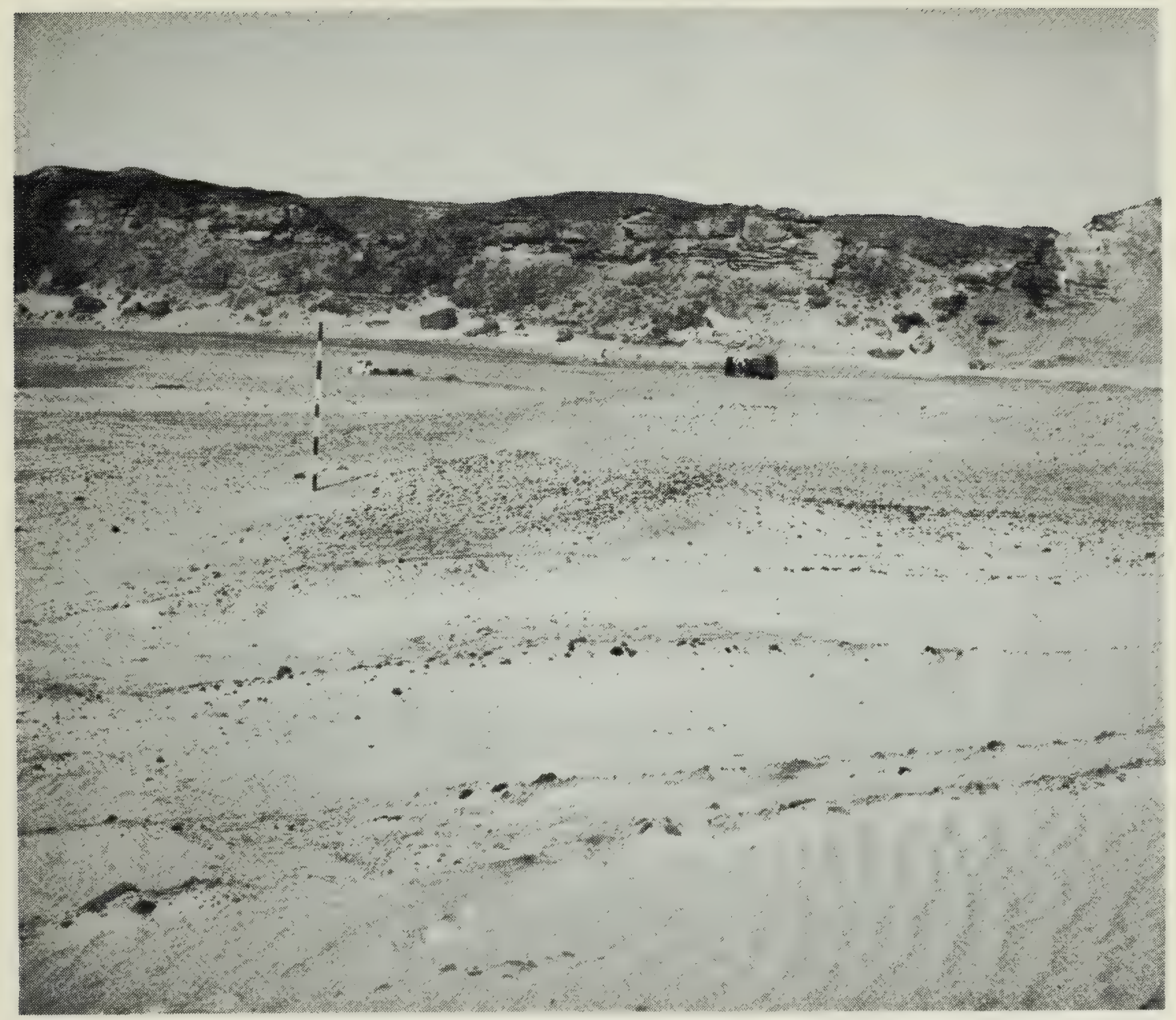

Fig. 3 View of Gebel Silsila III from approximately southeast showing the deflated sandy surface of the Kom Ombo Plain with patches of lag gravels. The Gebel Silsila fault in the Nubian sandstone forms the northeast wall of the graben and is seen in the background. Gebel Silsila III lies to the left of the Land-Rover near the foot of the scarp. (Photograph by P. E. L. Smith.)

depression, although a few bones and artifacts were found at the base covered by massive silt (Fig. 5). The occupation levels had been sealed in and preserved by hard, calcitic silts deposited by floods that occurred either after or perhaps caused its abandonment by the Sebekian occupants (Smith, 1967, 1968). For the purpose of the present paper, the four levels of the site are named: Level 0 for the mixed materials from the surface and subsurface; Level 1 for the Sebekian occupation level; Level 2 for the mixed Sebekian and Silsilian level; and Level 3 for the lower (Silsilian) occupation level.

GS IV Surface occurrence, mainly Silsilian, with some Sebilian intrusions.

GS v Surface occurrence, mainly Silsilian, with some mixture of Sebekian and Sebilian.

GS VI Surface occurrence, predominantly Silsilian.

GS VII Surface occurrence, mixed Sebilian, Silsilian and Sebekian.

GS VII Surface occurrence, mixed Sebilian, Silsilian, Sebekian and Menchian. 


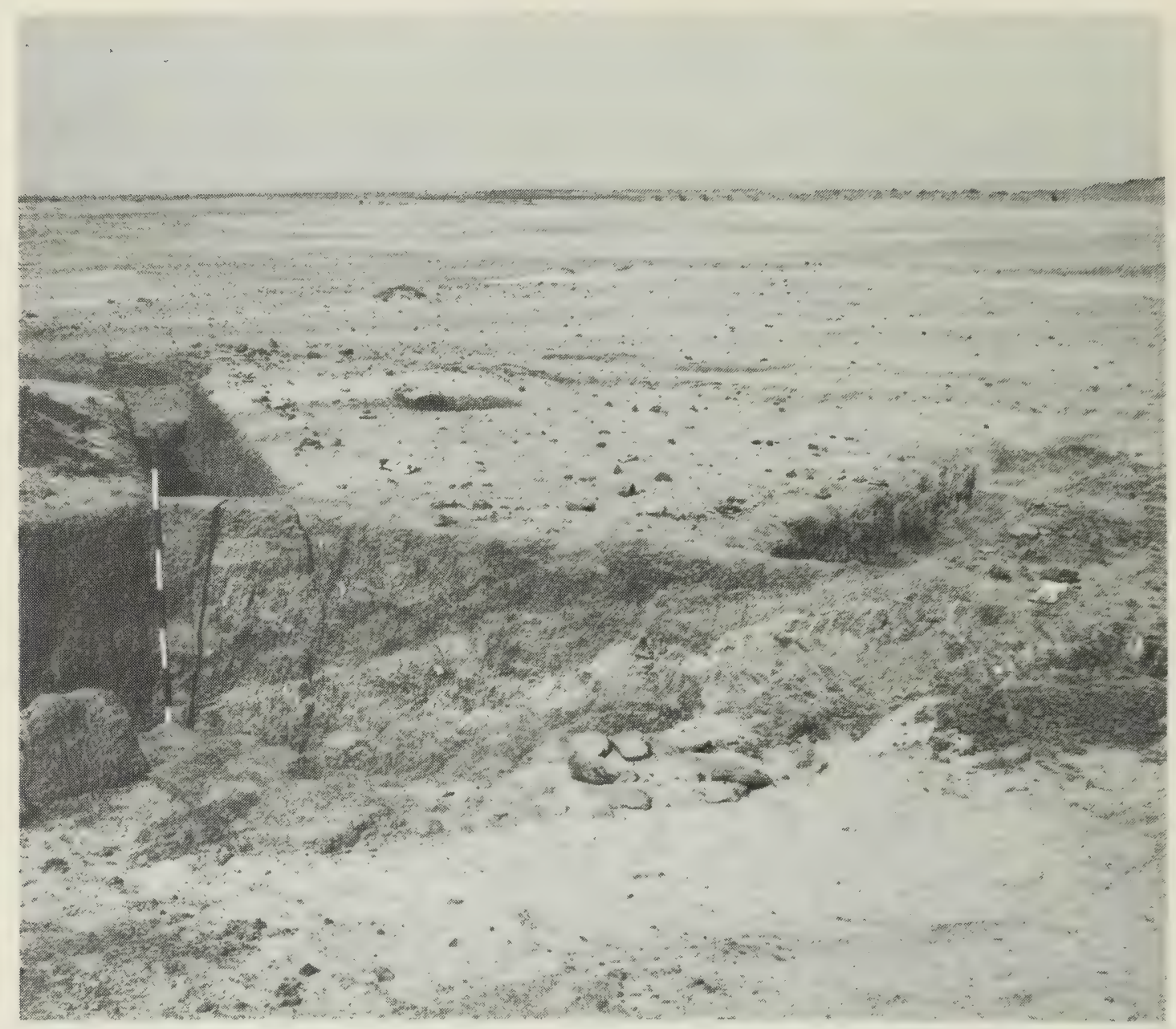

Fig. 4 View of the northwest wall of the excavation at Gebel Silsila III looking across the Kom Ombo Plain to the northwest. The position of the Nile River is indicated by the tops of the trees in the middle distance. The whitened areas in the wall indicate, from bottom to top respectively, Level 3 - Silsilian Industry (beneath the lower white line), Level 2 - mixed Silsilian and Sebekian industries (beneath the hachured area), Level 1 - Sebekian Industry (obliquely hachured area), and Level 0 - disturbed surface and subsurface mixed Silsilian and Sebekian industries. The layers dip towards the centre of the depression around which the site is concentrated. The diagonal trench is visible beyond the stadia rod. (Photograph by P. E. L. Smith.)

GS IX Surface occurrence, Silsilian.

GS x Surface occurrence, Sebilian.

GS XI Surface occurrence, Sebilian.

GS XII Surface occurrence, Sebilian.

GS XIII A series of surface occurrences (mixed Sebilian and Menchian) and a series of small mounds containing flint artifacts, ash, burned stones, silt, shells, and bones. The mounds are predominantly Sebilian with some Menchian admixture.

GS XIV Surface occurrence, Sebilian and Menchian mixed.

GS XV Surface occurrence, Sebilian and Menchian mixed.

GS XVI Surface occurrence, Sebilian and Menchian mixed.

GS XVII Surface occurrences, Sebilian with possible Menchian intrusions.

GS XVIII Surface occurrence on slope of depression, probably not in situ, mainly Sebilian. 


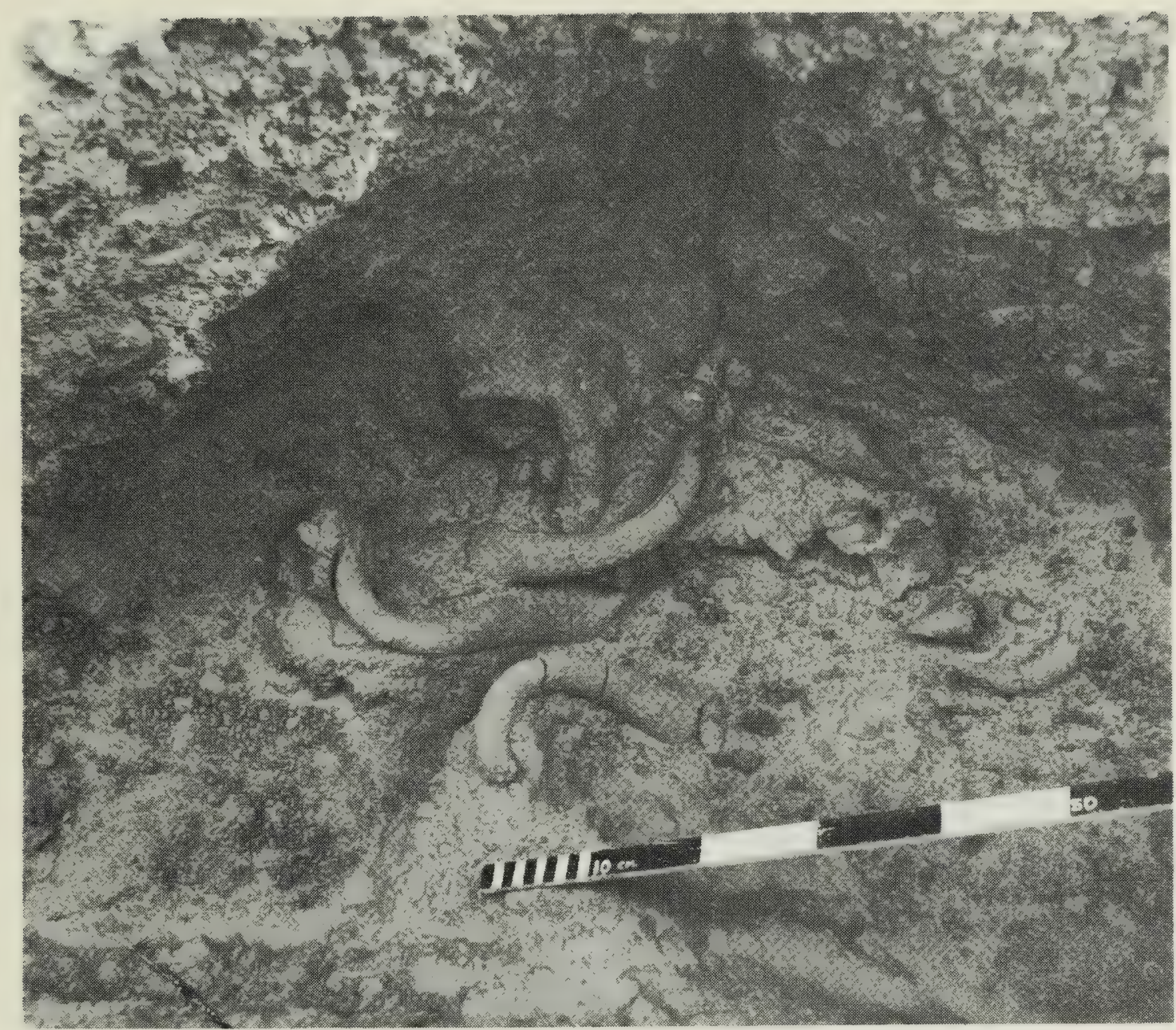

Fig. 5 Concentration of horncores of hartebeest (Alcelaphus buselaphus) within the diagonal trench at Gebel Silsila III. (Photograph by P. E. L. Smith.)

GS XIX Small collection of basalt flakes and grinding stones buried in silt; age and affiliation uncertain.

GS xx Surface occurrence, mixed Silsilian and Sebilian.

KHOR EL-SIL AREA

This is an area of "nearly flat to gently rolling" topography "with broad ridges separated by elongate, shallow depressions" (Fulton, MS 1964). The sites are located on the right side of the Manshiya Channel east of Silsila Station and are found on the ridges as part of a surface veneer that contains "irregularly shaped concretions".

KS I A surface site with an unnamed microlithic industry.

KS II Probably an encampment of the Halfan industry and contains grinding stones and hearths.

KS III An encampment and hearth of the Halfan industry.

KS IV A surface site with an unnamed microlithic industry, somewhat disturbed by stream action; there may be an admixture of materials from the neighbouring $\mathrm{KS}$ II site.

KS Misc. These materials represent surface finds from between KS II and III. 


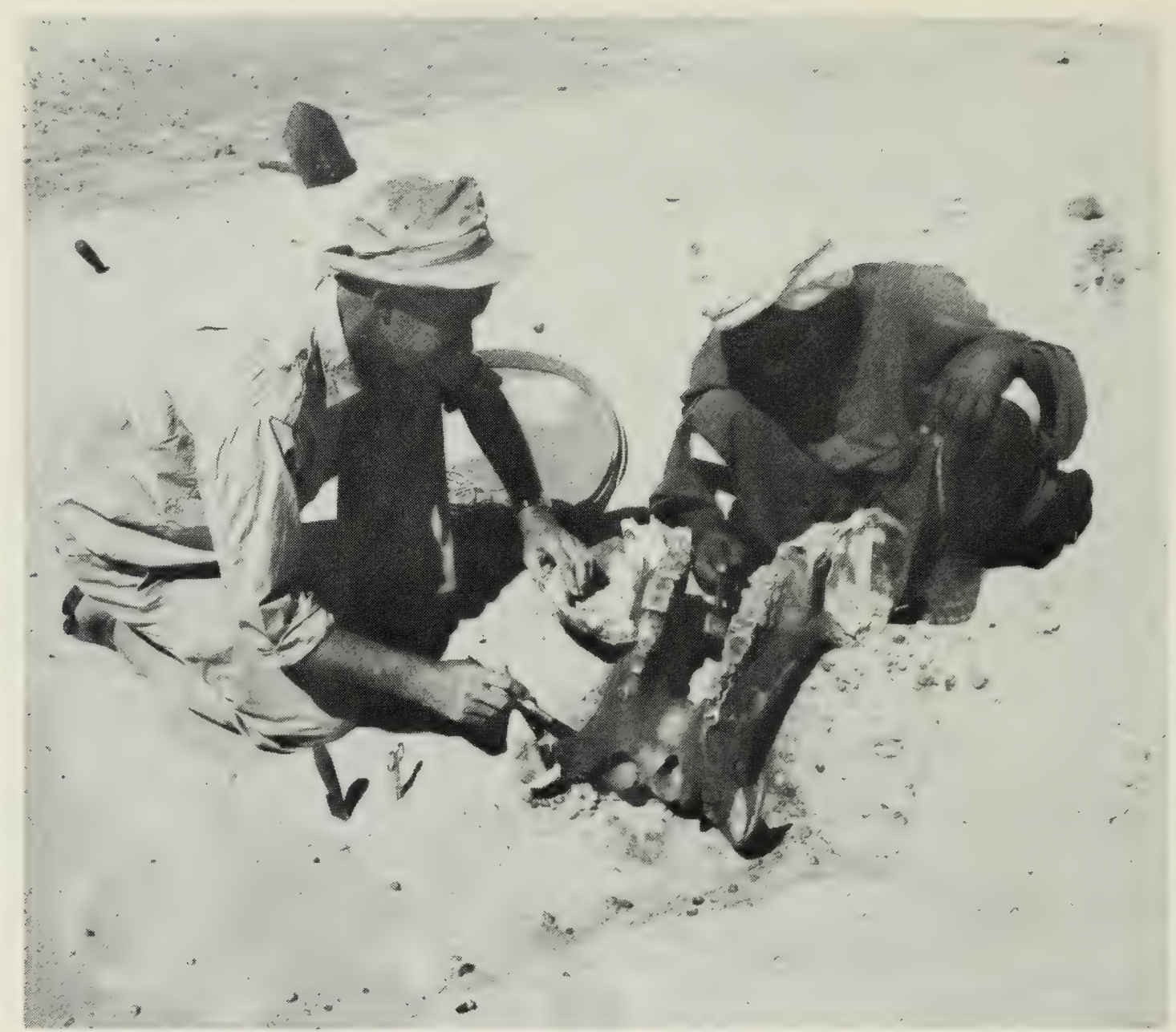

Fig. 6 Recovery of the mandible of hippopotamus (Hippopotumus amphihius) from Oasis Depression. (Photograph by P. E. L. Smith.)

THE SEBIL BAHARI-BAYARA AREA

This area is dominated by a "string of troughs and closed depressions which trends north from Bayara, swings west east of Mata'na Bahari and trends north once again south of Sebil Bahari" (Fulton, MS 1964). The major chain of depressions probably marks a former channel of the Nile which may have remained water-filled for some time after the main channel became located to the west near its present position. Accumulations of pebbles, bones, and shells and a band of oxidised, partiallycemented, well-sorted sand mark at least one well-defined water-level in this embayment (Fulton, MS 1964).

\section{The Sebil Series of Archaeological Sites}

These sites consist of isolated concentrations of tools, shells, and bones on or eroding from the surface of the Plain on the north-northwest banks of the Sebil Channel at various levels.

$\mathrm{S}_{\mathrm{I}} \quad$ Subdivided into $\mathrm{a}, \mathrm{b}, \mathrm{c}, \mathrm{d}$, and e.

$\mathrm{S}$ II Subdivided into $\mathrm{a}$ and $\mathrm{b}$.

S III Subdivided into a, b, c, d, and e.

$\mathrm{S}$ IV Undivided.

S v Subdivided into $a, b, c, d$, and e.

$S$ VI Undivided.

All these sites are located on the Sebil Channel at B and/or C levels.

$\mathrm{S}$ VII Undivided. Located on Sebil Channel at B or possibly A levels. 


\section{Gaillard's Sebilian Fauna}

Gaillard's (1934) described materials were recovered by Vignard (1923) around Kom Ombo from palaeolithic sites ascribed to the Sebilian industry. The locations given in Gaillard's text are slightly ambiguous, e.g., "de Kom Ombo et de Sébil" (p. 2), "aux environs de Kom Ombo et de Sébil" (p. 3), and "Tous les ossements du premier niveau, selon de M. Vignard, ont été trouvés en surface ou plus ou moins ensablés, au milieu de l'industrie en diorite ou en grès quartzeaux près de l'endroit marqué $\neq$ sur la carte" (E. Vignard, letter to C. Gaillard, from Kom Ombo, dated November 6, 1923, in Gaillard, 1934). The "endroit marqué $\neq$ " is about 1 kilometre northwest of the village of Sebil on Gaillard's (1934, p. 4, Fig. 1) map. Gaillard added in a footnote that since 1923 "plusieurs autres campements ont été visités". As the Sebil Area localities recorded by members of the Canadian Expedition comprise many isolated concentrations of tools and bones on the surface of the Kom Ombo Plain on the north-northwest banks of the Sebil Channel near the present village of Sebil, the bones studied by Vignard and Gaillard certainly came from the Sebil Area as recognised by the Canadian Expedition.

Gaillard (1934, p. 7) stated "La plupart des ossements fossiles de Sébil et de Kom Ombo ont été trouvés associés à l'outillage de second niveau" and that "Les lieux de gisement ou de campement sont très nombreux". He also mentioned a third level "Dans les stations de la troisième période il n'a été découvert que de rares fragments osseux et des dents isolées de quelques mammifères" (Gaillard, 1934, p. 8). Unfortunately Gaillard did not indicate from which level the specimens came, nor whether all came from near Sebil, referring only to the provenance as "Sébil-Kom Ombo" in most instances.

The specimens recovered by Vignard and described by Gaillard (1934) I presume to be derived mainly from the Sebil Area localities and, as some were found on the surface in sands, those that appear from his illustrations to have been deflated or eroded by desert aeolian weathering will be considered to be from the surface levels. The hippopotamus bones I consider to be Sebilian, perhaps of differing ages, as Gaillard (1934, p. 11) stated "Les ossements d'hippopotame sont de l'ancien niveau; les dents isolées proviennent du niveau récent à microlithes".

\section{Ages of the Archaeological Sites}

The ages of the various vertebrate midden deposits lie within the approximate range of 15,000 to 10,500 B.C. Eleven radiocarbon dates are available, of which ten are associated with the vertebrate fauna. The radiocarbon determinations are:

\section{Gebel Silsila}

Sites I and II No determinations.

Site III

Sebekian Assemblage

11,661 B.C. \pm 600 (M-1641) (Crane and Griffin, 1966)

12,150 B.C. \pm 450 (I-1292) (Smith, 1964) 
12,290 в.C. \pm 370 (I-1291) (Smith, 1964)

13,250 в.C. \pm 700 (M-1642) (Crane and Griffin, 1966)

14,050 B.C. \pm 800 (M-1551) (Crane and Griffin, 1965).

Silsilian Assemblage

No date for GS III where it underlies the Sebekian assemblage.

However a date of 13,360 B.C. \pm 200 (Y-1376) was determined

for a similar assemblage at Gebel Silsila IIB, Area 2B (Reed, 1965).

Sites IV to XII No determinations.

Site XIII 11,780 B.C. \pm 700 (I-1360) on ash from Mound H (Smith,

1967). Presumably refers to the Menchian industry.

Sites XIV to XX No determinations.

\section{Sebil}

Sites I to IV No determinations.

Site va 10,450 B.C. \pm 400 (I-1300) on shell (Smith, pers. comm.) 2,000 B.C. \pm 2280 (I-1299) on charcoal (Smith, pers. comm.).

Site VI No determinations.

Site VII 10,690 B.C. \pm 320 (GX-0583) on shell (Smith, 1967)

11,240 B.C. $\pm 340(\mathrm{GX}-0584)$ on shell (Smith, 1967)

12,000 B.C. $\pm 1190-1400$ (GX-0585) on shell (Smith, 1967).

\section{Khor el-Sil}

Sites I and II No determinations.

Site XIII 11,780 B.C. \pm 700 (I-1360) on ash from Mound H (Smith, 1967).

Site IV No determinations.

No determinations are available for any finds at Bayara A or B, Fatira, and Oasis Depression.

Only Gebel Silsila III is a true stratified site, containing Sebekian and Silsilian deposits. The other samples come from surface or slightly subsurface levels that in some are mixed and in others reflect homogenous assemblages. The 15,050 B.C. \pm 600 determination from Khor el-Sil III and that of 14,050 'B.C. \pm 800 from the Sebekian deposits at Gebel Silsila III are the two oldest dates available from the sites in the Kom Ombo Plain. Unfortunately these determinations overlap one another and that from the Sebekian at Gebel Silsila III overlaps the single Silsilian date of 13,360 B.C. \pm 200 . Therefore, the vertebrate materials cannot be arranged in any convincing chronological order on the radiocarbon evidence. Similarly, the vertebrate faunas from the individual sites (see below) provide no indications of divergent ages or climatic conditions by which a temporal sequence might be suggested. 


\section{Materials and Methods}

\section{Specimens}

The vertebrate specimens comprise bones and teeth in whole or fragmentary states of preservation and derive from Pisces, Reptilia, Aves and Mammalia. Fish remains are numerous and consist of more or less complete skulls of widely varying sizes (30-250 mm long), many mandibular, hyoid and vertebral elements, and few appendicular spines or bones. The reptilian remains are scarce, small, and isolated. Avian materials comprise mainly remains of longbones or girdles, with some vertebral and distal appendicular elements. The mammalian remains consist of teeth, cervical vertebrae, horncores, ends of longbones, and distal appendicular elements, all usually damaged and the bones broken in the marrow cavities.

As the materials represent the refuse of prehistoric Nile peoples, breakage of the longbones for their marrow and charring of bones during roasting or in a subsequent fire is expected and is present. Some selection can also be expected because hunting or fishing methods may be more suitable to the collection of one faunal taxon than to another. Thus the fish are mainly Nile catfish (Clarias anguillaris), and among the mammals hartebeest (Alcelaphus buselaphus) and wild cattle (Bos primigenius) are most numerous.

Conversely, there are no amphibians recorded (even by chance inclusion), few reptiles, none of which are snakes, and no ostrich (Struthio camelus), giraffe (Giraffa camelopardalis), elephant (Loxodonta africana), or rhinoceros (Ceratotherium simum or Diceros bicornis).

The specimens were covered by a hard calcitic matrix that cemented particles of silt or other bones to the specimens. Some specimens had been exposed to weathering by water-rounding and cracking by rain and sun before interment, and some had been broken by man or charred by fire.

Specimens that became secondarily exposed by deflation of their original deposit show the typical faceted weathering patterns of desert aeolian erosion. There are few signs of more recent frost cracking, although fissuring or slight displacement of articulated bones before interment had taken place and the parts subsequently cemented together in their displaced relationship by the desert calcrete.

The sizes of samples are not considered zoologically significant, nor has any attempt been made to assess the numbers of individuals present in any one sample. Because more excavation was undertaken at Gebel Silsila III than at any other site, the sample of vertebrate material from there is the largest. Alternatively, as the surface collecting at the Oasis Depression near Gebel Silsila was relatively easy, this sample is relatively numerous but biased towards selection of the larger elements and thus remains of larger mammals. Last, because the taxa with the more numerous remains present in the larger samples are also those taxa that appear more often at the other sites, no real significance can be attached to the presence or absence of any one taxon at a site from which only a small sample of material was obtained. 
Gaillard (1934) lamented the lack of any rodent material which he stated Vignard (1923) recorded as plentiful in sites in the Sebil Area. Such material is almost absent from the Canadian Expedition's collections.

\section{Laboratory Preparation}

The specimens were first cleaned with hand tools and, as with much of the deflated Oasis Depression material, restored without further preparation. This was possible because most of the matrix had been removed from these specimens by the process of deflation, the bones and teeth being harder than the matrix because of their calcitic impregnation.

The specimens that had been excavated and to which calcitic-silt matrix still adhered were cleaned by a small hand vibrating tool, by hammer and chisel, or by immersion in $10 \%$ by volume glacial acetic acid in tap water. The mechanical preparation was only suitable for large and strong specimens, such as those of Bos or Hippopotamus, or on those in which very little matrix adhered to the specimen. The chemical preparation had to be carried out with extreme caution as the specimens, especially the fish materials, tended to disintegrate into a porridge of bone in a few hours. Consequently, a cycle of development, washing, and stabilization of the newly exposed bone or tooth surface was adopted, and some specimens required five or six cyclic treatments. After the loss of a few specimens by leaving them in acetic acid overnight, chemical development was carried out during the day when the progress and softness of the exposed bone could be monitored. Stabilization of the exposed surfaces was carried out by two or more soakings with dilute "C.I.L. Household Cement" (Canadian Industries Limited) in acetone, with a final soaking and covering in dilute "Elvaset" (du Pont of Canada Limited). Specimens were then labelled, catalogued, and identified.

\section{Cataloguing}

Specimens were recorded in the field by site and subsection or locality within a site. In the laboratory, specimens were given accession numbers that were later superseded by catalogue numbers within the Collection of Vertebrate Fossils of the Royal Ontario Museum, Toronto, where all specimens are deposited. Each specimen is identified by museum catalogue number and by site and subsection, e.g., ROM VP 8004, GS III/14K/1fLevel 0 , indicating that specimen 8004 derives from Gebel Silsila III, subsection $14 \mathrm{~K} / 1 \mathrm{f}$, and at Level 0 , the surface and subsurface deposit.

Throughout this report specimens are referred to only by number if they are part of the Collection of Vertebrate Fossils in the ROM, but Recent mammalian specimens are cited as ROM 91.11.1.197a or UTZ 28.W.3-1 for specimens in the ROM or Department of Zoology, University of Toronto, respectively.

\section{Treatment of the Samples}

Specimens were sorted into genera and all assignments of specimens to genera were checked during the description and measurement of the elements. With one exception, the numbers of specimens of any one genus within a sample were too small to allow any possibility that more than one 
species was involved, the exception being two possible species of Gazella. Although the samples from each site were recorded separately so that each individual sample was identified as a separate fauna, samples from associated sites were combined only where suggested by Dr. P. E. L. Smith. Significant comparisons within the same taxon between sites was not possible, and thus all taxa except one are considered as units. The exception is the large bovines, where confusion among Bos, Syncerus, and Homoioceras is possible, and also between Bos primigenius and B. brachyceros, where identification rests upon the horncores only. In only Bos, therefore, are the taxa considered together for comparison, and each specimen is discussed sample by sample.

\section{Mensuration}

All measurements of specimens are given in millimetres $(\mathrm{mm})$ unless otherwise specified. The accuracy of measurements is to $0.1 \mathrm{~mm}$, although the dial calipers used allow accuracy to $0.02 \mathrm{~mm}$. Estimated measurements are followed by "e", e.g., 20e or 20.4e indicate estimated measurements of twenty or twenty-point-four millimetres, respectively. Dimensions that measure slightly smaller than they would have originally because of wear or minor breakage of a reference point are followed by "+", e.g., 20.4+.

Symbols used in the tables of measurements are "-" to indicate an unobtainable measurement because of major breakage, " 0 " to indicate that the dimension does not exist on the specimen, and a blank to indicate absence of reported data or non-existent reference points on the material. Measurements located between columns headed "left" or "right" containing measurements from one side only indicate bilateral dimensions.

Taxonomic groups referred to elsewhere in this report follow Greenwood et al. (1966) for Pisces, Villiers (1958) or Loveridge and Williams (1957) for Reptilia, Etchécopar and Hue (1964) for Aves, and Hoogstraal $(1963,1964)$ for Mammalia. 


\title{
Systematic Treatment
}

\author{
Class Osteichthyes \\ Order Siluriformes \\ Family Clariidae
}

Pisces

Clarias anguillaris-Nile catfish, quarmouth (Figs. 7, 8, 9A)

MATERIAL

Obtained from:

Oasis Depression A.

Bayara A.

Gebel Silsila Localities-II; III, Surface and Subsurface, mixed Sebekian and Silsilian-Level 0; III, Sebekian-Level 1; III, mixed Sebekian and Silsilian-Level 2; III, Silsilian-Level 3; IX; X; XI; XIII, Sectors 2, 2a, and 3, and Mounds E, G, and K; XIV; XV; Miscellaneous, near Localities III-VIIA.

Sebil Localities- I; III; V.

Khor el-Sil Localities-Ia; IIa; IIb; III(2); III(3); IV; Miscellaneous (II/III).

\section{CONSIDERATION}

Abundant remains of a large, flat-headed catfish from Gebel Silsila Site III and traces of presumably this fish from the other Gebel Silsila, Oasis Depression, Sebil and Bayara sites (Figs. 7, 8, 9A) make it possible to report $C$. anguillaris from the Nile at Kom Ombo at the time of the deposit of the archaeological materials. C. lazera may be present but represented only by undiagnostic fragments. Both these species are present in the Nile River at Aswan today, and both are morphologically similar. Boulenger (1911, pp. 221-223, 226-228 and 235-237) gave key and distinguishing characters, sketches of the whole fish, and dorsal views of the skull (ibid, Figs. $192,197)$ for both species. In both the skull is $1 \frac{1}{2}-12 / 3$ times as long as broad, and the dorsal surface is coarsely granulate in adults. The occipital margin is angular, although it may be rounded in $C$. lazera, the frontal fontanelle is sole- or knife-shaped, although it may be elliptical in $C$. anguillaris, and varies between 3-5 times as long as broad and 31/2-5 times in the length of the head in $C$. anguillaris and 21/2-4 times as long as broad and $31 / 2-6$ times in length of head in $C$. lazera, and the occipital fontanelle is small and in advance of the occipital process. The premaxillary bands of teeth are 51/2 (young)-8 times as long as broad in C. anguillaris and 4 (young)-6 times as long as broad in $C$. lazera. The vomerine teeth are granular in $C$. lazera and mostly conical but sometimes subgranular behind, in $C$. anguillaris. The teeth are arranged in crescentic bands that are continuous or nearly so, and that are as broad or slightly narrower as the premaxillary band in $C$. anguillaris and $1 \frac{1}{2}-2 \frac{1}{2}$ times as wide as the premaxillary band in $C$. lazera. These bands may also bear a posterior median process, the anterior mandibular teeth may be pointed and the posterior granular in $C$. lazera. The pectoral fins and spines are nearly identical, and the clavicles are hidden under the skin in $C$. anguillaris and nearer the surface with striated or rugosely granulated superficial surfaces 
in $C$. lazera. The maximum sizes of the two species are given by Boulenger as 750 and $1170 \mathrm{~mm}$ for $C$. anguillaris and $C$. lazera, respectively.

Apart from size differences, only the rounded occipital process, the relatively coarser mammilate sculpturing on the cranial roof, the granular anterior vomerine and pointed mandibular teeth, the presence of a posterior vomerine dental process, the proportions of the vomerine tooth band, and the superficial sculptured clavicle distinguish $C$. lazera from $C$. anguillaris.

Boulenger's (1911, Figs. 192, 197) diagrams suggest that the head of C. anguillaris could be about $200 \mathrm{~mm}$ and that of $C$. lazera about $300 \mathrm{~mm}$, when the total lengths of $750 \mathrm{~mm}$ and $1170 \mathrm{~mm}$, respectively, are considered. However, the illustrations also suggest that $C$. anguillaris has a squarer head than $C$. lazera, lateral line canals on the surface of the skull, a less prominent but more angular occipital process and less rounded postero-lateral processes.

The larger and more complete crania (e.g., 8001, Figs. 7, 8; 8004) measure more than $200 \mathrm{~mm}$ in median length and with complete supraoccipital processes should have been about $250 \mathrm{~mm}$ long. The supraoccipital process in 8206 is pointedly angular at about $80^{\circ}$ and resembles that illustrated for $C$. anguillaris by Boulenger (1911, p. 227, Fig. 192). The frontal fontanelle is slim with a narrow slit-like foramen as in $C$. anguillaris, is $31 / 2-4$ times longer than wide and one-quarter the length of the skull. In shape the frontal fontanelle resembles that of $C$. anguillaris (Fig. 9A, 8206) and C. lazera (Fig. 7, 8001). All the cranial fragments that have the prefontal and pterotic-sphenotic areas preserved bear marked oblique lateral line canals, as illustrated by Boulenger only for $C$. anguillaris. The vomerine teeth are conical or peg-like, arranged in a continuous crescentic band, without any posterior median extension of the band, although the vomer is slightly broader than the preserved premaxillary processes.

No sculptured clavicles were identified, all pectoral spines are serrated towards their distal ends, and all cranial fragments show only small mammilate sculpturing on their superficial surfaces.

The Nile catfish remains are therefore assigned to Clarias anguillaris because most of the observed characters agree with those described for this species. A skull of $C$. anguillaris was reported by Stromer (1904) from the "Diluvium im Norden des Fajum, die sich in nichts von solchen der noch im benachbarten Birket el Querun-See lebenden Art unterschieden" (Peyer, 1928). Gaillard (1934) reported $C$. anguillaris and a single fragment of $C$. lazera from the Sebil Area. But this fragment is from a very large individual and apparently represents the frontal processes bounding the anterior part of the fontanelle. The fragment (Gaillard, 1934, Pl. VII, Fig. 2) is about $50 \mathrm{~mm}$ in length on the mid-dorsal line and must be from an individual at least twice as large as specimen 8001 from Oasis Depression; its maculations are less than twice as large. Gaillard's specimen may therefore represent only a fragment from a very large individual of $C$. anguillaris rather than $C$. lazera.

Many skeletal elements are well preserved and provide evidence of the large size to which this catfish grew. Some of the larger vertebrae show 


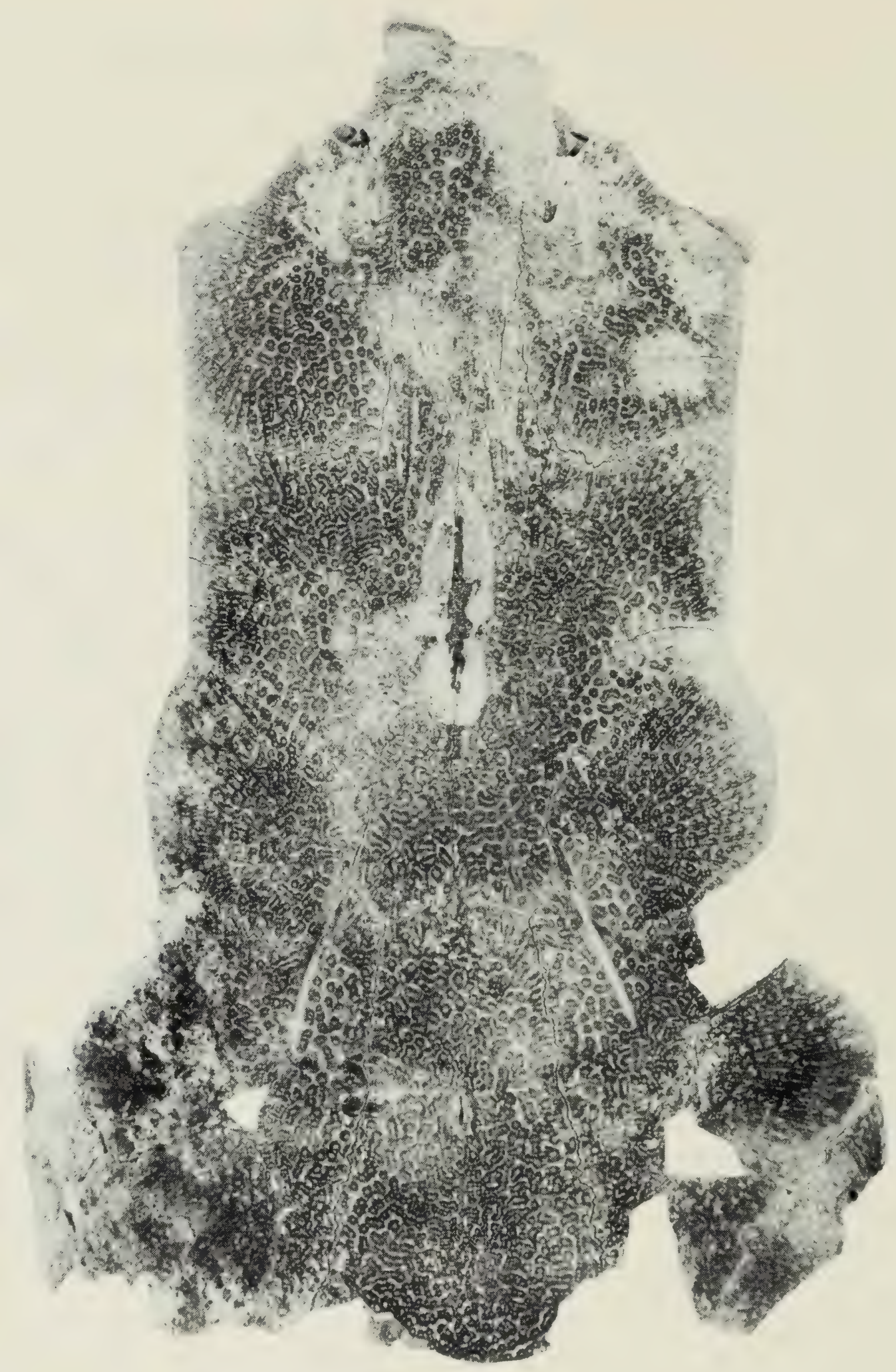

Fig. 7 Clarias anguillaris. Dorsal aspect of partial cranium 8001 from Oasis Depression $\mathrm{A}$. Bar $=10 \mathrm{~mm}$. 


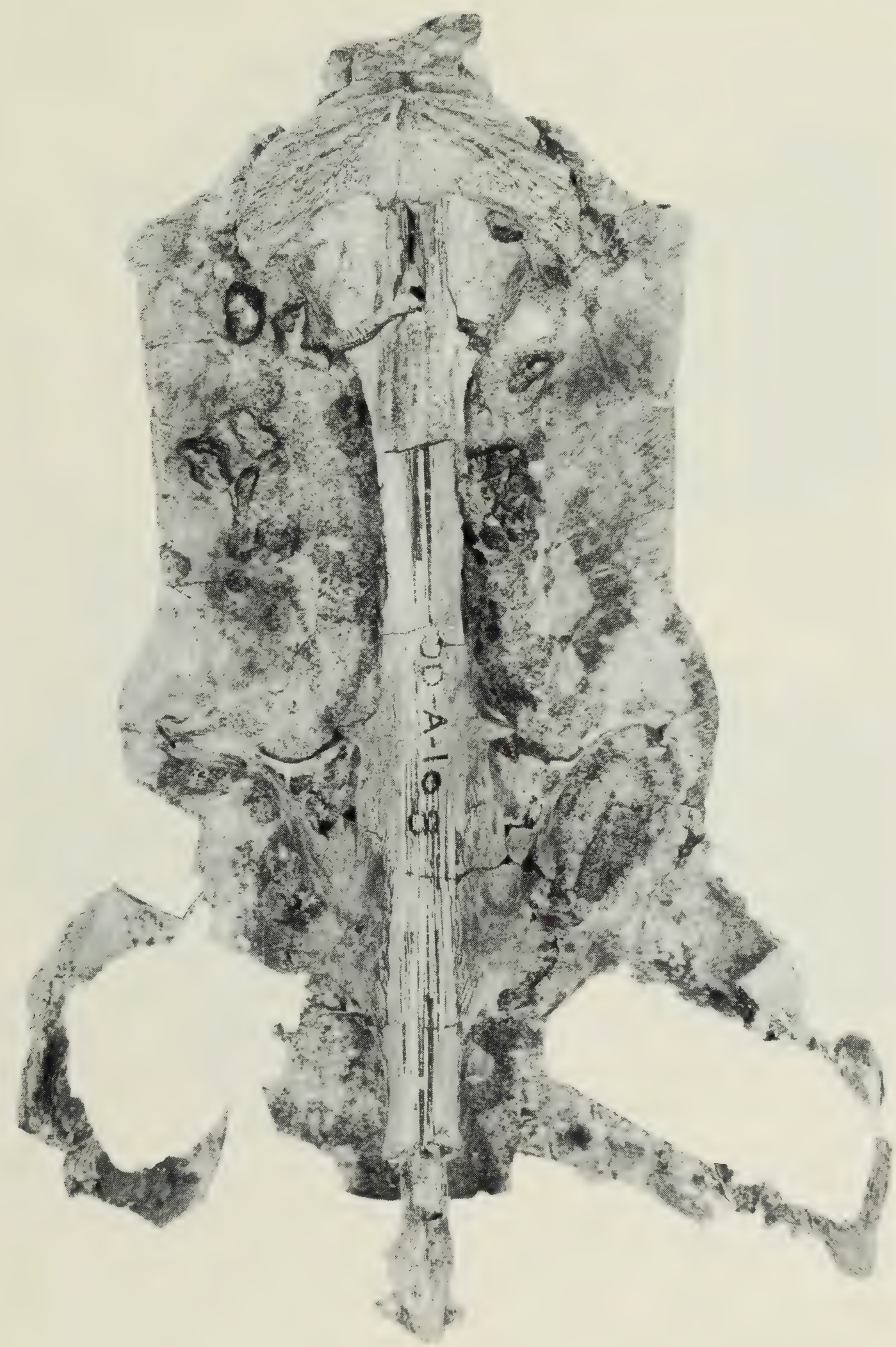

Fig. 8 Clarias anguillaris. Ventral aspect of partial cranium 8001 from Oasis Depression $\mathrm{A}$. Bar $=10 \mathrm{~mm}$. 
between seven and ten growth rings which suggest that some of the individuals may have been 10 years old at death.

Measurements of some of the larger elements are as follows:

\section{Dimension}

Transverse diameter of centrum of largest vertebra

Tranverse diameter of largest quadrate's mandibular articulation

Transverse diameter of largest articular's quadrate articulation

Dorsoventral depth of dentary-articular suture of largest preserved specimen

Overall length of largest pectoral spine (broken on tip)

Diameter of articulation of largest preserved pectoral spine's proximal end

Anteroposterior diameter of largest coracoid

\section{Specimen}

$8136 j \quad 16.7$

$8038 \quad 16.7$

$8154 \quad 17.4$

$8095 \quad 15.3$

$8057 \quad 61.5$

$8057 \quad 17.3$

$8123 \quad 17.6$

Greenwood (1968) reported not only Clarias sp. but also Synodontis clarias from the Wadi Halfa Nubian sites. It is possible that this genus is represented at Kom Ombo, although no specimens have been identified to this catfish.

\section{Order Cypriniformes}

Family Cyprinidae

Barbus bynni-African barbel

MATERIAL

Obtained from:

Gebel Silsila Locality III, Surface and Subsurface, mixed Sebekian and Silsilian-Level 0.

CONSIDERATION

Specimen 8410 strongly resembles the same tooth and bony area in Cyprinus carpio at about $50 \mathrm{~cm}$ long. But $C$. carpio is not native to the Nile River as is Barbus bynni, which is a native cyprinid that reaches the probable size of the individual from which the specimen came, i.e. 47 and $57 \mathrm{~cm}$ respectively (Boulenger, 1909, p. 305), and the specimen is assigned to Barbus sp., probably B. bynni. The specimen from Kom Ombo agrees with the left lower pharyngeal of B. bynni illustrated by Greenwood (1968, p. 102, Fig. 1, Nos. 3 and 4).

\section{Order Perciformes}

Family Centropomidae

Lates niloticus_-Nile perch (Figs. 9B, 9C)

MATERIAL

Obtained from:

Fatira Locality E.

Gebel Silsila Locality III, Sebekian-Level 1.

CONSIDERATION

Vertebra 8411 (Figs. 9B, 9C) shows the marked ossification of connective tissues on its ventral and laterodorsal surfaces, characteristic of Lates. 


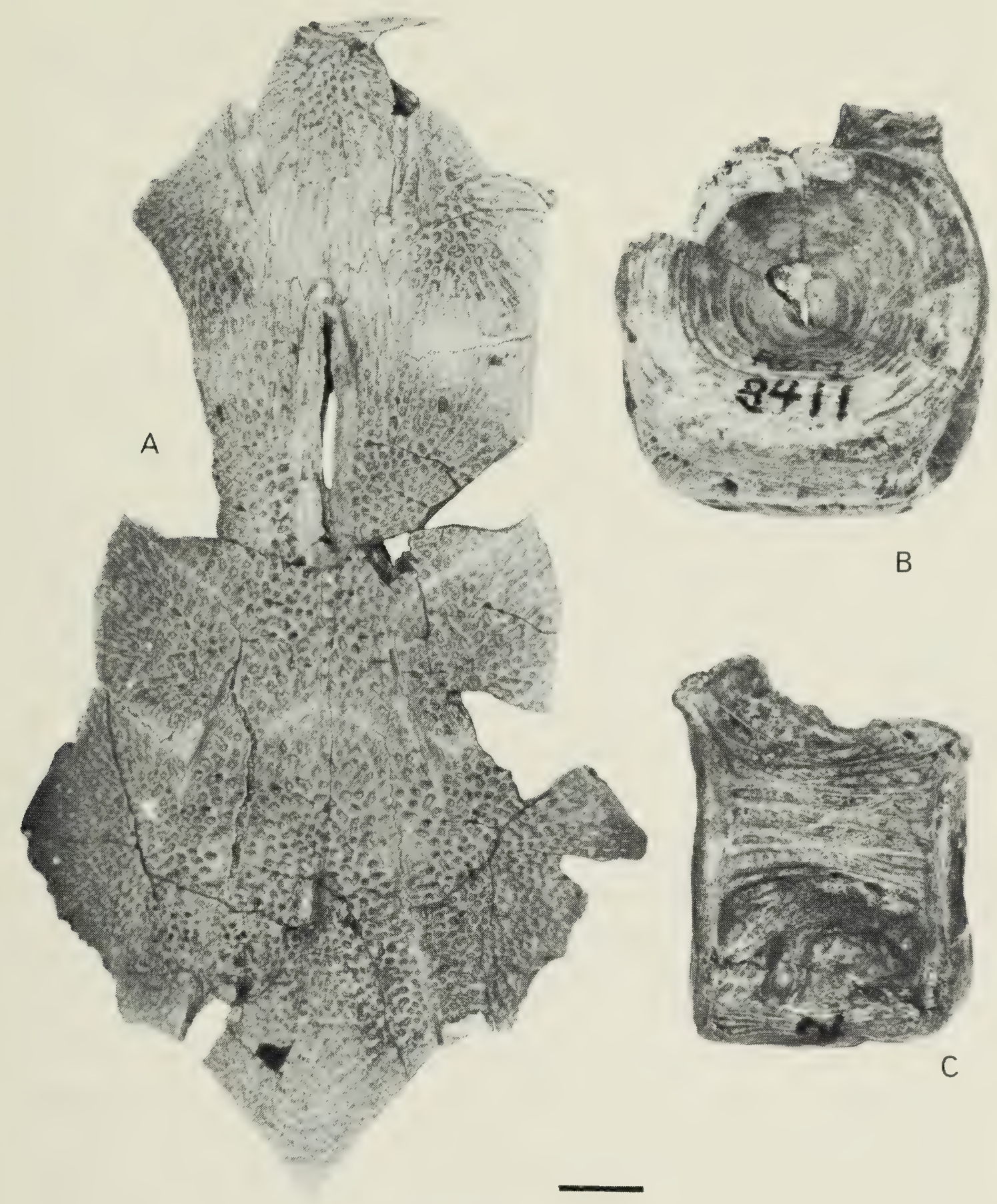

Fig. 9 Clarias anguillaris and Lates niloticus.

A. Clarias anguillaris. Dorsal aspect of partial cranium 8206 from Sebil III.

B, C. Lates niloticus. Vertebra no. 3 to 6,8411 from Fatira E. B = posterior aspect, $\mathrm{C}=$ right lateral aspect.

$\mathrm{Bar}=10 \mathrm{~mm}$.

Remnants of the articulation of the dorsal spine are present on the dorsal margin of the posterior centrum. The ventral surface is flattened where the swim bladder lies against it, there are no ventrolateral processes, as in the vertebrae lying above the posterior part of the abdominal cavity, nor any of the modifications present in the vertebrae directly behind the skull. The vertebra is therefore identified as between nos. 3 to 6 bchind the head.

The vertebra measures 43 and 42.5 in anterior and posterior transverse diameters, 36.5 and 38 in anterior and posterior dorsoventral diameters, and 31.5 in anteroposterior length. There are 13 growth rings on both 
anterior and posterior faces suggesting that the individual was about 13 years old at death. The length of the fish is estimated to have been about $130 \mathrm{~cm}$, which is within the range of size for living L. niloticus (Boulenger, 1911).

The hyoid specimen 8412 is large, 66.0 long by 18.8 in maximum diameter, and may derive from L. niloticus.

\section{Reptilia}

\section{Class Reptilia \\ Order Chelonia \\ Family Trionychidae}

Trionyx triunguis-Nile soft-shelled turtle

\section{MATERIAL}

Obtained from:

Oasis Depression G.

Gebel Silsila Localities-III, Surface and Subsurface, mixed Sebekian and Silsilian-Level 0; III, Sebekian-Level 1; III, mixed Sebekian and Silsilian-Level 2.

Sebil IV.

\section{CONSIDERATION}

The trionychid fragments are assigned to Trionyx triunguis, the only extant species of the genus in Africa (Villiers, 1958, p. 205). The carapace, costal fragments, and hypoplastral fragment are all vermiculated in the typical patterns illustrated by Villiers (1958, p. 202, Fig. 178 and p. 204, Fig. 179) for modern specimens. The internal surfaces of the costal fragments bear the raised and striated ribs adpressed to the vermiculated dermal plate typical of Trionyx. The vertebrae, water-worn and badly preserved, have elongate keeled centra, small zygapophyses, and vestigial transverse processes.

The presence of $T$. triunguis in human midden remains is not surprising as it is a delicacy of the Nile peoples, where it has been hunted for hundreds, possibly thousands of years, yet a few manage to survive in Egypt (Loveridge and Williams, 1957, p. 433). The fragmentary nature of the carapace and plastral specimens and their midden provenance support this contention.

The vertebral elements measure 28.0, 26.0 and 26.0 in length and $18+$, 24.0 and $20 \mathrm{e}$ length of the centrum for specimens 8419,8417 , and 8420 respectively. The costal fragments show varyingly developed vermiculate patterns that indicate that the individuals were adult when they died. 
Order Pelecaniformes

Aves

\section{Family Phalacrocoracidae}

Phalacrocorax carbo-cormorant or shag (Figs. 10M to 10P)

MATERIAL

Obtained from:

Gebel Silsila Localities-III, Surface and Subsurface, mixed Sebekian and Silsilian-Level 0; III, Sebekian-Level 1.

\section{CONSIDERATION}

The coracoids $(8427,8428,8429$, Figs. 10M, 10N) are solidly built with keeled sternal facets, no strong coracobrachialis scars, rounded shafts, strong procoracoids, flattened scapular and glenoid facets and coarsely sculptured coracohumeral ends. The carpometacarpi (8426, 8430, Fig. 100 ) show the medial longitudinal ridging, square metacarpal i process, and blunt carpal trochleae typical of the tarsometatarsi $(8432,8433)$ have the longitudinal ridging, the proximal tendinal canals, sculptured cotylae, large proximal foramina, and with distal ends that bear keeled third phalangeal trochleae, somewhat grooved second, the rounded fourth trochleae and the obvious distal intermetatarsal foramen between the second and third, about $6 \mathrm{~mm}$ from the extremity. The ends of the humerus (8425) and femur (8431) are fragmentary but agree with those of Phalacrocorax.

The identification of these specimens to Phalacrocorax carbo is based on direct comparison of generic characters and matching size. The present subspecies in Egypt is $P$. carbo sinensis (Etchécopar and Hue, 1964, p. 44), and the fossil form does not differ significantly from the extant form on the evidence of the material from Kom Ombo.

Measurements of the better specimens are:

\section{Dimension}

Coracoid

\section{Specimen}

Anteroposterior diameter, brachial tuberosity to bicipital

attachment

$11.4 \quad 11.2$

Anteroposterior diameter over glenoid facet

Anteroposterior diameter over procoracoid

Least anteroposterior shaft diameter

Transverse diameter of bicipital attachment

Transverse diameter over glenoid facet

Transverse diameter of shaft

Anteroposterior diameter of sternal facet

Thickness over sternal facet

$\overline{9.0} \quad 8.5$

$\begin{array}{ll}7.8 & 6.3 \\ 5.8 & 5.2\end{array}$

$5.8 \quad 5.2$

8429

$15.5+$

Thickness of shaft over coracobrachialis area

\section{Carpometacarpus}

Transverse diameter over carpal trochlea

Transverse diameter over pisiform process

Transverse diameter of metacarpal il shaft

Length of metacarpal I process 

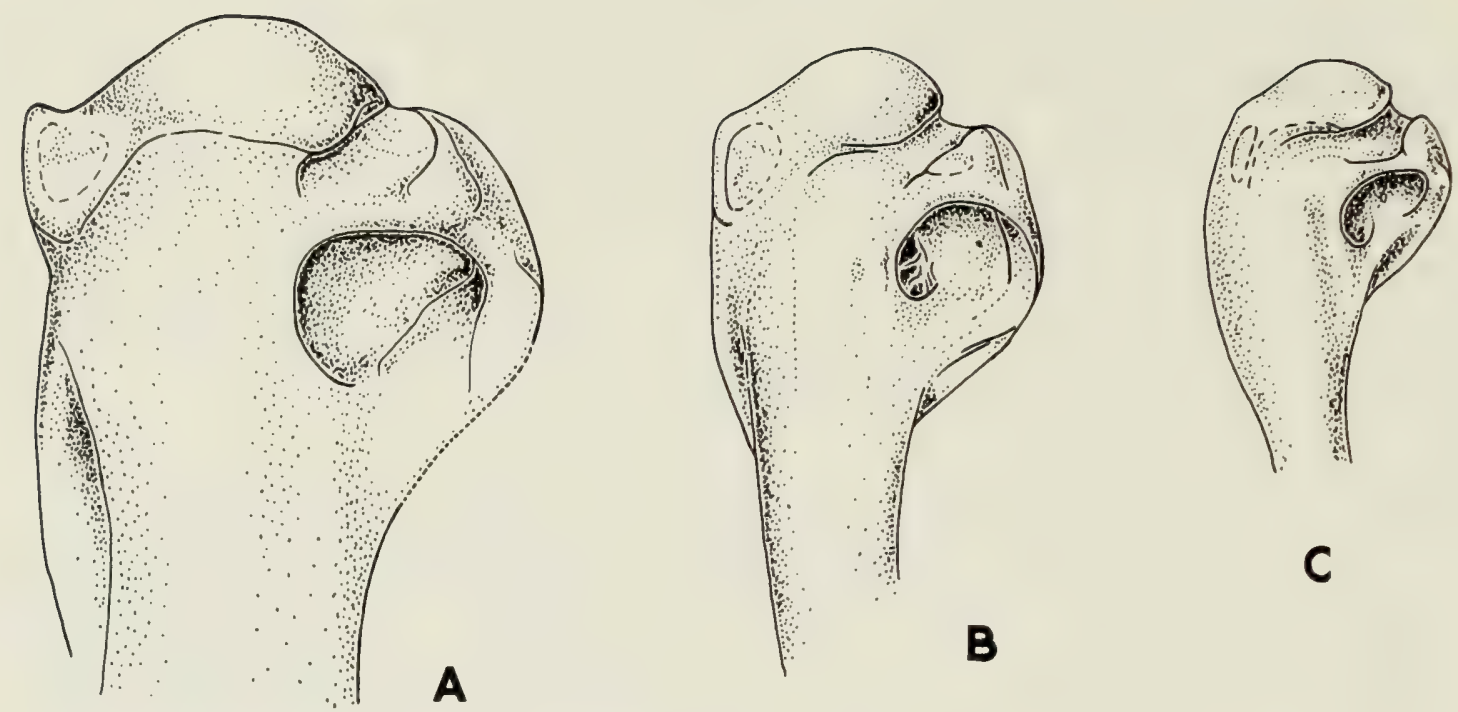

\section{C}

B

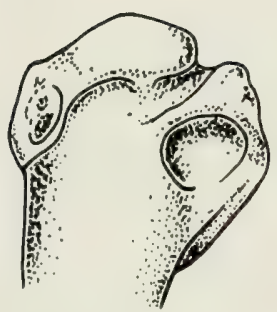

D

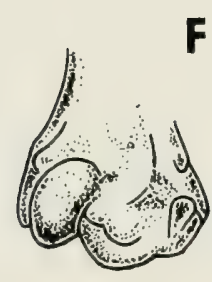

G

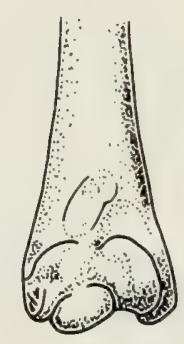

H
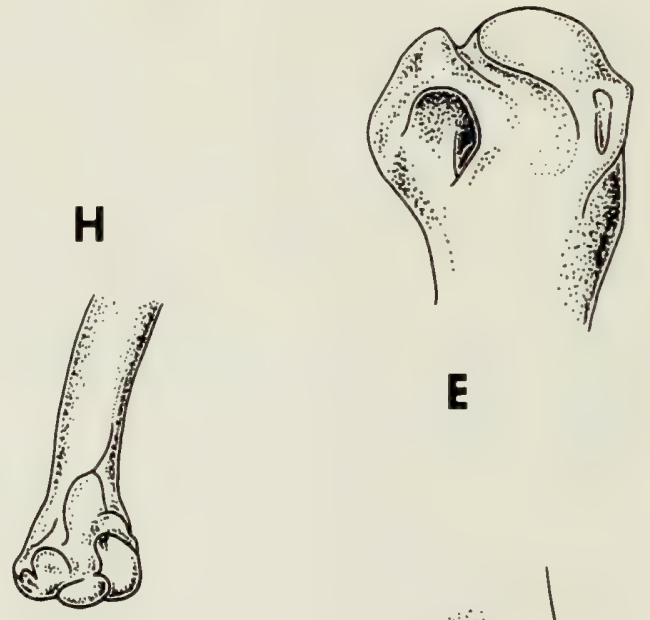

E

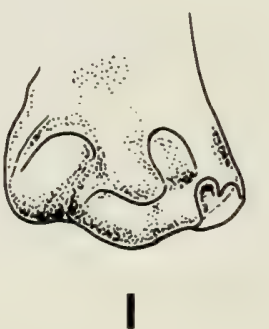

Fig. 10 Avian skeletal elements, mainly from Gebel Silsila III.

A. Anser fabalis; left humerus, proximal end in anconal aspect, partly restored, from Gebel Silsila III, Level 2, mixed Sebekian and Silsilian industries (8449).

B. Anser albifrons; left humerus, proximal end in anconal aspect, from Gebel Silsila III, Level 1, Sebekian Industry (8446).

C. Anas penelope; left humerus, proximal end in anconal aspect, from Gebel Silsila III, Level 2, mixed Sebekian and Silsilian industries (8484).

D. Anas acuta; left humerus, proximal end in anconal aspect, from Gebel Silsila III, Level 1, Sebekian Industry (8500).

E. Aythya ferina; right humerus, proximal end in anconal aspect, from Gebel Silsila III, Level 2, mixed Sebekian and Silsilian industries (8512).

F. Anas acuta; right humerus, distal end in palmar aspect, from Gebel Silsila III, Level 0, surface mixed Sebekian and Silsilian industries (8494).

G. Mergus serrator; left humerus, distal half in palmar aspect, from Gebel Silsila III, Level 1, Sebekian Industry (8519).

H. Anas crecca; left humerus, distal half in palmar aspect, from Gebel Silsila III, Level 2, mixed Sebekian and Silsilian industries (8476).

I. Tadorna ferruginea; right humerus, distal end in palmar aspect, from Gebel Silsila III, Level 2, mixed Sebekian and Silsilian industries (8452). 

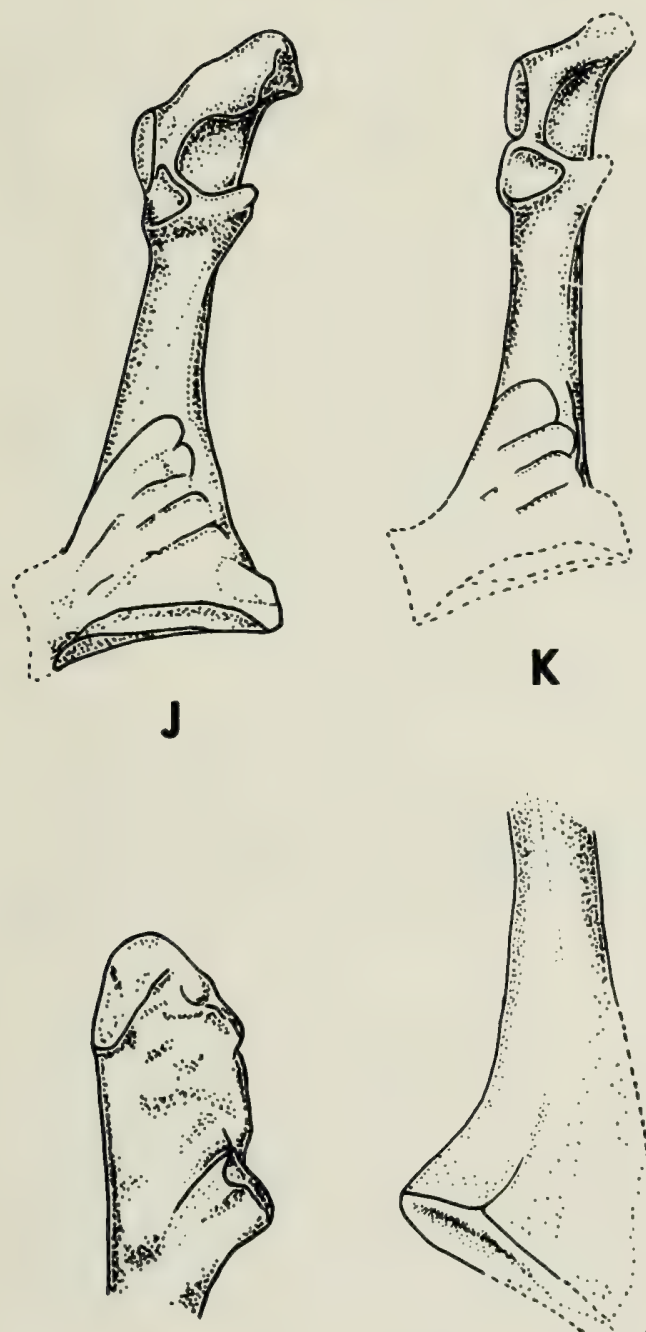

M

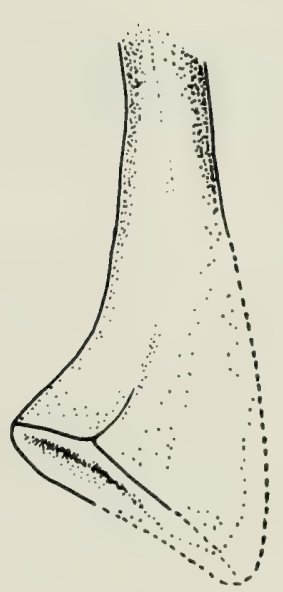

$\mathbf{N}$

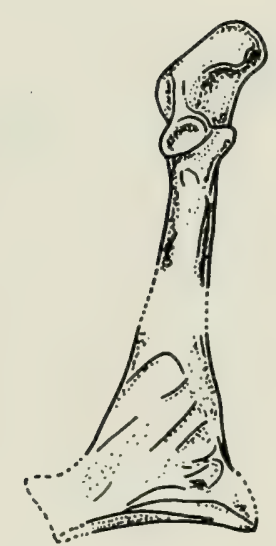

L

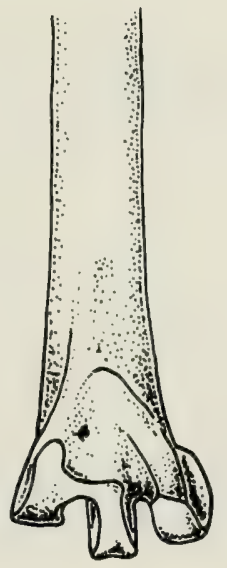

Q

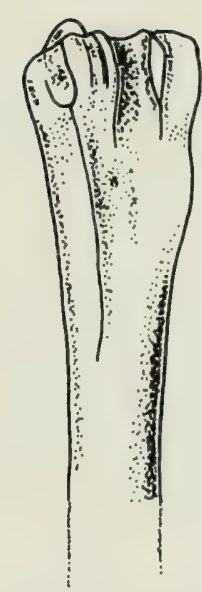

0

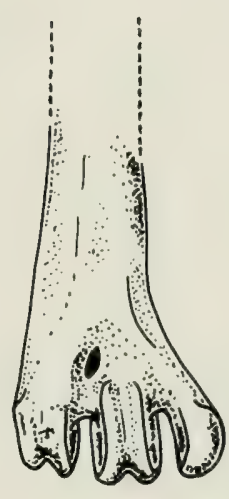

$\mathbf{P}$

J. Anas platyrhynchos; left coracoid, in dorsal aspect, from Sebil III (8464).

K. Anas acuta; left coracoid, in dorsal aspect, humeral end from Gebel Silsila III, Level 2, mixed Sebekian and Silsilian industries (8506, reversed), sternal fragment from Gebel Silsila III, Level 2, mixed Sebekian and Silsilian industries $(8505)$.

L. Anas crecca; left coracoid, in dorsal aspect, humeral end from Gebel Silsila III. Level 1, Sebekian Industry (8470), and sternal end from Gebel Silsila III, Level 0, surface mixed Sebekian and Silsilian industries (8466).

M. Phalacrocorax carbo; right coracoid, humeral end in ventral aspect, from Gebel Silsila III. Level 1, Sebekian Industry (8427).

N. Phalacrocorax carbo; left coracoid, sternal end in ventral aspect, from Gebel Silsila III, Level 1. Sebekian Industry (8429).

O. Phalacrocorax carbo; left carpometacarpus, proximal end in medio-anterior aspect, from Gebel Silsila III, Level 1, Sebekian Industry (8432).

P. Phalacrocorax carbo; left carpometacarpus, distal end in posterior aspect, from Gebel Silsila III, Level 1, Sebekian Industry (8433).

Q. Ardea cinerea; left tarsometatarsus, distal end in posterior aspect, from Gebel Silsila III, Level 2. mixed Sebekian and Silsilian industries (8444).

Scale $=50 \mathrm{~mm}$. 
Transverse diameter of distal end

Anteroposterior diameter of distal end

Tarsometatarsus

Transverse diameter of proximal end

Anteroposterior diameter of proximal end

Anteroposterior diameter in middle tendinal canal

Least transverse diameter of shaft

Least anteroposterior diameter of shaft

Transverse diameter over metatarsal trochleae

Anteroposterior diameter over metatarsal trochleae

\section{Family Ardeidae}

Ardea cinerea-grey heron (Fig. 10Q)

\section{MATERIAL}

Obtained from:

Gebel Silsila Localities-III, Surface and Subsurface, mixed Sebekian and Silsilian-Level 0; III, Sebekian-Level 1; III, mixed Sebekian and Silsilian-Level 2; $\mathrm{x}$.

\section{CONSIDERATION}

The tarsometatarsal shaft and articulations (8444, Fig. 10Q) exhibit a smooth, straight and flattened shaft, rounded second and fourth and lightly grooved third phalangeal trochleae, and a small distal foramen. The specimens agree in their characteristics and in size (8444) with material of recent Ardea sp. and probably represent $A$. c. cinerea, which is the present Egyptian subspecies.

The ulnar fragment matches that of $A$. cinerea in its intermuscular lines and the position of the nutrient foramen. Fragments of the shaft are tentatively assigned to $A$. cinerea after comparison with recent specimens.

Measurements of the tarsometatarsal specimens are:

\section{Dimension}

Transverse diameter over metatarsals II-IV distal trochleae

Transverse diameter of metatarsal II distal trochlea

Anteroposterior diameter of metatarsal in distal trochlea

Transverse diameter of metatarsal III distal trochlea

Anteroposterior diameter of metatarsal III distal trochlea

Transverse diameter of metatarsal Iv distal trochlea

Anteroposterior diameter of metatarsal Iv distal trochlea

\section{Family Plataleidae}

Platalea leucorodia-spoonbill

\section{MATERIAL}

Obtained from:

Gebel Silsila Localities-III, Sebekian-Level 1; IX.

Sebil I. 
The anterior carinal fragment of the sternum (8439) has the nearly straight anterior margin, the continuous and widened coracoid sulcus with deep dorsal lip, the rolled internal margin and the hollowed posterointernal surface with small median keel and lateral pockets characteristic of Platalea. The ulnar fragment (8438) has a straight shaft, no development of papillae for the insertion of the secondaries, lightly figured surface to the shaft, and a shallow insertion proximal to the distal modelling. Both these specimens agree in size and conformation with the relative parts of $P$. leucorodia, and probably represent $P$. leucorodia major, which is the present common subspecies in Egypt, although only as a migrant (Etchécopar and Hue, 1964, p. 73).

The two ulnar shaft fragments (8437 and 8438) measure 7.1 and 7.5 by 6.5 and 5.7 in their greater and lesser shaft diameters, respectively.

\section{Order Ciconiiformes \\ Family Phoenicopteridae}

Phoenicopterus antiquorum - greater flamingo

\section{MATERIAL}

Obtained from:

Gebel Silsila III, Surface and Subsurface, mixed Sebekian and Silsilian -Level 0.

\section{CONSIDERATION}

The fragmentary nature of the specimens $(8435,8436)$ allows only partial comparison, but matching intermuscular lines, possible nutrient foramina, indistinct papillae on the proximal end, and distal radial depressions correspond with those observed on the ulna of Phoenicopterus antiquorum.

\section{MATERIAL}

\section{Plectropterus gambensis-spur-winged goose}

Obtained from:

Gebel Silsila III, Surface and Subsurface, mixed Sebekian and Silsilian.

\section{CONSIDERATION}

The glenoid end of the scapula (8513) lacks the furcular process, is typically anserine, with a small, discrete, centrally located pneumatic foramen and a shallowly concave, medial face. It resembles those of Anser albifrons in all characters except for the concave medial face and slight variation in the shape of the coracoidal-glenoid facet on the lateral face. As the fragment cannot be assigned to any of the species of Anser, Branta or to Alopochen, it is provisionally assigned without comparison to Plectropterus gambensis, as this goose is a possible visitor from the Sudan (Etchécopar and Hue, 1964, p. 105) and may have been present some 13,500 years ago when the area was probably wetter (Butzer and Hansen, 1968, Table 3-7).

Measurements of the glenoid end of the scapula are: 
Diameter furcular to coracoid articulation

\section{Order Anseriformes}

\section{Family Anatidae}

Anser albifrons-white-fronted goose (Fig. 10B)

\section{MATERIAL}

Obtained from:

Gebel Silsila III, Sebekian-Level 1.

Sebil v.

\section{CONSIDERATION}

The humeri (8446, 8447, Fig. 10B) show an elongate, bulbous caput with a squarer posterointernal arc; a V-shaped, shallow, ligamental furrow; a broad capital groove with beaded anconal margin to the caput; an angular and laterally flattened deltoid crest; small external tuberosity; pear-shaped pectoral attachment; and large rounded and internally smooth pneumatic foramen in the rounded proximal end. The shaft is relatively small, with the shallow olecranon and deep impression of the brachialis antiquus and strong anterior ligamental attachment on the distal end characteristic of geese. In the above characters and in size these specimens are more similar to humeri of Anser anser than to those of $A$. fabalis; but, as $A$. anser is uncommon or rare in North Africa (Etchécopar and Hue, 1964, p. 84), they are assigned to $A$. albifrons, which is the "plus commune des Oies hivernant en Égypte" (ibid., p. 85).

Measurements of the humeral fragments are:

\section{Dimension}

Transverse diameter external tuberosity to bicipital crest

Transverse diameter caput to externaltuberosity

Anser fabalis_-bean goose (Fig. 10A)

MATERIAL

Obtained from:

Gebel Silsila III, mixed Sebekian and Silsilian-Level 2. CONSIDERATION

The proximal end of the left humerus (8449, Fig. 10A) is from a very large anserine bird, larger than any assigned to other species of Anser or Branta.

The caput is oblong to ovally rectangular, the internal tuberosity is massive, the ligamental furrow is broad, deep and open medially, the 
capital groove is wide, the anconal margin of the caput rounded to smooth, the pectoral attachment heart-shaped, the external tuberosity prominent, and the deltoid crest hollowed laterally. Except in size and in minor details, the specimen agrees well with humeri of Anser anser and those ascribed to $A$. albifrons. It is assigned to $A$. fabalis, the largest species of goose recorded from Egypt, e.g., total lengths of $87 \mathrm{~cm}$ versus 85 for $A$. answer, 75 for $A$. albifrons, 65 for $A$. erythropus, 60, 67, and 54 for Branta bernicla, B. leucopsis, and B. ruficollis, respectively, and 70 for Alopochen aegyptiacus (Etchécopar and Hue, 1964, pp. 84-90).

Measurements of the specimen are:

\section{Dimension}

Transverse diameter external tuberosity to bicipital crest 39.7

Transverse diameter caput to external tuberosity $\quad 29.0$

Anteroposterior diameter of caput $\quad 13.4$

Anteroposterior diameter over internal tuberosity $12.8+$

Estimated diameter of pneumatic foramen $13 \mathrm{e}$

Branta sp., ? B. bernicla-brent, or

B. ruficollis-red-breasted goose

MATERIAL

Obtained from:

Gebel Silsila III, Sebekian-Level 1.

\section{CONSIDERATION}

The glenoid end of the left scapula (8450) shows the oval pneumatic foramen, broadly ovoid glenoid facet, small coracoidal articulation, concave and striated internal surface, and anterointernal furcular ridge typical of Branta species. The specimen closely resembles that of modern $B$. bernicla, except that the internal surface is more markedly concave and the lateral muscular insertions are slightly different in shape. The specimen may therefore derive from $B$. bernicla, the brent goose, which has been recorded in Egypt (Nicoll, 1919; Etchécopar and Hue, 1964, p. 87), or from $B$. ruficollis, the red-breasted goose, which occurs only accidentally in Egypt today but which wintered in Egypt during pharaonic times (Etchécopar and Hue, 1964, p. 89).

Measurements of the scapula glenoid region are:

\section{Dimension}

Diameter furcular to coracoidal articulation $\quad 16.2 \mathrm{e}$

Diameter furcular process to glenoid margin $\quad 20.8$

Diameter over neck and glenoid margin $\quad 15.5$

Thickness over neck and glenoid facet 15.8

Tadorna ferruginea — ruddy sheld duck (Fig. 10I)

MATERIAL

Obtained from:

Gebel Silsila Localities-III, Sebekian-Level 1; III, mixed Sebekian and Silsilian-Level 2. 


\section{CONSIDERATION}

The distal articulation of the right humerus (8452, Fig. 10I), although damaged on the lateral margin, is remarkably similar in conformation and size to material of living Tadorna but is larger than most specimens of $T$. tadorna, the sheld duck, and is therefore assigned to $T$. ferruginea. The entepicondyle has the double ligamentous insertions, the internal condyle is globular with a well-developed lateral extension, the entepicondylar eminence is broad, strong and low, the intercondylar furrow is rounded at the base and the olecranal fossa is shallow and broad, all characters found in Tadorna.

Measurements of the distal end of the humerus are:

\section{Dimension}

Transverse diameter over epicondyles

Anas platyrhynchos-mallard (Fig. 10J)

MATERIAL

Obtained from:

Gebel Silsila Localities-III, Surface and Subsurface, mixed Sebekian and Silsilian-Level 0; III, Sebekian-Level 1; III, mixed Sebekian and Silsilian-Level 2.

Sebil III.

\section{CONSIDERATION}

The nearly complete left coracoid (Fig. 10J) from Sebil Locality III (8464) and the humeral and sternal ends of left coracoids from Gebel Silsila Locality III $(8456,8458)$ resemble those of Anas platyrhynchos in size, elongate furcular facets, enlarged coracohumeral surfaces, coracobrachialis scars, and sternal facets. The two carpometacarpal specimens $(8459,8460)$ are indistinguishable from those of $A$. platyrhynchos and show the separated internal ligamental fossa and pisiform attachment and the large external ligamental pit of $A$. platyrhynchos. These specimens may therefore represent Anas p. platyrhynchos which is the extant subspecies of the mallard that winters in Egypt.

Measurements of the coracoid and carpometacarpal specimens are:

\section{Dimension}

Coracoid

8464

Overall length

Maximum anteroposterior diameter of humeral end

Anteroposterior diameter over glenoid facet

Anteroposterior diameter over procoracoid

Oblique diameter over coracohumeral facet

Lesser diameter over glenoid facet

Transverse diameter over procoracoid

Least anteroposterior diameter of shaft 
Anas crecca-teal (Fig. 10H and 10K)

MATERIAL

Obtained from:

Gebel Silsila Localities-III, Surface and Subsurface, mixed Sebekian and Silsilian-Level 0; III, Sebekian-Level 1: III, mixed Sebekian and Silsilian-Level 2; $\mathrm{X}$.

\section{CONSIDERATION}

The coracoid fragments $(8465,8466,8469 ; 8470$, Fig. 10K) are small, lightly built, and match those of extant Anas crecca in size and morphology. They bear lunate furcular facets, small angular procoracoids and glenoid margins, square-sectioned shafts, and lightly marked coracobrachialis scars. The caput humeri (8467) is elongately oval, and the distal humeral specimens $(8468,8471,8477)$ have sharp entepicondylar and low ectepicondylar prominences, small deep olecranal fossae, simple lateral and double insertions for the medial epicondylar tendons as in $A$. crecca. The ulnar specimen (8479) shows the small tendinal groove, the simple trochlea and prominent exterior condyle, and the carpometacarpal specimens show the angular metacarpal II shaft, the deep internal and external ligamental fossae, as in recent $A$. crecca.

A left coracoid, humerus and ulna of $A$. crecca ?crecca, catalogued as 72053 in the collections of the Department of Ornithology, Royal Ontario Museum, was obtained by E. Naville and H. R. Hall in 1905-1907 from Deir el-Bahari, near Thebes. Hall (in Naville and Hall, 1913, p. 18) noted that "Even cakes of bread and a small bird, relics of the workmen's meals, were found in the debris." A small bird is shown in Naville and Hall's (1913) Plate 28 but is not a teal and, if part of a meal, it was uneaten as the skeleton is entire and not disarticulated. The date for these remains is suggested as XIvth dynasty by Hall and the Royal Ontario Museum specimens are noted as "c. 1400 B.c." on their label. Hall's remark may have been in reference to these specimens, as in a footnote (Naville and Hall, 1913 , p. 21) he said "The author of this chapter has illustrated it chiefly from the objects assigned to the British Museum and Oxford, owing to his inability to visit the numerous other museums, notably those of America, to which large selections of the smaller objects from Deir el-Bahari were also assigned."

Dr. C. T. Currelly of the Royal Ontario Museum was associated with the Deir el-Bahari excavations and wrote a section in Naville and Hall's (1913) report, and therefore the bird remains referred to by Hall may have been recorded in his field notes and may be those now housed in the ROM.

The extant subspecies of teal in Egypt is A. c. crecca, and the fossil specimens and those from Deir el-Bahari may represent this taxon.

Measurements of the better preserved specimens are: 
Maximum anteroposterior diameter of humeral end

Anteroposterior diameter over glenoid facet

Anteroposterior diameter over procoracoid

Least anteroposterior diameter of shaft

Oblique diameter of coracohumeral surface

Transverse diameter over glenoid facet

Transverse diameter over procoracoid

Anteroposterior diameter of sternal end

Transverse thickness of sternal end

$\begin{array}{lll}5.1 & 5.6 & 5.5\end{array}$

$\begin{array}{lll}5.3 & 5.3 & 5+\end{array}$

$\begin{array}{lll}3.3 & 3.6 & 3.7\end{array}$

$5.0-5.1$

$\begin{array}{lll}3.9 & 3.6 & 4.0\end{array}$

$\begin{array}{lll}4.3 & 5.1 \quad 4.2\end{array}$

$8466 \quad 8465$

$13.7 \quad 13+\quad 13.3$

$\begin{array}{lll}2.7 & 2.8 & 2.5\end{array}$

\section{Humerus}

8467

Transverse diameter of caput

Anteroposterior diameter of caput

10.3

4.9

Transverse diameter of shaft

Anteroposterior diameter of shaft

Transverse diameter of distal articulation

Anteroposterior diameter of distal articulation 5.7

Ulna

$\begin{array}{lll}9.8 & 10.2 \quad 9.7\end{array}$

Transverse diameter of distal end

Anteroposterior diameter of distal end

MATERIAL

Obtained from:

Gebel Silsila Localities-III, Surface and Subsurface, mixed Sebekian and Silsilian-Level 0; III, Sebekian-Level 1; III, mixed Sebekian and Silsilian-Level 2.

\section{CONSIDERATION}

The two humeral specimens $(8481 ; 8464$, Fig. 10C) are indistinguishable from similar parts of living Anas penelope in the squared internal outline and pointed lateral outline of the caput, the shallow V-shaped ligamental furrow, the relatively massive internal tuberosity that partly hides the oval pneumatic foramen, the wide capital groove with the sinuous anconal margin to the caput, and the weak pectoral attachment at the proximal end of the angular deltoid crest.

Measurements of the proximal end of the left humerus are:

\section{Dimension}

Transverse diameter external tuberosity to bicipital crest

Transverse diameter caput to external tuberosity

Anteroposterior diameter of caput

Anteroposterior diameter over internal tuberosity 
MATERIAL

Obtained from:

Gebel Silsila Localities-III, Surface and Subsurface, mixed Sebekian and Silsilian-Level 0; III, Sebekian-Level 1; III, mixed Sebekian and Silsilian-Level 2; XIII.

\section{CONSIDERATION}

The coracoid fragments $(8487,8488,8498 ; 8505$ Fig. 10K; 8506) agree well with those of living Anas acuta in size, conformation of the procoracoid and bicipital attachment, and shape of the coracobrachialis scars. The scapular fragments $(8489,8499)$ have narrow necks, elongate glenoid facets, bluntly rounded furcular articulations, and are indistinguishable from those of $A$. acuta. The humeral fragments $(8490,8491,8492,8493$; 8494 Fig. 10F; 8495; 8500 Fig. 10D; 8501, 8502, 8503, 8504) provide the best comparison because of their relative abundance.

All have capites humerorum with a slight medial 'cingulum' and a nearly straight and undercut anconal margin that curves into the pectoral attachment. The pneumatic foramen is nearly round, the capital groove wide and deep, and the ligamental furrow broad and smooth. The double tendinous insertions on both epicondyles of the distal articulations are characteristic of smaller dabbling ducks. The entepicondyles are wide, the olecranal fossa is broad and deep, and the external tricipital groove is raised to the level of the ectepicondyle. The range of size of these specimens suggests that both males and females are represented in the sample.

Measurements of the better preserved specimens of $A$. acuta are:

\section{Dimension}

\section{Coracoid}

Anteroposterior diameter over glenoid facet

Anteroposterior diameter over procoracoid

Least anteroposterior diameter of shaft

Transverse diameter over glenoid facet

Transverse diameter over procoracoid

\section{Scapula}

Diameter furcular to coracoidal articulation

Diameter furcular process to glenoid margin

Diameter over neck and glenoid facet

Thickness over neck and glenoid facet

Greater diameter of neck

Lesser diameter of neck

$\begin{array}{rc}8506 & 8505 \\ 6.3 & - \\ 6.0 & - \\ - & 5.0 \\ 6.6 & - \\ 7.3 & - \\ 8499 & 8489 \\ 7.8 & 7.6 \\ 10.0 & 10.2 \\ 7.9 & 7.9 \\ 3.2 & 3.3 \\ 4.2 & 4.3 \\ 2.7 & 2.6\end{array}$

\section{Humerus}

Transverse diameter external tuberosity to bicipital crest

Transverse diameter caput to external tuberosity

Anteroposterior diameter of caput

Anteroposterior diameter over internal tuberosity

Maximum transverse diameter of pneumatic foramen

$\begin{array}{rrrrr}8501 & 8500 & 8491 & 8490 & 8492 \\ 18.7 & 18.4 & 17.6 & 19.5 & 19.3 \\ 14.0 & 13.7 & 12.6 & 13.0 & 13.4 \\ 6.9 & 7.1 & 6.4 & 6.4 & 7.0 \\ - & 7.3 & - & - & - \\ - & 6.2 & 6.5 & - & - \\ & & & & 37\end{array}$


Transverse diameter of distal end

$$
\text { Anas sp.-unidentified duck }
$$

MATERIAL

Obtained from:

Gebel Silsila Localities-III, Surface and Subsurface, mixed Sebekian and Silsilian-Level 0; III, mixed Sebekian and Silsilian-Level 2.

\section{CONSIDERATION}

These specimens suggest Anas cf. acuta or possibly Aythya ferina. The caput humeri (8510) measures 13.1 by 6.6 in transverse and anteroposterior diameters, which are within the ranges of variation recorded for $A$. acuta but slightly small for those of $A$. ferina. Unfortunately the specimens are too fragmentary to be assigned to species with any certainty.

$$
\text { Aythya ferina-pochard (Fig. 10E) }
$$

MATERIAL

Obtained from:

Gebel Silsila Localities-III, Sebekian-Level 1; III, mixed Sebekian and Silsilian-Level 2.

\section{CONSIDERATION}

The two proximal ends of humeri $(8511 ; 8512$, Fig. 10E) best resemble those of Aythya ferina and are similar to those of $A$. marila, the scaup. They show the sigmoid margin of the caput in anconal aspect, which is without a 'cingulum' and in which the margin is not undercut or beaded. The posterointernal edge of the caput is strongly squared in the capital groove, the ligamental furrow sharpens to a ' $\mathrm{V}$ ' medially and the internal tuberosity is strong and deltoid. The pneumatic foramina are round, the pectoral attachment is shallowly concave and elongate, and the bicipital surface is shallowly convex. These specimens are tentatively assigned to Aythya cf. ferina rather than $A$. marila on morphological resemblances and because of their slightly smaller size.

Measurements of the proximal ends of the humeri are:

\section{Dimension}

Transverse diameter external tuberosity to bicipital crest

Transverse diameter caput to external tuberosity

Anteroposterior diameter of caput

Anteroposterior diameter over internal tuberosity

Maximum transverse diameter of pneumatic foramen

\section{Mergus merganser-goosander}

MATERIAL

Obtained from:

Gebel Silsila Localities-III, Sebekian-Level 1; III, mixed Sebekian and Silsilian-Level 2. 


\section{CONSIDERATION}

Both coracoid specimens $(8514,8515)$ lack the necks and brachial tuberosities. The bones are large, heavy and squared in section below the procoracoid process, the coracoidal fenestra lacks a sternal margin, the scapular facet is broad and shallow, the glenoid facet small and trapezoid and the bicipital attachment is more prominent than the procoracoid. The humeral specimens $(8516,8517)$ show a shallow brachialis anticus insertion, a rounded brachial depression, a steep, lunate olecronon fossa, a shallow external tricipital groove and narrow ectepicondylar eminence. In all these characters and in size the Kom Ombo materials do not differ from the relative elements in Mergus merganser.

Measurements of the coracoid and humeral fragments are:

\section{Dimension}

\section{Coracoid}

Anteroposterior diameter over procoracoid

Least anteroposterior diameter of shaft

Transverse diameter over procoracoid

\section{Humerus}

Anteroposterior diameter of shaft

Transverse diameter of shaft

Anteroposterior diameter of distal end

$$
\text { Mergus serrator-red-breasted merganser (Fig. 10G) }
$$

\section{MATERIAL}

Obtained from:

Gebel Silsila Localities-III, Surface and Subsurface, mixed Sebekian and Silsilian-Level 0; III, Sebekian-Level 1.

\section{CONSIDERATION}

These humeral fragments $(8518 ; 8519$, Fig. 10G) resemble those described for Mergus merganser but are smaller and resemble more closely the relevant regions in the humeri of $M$. serrator.

Measurements of these specimens are:

\section{Dimension}

$8518 \quad 8519$

Lesser diameter of shaft

Greater diameter of shaft

Anteroposterior diameter of distal end

Transverse diameter of distal end

$\begin{array}{rr}8518 & 8519 \\ - & 4.8 \\ - & 6.2 \\ 11.3 & 12.3 \\ 8.0 & 7.7\end{array}$

\section{Mergus albellus-smew}

MATERIAL

Obtained from:

Gebel Silsila Localities-III, Surface and Subsurface, mixed Sebekian and Silsilian-Level 0; III, Sebekian-Level 1.

\section{CONSIDERATION}

The sternal portion of the coracoid (8520) matches that of recent Mergus albellus in the pattern of small ridges on the coracobrachialis attachment, 
the sternal facet as preserved, and in the section of the shaft. The proximal end of the carpometacarpus (8523) is badly damaged, lacks the carpal trochlea, and is tentatively assigned to $M$. albellus, which it best resembles.

\title{
Order Falconiformes \\ Family Falconidae
}

\author{
Milvus migrans—black kite
}

MATERIAL

Obtained from:

Gebel Silsila III, Surface and Subsurface, mixed Sebekian and Silsilian -Level 0.

\section{CONSIDERATION}

The proximal section of the humeral shaft (8524) comprises the abraded deltoid that extends $10 \mathrm{~mm}$ without reaching the level of the bicipital surface, the deltoid crest is small and on the lateral side of the shaft and there is no nutrient foramen visible. The specimen best resembles that of a kite of the genus Milvus, and is similar in size to $M$. migrans. The present Egyptian subspecies is $M . m$. aegyptius.

\section{Family Pandionidae}

$$
\text { Pandion haliaetus-osprey }
$$

MATERIAL

Obtained from:

Gebel Silsila III, mixed Sebekian and Silsilian-Level 2.

\section{CONSIDERATION}

The ungual phalanx (8525) has lost the end of the claw but agrees perfectly with that of the left pedal third digit of Pandion haliaetus in size, asymmetry and conformation of the volar retractor process.

Measurements of the ungual phalanx are:

\section{Dimension}

Volar-plantar diameter over proximal end

Volar-plantar diameter at base of claw

Transverse diameter over proximal end

\section{Family Accipitridae}

Aquila chrysaëtos-golden eagle

MATERIAL

Obtained from:

Khor el-Sil III.

\section{CONSIDERATION}

The rib fragment (9028) was compared with ribs of both Aquila chrysaëtos and the imperial eagle, A. heliaca, in the collections of the Department of Ornithology, Royal Ontario Museum. It resembles the sixth rib on the right side of $A$. chrysaëtos in size, conformation of the anterior and posterior margins of the superficial area, the presence of pneumatic perforations on the posterior surface at the junction of the superficial shelf 
and the keel and their lack on the anterior surface, and in the shape of the tubercular facet. The fragment is similar in size and general shape to that of $A$. heliaca, but in this species none of the posterior ribs show any pneumaticity. The specimen is large when compared with some specimens of $A$. chrysaëtos and matches best with those from females and therefore may represent a female individual.

A. chrysaëtos is present in Egypt today, and nests in the Sinai mountains. Etchécopar and Hue (1964, p. 12) stated "Ce n'est pas une espèce exclusivement montagnarde ... Certes on la trouve dans les grands massifs (Atlas, Hoggar, Sinai) mais elle se maintient dans la plaine quand elle n'est pas trop pourchassée." Its presence in the Kom Ombo region is therefore not unlikely, as the hills of the eastern desert or even the scarps of the Burg el-Makhazin would provide suitable roosting habitat.

The occurrence of the golden eagle may be correlated with the presence of a small dog, gazelle, and Cape hare in the fauna as these animals constitute part of the diet of this eagle. Etchécopar and Hue (1964, p. 124) considered "Ses victimes varient selon le milieu où il vit, et vont du Chacal ou de la Gazelle aux Outardes ou au Corbeaux. Mais, la taille moyenne des proies est souvent très modeste (petits mammifères) quoique le lièvre lui paie un lourd tribut."

\section{Order Galliformes \\ Family Gruidae}

Grus grus-crane

MATERIAL

Obtained from:

Sebil IV.

\section{CONSIDERATION}

The fragmentary specimen of the coracoid (8526) matches the coracoidal foraminal region in the shape of both apertures of the foramen, in the section of the bone at that point, and the size of the left coracoid of Grus grus.

\section{Order Charadriiformes \\ Family Charadriidae}

\section{Numenius ?arquatus_curlew}

MATERIAL

Obtained from:

Gebel Silsila III, Sebekian-Level 1.

\section{CONSIDERATION}

The specimen (8527) best resembles the distal end of a left ulna of Numenius arquatus in the shape of the condyles, the shallow, broad distal radial depression, and the extensive tendinal groove extending up the shaft which becomes a nearly closed channel over the external condyle. 
Aves indet.

MATERIAL

Obtained from:

Gebel Silsila Localities-III, Surface and Subsurface, mixed Sebekian and Silsilian-Level 0; III, Sebekian-Level 1; III, mixed Sebekian and Silsilian-Level 2; XIV; XV.

\section{CONSIDERATION}

These specimens are either juvenile and therefore lack the adult cortex and processes, or so badly worn that no possible determinations to taxa could be made except from size and general conformation. They are recorded solely to show that avian remains are recorded at Gebel Silsila Localities XIV and XV, and that no avian material is known from Gebel Silsila Locality III, Level 3, Silsilian culture.

\section{Mammalia}

\section{Order Primates}

\section{Family Hominidae}

Homo sapiens-man (Figs. 11A to 11D)

MATERIAL

Obtained from:

Oasis Depression.

Gebel Silsila III, Silsilian-Level 3.

\section{CONSIDERATION}

The presence of man in the fauna is attested to by the materials that were excavated from midden debris associated with human artifacts of Silsilian, Sebekian and later cultures. The upper incisor (8560, Figs. 11A to 11D) exhibits edge to edge occlusal wear on the incisive crest which is sufficient to expose the dentine. The crown is bulbous, especially on the lingual enamel margin, and has lost the lateral and mesial enamel by spalling. No signs of resorption of the root can be observed, so it is likely that the child was less than 7 years old. The tooth appears to be within the range of variation of modern Caucasian children's incisors with a smoothly convex buccal surface and light mesial and distal oblique grooves from the centre of the incisive edge to the sides of the cingulum on the lingual face. The specimen measures 17.0, 15.9 and 15.9 in mesiodistal, buccolingual and buccal crown height respectively.

An upper first milk incisor from Oasis Depression was recognised before preparation but, unfortunately, was lost by disintegration while under treatment in acetic acid. 


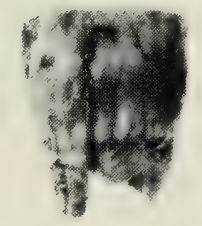

A

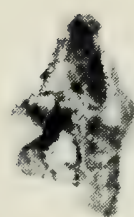

B

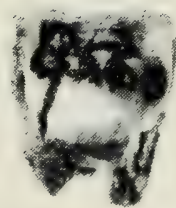

C

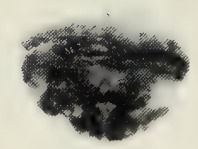

D

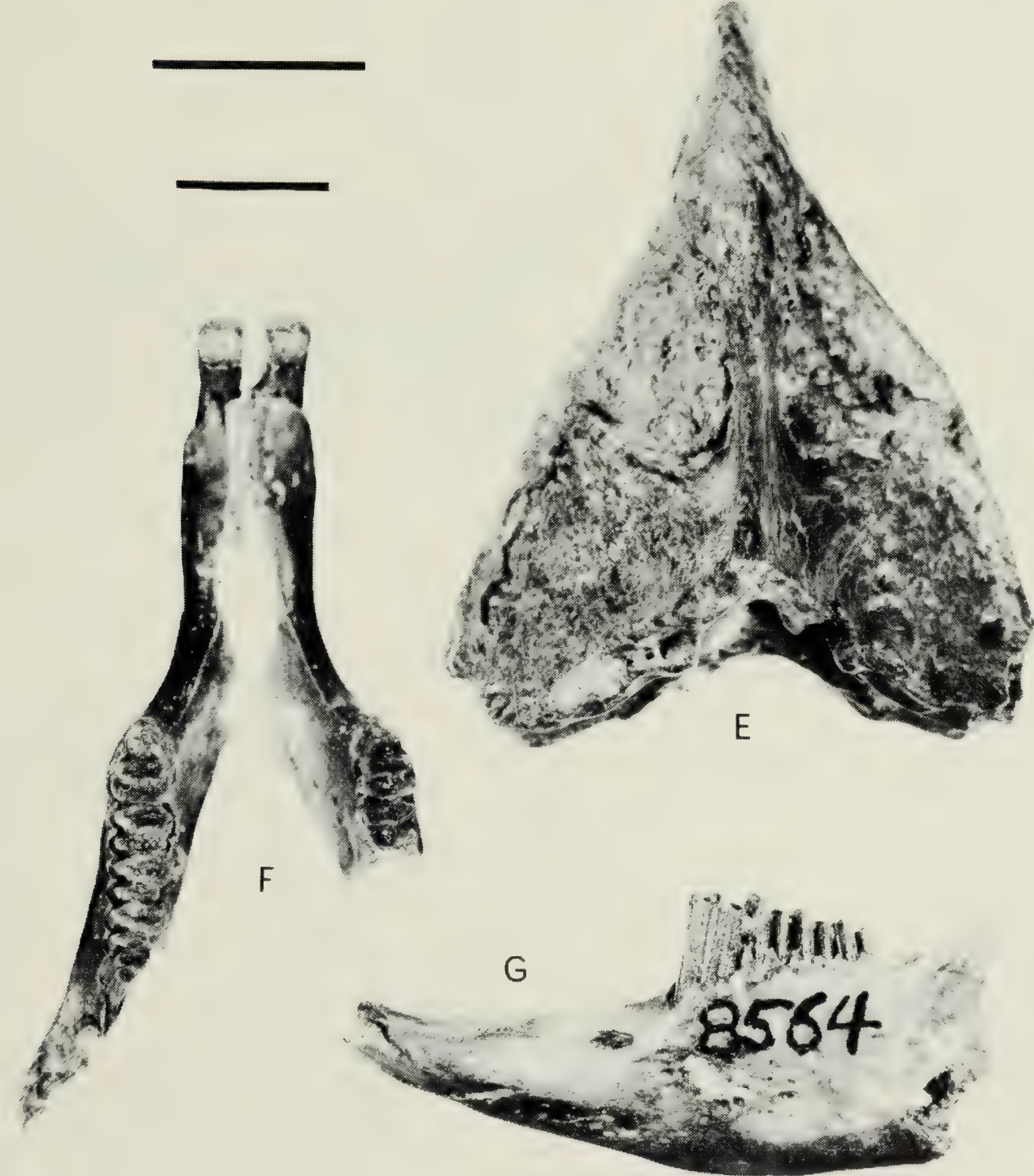

Fig. 11 Homo sapiens, Hyaena hyaena, and Lepus capensis.

A-D. Homo sapiens. Left upper first milk incisor 8560 from Gebel Silsila III, Level 3, Silsilian Industry. $\mathrm{A}=$ buccal aspect, $\mathrm{B}=$ distal aspect, $\mathrm{C}=$ lingual aspect, $\mathrm{E}=$ occlusal aspect. Upper bar $=30 \mathrm{~mm}$.

E. Hyaena hyaena. Nuchal fragment 8562 from Sebil III, posterior aspect. Lower bar $=10 \mathrm{~mm}$.

F, G. Lepus capensis. Mandibular specimens. $F=$ occlusal aspect of partial mandible with left $P_{3}-M_{3}$ and right $P_{3}-M_{1} 8563$ from Gebel Silsila vII. $G=$ buccal aspect of partial left dentary with $\mathrm{P}_{3}-\mathrm{M}_{2} 8564$ from Sebil III. Lower bar $=10 \mathrm{~mm}$. 


\title{
Order Carnivora \\ Family Canidae
}

\author{
Canis sp., probably \\ Canis lupaster-Egyptian wolf-jackal, \\ or C. familiaris-domestic dog
}

MATERIAL

Obtained from:

Gebel Silsila $\mathrm{X}$.

CONSIDERATION

The damaged condyle of a right dentary (8561) measures 10.3 in condylar diameter and more than 17.5 in transverse diameter. It is thus comparable to that of a domestic dog, Canis familiaris, or that of the Egyptian wolfjackal, C. aureus lupaster, which was recorded by Hoogstraal (1964) from the same area. The condyle is fairly strongly constructed and the anterolateral surface of the condyle and associated areas of the coracoid and ascending ramus are deeply concave, both characteristic of $C$. familiaris or C. lupaster.

\section{Family Hyaenidae}

Hyaena hyaena-striped hyaena (Fig. 11E)

MATERIAL

Obtained from:

Sebil III.

CONSIDERATION

The nuchal fragment (8562, Fig. 11E) is well ossified, was broken before deposition, and appears to be from a mature individual. The nuchal plate is more pointed than in old males of $H$. hyaena, and thus may derive from a young adult or a female. Spotted hyaena (Crocuta crocuta) was reported by Gaillard (1934) as "Hyaena crocuta Erxleben, race spelaea" from the Sebil Area on the evidence of a single damaged right dentary with $\mathrm{P}_{2}-\mathrm{P}_{3}$ and parts of other teeth. Measurements of this specimen agree best with those given by Gaillard for other $H$. spelaea, and thus both H. hyaena and C. crocuta appear to have been present.

\section{Order Lagomorpha}

\section{Family Leporidae}

Lepus capensis-Cape hare (Figs. 11F, 11G, and 12)

MATERIAL

Obtained from:

Gebel Silsila viII.

Sebil III.

\section{CONSIDERATION}

The two lagomorph specimens, a partial left dentary and the occlusal regions of a mandible (8564, Figs. 11F, 11G, and 12A; 8563, Figs. 12B 

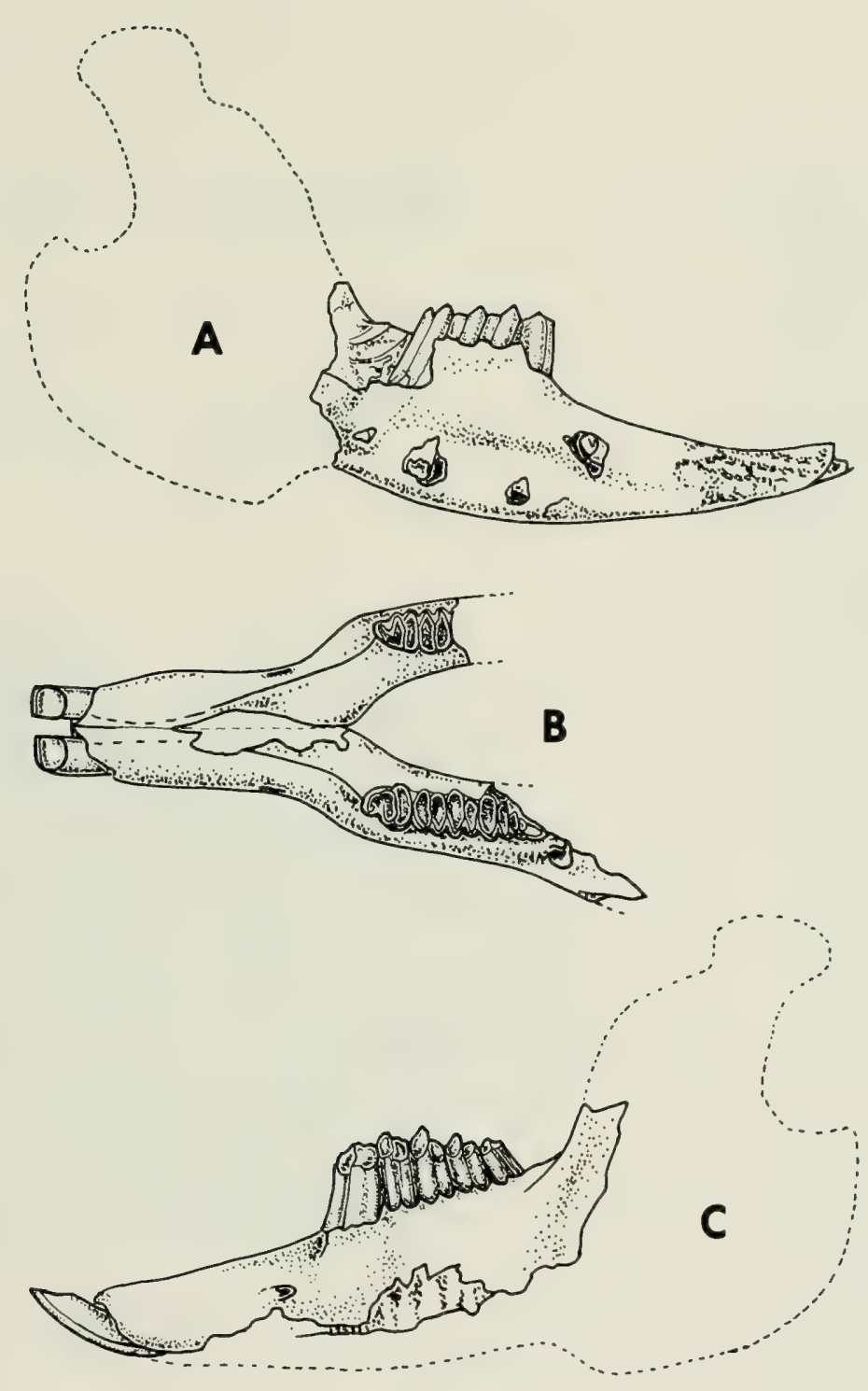

Fig. 12 Lepus capensis. Aspects of fragmentary mandibles. A - medial aspect of partial left dentary with $\mathbf{P}_{3-4}, \mathbf{M}_{1-2}$, from Sebil III (8564). B - occlusal and $\mathrm{C}$ - left lateral aspects of partial mandible with left $\mathrm{P}_{3-4}, \mathbf{M}_{1-3}$ and right $P_{3-4}$, from Gebel Silsila viI $(8563)$. Scale $=50 \mathrm{~mm}$.

and 12C) confirm Reed and Turnbull's (MS 1967) report of a hare. It is impossible to assign this material to a subspecies of $L$. capensis, but $L$. $c$. isabellinus is the presently extant form (Hoogstraal, 1963).

The two specimens are well matched for size and morphological characteristics. Measurements of the specimens are:

\section{Dimension}

$8564 \quad 8563$

Transverse diameter over diastema

$9.0 \mathrm{e} \quad 9.1$

Length of diastema

$19.9 \quad 21.1$

Length over $\mathrm{I}_{1}$ 's to $\mathrm{M}_{3}$ 's in occlusal plane

42.1

Mesiodistal diameter of $\mathbf{I}_{1}$

left left right

Buccolingual diameter of $I_{1}$

- 2.93 .0

Length $\mathbf{P}_{3}-\mathbf{M}_{3}$

$-\quad 2.4$
$-\quad 2.4$

$\mathbf{P}_{3}$ mesiodistal length

- $16.0-$ 
$\mathrm{P}_{3}$ buccolingual width

$\mathrm{P}_{4}$ mesiodistal length

$\mathrm{P}_{4}$ buccolingual width

$M_{1}$ mesiodistal length

$M_{1}$ buccolingual width

$M_{2}$ mesiodistal length

$\mathrm{M}_{2}$ buccolingual width

$\mathbf{M}_{3}$ mesiodistal length

$\mathrm{M}_{3}$ buccolingual width

Transverse width over I's

Transverse width between $P_{4}$ 's

Transverse width over $\mathbf{P}_{4}$ 's

\title{
Order Rodentia \\ Family Muridae
}

\author{
?Nesokia indica-Egyptian bandicoot \\ or pest rat (Figs. 13A and 13B)
}

MATERIAL

Obtained from:

Khor el-Sil Localities-IIb; III.

\section{CONSIDERATION}

The few fragments attributed to Nesokia indica are not diagnostic but resemble specimens of recent $N$. indica in the Collection of Mammals, National Museum of Natural History, Washington, D.C., and in the Collection of Mammals, British Museum (Natural History), London, in size and characters of the relevant parts. The three lower incisive specimens ( 9029 , 9030 and 9031) measure 2.3, 2.8, and 2.9 in transverse diameter of the enamel, and 2.6, 2.9, and 2.9 in buccolingual diameter, respectively. The enamel has a flat buccal surface, is white, greyish, greenish, or light brown, and wears to a more rounded lateral angle on the cutting edge than in Lepus or Tachoryctes. The pulp cavity does not appear to become completely filled with secondary dentine, as it is still visible on the wear facet in specimen 9029 (Fig. 13A).

Robinson (1966) recorded a lower jaw of $N$. indica from an upper Palaeolithic site, number 6B28, Dabarosa West, about $1 \mathrm{~km}$ west of the Nile river and $1.5 \mathrm{~km}$ west of Wadi Halfa, in the Sudan. Hoogstraal (1963, p. 27) stated of $N$. indica suilla, the extant form now confined to the lower Nile, the Fayum depression, Wadi Natroun, and the Bahariya Oasis, that "The shallow, moist tunnels of this animal are dug in or near gardens or cultivated plots, on desert slopes near saline lakes and in palm groves, ditch sides, or dykes." "Chief food plants appear to be Typha latifolia and Alhagi maurorum, fleshy parts of which are stored in chambers beside the burrows."

The presence of $N$. indica in the Kom Ombo Plain deposits connects the Wadi Halfa record with the extant range of the species and confirms that during the late Pleistocene the range of the species extended considerably 


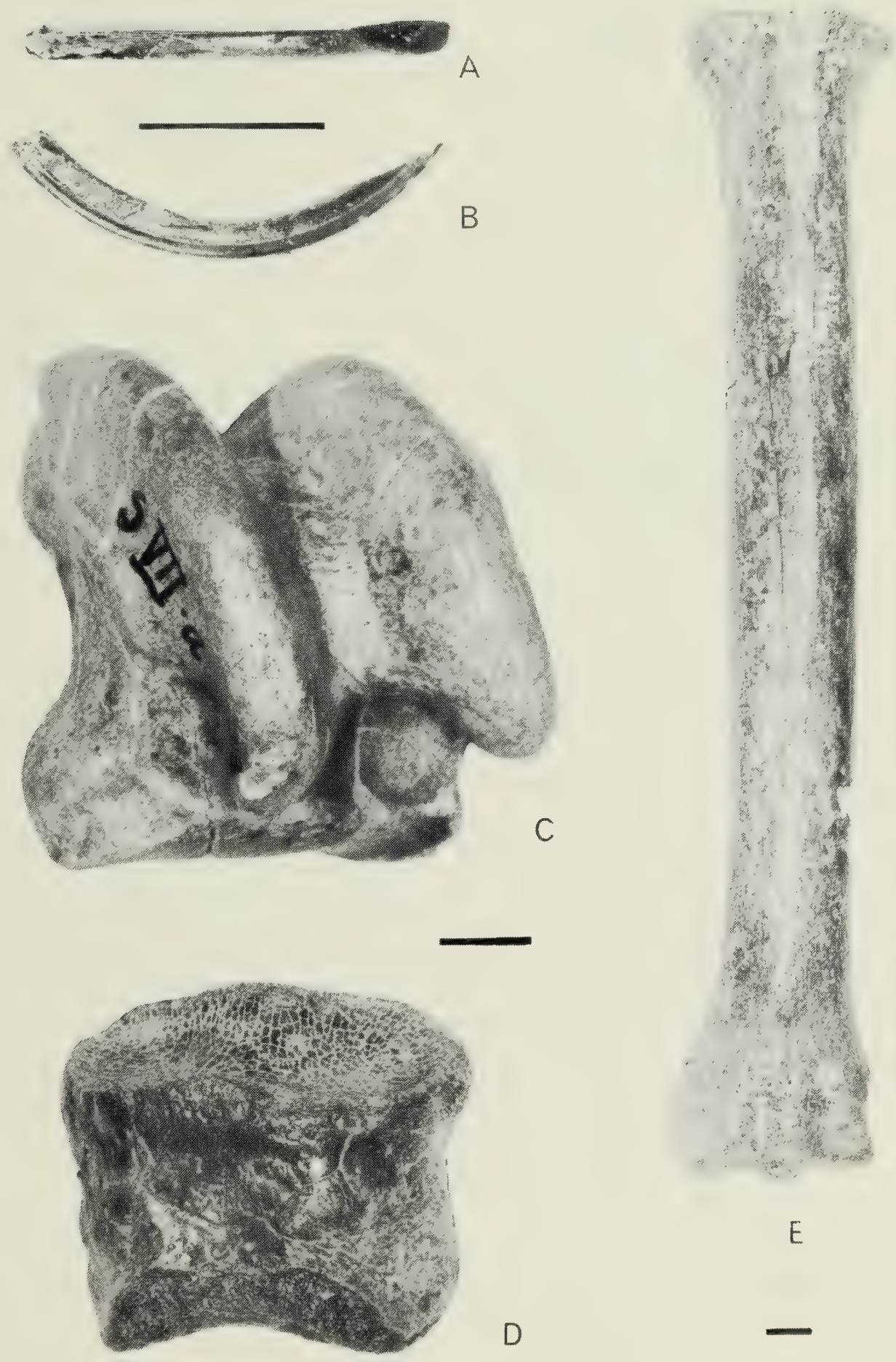

Fig. 13 Nesokia indica and Equus asinus.

A, B. Nesokia indica. Right lower incisor 9029 from Khor el-Sil ub. A = occlusal aspect, $\mathrm{B}=$ lateral aspect. Bar $=10 \mathrm{~mm}$.

C-E. Equus asinus. Postcranial elements. $\mathrm{C}=$ tibial aspect of left astragalus 8454 from Sebil vira, $\mathrm{D}=$ anterior aspect of middle phalanx 8584 from Sebil I, E = anterior aspect of right metatarsal III 8597 from the surface of the Sebil Area. Bars $=10 \mathrm{~mm}$.

to the south up the Nile valley. The presence of Nesokia may indicate moist conditions, at least in the riverine areas bordering the Nile at Kom Ombo, and may reflect a higher level of the Nile at that date or a moister climate. 

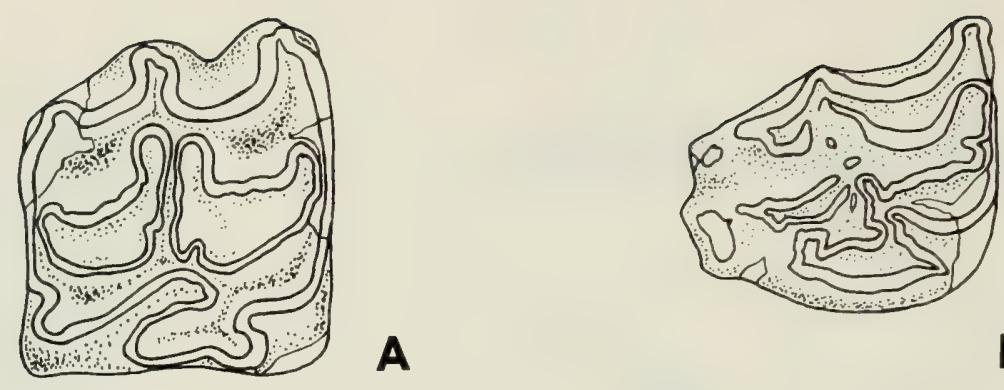

B
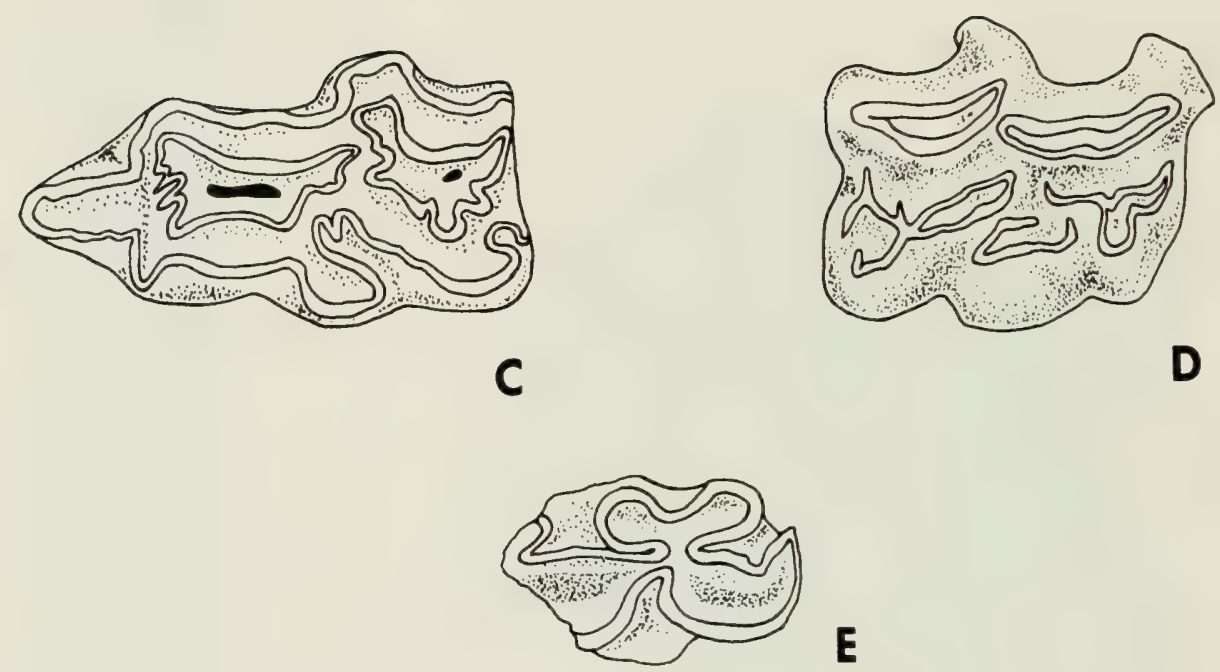

E

Fig. 14 Equus asinus cf. africanus. Occlusal aspects of cheek teeth. Permanent upper dentition: $A$ - damaged and worn right $\mathbf{M}^{1}$ from Sebil VII (8593); B damaged newly worn right $\mathbf{M}^{3}$ from Sebil Miscellaneous area (8595). Milk upper dentition: C - worn left $\mathrm{p}^{2}$ from Sebil vil (8591); D - newly worn right $\mathrm{p}^{3}$ from Sebil viI (8592). Permanent lower dentition: E - fragmentary right molar from Sebil viI (8594).

Unshaded areas on A and B indicate restored outlines. Secondary dentine in $A$ and $E$ indicated by grouped stippling within areas of dentine. Cavities in the cementum within the fossettes in $\mathrm{C}$ indicated by solid black areas. All projections are parallel to the wear planes. Scale $=50 \mathrm{~mm}$.

\section{Family Equidae}

Equus asinus cf. africanus-

Nubian wild ass (Figs. 13 and 14)

MATERIAL

Obtained from:

Oasis Depression G.

Gebel Silsila Localities-I; X; XI; XVII.

Sebil Localities-I; II; III; VII; Miscellaneous.

\section{CONSIDERATION}

The dental material includes only one well worn right upper first molar (8593, Fig. 14A), the buccal half of a right upper first molar (8575), a damaged right upper third molar (8595, Fig. 14B) and two milk premolars, a left upper second and a right upper third (8591, Fig. 14C and 8592, Fig. 
14D, respectively). The permanent teeth have buccally concave bowed ectolophs, overhanging parastyles and mesostyles, a mesially elongate and bilobate protocone, no pli caballin, weak or absent plis prefossette and plis protoconule, weak plis postfossette, and a small hypoglyph. The milk elements, as far as can be observed, show similar characters of the ectolophs, more complex plication of the fossette walls, and the absence of the mesial extension of the protocone of $\mathrm{p}^{2}$, as is usually present in equid milk premolars.

In general characteristics these teeth cannot be assigned to any of the recently extant species of zebras as bowed ectolophs are characteristic of $E$. burchelli, whereas the other characters are usual in E. quagga or less often in E. zebra (Cooke, 1943). The incisive fragment (8578) is too fragmentary, and gives no data on the presence or absence of infundibula in the lower incisors. The worn $\mathrm{rM}^{1}$ (8593) measures $27.2 \times 25.1$ for the buccolingual and mesiodistal diameters across the enamel of the occlusal surface respectively, whereas in all three species of zebras the buccolingual diameters lie between 21 and $26 \mathrm{~mm}$. The larger size and absence of the pli caballine suggest that the equid was an ass. Higgs (1967) gave ranges of $24.5,27.0$ and 25.0 by $25.5,24.0$ and 30.0 for (buccolingual ?) breadth and (mesiodistal ?) length, respectively, for the crowns of three upper molars of Equus sp., from Haua Fteah, which he considered "to be in accordance with the criteria used by Boule (1899) ... to distinguish $E$. mauritanicus specimens." However, E. mauritanicus is probably a subspecies of $E$. burchelli and therefore a zebra (Boule, 1899; Romer, 1928, p. 121; Romer, 1935, p. 172). Gaillard (1934) tentatively reported $E$. asinus from the Sebil area, and Oakley (1965) and Reed and Turnbull (1969; MS 1967) reported Equus cf. asinus and E. asinus, respectively, from the same levels at Kom Ombo that provided my material. Hoogstraal (1964) stated that E. a. taeniopus is the presently extant subspecies in the area.

Measurements of the cheekteeth are:

$\begin{array}{lcccccc}\text { Dimension } & 8593 & 8591 & 8592 & 8575 & 8595 & \begin{array}{c}\text { Gaillard } \\ (1934)\end{array} \\ & r M^{1} & l p^{2} & r p^{3} & r M^{1} & r M^{3} & M^{3} \\ \text { Mesiodistal length } & 25.1 & 40.3 & 31.4 & 26.2 & 24.2 & 27 \\ \text { Buccolingual width over enamel } & 27.2 & 19.9 & 18.5 \mathrm{e} & - & 20.3 & 24 \\ \text { Length of protocone } & 11.3 & 7.4 & 9.2 \mathrm{e} & - & 13.2 & \end{array}$

The milk left lower or right upper second incisor (8590) possesses a well developed mark and measures 18.6 by 9.8 and 21.1 by 4.4 for mesiodistal and buccolingual diameters of the crown and mark, respectively.

The right lower third molar fragment (8594, Fig. 14E) shows well arced buccal enamel margins, a narrow rounded Y-shaped metaflexid, and rounded metaconid and metastylid. A rounded metastylid is not usually present in any of the zebras (Cooke, 1943) and is present in $\mathbf{P}_{4}-\mathbf{M}_{3}$ of A sinus somaliensis (Quinn, 1957, Pl. II, Fig. 2).

All the evidence available from the dental material suggests that the small equid from Kom Ombo is a variety of E. asinus, and not one of the 
caballine or zebra-like equids. There is thus agreement between Gaillard's (1934) ass material and the more recently obtained sample.

The postcranial material is mainly fragmentary and undiagnostic to species (Fig. 13C to 13E). Measurements of the better preserved specimens are given only for completeness. The axis is badly deflated but shows the elongation, flattened odontoid, and divided atlanteal facets typical of the equidae. The other postcranial material is equine of small size.

The few comparative measurements of metacarpal, tibial, and phalangeal specimens from Gaillard's (1934) Sebil material and Gautier's (1968) Lake Nasser material agree in general size and proportions with those available from the more recent Kom Ombo excavations. All are assignable to $E$. asinus, probably E. asinus africanus. Similarly Gautier's comparable measurements of phalanx II agree with those from the recent Kom Ombo excavations and are assignable to $E$. asinus.

Gaillard's (1934) material from the Sebil Area comprised lower jaw fragments, a score of isolated molars in poor states of preservation, and some broken limb-bones. Of these, only the distal end of a tibia and a third upper molar are directly comparable with the Canadian Expedition's equid material through his illustrations and measurements, with which they agree within the normal ranges of variation for small equids. Gaillard gave measurements for the distal end of a right metacarpal III of 37, 29 and 19 in transverse articular diameter, diameter of the diaphysis and anteroposterior thickness, respectively, and for a pedal phalanx I of $70,43,34$ and 26 in total length, proximal transverse diameter, distal transverse diameter and minimum diameter of the diaphysis, respectively.

Gaillard (1934) assigned a single left lower molar, possibly $\mathbb{I P}_{4}$, and part of a right dentary with the second premolar, $\mathrm{rP}_{2}$, to Equus caballus and some 20 isolated teeth and other mandibular fragments to E. asinus.

The two upper molars ascribed to $E$. asinus by Gaillard (1934, p. 22 and Pl. II, Figs. 5 and 6) possess plis caballins, as noted by him, but are ascribed to $E$. asinus rather than $E$. caballus because "chez les chevaux le lobe postérieur" of the protocone "est plus grand d'avant en arrière que le lobe antérieur, chez les ânes la proportion est inverse: le lobe postérieur, examiné par la face externe, est plus petit que le lobe antérieur. En d'autres terres, la troisième molaire supérieure des Asiniens est relativement beaucoup plus courte dans le sens antéropostérieur que la troisième molaire supérieure dans les Caballins."

Unfortunately Gaillard's illustrations show that both third upper molars possess protocones with longer distal than mesial portions, which he stated to be characteristic of a caballine horse, and thus could be assigned to $E$. caballus. Upper cheekteeth of asses, in comparison with those of true horses, generally possess mesiodistally short and bilobed protocones, except for $\mathrm{M}^{3}$ where they may be more elongate, secondary plis either rudimentary or small but simple, and a pli caballin that may be absent, rudimentary, or present only during the early stages of wear (Petit, 1939). On these criteria both of the upper molars assigned to $E$. asinus and the $\mathrm{M}^{3}$ assigned to $E$. caballus by Gaillard were correctly determined. 
Gaillard assigned the lower jaw teeth and fragment to E. caballus because "Le pli d'email antérieur couvre presque la totalité de l'épaisseur de la dent (pl. II, fig. 2), tandis que chez l'âne ce pli n'atteint, nous l'avons vu, que les deux tiers environ de la face antérieure (pl. II, fig. 10)." If "le pli d'email antérieur" refers to the parastylid, this is a valid character (Petit, 1939). The presence of a V-shaped metaconid-metastylid groove, the anterolateral orientation of the reëntrant between the paralophid and protoconid, rounded rather than elongate or angular lingual enamel figures, and the mesiodistally longer entoconid characterize the tooth as deriving from an ass rather than a true horse (Petit, 1939; Reed and Turnbull, 1969). A strong external pli caballinid (pli ectostylid) in the ectoflexid is possible in both asses and horses, although in general it is a highly variable and individual feature (Petit, 1939). Gaillard's equid lower molar should therefore be assigned to $E$. asinus, as suggested by Reed and Turnbull (1969). Other lower teeth assigned to E. asinus, also illustrated in the same plate by Gaillard (1934, Pl. II, Figs. 4, 4a, 9, 10 and 10a), possess incipient plis caballinids only, less extensive parastylid ridges and rounded or less angular metastylids, all characters typical of asses.

As Gaillard's materials all derived from a surface collection and as both $E$. caballus and $E$. asinus were present, the probability that the materials were derived from different ages is high. No record of $E$. caballus is known from any of the other levels in the Kom Ombo Plain's deposits for which a Late Palaeolithic age is suggested, and the presence of this species at this time in the area must be considered to be unsubstantiated.

Measurements of the better preserved postcranial elements are:

\section{Axis}

Length of odontoid to posterior centrum

Transverse diameter of odontoid

Transverse diameter of atlanteal facets

Transverse diameter of posterior centrum

Transverse diameter of postzygapophyses

Minimum diameter of body

Thoracic vertebra

Transverse diameter across processes

Transverse diameter across anterior costal demifacets $\quad 56.5$

Transverse diameter across posterior costal demifacets $\quad 55.5$

$\begin{array}{ll}\text { Transverse diameter of anterior centrum } & 29.4\end{array}$

Transverse diameter of posterior centrum $\quad 32.1$

Dorsoventral depth of anterior centrum $\quad 26.8$

Dorsoventral depth of posterior centrum $\quad 32.9$

Depth from mammilate to inferior process on transverse process $36+$

Anteroposterior length of centrum over margins 36.6

\section{$\begin{array}{ll}\text { Sacrum } & 8567\end{array}$}

Transverse diameter of anterior centrum $\quad 52 \mathrm{e}$

Dorsoventral diameter of anterior centrum 22.5

Ectocuneiform $\quad 8582$

Transverse diameter $\quad 36.5$

Anteroposterior diameter $\quad 30.0$

Proximodistal depth of lamina $\quad 10.4$

Maximum proximodistal depth $\quad 15.2$ 
Transverse diameter of shaft

Anteroposterior diameter of shaft

Transverse diameter over condyles

Transverse diameter of medial condyle

Transverse diameter of lateral condyle

Transverse diameter of intercondyloid notch

Transverse diameter of trochlea

Anteroposterior diameter over condyles and trochlea

\section{Tibia}

Distal transverse diameter

\section{1}

$55+$

Distal anteroposterior diameter

Diameter across astragalar trochlear grooves

\section{Astragalus}

Proximodistal length

Transverse diameter over navicular facet

Anteroposterior depth over navicular facet

Transverse diameter over tibial trochlea

Anteroposterior depth on medial surface

Anteroposterior depth on lateral surface

\section{Calcaneum}

Maximum length

Transverse width

Transverse diameter of calcar

Proximodistal depth over coronoid

$\begin{array}{cc}8586 & 8542 \\ 57.5+ & - \\ 41+ & 41.2 \\ 44.1 & 41 \mathrm{e} \\ & 8454 \\ & 54.8 \\ & 46.2 \\ & 30.7 \\ & 43.0 \\ & 45.8 \\ & 32.4\end{array}$

Gaillard

(1934)

65

42

45

8596

$50 \mathrm{e}$

42.5

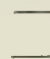

8568

$90+$

19.3

42.1

\section{Metatarsals II and III}

\section{II}

III

Maximum length
Proximal anteroposterior
diameter
Proximal transverse diameter
Midshaft anteroposterior
diameter
Midshaft transverse diameter
Distal anteroposterior diameter
over keel
Distal anteroposterior diameter
over shoulder
Distal transverse diameter
Phalanx II
Total length
Proximal anteroposterior depth
Proximal transverse width
Midshaft anteroposterior depth
Midshaft transverse width
Distal anteroposterior depth
Distal transverse width

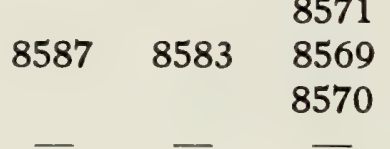

8589

8597

Gautier

(1968)

$\begin{array}{llll}21.7 & 32.9 \quad-\quad & - & 41.5\end{array}$

$\begin{array}{llll}13.2 & 40.0 \quad 47.8 \quad-\quad 45.1\end{array}$

- $-\quad-$

- $\quad 27.8$

25

29.3

26.7

Anteroposterior length

$45 \mathrm{e}$

Transverse width

Height of extensor crest above plantar plane

$60.3+$ 


\section{Order Artiodactyla \\ Family Hippopotamidae}

Hippopotamus amphibius-hippopotamus

(Figs. 15 to 19 )

MATERIAL

Obtained from:

Oasis Depression Localities-A; B; C; D.

Bayara A.

Gebel Silsila Localities-III, Surface and Subsurface, mixed Sebekian and Silsilian-Level 0; III, Sebekian-Level 1; X; XIII, Sector 2; XIII, Sector 2a; XIII, Mound H; XIV-XV.

Sebil Localities-I; III; IV; v; VI; Miscellaneous (III/IV).

Khor el-Sil Localities-Ia; IV; Miscellaneous (II/III).

\section{CONSIDERATION}

The hippopotamus materials will be considered as a single entity, since all Recent Hippopotamus comprise the nominate species, $H$. amphibius L., and even racial differences are probably completely invalid (Hooijer, 1950).

The partial skull (8598, Fig. 15) comprises most of the dorsal roof, nuchal plate, basicranial region, zygomatic arches, roots of left $\mathbf{M}^{3}$ and fragments. The lachrymal lies between the frontal and maxilla and has the usual posteroexternal prolongation to the margin of the orbit, as in advanced $H$. amphibius but not in $H$. protamphibius or the pigmy Choeropsis liberiensis. The Kom Ombo specimen more closely resembles Hooijer's (1950, p. 25, Fig. 3) specimen no. 6. The orbital angle of the Kom Ombo specimen appears large, and the dorsal surface of the posteroexternal tongue is reduced and fused to the frontal. The measurements of the skull, when compared with those from Recent $H$. amphibius, suggest that the skull may represent an old male because of the greater zygomatic and nuchal development.

The damaged mandible (8599, Figs. 6 and 16) lacks both condyles and coronoids, first lower incisors, second premolars and right first molar, and has well worn teeth characteristic of an old adult. The loss of $\mathrm{rM}_{1}$ in life produced excessive wear on the right $\mathrm{P}_{3}, \mathrm{P}_{4}$ and $\mathrm{M}_{2}$, which shows as reduced enamel patterns in these teeth. In other aspects the jaw is unremarkable.

Most of the postcranial material is damaged and fragmentary and only the podial, metapodial and tibial specimens provide useful measurements. The atlas (8641) resembles that illustrated by Reynolds (1922, p. 17, Figs. $2 \mathrm{~A}, \mathrm{~B})$ but differs in details; the axes are generally too fragmentary for comparison with Reynolds' (1922, p. 17, Fig. 2c) illustration.

The metacarpals II and IV (8609, Figs. 18A, 18B; 8610, Figs. 18C and $18 \mathrm{D}$, respectively) are massive and greater in cross-sectional area than those of a modern specimen in the Collection of the Department of Zoology, University of Toronto (UTZ 28.W.3-1), and the metatarsal v (8625) is similarly larger. 


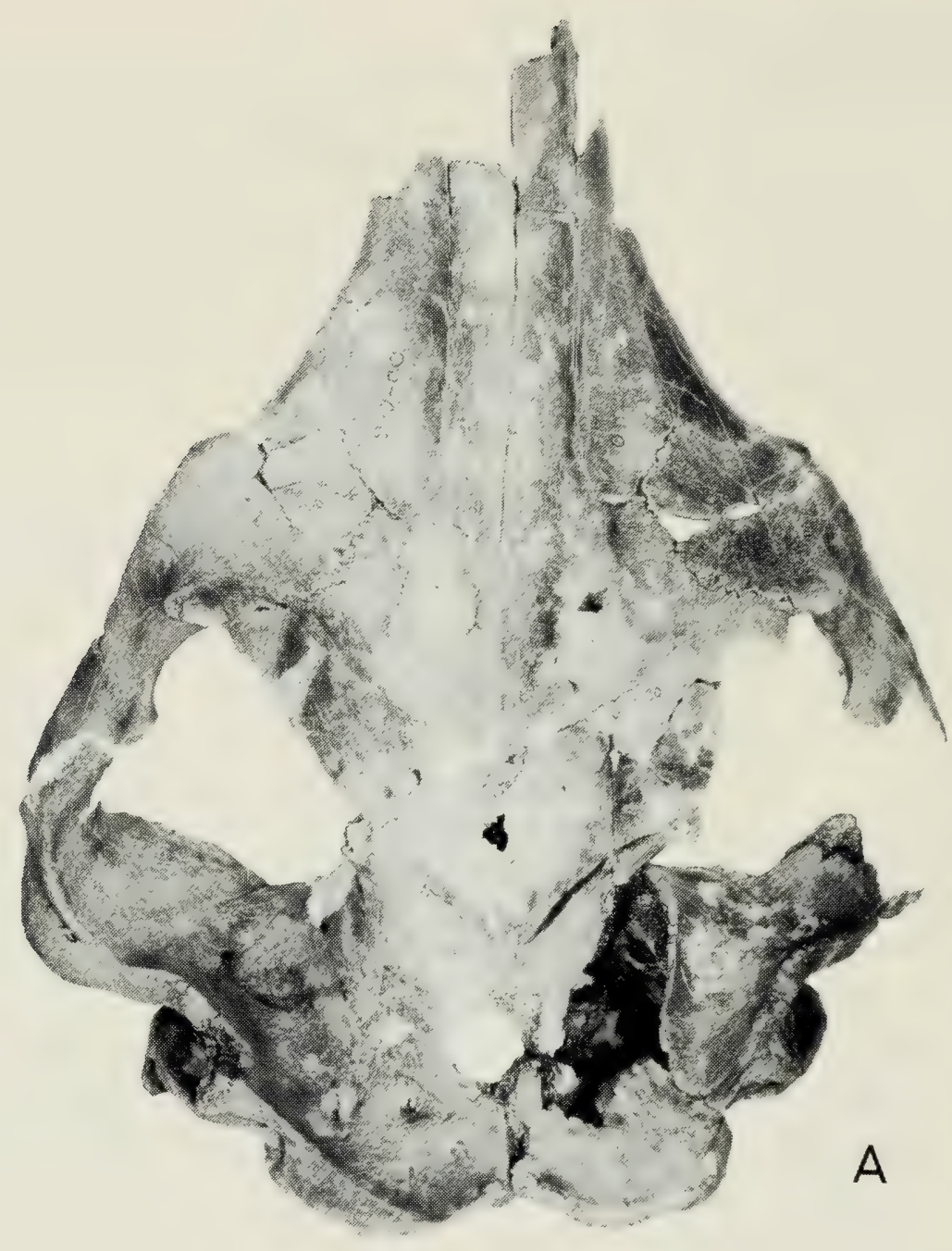

A

\section{B}

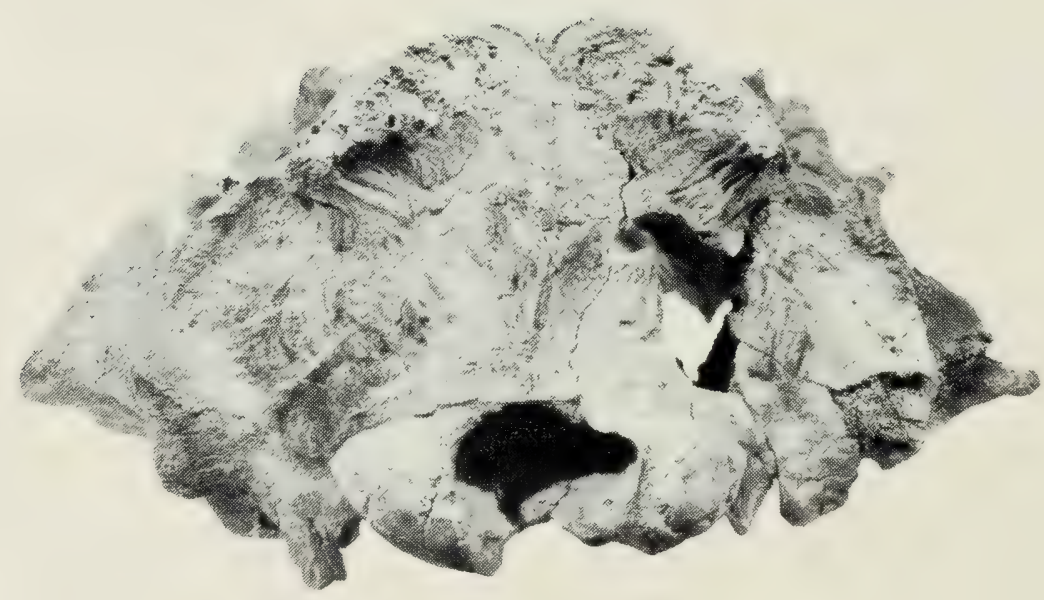

Fig. 15 Hippopotamus amphibius. Damaged and partial skull 8598 from Oasis Depression $\mathrm{A} . \mathrm{A}=$ dorsal aspect, $\mathrm{B}=$ nuchal aspect. $\mathrm{Bar}=50 \mathrm{~mm}$. 

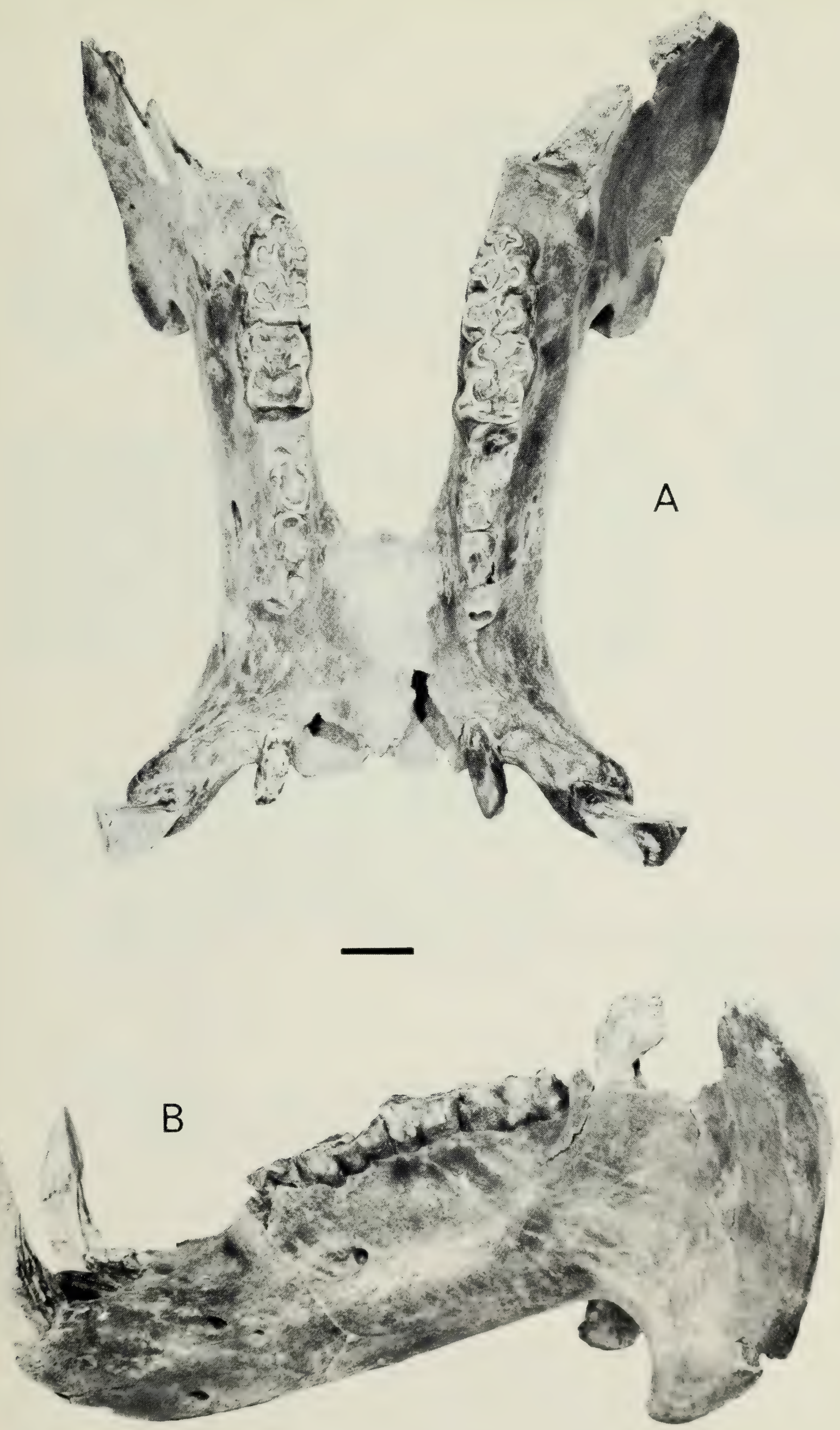

Fig. 16 Hippopotamus amphibius. Damaged mandible 8599 from Oasis Depression. $\mathrm{A}=$ occlusal aspect, $\mathrm{B}=$ left lateral aspect. $\mathrm{Bar}=50 \mathrm{~mm}$. 

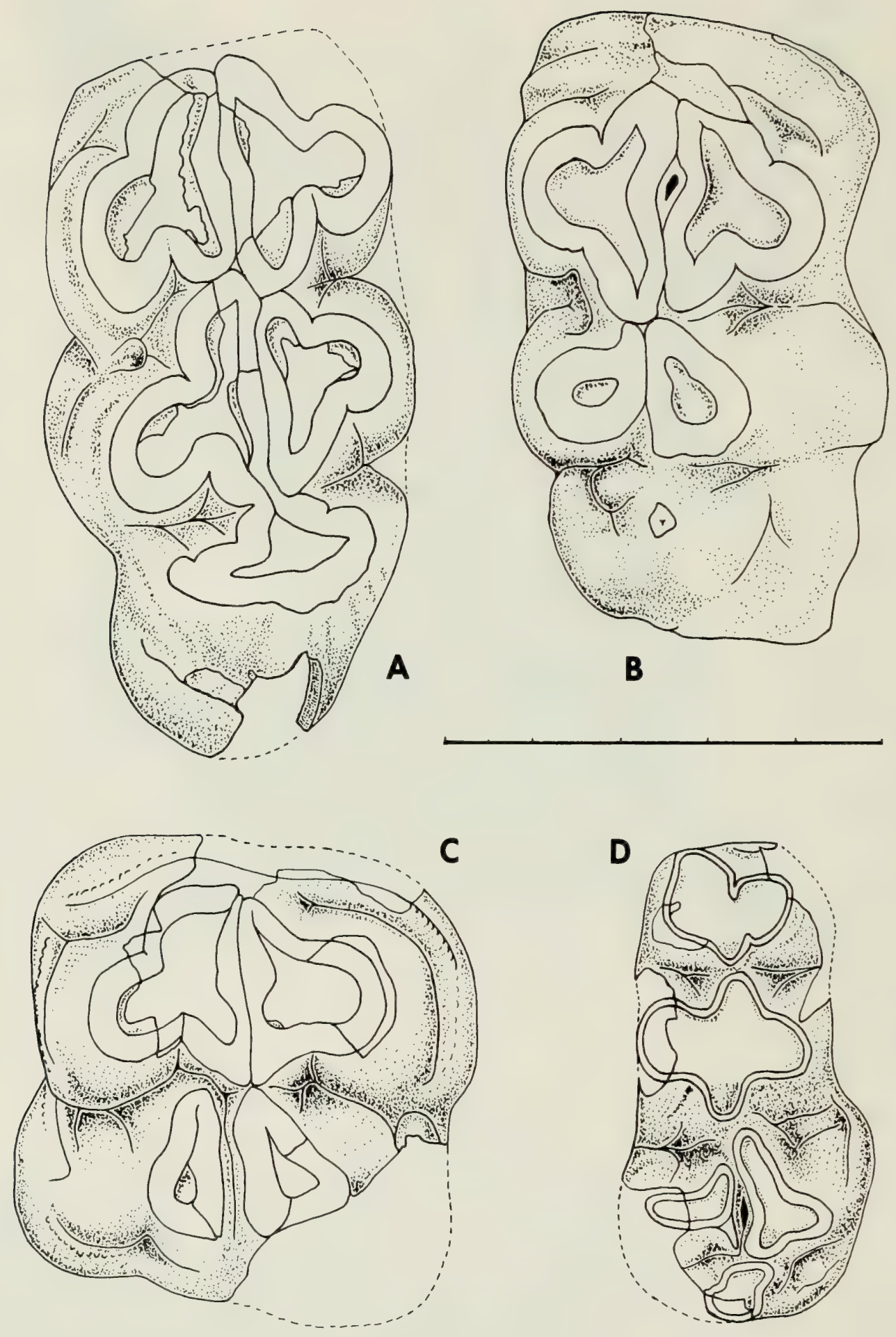

Fig. 17 Hippopotamus amphibius. Occlusal aspects of cheek teeth. A - damaged and partly worn left $\mathbf{M}_{3}$ from Gebel Silsila XIII (8618). B - newly worn right $M_{3}$ from Sebil vi (8639). C - partial newly worn left $M_{2.2}$ from Gebel Silsila XIII (8621). D - damaged and worn milk right $\mathrm{p}_{4}$ from Sebil vi (8638). Broken lines indicate restored outlines. Worn enamel surfaces unshaded and restored; dentinal surfaces shaded where preserved; and missing portions of teeth unshaded. Scale $=50 \mathrm{~mm}$. 

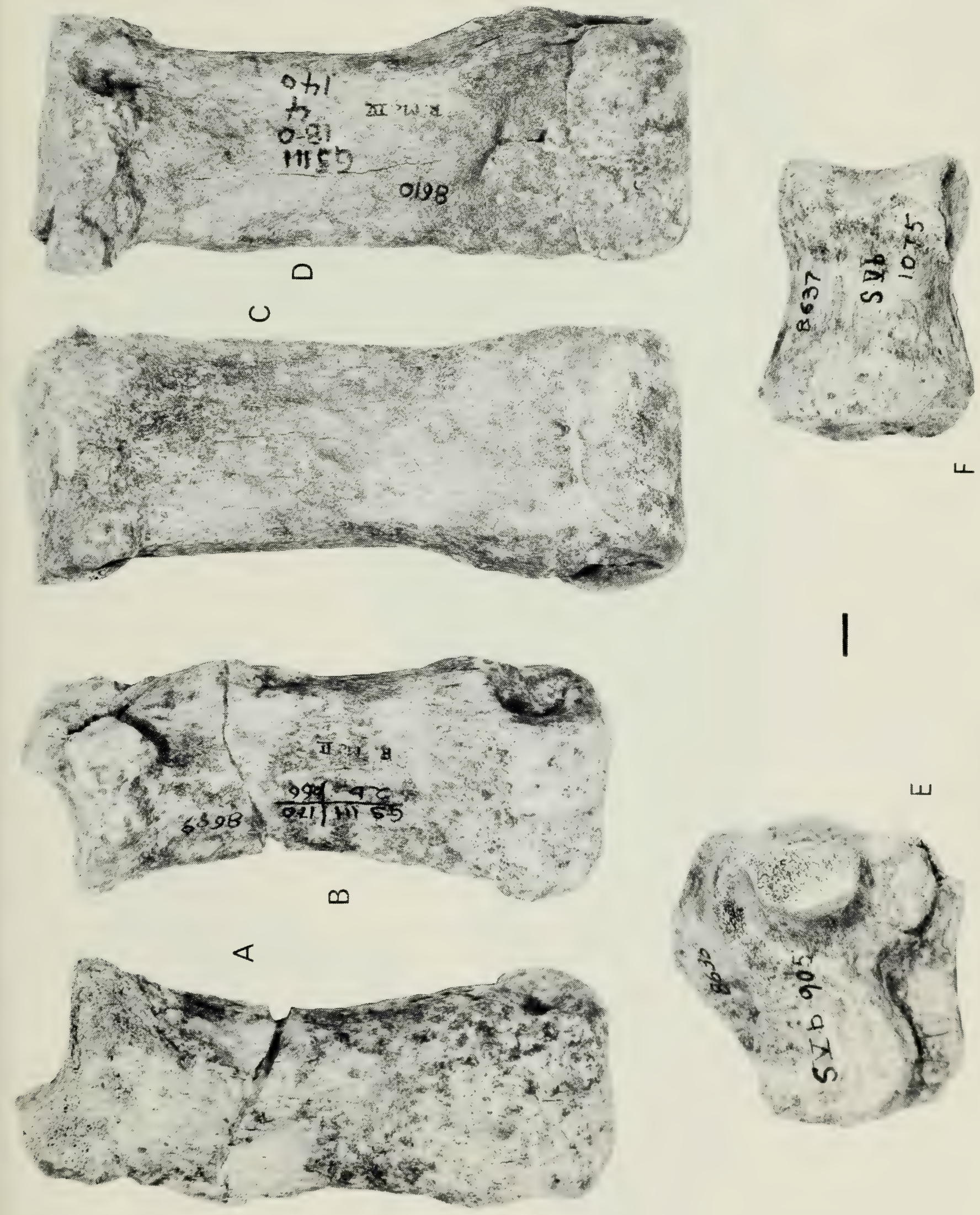

Fig. 18 Hippopotamus amphibius. Podial elements.

A, B. Right metacarpal II 8609 from Gebel Silsila III, Level 1, Sebekian Industry. $\mathbf{A}=$ anterior aspect, $\mathbf{B}=$ posterior aspect.

C, D. Right metacarpal IV 8610 from Gebel Silsila III, Level 1, Sebekian Industry. $\mathrm{C}=$ anterior aspect, $\mathrm{D}=$ posterior aspect.

E. Proximomedial aspect of right navicular 8636 from Sebil vb.

F. Anterior aspect of manual phalanx II 8637 from Sebil vb.

Bar $=10 \mathrm{~mm}$. 


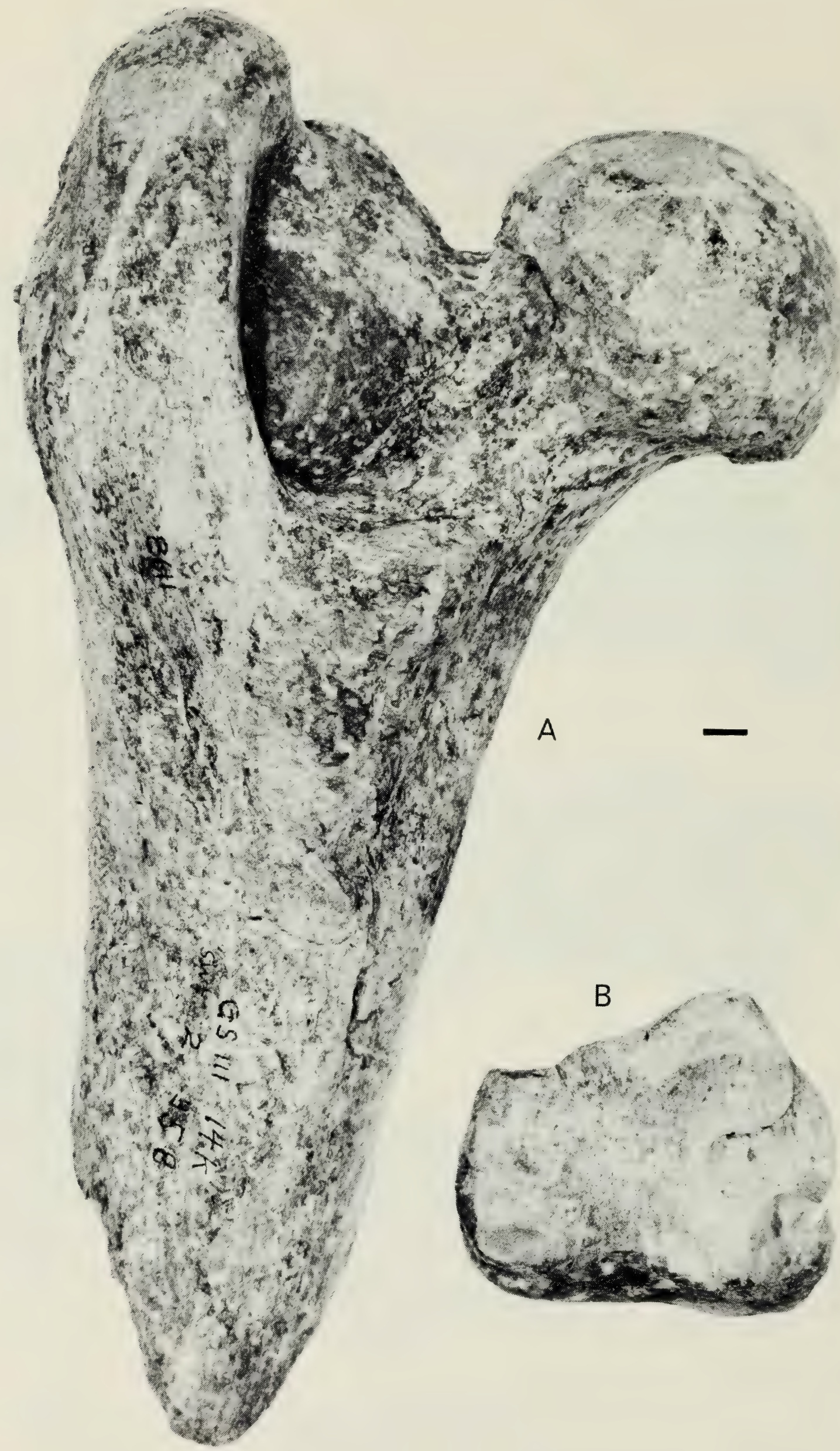

Fig. 19 Hippopotamus amphibius. Femoral and tibial fragments. $\mathrm{A}=$ posterior aspect of proximal end of left femur 8611 from Gebel Silsila III, Level 2, mixed Silsilian and Sebekian industries. $B=$ astragalar articulation of left tibial fragment 8635 from Sebil vb. Bar $=10 \mathrm{~mm}$. 
The manual phalanx I (8626) is weathered and damaged and matches that on the comparative manus (UTZ 28.W.3-1).

The phalanx II (8637, Fig. 19F) is identified as manual rather than pedal because of the large insertion scars for the volar sesamoid ligaments and its heavier build. As with the metacarpals, this specimen is larger and more massive but appears small in comparison with the associated second digit's metacarpal and proximal phalanx of the recent specimen (UTZ 28.W.3-1).

The coxal fragment (8603) articulates well with the proximal end of the femur (8611, Fig. 19A), which resembles that illustrated by Reynolds (1922, p. 29, Figs. 13A, B) and falls within the ranges of measurements given by Reynolds (1922, p. 32).

The distal ends of the tibiae (8635, Fig. 19B; 8634) fall within the ranges given by Reynolds (1922, p. 32) for fossil and Recent Hippopotamus in British collections.

The distorted and irregular formation of the tusk fragments (8622) reveal much dentine and some enamel. The tusk is flattened and the enamel is transversely and longitudinally ridged. This condition may have been pathological from disease or malformation, or the result of a battle between males, or damage caused by an unsuccessful attempt by the inhabitants of the Kom Ombo Plain to take this individual.

Gaillard (1934) reported "Hippopotamus amphibius Linné, race major Owen" from the Sebil Area at Kom Ombo. His materials included maxillary fragments with well preserved molars, a premolar and a canine fragment, an astragalus, many broken vertebrae, an occiput with condyles, other skull and facial fragments, two distal articulations of femora and a metatarsal.

Gaillard was unable to distinguish his dental material from that of living African $H$. amphibius on qualitative characteristics but assigned it to $H$. $a$. major Owen because of its larger size. He recorded the diameters across the occipital condyles as 163 and of the distal condyles of the femur as 150 in the Sebil material, but the largest living individuals do not exceed 150 and 135, respectively, for these dimensions (Hooijer, 1950). The astragalus measured 90 and 86 for the length of the lateral and medial faces, respectively.

Vignard (1955, pp. 703-704) reported the occurrence of another specimen from the floor of the Wadi Shait "j'avais trouvé en juin 1922,..., un squelette d'Hippopotamus amphibius major" which was specifically determined by Gaillard (1934).

The individuals that Gaillard had to consider were larger than any of the Recent $H$. amphibius measured by Hooijer (1950, Table 1b, opp. p. 112), which are between 120 and 147 across the occipital condyles and 105-106 for the length on the lateral face of the astragalus. The Canadian Expedition's materials of Hippopotamus are not as large as those recorded by Gaillard and resemble the Recent $H$. amphibius in size. Size variation alone may be responsible for these differences and all the material of the Kom Ombo Plain hippototami may represent $H$. amphibius, as suggested by Hooijer (1950). 
Measurements of some of the better preserved specimens of $H$. amphibius from the Kom Ombo Plain and comparative ranges of variation of these measurements, with sample sizes in parentheses, for Late Pleistocene and Recent $H$. amphibius are:

\section{Dimension}

\section{Cranium}

Width across zygomatic arches

Width at narrowest part of skull in front of infraorbital foramen

Measurement across orbits at frontolachrymal suture

Transverse measurement of cranium at its narrowest point behind orbits

Vertical height from intercondylar notch to top of sagittal crest

Transverse diameter of foramen magnum

Transverse diameter of occiput

\section{Mandible}

Transverse diameter at the base of the canines

Transverse measurement across rami at posterior end of symphysis

Diameter across anteroinferior projection of angle

Length of mandibular symphysis

Length of lower diastema

Length from front of mandible to $\mathbf{M}_{3}$

Height of ramus at $\mathbf{M}_{2}$

\section{Dentition}

Greater diameter of $I_{1}$

Greater diameter of $\mathbf{I}_{2}$

Length of $\mathrm{C}_{1}$ on outer curvature

Greater diameter of $\mathrm{C}_{1}$

Lesser diameter of $\mathrm{C}_{1}$

Length of $\mathbf{P}_{2}-\mathbf{M}_{3}$

Length of $\mathbf{P}_{2}-\mathbf{P}_{4}$

Length of $\mathbf{M}_{1}-\mathbf{M}_{3}$

$\mathrm{P}_{3}$ mesiodistal diameter

$\mathrm{P}_{3}$ buccolingual diameter

$\mathrm{P}_{4}$ mesiodistal diameter

$\mathrm{P}_{4}$ buccolingual diameter

$M_{1}$ mesiodistal diameter

$\mathrm{M}_{1}$ buccolingual diameter

$\mathrm{M}_{2}$ mesiodistal diameter

$\mathrm{M}_{2}$ buccolingual diameter

$\mathrm{M}_{3}$ mesiodistal diameter

$\mathrm{M}_{3}$ buccolingual diameter

60

8618
Recent $H$. amphibius

8598

$\mathrm{R}=$ Reynolds $(1922$, p. 9)

$\mathbf{H}=$ Hooijer (1950, Table 1)

$430 \mathrm{e}$

$\begin{array}{ll}\text { H } 327 & -458\end{array}$

R $393-474$

$120 \mathrm{e}$

$\begin{array}{lll}\text { H } & 89 & -174\end{array}$

R $101-146$

227

R 221.5-273

140

211

R 122.5-146

$\begin{array}{lll}\text { R } 150 & -216.5\end{array}$

H $163-222$

68

R $49-75$

310

H $223-341$

8599

365

256

489

178

137

$\begin{array}{lll}\text { R } 317 & -450\end{array}$

H $235-406$

R $213-268$

R 447.5-494

$\begin{array}{lll}\text { R } & 167 & -211\end{array}$

H $135-224$

$\begin{array}{lll}\mathrm{H} & 95 & -154\end{array}$

446

H $380-468$

146

H $109-154$

\section{9}

right left Hooijer (1950)

$\begin{array}{llll}48.0 & 47.0 & 31-59 & \text { (23) }\end{array}$

$\begin{array}{llll}30.2 & 28.8 & 20-32 & (20)\end{array}$

$\begin{array}{llll}30.2 & 28.8 & 20-295 & (29)\end{array}$

$\begin{array}{llll}54.1 & 52.9 & 38-73 & (19)\end{array}$

$32.4 \quad 32.3 \quad 25-51 \quad$ (20)

$280 \mathrm{e} \quad 283 \mathrm{e} \quad 232-293 \quad$ (19)

$110 \mathrm{e} \quad 107 \mathrm{e}$

$170 \quad 184 \quad 149-183$

$35 \quad 38.2$

$\begin{array}{ll}24.2 & 25.9\end{array}$

$38.6 \quad 32.0$

$29.2 \quad 28.9$

- $\quad 41.5 \quad 42-57$

35.3

29- 39

56.3

\section{5}

$51-66$

45.0

45.5

$35-47$

64- 86 
$M^{1}$ mesiodistal diameter

$\mathrm{M}^{1}$ buccolingual diameter

$\mathrm{M}^{2}$ mesiodistal diameter

$\mathrm{M}^{2}$ buccolingual diameter

$\mathrm{p}_{4}$ mesiodistal diameter

$\mathrm{p}_{4}$ buccolingual diameter

$\begin{array}{lc}8614 & \text { Gaillard } \\ 40 \mathrm{e} & (1934) \\ 36.5 \mathrm{e} & 53 \\ 56.5 & 65\end{array}$

41.5

8638

54.5

29.4

IV

Recent

Recent

Hooijer

8609 28.W.3-1 (1950, p. 90)

UTZ Hooijer

28.W.3-1 (1950, p. 96)

Total length

$141.5 \quad 113.7$

$130 \quad(2)$

$\begin{array}{rr}8610 & 28 . \\ 156.0 & 135.0\end{array}$

Proximal transverse width

$49.3 \quad 33.8$

35-38 (2)

$60.4 \quad 46.2$

Proximal anteroposterior depth $50.1 \quad 31.7$

43-46

(2)

$60.6 \quad 38.5$

Midshaft transverse width $41.6 \quad 29.5 \quad 36-39(2)$

Midshaft anteroposterior depth

$23.0 \quad 18.0 \quad 24-28(2)$

Distal transverse width

$51.1 \quad 33.4$

Distal anteroposterior depth

$39.2 \quad 31$

$(20$

Distal articular width

$45.8 \quad 33.0 \quad 38-41$

$48.2 \quad 34.0$

$55.4 \quad 38.6$

\section{Manual Phalanges I of Digits II and III}

Total length

Proximal transverse width

Proximal anteroposterior depth

Midshaft transverse width

Midshaft anteroposterior depth

Distal transverse width

Distal anteroposterior depth

\section{Femur}

Transverse diameter at proximal end measured across head and greater trochanter

Anteroposterior diameter of head

Anteroposterior diameter at midshaft

(2)

Phalanx I,

Digit II

Phalanx I,

Digit III

$$
\text { UTZ }
$$

UTZ

\begin{tabular}{ll|ll}
8626 & $28 . W .3-1$ & 8637 & $28 . W .3-1$
\end{tabular}

\begin{tabular}{ll|ll}
62.7 & 66.5 & 69.8 & 65.1
\end{tabular}

\begin{tabular}{ll|ll}
31.9 & 33.2 & 52.9 & 41.1
\end{tabular}

\begin{tabular}{ll|ll}
$30 \mathrm{e}$ & 31.2 & 38.0 & 35.4
\end{tabular}

\begin{tabular}{ll|ll}
20.4 & 20.3 & 40.1 & 29.4
\end{tabular}

\begin{tabular}{ll|ll}
22.2 & 24.0 & 25.5 & 18.8
\end{tabular}

\begin{tabular}{ll|ll}
26.8 & 24.1 & 45.0 & 35.5
\end{tabular}

\begin{tabular}{ll|ll}
$27 \mathrm{e}$ & 22.1 & 26.8 & 21.0
\end{tabular}

Fossil and Recent

Reynolds Hooijer

$8611 \quad(1922$, p. 32) $\quad(1950$, p. 104-5)

$194.5 \quad 157.5-202 \quad(5) \quad 167-174$ (2)

$87.7 \quad 71-96.5(5) \quad 82-89$ (2)

$72.2 \quad 58.5-82.5(5) \quad 62-69(2)$

\section{Tibia}

Transverse diameter at distal end

Anteroposterior diameter at distal end
$8635 \quad 8634$

$\begin{array}{ccccc}89.1 & 95.5 & 93 & -107.5(3) & 98-103(2) \\ 69.6 & 74.9 & - & 78-87(2)\end{array}$


Transverse diameter

Anteroposterior diameter

Proximodistal diameter anteriorly

Proximodistal diameter posteriorly

\section{Metatarsal V}

\section{Family Bovidae, Subfamily Bovini}

The Genera Homoioceras, Syncerus and Bos

Gaillard (1934) reported Homoioceras (Bubalus) vignardi, Bos primigenius, and B. brachyceros as occurring at Kom Ombo. Smith (1967) referred to "a fairly complete sub-fossilised large Bos skull" seemingly associated with "a possible derivative of the Sebilian (Sebilian IV in Vignard's classification ?)", and that "another smaller Bos skull found nearby" ... "promise to throw considerable light on the problem of the races of wild cattle (primigenius or brachyceros) claimed to be extant in the Nile Valley in pre-Neolithic times." Reed and Turnbull (1969; MS 1967) recorded Bos primigenius and the possibility of Homoioceras vignardi from Kom Ombo, but discarded Gaillard's (1934) identification of B. brachyceros because the criteria on which he based his distinction between Bos primigenius and B. brachyceros represented wear and not speciation. Bate (1949) recognised that Gaillard's (1934) description of "Bubalus" vignardi was not that of the Asiatic genus and erected Homoioceras to include the extinct longhorned African buffaloes. Bate (1951) described in detail H. singae Bate 1949 from a probably earlier part of the Upper Pleistocene deposits on the Blue Nile at Singa, Sudan. Gentry (1967, p. 277, Fig. 11) illustrated right M's of Homoioceras, Syncerus, and Bos primigenius and briefly discussed their basal pillars (endostyles). Elsewhere in his paper Gentry remarked on the conditions of various characters in these and other bovid genera.

Gaillard's (1934) description of "Bubalus" vignardi was based on the second and third upper left molars and an imperfect horncore, that are considered later in this paper. Reed and Turnbull (MS 1967) assigned these teeth to Bos primigenius but did not mention the horncore that Bate $(1949,1951)$ apparently considered to represent her genus Homoioceras. Moreover, Bate did not suggest that some of the teeth described by Gaillard may not have been from Homoioceras.

Bate (1951) described the almost complete skull of $H$. singae, reviewed other records of possible Homoioceras, and considered the systematics of the fossil long-horned African buffaloes. Unfortunately, although the skull possessed a complete upper dentition, it was neither described nor illustrated adequately for comparison. 


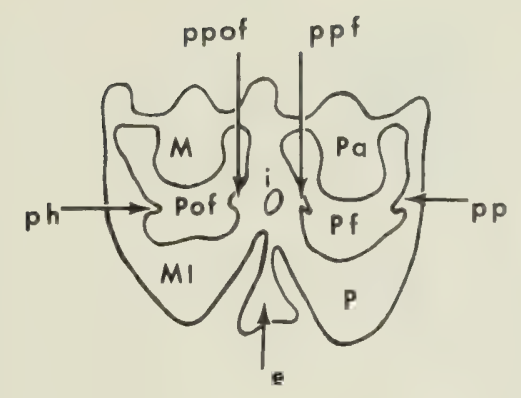

Buccal

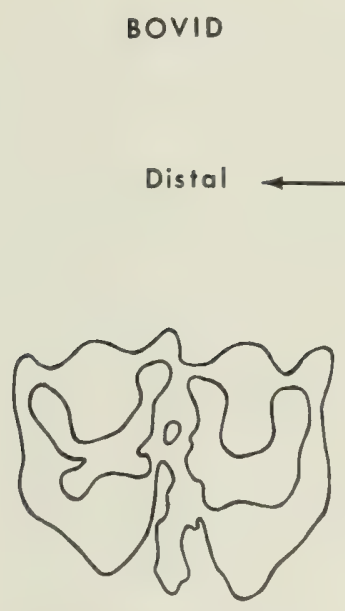

SYNCERUS

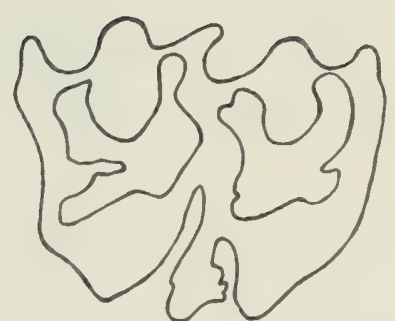

BOS

Fig. 20 Bovine upper molar patterns. Patterns of the enamal cusps and lophs in the upper molar of an idealised bovine, Bos as in B. primigenius, Syncerus and Homoioceras (redrawn after Gentry, 1967, Fig. 11, partim). $M=$ metacone, $M I=$ metaconule, $P=$ protocone, $P a=$ paracone, $e=$ endostyle or lingual basal pillar, $i=$ interfossette or middle cement lake, $P f=$ prefossette or anterior cement lake, $P$ of $=$ postfossette or posterior cement lake, $p p=$ pli protoloph, $p p f=$ pli prefossette, $p$ pof $=$ pli postfossette, and $p h=$ pli hypoloph. Diagrams not to same scale.

Gentry (1967), in his comparative discussion of the bovine or antilopine affinities of Pelorovis oldowayensis, made mention of many characteristics of both Asiatic and African buffaloes and illustrated occlusal views of their right $\mathrm{M}^{2}$ 's. As the material available from Kom Ombo is fragmentary and no buffalo skull is present, only those remarks pertaining to preserved parts of the skeleton will be summarised. The observed individual and age variation in these characters appears wide, and they may only be considered as indicative rather than absolute criteria for distinguishing among genera.

The occlusal surfaces of the upper molars of Homoioceras and Syncerus (Fig. 20) both possess interfossettes, which are absent in molars of Bos. The interfossette is larger in Homoioceras than in Syncerus, and more lingually placed. The prefossette has no plis in Syncerus, a pli prefossette and possibly small or incipent pli protoloph in Homoioceras, and the pli protoloph in Bos. The postfossette has a pli hypoloph and incipient pli postfossette in Syncerus, but only the pli hypoloph occurs in both Homoioceras and Bos. The shape of the lakes or fossettes is variable, those of the buffaloes being squarer and with larger lingual portions of the para- and 


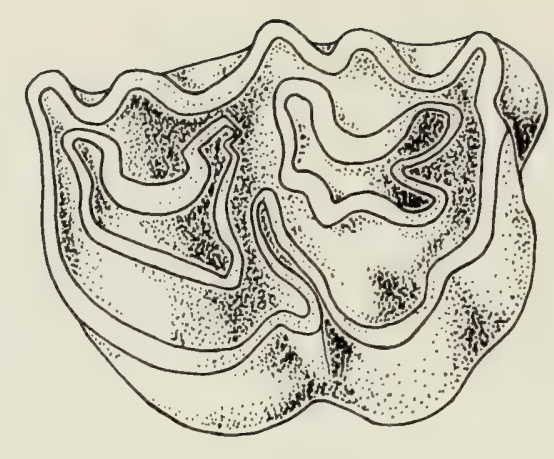

Fig. 21 Bos primigenius. Occlusal aspect of left upper $\mathbf{M}^{3}$ from Kom Ombo, redrawn from Gaillard (1934, PI. v, Fig. 4). Scale $=50 \mathrm{~mm}$.

meta-cones, and those of Bos being obliquely distorted, especially the postfossette, and the lingual portions of the para- and meta-cones being less prominent. The interlophar endostyles or basal pillars are also variable, those in Homoioceras being broad, deltoid or rectangular in section and attached more towards the sides of the metaconule rather than to the protocone or equally to both, while those of Bos and Syncerus are attached to the distal side of the protocone and are more mesiodistally compressed.

Ranges of variation in dental characters are wide and overlapping among bovine genera. The single third molar of Bos primigenius reported by Gaillard (1934, Pl. v, Fig. 4) is redrawn in Fig. 21 and illustrates some of the variation encountered in Bos. The buccal surfaces of the molars have localised well-marked outbowings in larger Bos and possibly Homoioceras, but less so in Syncerus and smaller Bos. Similarly the larger bovines may have more complex enamel walls in the fossettes than the smaller. The coronoid process of the dentary is not strongly curved in $H$. nilssoni and Bos primigenius. The central fossette of $\mathrm{P}_{4}$ opens medially in Bos, is usually enclosed in Syncerus, and is all but closed in Homoioceras nilssoni.

The femur of Syncerus, and probably also of $H$. nilssoni, has a deeper hollow in anterior aspect between the articular head and the greater trochanter than in Bos. Bos also tends to have a steeper slope on the dorsal edge of the articular head in anterior view than in other genera.

The medial malleolus of the tibia is shorter, and the ridge for the astragalo-metatarsal ligament on the medial side of the astragalus is weaker in Syncerus than in other bovid genera.

The astragalus of $H$. nilssoni has a backwardly directed extension "on the back part of the top of the medial side" when viewed from the anterior.

The metapodials of Syncerus and the metacarpals of Bos primigenius are more anteroposteriorly compressed than in other bovid genera, and no distal anterior or posterior intermetapodial foramina are present in adult Syncerus.

The metapodials of Syncerus and the metacarpals of Bos primigenius are more anteroposteriorly compressed than in other bovid genera, and no anterior or posterior intermetapodial foramina are present in adult Syncerus.

Syncerus and H. nilssoni have a smaller posterior eminence behind the lateral tuberosity of the humerus than Bos, and the infraspinatus insertion 
is level with the anterior edge of the humerus in Bos and $H$. nilssoni but posterior to it in Syncerus. The bicipital groove is narrower in anterior view in Bos than in other bovid genera, and the distal medial condyle of the humerus may be taller anteroposteriorly in $H$. nilssoni than in other bovines.

The medial side of the medial articular facet at the top of the radius is rim-like in anterior view in Bos and $H$. nilssoni but rounded in other bovid genera. The ridge between the posterior surface of the scaphoid and lunate facets on the distal end of the radius tends to be more slanted and less marked in Syncerus and H. nilssoni than in Bos. The tubercle towards the front of the dorsal facet of the scaphoid is more sharply marked in Bos than in other bovids. The distal edge of the medial side of the scaphoid is less indented in Syncerus than in other bovid genera and this is correlated with an absence of a projection towards the posterior end of the upper surface of the magnum-trapezoid.

Bos often has larger vertebrarterial foramina in the axis than do Syncerus or H. nilssoni.

\section{Consideration of Bovinae by Sites}

\section{OASIS DEPRESSION}

The upper cheek teeth $(8645 ; 8643$, Fig. 22E; 8644, Fig. 22H; 8642) are massive and show plis hypoloph, no other plis, endostyles and no interfossettes, and slightly oblique fossettes, as in Bos primigenius. The lower cheek teeth are similarly massive, show ectostylids even between the hypoconid and hypoconulid (8649), and may be assigned to the same species.

The horncore fragment (8653) is from a core whose greater and lesser diameters were at least 100 by 70 , and whose form was curved and slightly helical. The two diameters do not disagree with those recorded for the larger skull from Sebil va (8835), that is identified as $B$. primigenius. Similarly, the occipital condyles (8655) measure 131 in transverse overall diameter by 50 for dorsoventral diameter, and the foramen magnum measures 46.0 by 39.5 for the transverse and dorsoventral diameters. The width across the occipital condyles does not differ markedly from that reported for the small skull from Sebil IV (8827) also identified as $B$. primigenius.

The medial and anterior margins of the proximal articulation of the radius (8676 and 8677) are both thin and rim-like, as in Bos and Syncerus. There are large anterior and posterior distal intermetapodial foramina (8680, 8699, 8681, 8697, 8698), as in Bos and Homoioceras.

Therefore, because of the characters of the teeth, horncore, metapodials and radii, and because of its size, the bovid from the Oasis Depression is identified as Bos primigenius. Measurements of the better preserved specimens are given under that species.

BAYARA A AREA

The horncore fragment (8706) derives from near the base of the right horncore, is decurved and measures 63 by 47.0 in greater anteroposterior and lesser dorsoventral diameters, respectively. The ratio of these measure- 
ments agrees with those for the horncore on the smaller skull from Sebil IV (8827, Figs. 25, 26), i.e., 74.6 and 77.4, respectively, for the lesser diameter $\times 100 /$ the greater diameter. These specimens are therefore assigned to $B$. primigenius.

GEBEL SILSILA I

The identification to species of the remains from GS I is impossible. Cervical vertebra vi (8709) resembles the illustration of the same element of $B$. primigenius (Reynolds, 1939, p. 19, Fig. 7) although the inferior lamella has a straight and vertical margin. The juvenile calcaneum resembles that from any large bovid, e.g., Bos taurus and Bison bison at that age. The cement lake or fossette has a small internal pli and is also typically bovine.

These specimens probably represent B. primigenius rather than Syncerus or Homoioceras.

GEBEL SILSILA II

The fragment is small and only indicates that $B$. primigenius was present in this site.

\section{GEBEL SILSILA III}

III-Level 1, Sebekian Industry

The well worn upper first molar (8713, Fig. 22c) has rectangular fossettes, no interfossette, a small pli hypoloph, strongly developed cones, and a mesiodistally compressed endostyle. Except for the absence of any pli protoloph and the squared fossettes, both characters that change with wear, this molar is typical of $B$. primigenius. The newly worn upper first and second molars (8716, Fig. 23A; 8715, Fig. 22D) show few of the characters developed in the more worn tooth, although both show incipient plis hypoloph, strong styles, and 8716 (Fig. 23A) has an interfossette with the endostyle apparently connected to the mesial wall of the metaconule, as in Homoioceras. The upper premolar (8714) is large, with thick enamel and a wavy distolingual enamel margin to the fossette.

The milk premolars (8716, Fig. 23A) reflect the increased molarisation of the third and fourth milk premolars typical of bovines, $\mathrm{p}^{4}$ being a replica of a worn $\mathbf{M}^{1}$ with an endostyle and pli hypoloph. There is less molarisation in $\mathrm{p}^{3}$, as the protocone is not distinctly selenodont and has no separate root. The $\mathrm{p}^{2}$ shows no selenodont pattern but is massive with two relict fossettes and only two roots, thus differing from $\mathrm{P}^{2}$ with three roots.

The dental characteristics suggest that both B. primigenius and Homoioceras or Syncerus are present in this deposit. But all the adult teeth could derive from any of the three taxa as their dental characters are variable, especially since the permanent molars in 8715 (Fig. 22D) and 8716 (Fig. 23A) are similar in size and have not yet been worn to give the adult occlusal pattern.

The horncore fragment (8717) is thin-walled and compressed, and is assigned to Bos cf. primigenius.

The dentaries $(8719,8718)$ have relatively straight coronoids as in Homoioceras and B. primigenius. The metacarpal (8724) is anteropos- 


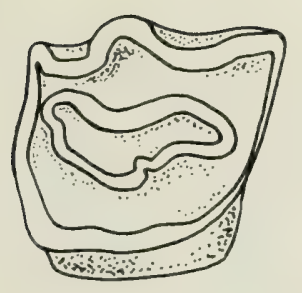

A

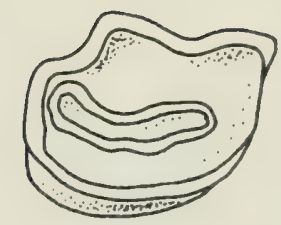

B
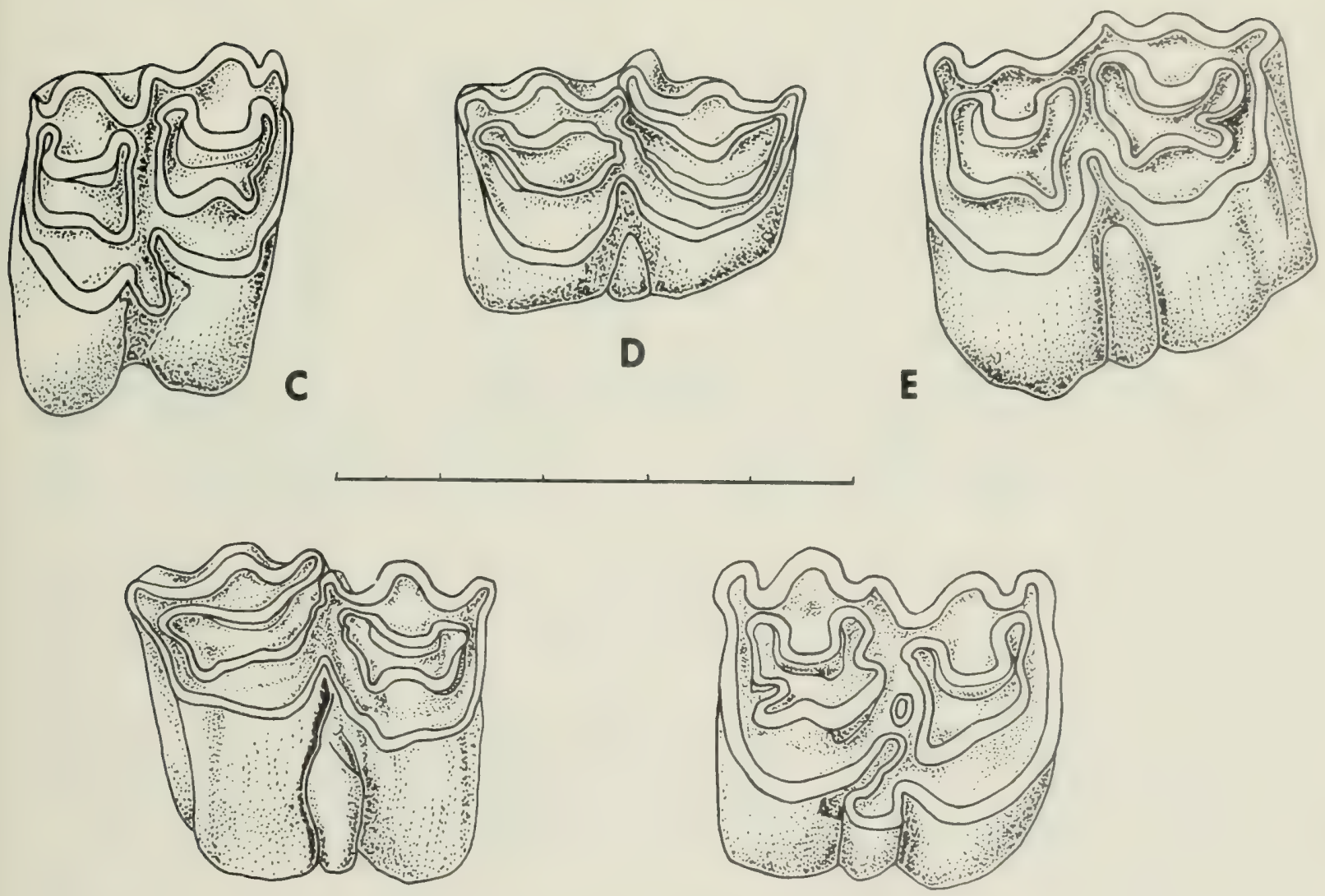

$\mathbf{F}$

G

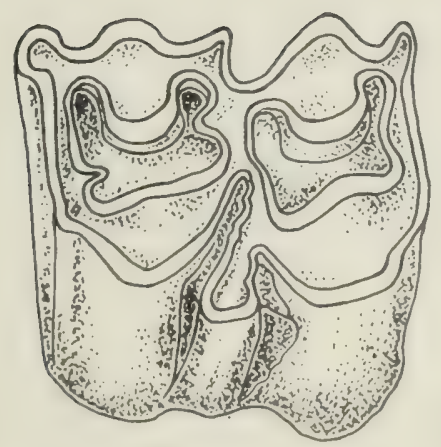

H

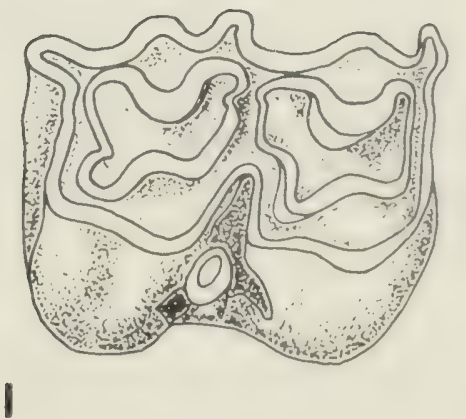

Fig. 22 Bos primigenius. Occlusal aspects of upper permanent dentition. A - worn left P4 from Gebel Silsila III, Level 1, Sebekian Industry (8712). B - well worn left $\mathrm{P}^{4}$ from Sebil viI (8863). C - well worn left $\mathrm{M}^{1}$ from Gebel Silsila III. Level 1, Sebekian Industry (8713, associated with 8712). D - newly worn left $\mathbf{M}^{2}$ from Gebel Silsila III, Level 1, Sebekian Industry, partly restored (8715). E - worn left $\mathbf{M}^{2}$ from Oasis Depression B (8643). F - newly worn right $\mathrm{M}^{1}$ from Gebel Silsila $\mathrm{x}(8736)$. G - well worn right $\mathrm{M}^{1}$ from between Sebil III and IV, slightly restored (8872). H - well worn right $\mathrm{M}^{2}$ ? from Oasis Depression B, slightly restored (8644). I - worn right $\mathrm{M}-$ from Gebel Silsila XIII (8750). Outlined areas of heavy shading near endostyles represent remnants of lingual cementum. Scale $=50 \mathrm{~mm}$. 

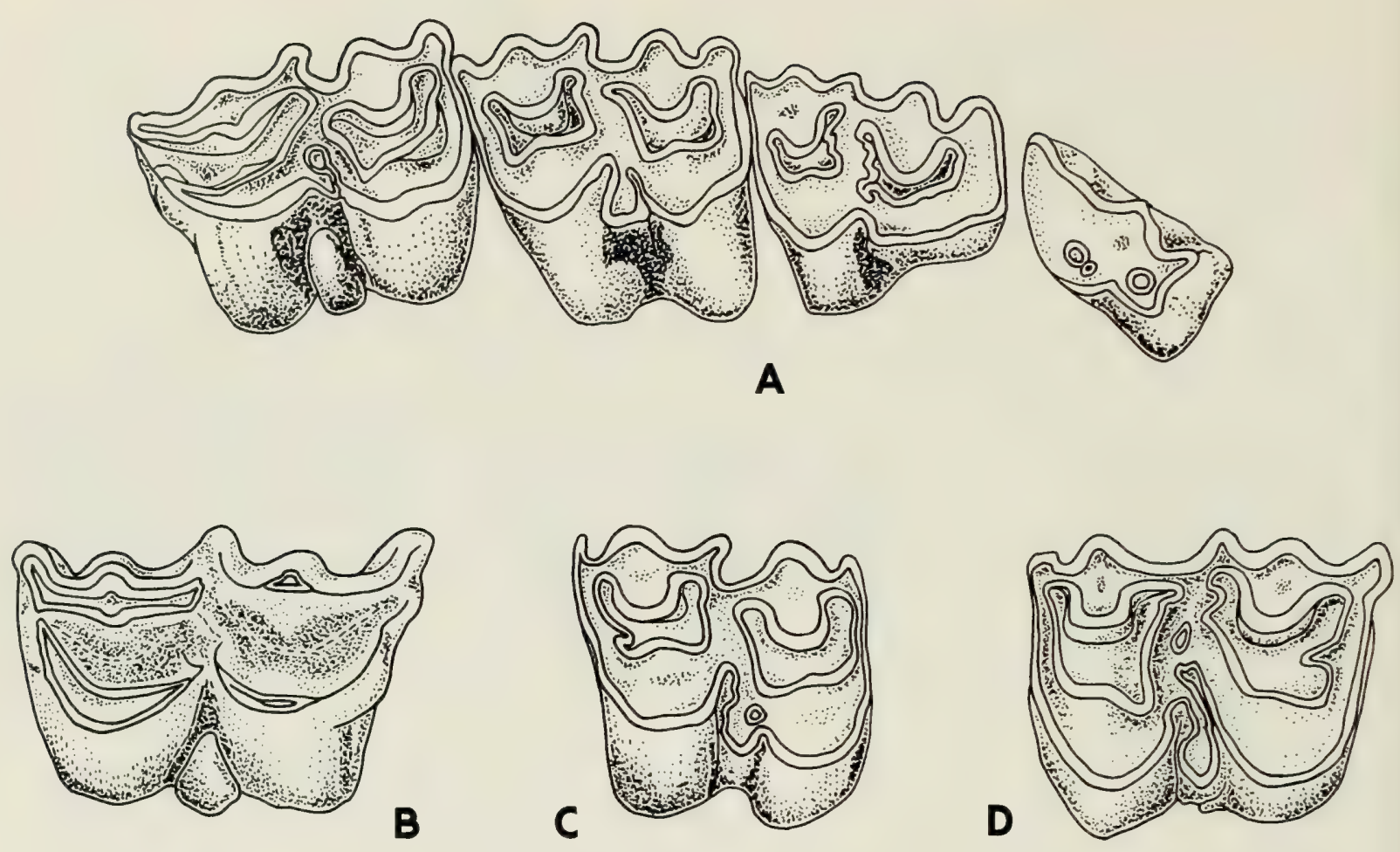

Fig. 23 ?Bos primigenius. Occlusal aspects of upper dentition. A - worn right milk $\mathrm{p}^{2-4}$ and newly functional $\mathrm{M}^{1}$ from Gebel Silsila III, Level 1, Sebekian Industry (8716). B - newly worn left $M^{2}$ from Gebel Silsila XIII (8747). $\mathrm{C}$ - well worn right $\mathrm{M}^{1}$ from Sebil v, slightly restored (8830). D - worn left $\mathbf{M}^{2}$ from Sebil III, slightly restored (8811). These cheek teeth are assigned provisionally to $B$. primigenius but exhibit characteristics of either Homoioceras or Syncerus (see text). Outlined areas of heavy shading near endostyles indicate remnants of lingual cementum. Scale $=50 \mathrm{~mm}$.

teriorly compressed as in Syncerus and $B$. primigenius. The astragalus (8726b) lacks a backwardly directed medial process. The metatarsals (8726a, 8727 ) do not appear to be anteroposteriorly compressed and both metatarsal specimens and the metacarpal (8724) retain both anterior and posterior intermetacarpal foramina, although in all three they are small and suggestive of $B$. primigenius.

The material from Gebel Silsila III (Sebekian level) is assigned to $B$. primigenius and measurements of the more complete specimens given under this species.

\section{III-Level 3, Silsilian Industry.}

The upper second molar (8729) resembles that of Bos primigenius in having only a pli hypoloph, a mesiodistally compressed endostyle, obliquely slanted fossettes, no interfossette, and normally developed para- and metacones.

The third upper molar (8730) resembles the second but is larger and is producing an interfossette which is being exposed as wear of the lingual interlophar area proceeds.

The material from the Silsilian (Level 3) at Gebel Silsila III is identified as from $B$. primigenius. Measurements of the upper molars are given under that species. 


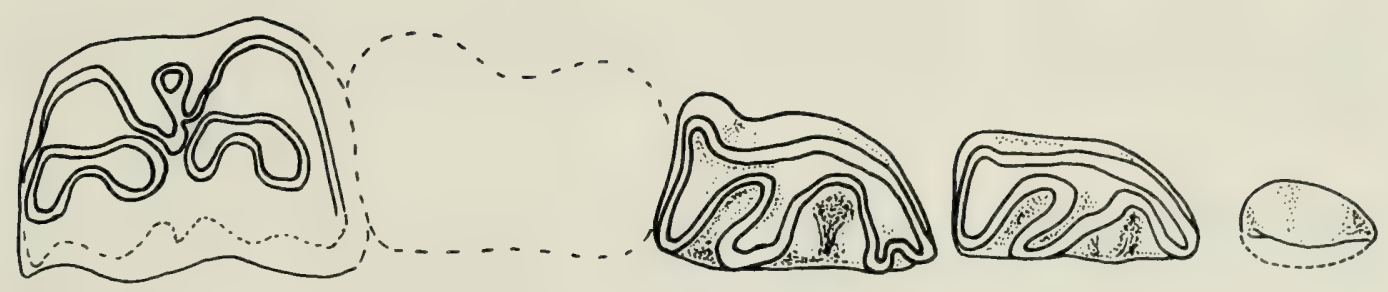

A

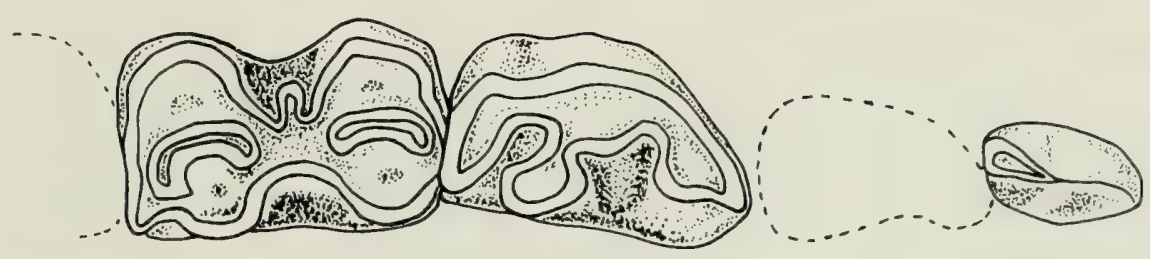

B

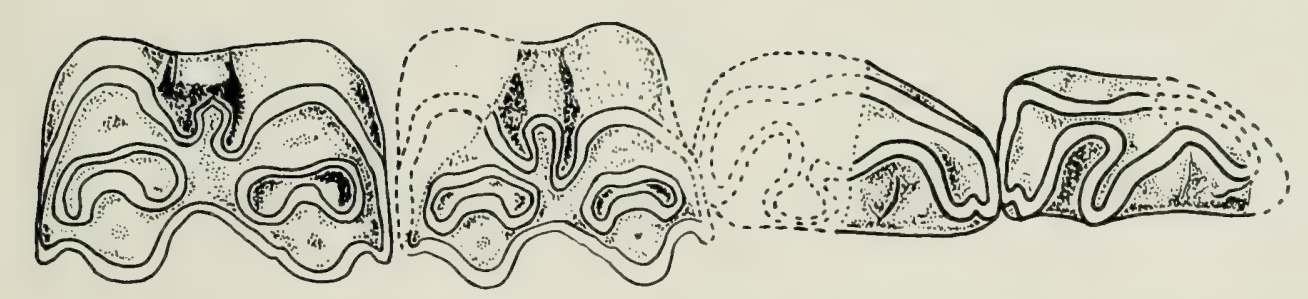

C
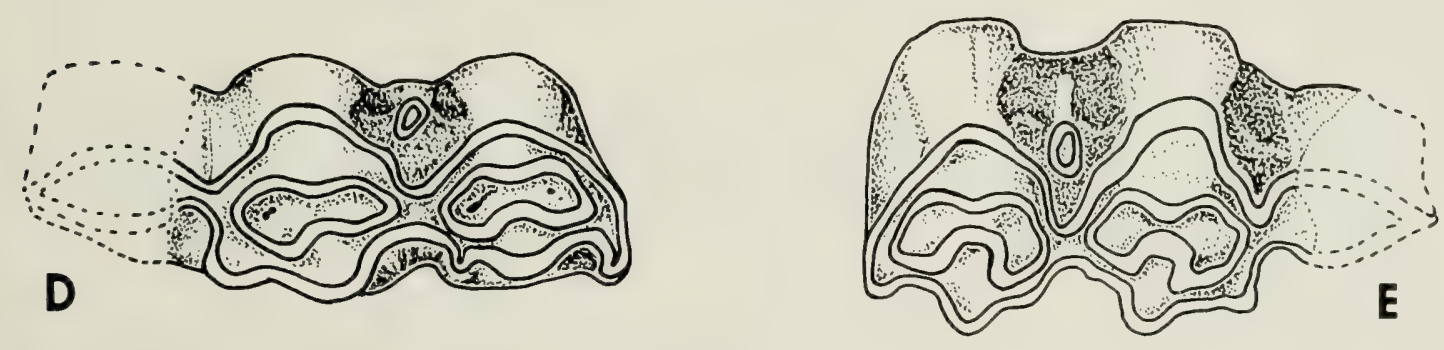

Fig. 24 Bos primigenius. Occlusal aspects of lower permanent cheek teeth. A - worn left $\mathbf{P}_{2-4}$ and $\mathbf{M}_{2,}$, with $\mathbf{P}_{2}$ and $\mathbf{M}_{2}$ damaged, from Gebel Silsila XVII (8765). $\mathrm{B}$ - well worn left $\mathrm{P}_{2}, \overline{\mathrm{P}}_{4}$ and $\overline{\mathbf{M}}_{1}$ from Sebil vi (8862). C - worn partial left $\mathbf{P}_{3}-\mathbf{M}_{1}$ and entire $\mathbf{M}_{2}$ from Sebil vi $(8832,8833$ and 8834$)$. D - worn partial left $\mathbf{M}_{3}$ from between Gebel Silsila XIV and XV (8764). E - worn partial right $\mathbf{M}_{3}$ from Gebel Silsila IX (8722). Outlined areas of heavy shading near stylids and in reentrants indicate remnants of cementum. Alveolar outlines do not contain restored enamel patterns. Scale $=50 \mathrm{~mm}$.

\section{GEBEL SILSILA VII}

The frontal fragments (8732) were from a skull in which the sagittal region between the frontals was flat or slightly convex, the sinus separated the braincase from the outer surface by about 25 and the flattened region was at least 100 in diameter. The specimen agrees well with the mid-frontal region of the large skull, 8835 (Fig. 27) in which these areas are visible, and is therefore identified as from $B$. primigenius. The horncore fragment (8733) resembles the posterodorsal area at the base of the right horncore on the same skull (8835). 
The material from Gebel Silsila vII is identified as deriving from $B$. primigenius because it corresponds to the same areas of a skull of this species.

GEBEL SILSILA IX

The occlusal pattern of specimen 8735 resembles that of both Bos and Syncerus. It is assigned to cf. $B$. primigenius because of its size but could derive from Syncerus.

GEBEL SILSILA X

The associated upper molars (8736, Fig. 22F; 8737) resemble those of $B$. primigenius, in that there are no interfossettes, the fossettes are slanted, and there are indications that only a plis hypoloph will develop. The third molar (8738) shows no diagnostic characters.

These specimens are assigned to $B$. primigenius on morphology and size, and their measurements are given under this species.

GEBEL SILSILA XIII

XIII-Sector 1 .

The trapezoid (8742) is massive and from a large individual. The astragalus (8743) is well weathered, deflated, and from a large bovid. Both bones could derive equally well from B. primigenius, Syncerus caffer, or Homoioceras.

XIII-Sector 2.

The dentary (8744) is from a large bovid calf and the cement lakes are large and show a single pli. All specimens could derive from either $B$. primigenius or $S$. caffer.

XIII-Sector 3.

The condyle (8746) is large and is similar to those from the Sebekian of Gebel Silsila III. It can be assigned to $B$. primigenius, although a small buffalo cannot be eliminated as a possible source.

XIII-Sector 4.

The upper second molar (8747, Fig. 23в) is from a large animal. There are indications of plis prefossette and hypoloph, a large endostyle, large lingual bows to the para- and meta-cones but no sign of an interfossette. These characters suggest a buffalo, possibly Homoioceras, but variation in molar patterns of cow-like bovines is so great that probably it could derive equally well from $B$. primigenius.

XIII-Mound H.

None of this material is diagnostic except to a large bovine, probably $B$. primigenius or Syncerus. Measurements of the navicular-cuboid (8749) are given under $B$. primigenius.

XIII-Conclusions

The large bovine material from Gebel Silsila XIII is unsatisfactory for specific identification, as no horncore or larger, diagnostic elements were recovered. It is probable that Bos primigenius was present at Sectors 1, 2, 
3, and 4 and at Mound H, and that a buffalo, more likely Syncerus caffer than Homoioceras vignardi, may have been present at these localities also.

GEBEL SILSILA XIV

The premolar fragment (8751) matches well with a similar tooth from the Sebekian of Gebel Silsila III (8714), although it is more worn and has presumably lost the folded enamel observable in the fossette of the latter. The trapezoid (8760) is large and massive, and the cuneiform, although well water-worn and rounded, appears similarly constructed. The astragalus (8762, Fig. 29) is large and slightly deflated on its calcanear surface.

These specimens conform well to others associated with elements identified to $B$. primigenius from other sites and are assigned to this species. Measurements of the better preserved specimens are given under this species.

GEBEL SILSILA XIV-XV

A damaged third lower molar (8764) represents the only bovine material from this site. It is similar to $\mathbf{M}_{3}$ 's of $B$. primigenius and is assigned to this species.

GEBEL SILSILA XV

The condyle of the left dentary (8448) is comparable to those of either $B$. primigenius or $S$. caffer and is not assignable to species.

GEBEL SILSILA XVII

The dentary fragment (8765, Fig. 29A), although damaged and weathered, and from a younger individual, resembles that of $B$. primigenius from Sebil VI (8862) in details of the tooth pattern and in size. The caput femoris (8768) is large and massive, with an expansion over the neck, and measures 59 in anteroposterior diameter of the caput.

The specimens are identified as $B$. primigenius and other measurements are given under that species.

GEBEL SILSILA MISCELLANEOUS

The upper molar (8750, Fig. 221) shows a small pli hypoloph, obliquely distorted fossettes, and an endostyle associated with the metaconulid, and can be considered to derive from $B$. primigenius. Measurements of this specimen are given under this species.

The sacrum (8769) of a large bovine, possibly B. primigenius, was recovered from surface deposits. It is not mineralised or replaced, and appears to be more recent in age than the other specimens, and thus may represent a Dynastic or later $B$. taurus rather than the prehistoric species.

SEBIL I

The absence of the plis protoloph, prefossette and postfossette, the squareness of the fossettes, and the presence of a well developed but mesiodistally compressed interlophar endostyle indicate that the molars $(8770,8771)$ derive from Syncerus rather than Bos or Homoioceras. The absence of a discernable interfossette suggests $B$. primigenius, although this character is variably present in modern $B$. taurus. The medial malleolus of the tibia 
(8784) is pronounced, and the astragalo-metatarsal ligament is bounded by a strong groove. The metapodials are anteroposteriorly compressed as in $B$. primigenius and Syncerus.

The material from Sebil I is considered to represent only the single species, B. primigenius, although Syncerus cf. caffer is possible. Measurements of the more complete specimens are given under $B$. primigenius.

SEBIL II

The lower molar fragments (8797) are small and markedly buccolingually compressed for Homoioceras or Syncerus and may derive from a small individual of $B$. primigenius.

The posterior eminence of the lateral tuberosity of the humerus (8804) appears to have been large, the bicipital groove narrow, and the infraspinatus insertion is level with the anterior surface of the shaft. These are characters of Bos rather than Syncerus or Homoioceras.

The material from Sebil II is assigned to B. primigenius and is considered to represent at least two specimens of a single species. Measurements of the more complete specimens are given under $B$. primigenius. All other specimens from this site are fragmentary and undiagnostic.

SEBIL III

The associated left upper molars ( $\mathrm{M}^{2}$ 8811, Fig. 23D; $\mathrm{M}^{3}$ 8812) show only a pli hypoloph, and the $\mathrm{M}^{2}$ has an additional pli placed within the fossette towards the buccal margin and displaced from the usual position of the pli postfossette. Both molars have small, oval interfossettes, rectangular fossettes, and $\mathrm{M}^{2}$ has a mesiodistally compressed endostyle. The buccal ectoloph surface is strongly ridged, but the styles are not as narrow or prominent as in B. primigenius or Homoioceras. Because of the presence of the interfossette, the compressed endostyle, and the shape of the ectoloph and fossettes, these teeth resemble those of Syncerus, but because of variation within Bos in these characters, they are considered to derive from $B$. primigenius.

The fourth premolar, $1 \mathrm{P}^{4}$ (8810) lacks much of the buccal enamel but shows a strong mesiobuccal style and a small posterodistal pli within the fossette. The remaining material is undiagnostic, although the astragalus (8818) is similar in size to others considered to be from $B$. primigenius.

The material from Sebil III is assigned to $B$. primigenius and could have derived from a single individual. Measurements of the $1 \mathrm{M}^{2}$ and of the astralagus are given under $B$. primigenius.

SEBIL IV

The molar tooth fragments represent the prefossette and mesial enamel surface (8821), the buccal surface of a metacone (8822), the endostyle and lingual enamel surface of the metaconule (8823), the lingual half of the metacone (8824), a lower ectostylid (8825), and a fossettid (8826). The prefossette is rectangular, has no pli protoloph or prefossette and only a fragmentary interfossette. The endostyle is mesiodistally compressed. These characters suggest Syncerus cf. caffer, but as variation in B. primigenius was presumably similar to that now observable in $B$. taurus, these 
characters are probably insufficient as a basis for specifically separating the teeth from the skull which is identified as $B$. primigenius. This specimen $(8827$, Figs. 25, 26) shows the wide frontal table, widely placed orbits, and oval sectioned horns typical of Bos. This specimen and another cranium (8835, Fig. 27) are discussed under "Bos primigenius and Bos brachyceros".

SEBIL V

The upper molar specimens (8830, Fig. 23C; 8831) possess small plis hypoloph, mesiodistally compressed endostyles attached to the protocone walls, squared fossettes (8830, Fig. 23c), and a small round interfossette (8831), characters that suggest Syncerus. The fossettid in $\mathrm{P}_{4}$ (8832, Fig. 24c) opens medially as in Bos, and $\mathrm{M}_{1}$ and $\mathrm{M}_{2}(8833+8834$, Fig. 24c) possess ectostylids.

The skull table with horncores (8835, Fig. 27) is broad across the orbits and frontals and is typically flattened as in $B$. primigenius. This specimen and another cranium $(8827$, Figs. 25,26$)$ are discussed under "Bos primigenius and $B$. brachyceros". The horncore fragment (8836) is simply arched, oval in section towards the base, and without any ventral or posterior grooves.

The other fragments show a relatively straight coronoid on the dentary, no posteromedial extension on the astragalus, and anteroposteriorly compressed metapodials which possess intermetapodial foramina in the adult state. These characteristics are also indicative of Bos rather than Syncerus.

This material is assigned to $B$. primigenius because of the characters described above and in the skull (8835, Fig. 27; vide infra), whereas those of the teeth that suggest Syncerus are considered to be variants within $B$. primigenius of the sort seen in dental series of modern $B$. taurus. Measurements of the more complete material are given under $B$. primigenius.

SEBIL VI

A well worn series of left lower cheekteeth $\left(\mathrm{P}_{2}, \mathrm{P}_{4}\right.$, and $\mathrm{M}_{1} 8862$, Fig. 24B) from this site are similar in size and conformation to those from Sebil v (8832, 8833, and 8834, Fig. 24C) and this series is therefore assigned to $B$. primigenius. Measurements of this specimen are given under that species.

SEBIL VII

The left upper fourth premolar (8863, Fig. 22B) is well worn, lacks a pli within the fossette, and is large. The distal fossette of the upper molar (8864) shows a squared outline with a small pli hypoloph. The lunar and navicular-cuboid $(8867,8869)$ are massive, and the latter is as large as that in Syncerus caffer or B. primigenius.

The material from Sebil vil is assigned to $B$. primigenius. Measurements of the more complete material are given under $B$. primigenius.

SEBIL MISCELLANEOUS

The upper molar (8872) shows obliquely distorted fossettes, a pli hypoloph but no pli protoloph, an accessory pli placed buccally on the mesial wall 
of the postfossette, an interfossette in about the middle of the tooth, and a mesiodistally compressed endostyle attached to the distal wall of the protocone. Except for the small interfossettes and lack of pli protoloph, this tooth is typical of $B$. primigenius, or alternatively, except for the oblique fossettes, it could derive from Syncerus.

The horncore fragment (8876), is oval in cross-section and less curved than 8836 and could derive from $B$. primigenius. The coronoid process of the dentary is not strongly recurved. The axis vertebra is similar to that illustrated by Reynolds (1939, Fig. 6) for B. primigenius from Ilford, England, although he shows no ventral pit on the body between the atlanteal facets, as is present in specimen 8876 .

The right upper first molar (8872) appears to be from Syncerus, as do the other remains with the possible exception of the fragments of horncores, which more nearly correspond to those of $B$. primigenius. Nonetheless the material is assigned to $B$. primigenius because of the known variation within the species.

KHOR EL-SIL LOCALITIES

All the specimens from these localities that are assigned to $B$. primigenius as part of its teeth or skeleton are too fragmentary for any detailed or extensive description. All derive from a large bovid of the size of $B$. primigenius and none have characteristics that suggest either of the buffaloes.

\section{Bos primigenius and $B$. brachyceros}

Gaillard (1934) originally reported both Bos primigenius and B. brachyceros from Kom Ombo. Subsequently neither Reed and Turnbull (1969, MS 1967) nor Oakley (1965) have reported B. brachyceros, presumably referring "all the Bos to the species primigenius on the basis of size" (Reed and Turnbull, 1969, p. 55). Smith (1967) has commented that the two skulls considered here "promise to throw considerable light on the problems of the races of wild cattle (primigenius or brachyceros) claimed to be extant in the Nile Valley in pre-Neolithic times." The two specimens unfortunately lack both horncores, facial regions in front of the orbits and all teeth, and the larger specimen lacks the basicranial region also. Both are fully adult as the frontoparietal sutures are fused and the frontal sagittal sutures closed. The bases of the horncores show that the horns were decurved, as in the majority of recovered $B$. primigenius (Reynolds, 1939, Pl. IV).

Specimen 8827 (Figs. 25, 26), from locality Sebil IV, retains only the base of the left horncore and the right frontal and supraoccipital margins on the dorsal surface, the right horncore having been broken through its boss, and the nuchal margin and the nasal and left orbital regions broken away. The nuchal area lacks the paroccipital process and the dorsal and lateral areas near the external auditory meatus. Also, the auditory, left glenoid fossa, zygomatic arches, presphenoid, maxillary and palatopterygoid areas are absent. 


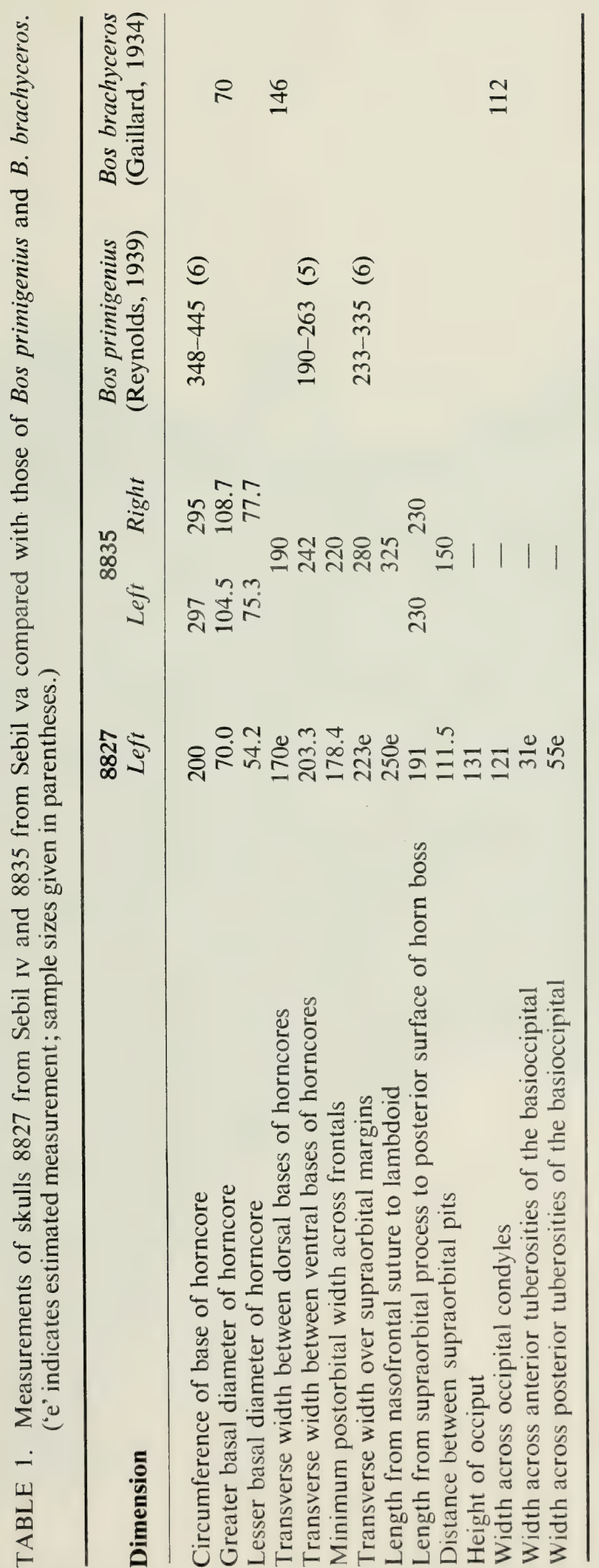




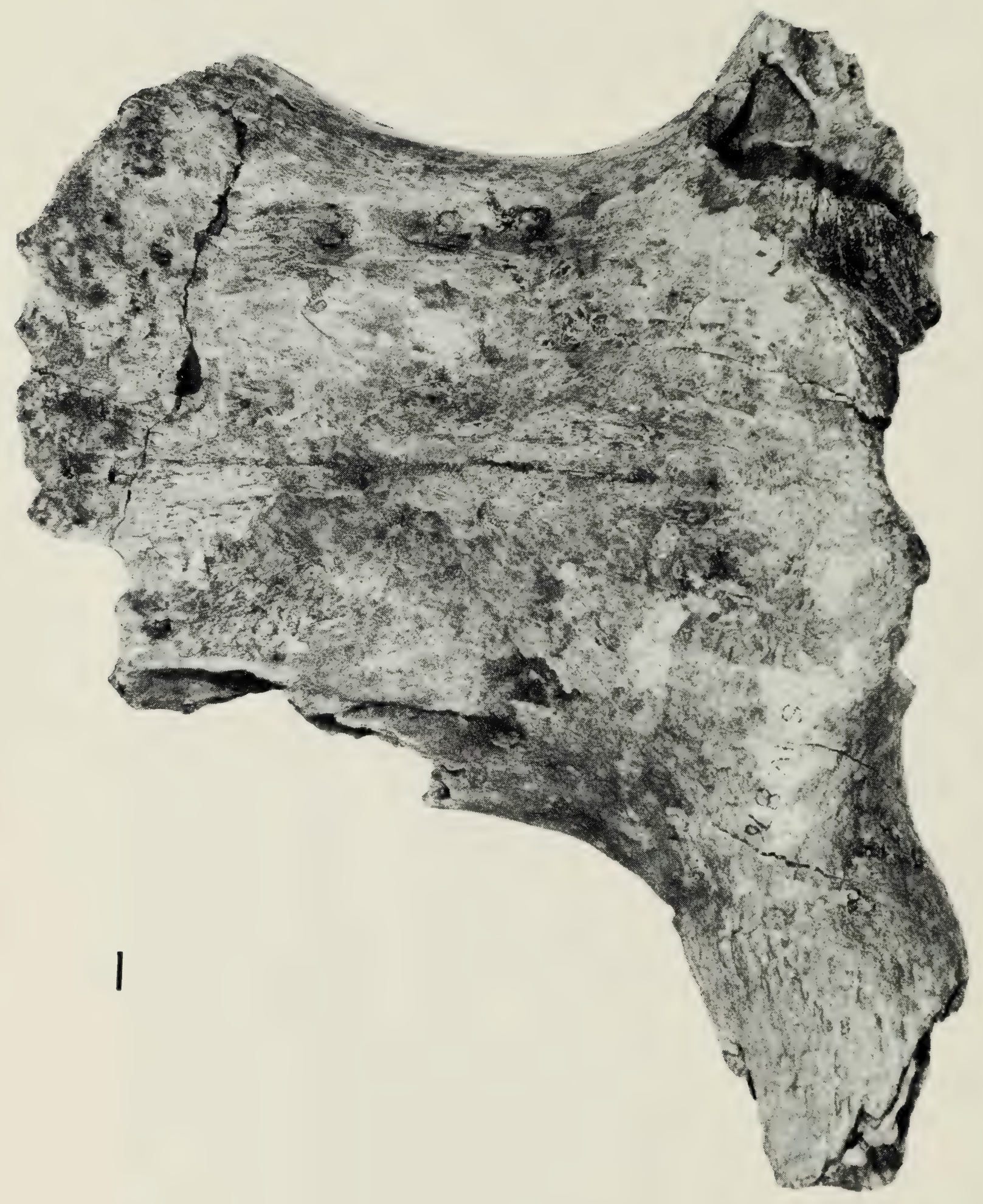

Fig. 25 Bos primigenius. Frontal aspect of partial female skull 8827 from Sebil Iv. Bar $=10 \mathrm{~mm}$. 


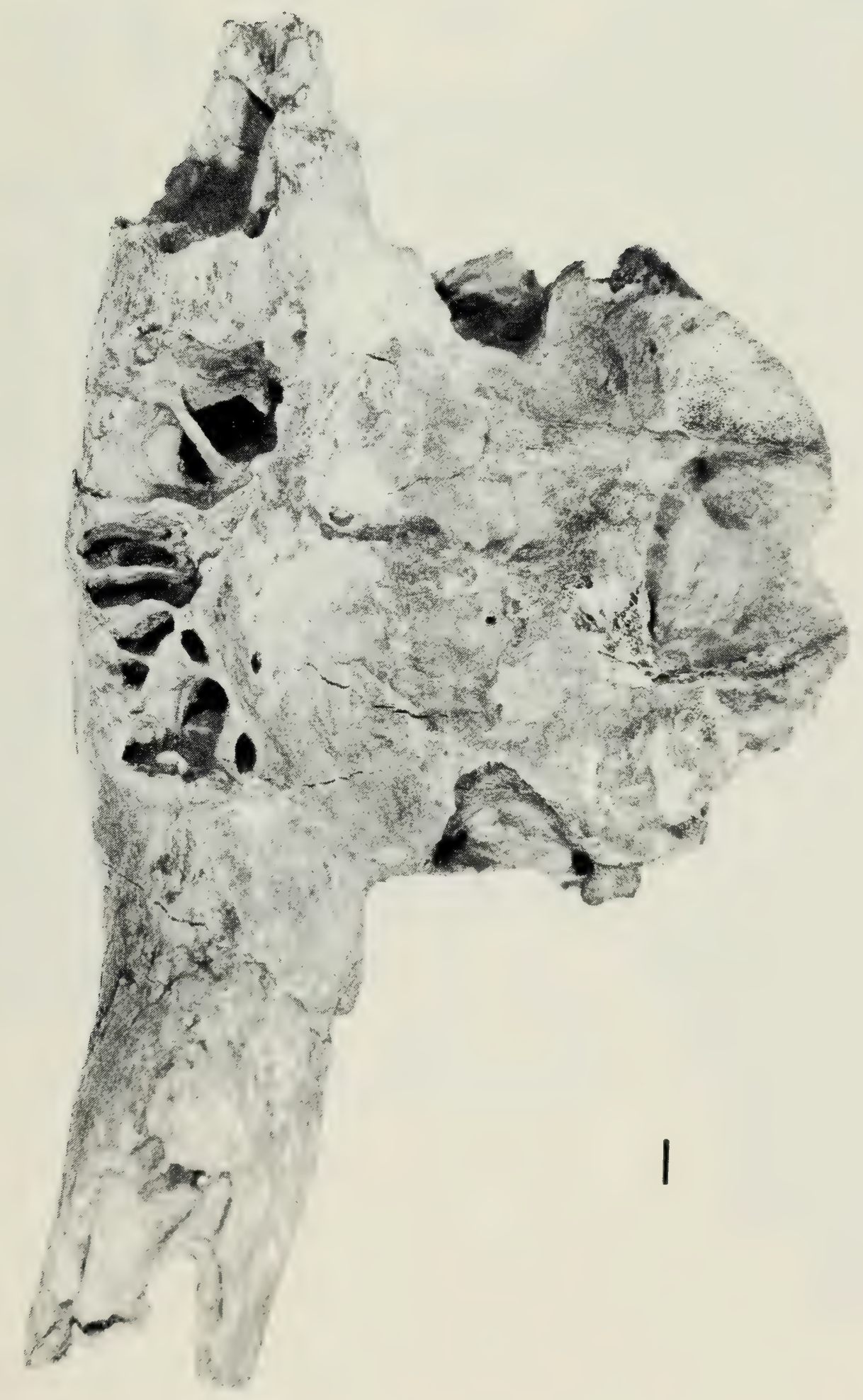

Hig. 26 Bos primigenius. Nuchal aspect of partial female skull 8827 from Sehil $\mathrm{N}$. Bar ... $10 \mathrm{~mm}$. 


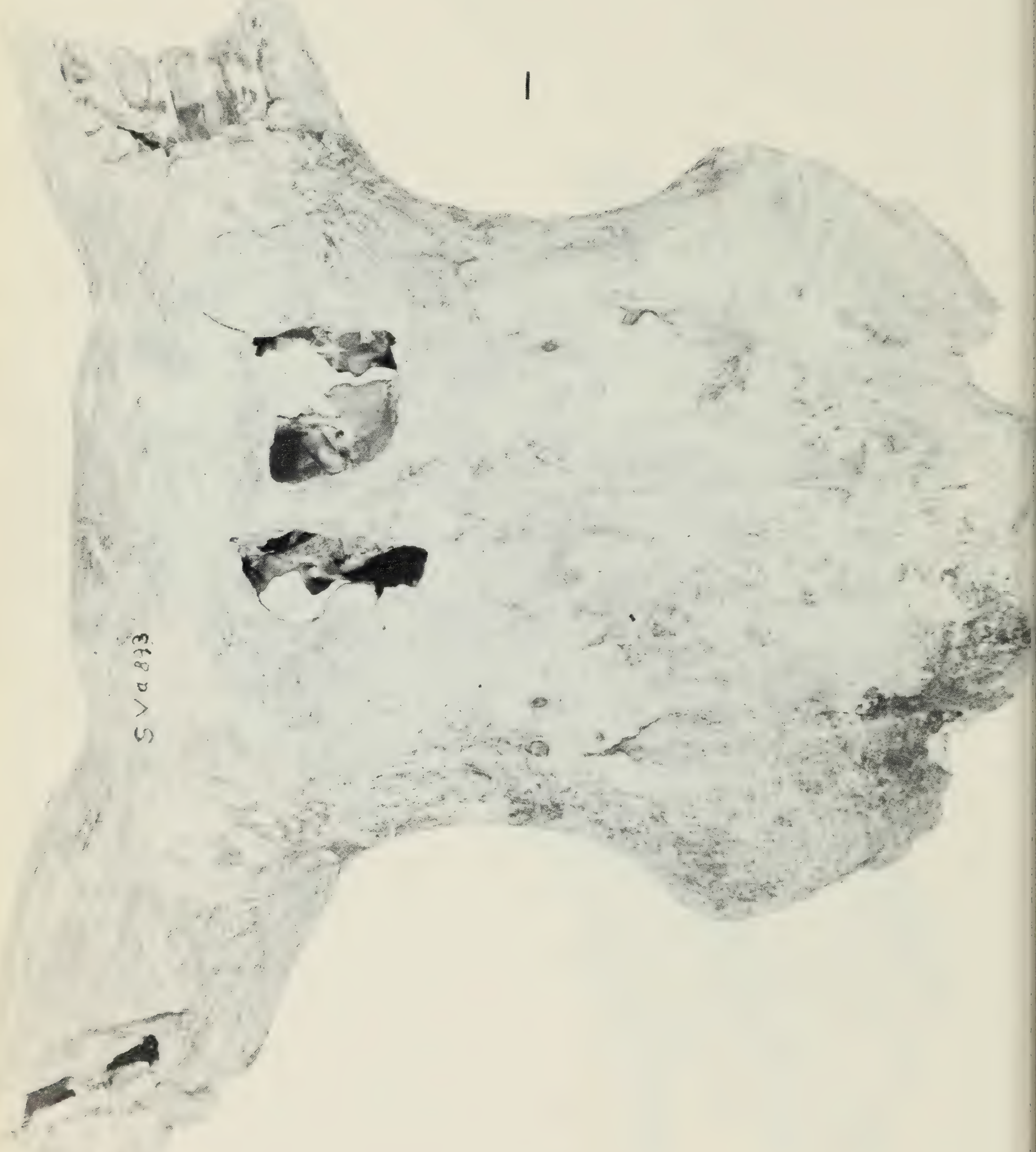

Fig. 27 Bos primigenius. Frontal aspect of partial male skull 8835 from Sebil va. Bar $=10 \mathrm{~mm}$. 

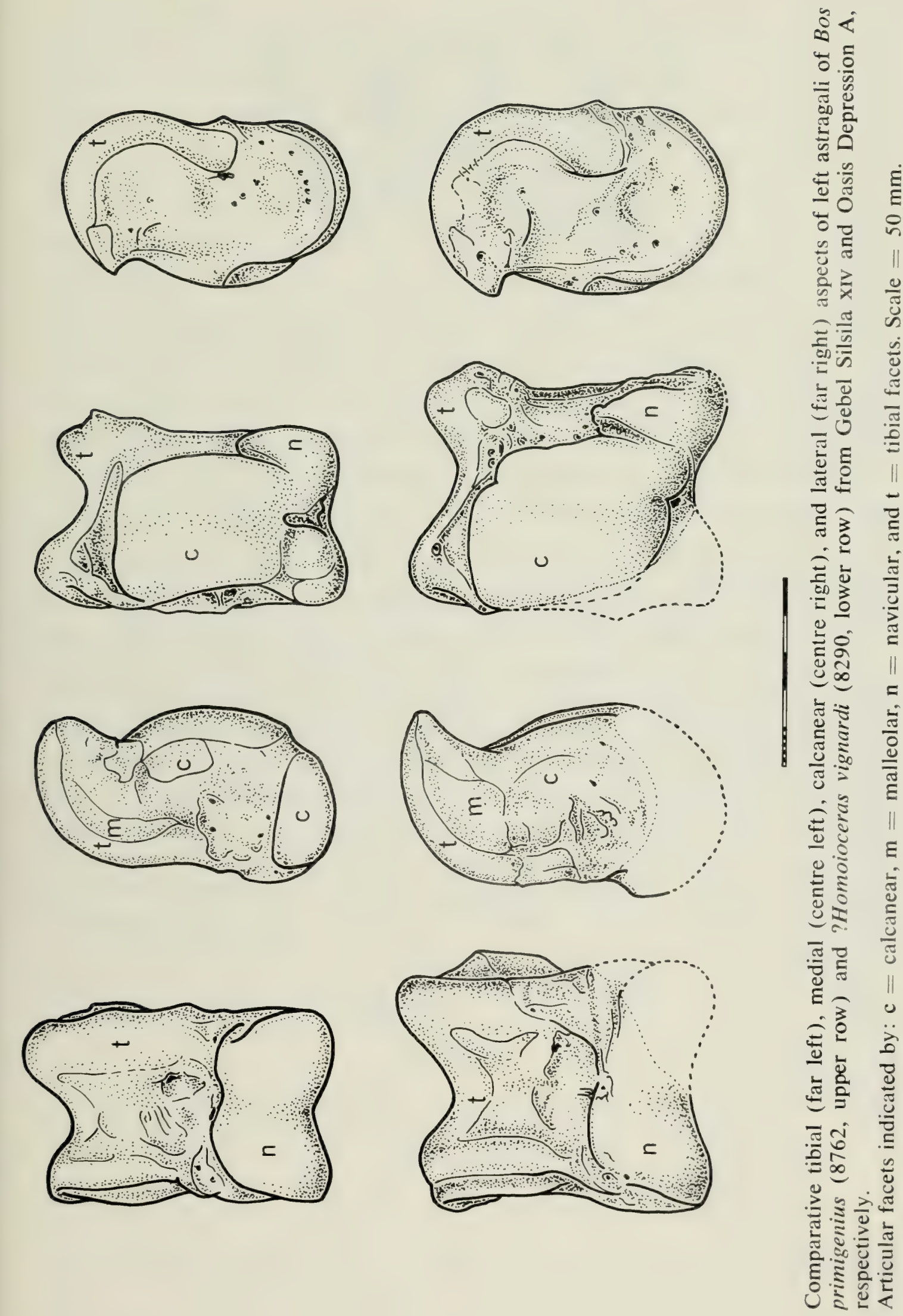


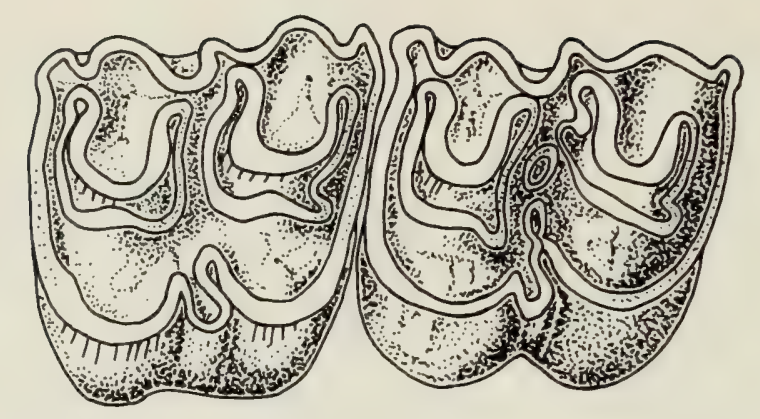

Fig. 29 Homoioceras vignardi. Occlusal aspect of left $\mathrm{M}^{2-3}$ from Kom Ombo, redrawn from Gaillard (1934, Pl. v, Fig. 6). Scale $=50 \mathrm{~mm}$.

Specimen 8835 (Fig. 25), from locality Sebil va, retains complete margins to the frontal table and the bases of both horncores, although there are two lacunae in the table between the horns, and all traces of the nasal and lachrymal areas are missing. In ventral aspect, the braincase has been broken through at approximately the level of the squamosal-parietofrontal sutures and anteriorly through the ethmoid plate. Thus the dorsal boundaries of the braincase, nasal passages and orbits are exposed.

Although the skull of 8835 is $20 \%$ larger than that of 8827 (Table 1, p. 75 ), both animals are proportioned similarly (Table 2 ). The only exception to this similarity is in the horncores, those of 8835 being about $33 \%$ larger in all three dimensions, whereas the cranium of 8835 is only about $20 \%$ larger than that of 8827 . These differences are probably attributable to sexual dimorphism and thus skull 8827 probably derives from a female and 8835 from a male. When these figures (Tables 1 and 2) are compared with those for British $B$. primigenius, the horns of the British specimens are proportionately and absolutely greater than those of 8835 , whereas the skulls show variation that is similar to those of the Kom Ombo specimens. Nonetheless, both samples are too small for the ranges of variation to be reliably expressed. When the ratios are considered, and the increased errors that they may contain allowed for, there is approximate agreement between both sets of data.

TABLE 2. Ratios of skulls 8827 from Sebil Iv and 8835 from Sebil va compared with those of Bos primigenius. ('e' indicates ratios based on estimated measurement or measurement from Gentry's Fig. 10 (1967); sample sizes given in parentheses.)

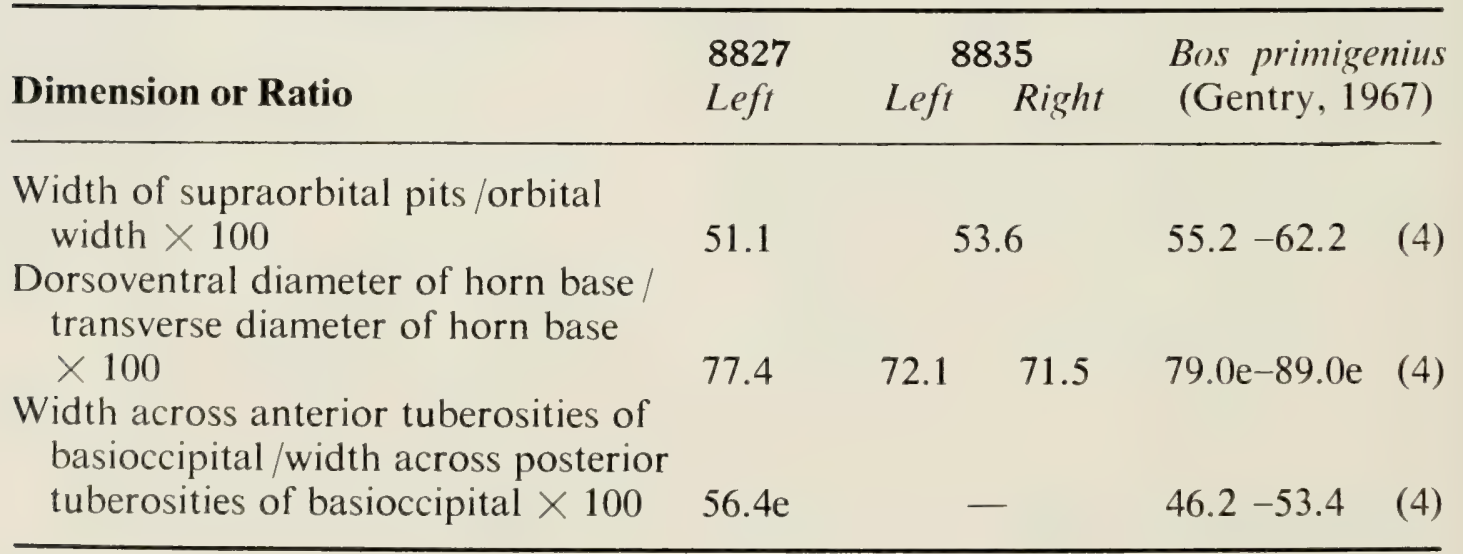


Bohlken (1962) discussed sexual dimorphism in domestic and wild cattle, including $B$. primigenius, and gave data that show ranges of variation that include the measurements of the two skulls from Kom Ombo within domesticated cattle but smaller than northern European $B$. primigenius. Therefore it might be suggested that the Kom Ombo B. primigenius was domesticated and undergoing the reduction in size attendant upon the process. However, the Nilotic B. primigenius was smaller than that of northern Europe, as might be expected in a more clement habitat, and the size differential would be a racial difference. Also, the presence of domesticated cattle $c .15,000$ to 11,000 B.C. would be the earliest record known, as the standing earliest record may be about 5,500 B.c. from Tepe Sabz at Deh Luran in Iranian Khuzistan (Reed, 1969, p. 375). An alternative date of about 5,000 B.c. is available for small cattle from the Halafian period of Banahilk in northern Iraq (Reed, 1961). Zeuner (1963) concluded that there is no reason why $B$. brachyceros cattle should not be derived from $B$. primigenius stock and that there was a monospecific origin for the true domestic cattle.

The skulls from the Sebil Area of the Kom Ombo Plain therefore can be considered as true $B$. primigenius, representing probably a female and a male. Moreover, the Egyptian race bore relatively smaller horns than the European but was otherwise of about the same size.

Measurements of the better preserved skeletal and dental elements probably deriving from $B$. primigenius from the Kom Ombo Plain and comparative ranges of variation of these measurements, with sample sizes in parentheses, for other B. primigenius are given on the following pages. 


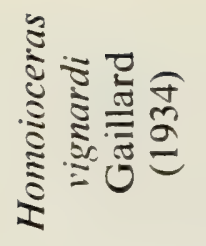

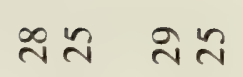

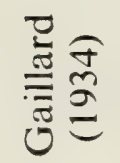

됴유

चิำ

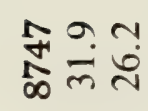

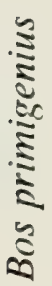

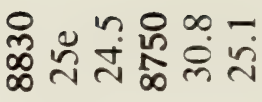

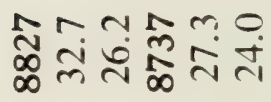

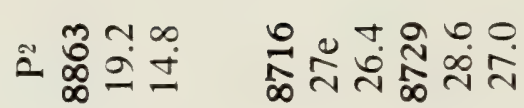

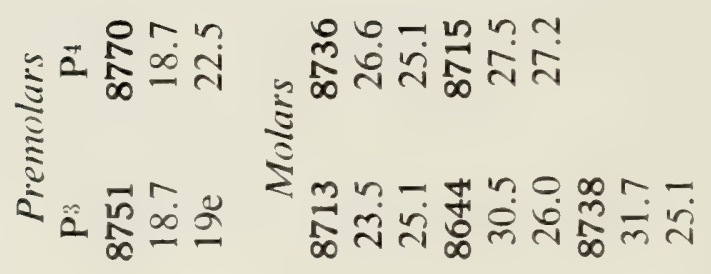

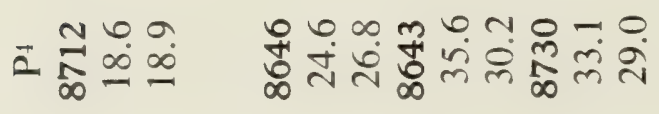

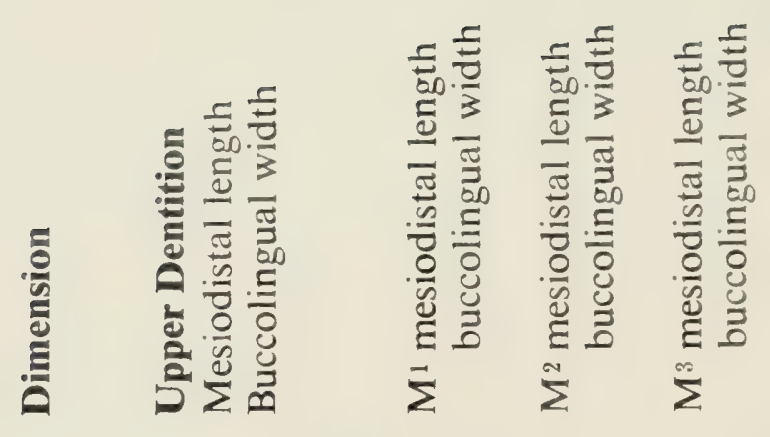




\section{Lower Dentition}

Incisors

$\mathrm{I}_{2}$ mesiodistal length

11.9

buccolingual width

10.6

Premolars

8765

8862

$P_{2}$ mesiodistal length

12.3

13.3

buccolingual width

$\mathbf{P}_{3}$ mesiodistal length buccolingual width

$\mathrm{P}_{4}$ mesiodistal length buccolingual width

Molars

$\mathrm{M}_{1}$ mesiodistal length buccolingual width

$\mathrm{M}_{2}$ mesiodistal length buccolingual width

$\mathrm{M}_{3}$ mesiodistal length buccolingual width

$45.6-$

$17.9 \quad 19.2$

$21.2 \quad 21 \mathrm{e}$

$10.7 \quad 13.2$

$21.7-\quad 23.4$

$\begin{array}{lll}30.0 & 14.0 & 14.2\end{array}$

8833

$27.6 \quad 26.2$

$18.1 \quad 17.2$

$8649 \quad 8765 \quad 8834$

$32.7 \quad 25.5 \quad 23.0$

$19.2-17.0$

Gaillard

$8764 \quad$ (1934)

Milk Dentition

8716

19.1

13.2

22.8

20.5

23.0

24.8

8744

31.1

14.3

buccolingual width

Lesser diameter of condyle (anteroposterior)

Height of condyle above ventral border

174.5

19.7

$22.9 \quad 19.6$

Height of coronoid above condyle

Transverse diameter in diastema

Dorsoventral diameter in diastema

\section{Vertebrae}

Atlas or Cervical I

8656

Anteroposterior length of ventral arch

Dorsoventral thickness of ventral arch

Axis or Cervical II

Length of body exclusive of odontoid

Width of odontoid

8657

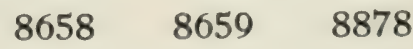

Width across atlanteal facets

Depth of atlanteal facets

$\begin{array}{rcrc}90 \mathrm{e} & 87.5 & - & 10.7 \\ 51 \mathrm{e} & 51.5 \mathrm{e} & 52.0 & 48.0 \\ 122 \mathrm{e} & 105 \mathrm{e} & 119.4 & 110 \mathrm{e} \\ 77 \mathrm{e} & 70 \mathrm{e} & 75.5 & 67.5\end{array}$




\begin{tabular}{|c|c|c|c|}
\hline \multicolumn{2}{|c|}{ Cervical III } & Lumbar? & Sacrum \\
\hline 8664 & 8662 & 8670 & 8769 \\
\hline $90 \mathrm{e}$ & 95.4 & 73.5 & $210 \mathrm{e}$ \\
\hline $52 \mathrm{e}$ & 60.5 & $43 \mathrm{e}$ & 31.8 \\
\hline 49.6 & 44.7 & 47.5 & 67.3 \\
\hline 90.4 & 100.0 & - & - \\
\hline $80 \mathrm{e}$ & 98.5 & - & - \\
\hline 51.9 & 55.8 & - & - \\
\hline 89.4 & $100 \mathrm{e}$ & 一 & - \\
\hline - & 24.0 & - & - \\
\hline - & 27.0 & - & - \\
\hline 8802 & 8851 & 8671 & 8672 \\
\hline 77.5 & 64.7 & 69.5 & 65.9 \\
\hline $66 \mathrm{e}$ & 53.7 & 52.7 & 55.7 \\
\hline $80 \mathrm{e}$ & - & 59.2 & $70+$ \\
\hline 33.2 & 26.4 & 23.6 & 30.0 \\
\hline $98 \mathrm{e}$ & - & 87.5 & 83.0 \\
\hline
\end{tabular}

Length of body

Depth of anterior centrum

Width of anterior centrum

Length between pre- and postzygapophyses

Least width across lamina

Length of neural arch in midline

Height of table above ventrum (posteriorly)

Dorsoventral diameter of neural canal (anteriorly)

Transverse diameter of neural canal (anteriorly)

\section{Scapula}

Anteroposterior diameter of glenoid

Transverse diameter of glenoid

Anteroposterior diameter of neck

Transverse diameter of neck

Anteroposterior diameter over coracoid

\section{Humerus}

8804

Proximal transverse diameter

Proximal transverse articular diameter

$115 \mathrm{e}$

Proximal anteroposterior diameter

$1 \overline{28.1}$

128.1
8673

Distal condylar transverse diameter

Minimum diameter of distal condyle

Height of medial epicondyle

Height of lateral epicondyle

\section{Radius}

Proximal transverse diameter

Proximal anteroposterior diameter

Distal transverse diameter

\section{8}

$\begin{array}{lll}47.5 & 46.7 & 39.8\end{array}$

- $\quad-\quad 65.1$

- $\quad 96.5 \quad 98.2$

Ulna

$$
\begin{array}{rcccc}
8676 & 8677 & 8678 & \begin{array}{c}
\text { Reynolds } \\
(1939, \text { p. 21) }
\end{array} \\
113.2 & - & - & 124-129 \quad(2) \\
53.0 & 56.5 & - & &
\end{array}
$$

Depth in semilunar notch

Length from anconaeus to olecranon

Anteroposterior depth of olecranon over anconaeus

Transverse diameter of olecranon plate

Transverse diameter of olecranon calcar

\section{Proximal Carpals}

Anteroposterior diameter

Transverse diameter

Proximodistal diameter

\section{Distal Carpals}

Transverse diameter

Anteroposterior diameter

Proximodistal diameter

$\begin{array}{ccc}\text { Cuneiform } & \text { Scaphoid } & \text { Lunar } \\ 8740 & \mathbf{8 7 7 8} & \mathbf{8 8 6 7} \\ 35 \mathrm{e} & 48.3 & 44.8 \\ 26.0 & 27.7 & 31.5 \\ 42 \mathrm{e} & 30.7 & 34.9\end{array}$

\begin{tabular}{rcr}
\multicolumn{3}{c}{ Trapezoids } \\
8760 & $\mathbf{8 7 4 2}$ & 8853 \\
48.4 & 55.7 & 49.2 \\
44.7 & 51.5 & 44.4 \\
23.5 & 28.2 & 23.6
\end{tabular}

Unciform 8723 


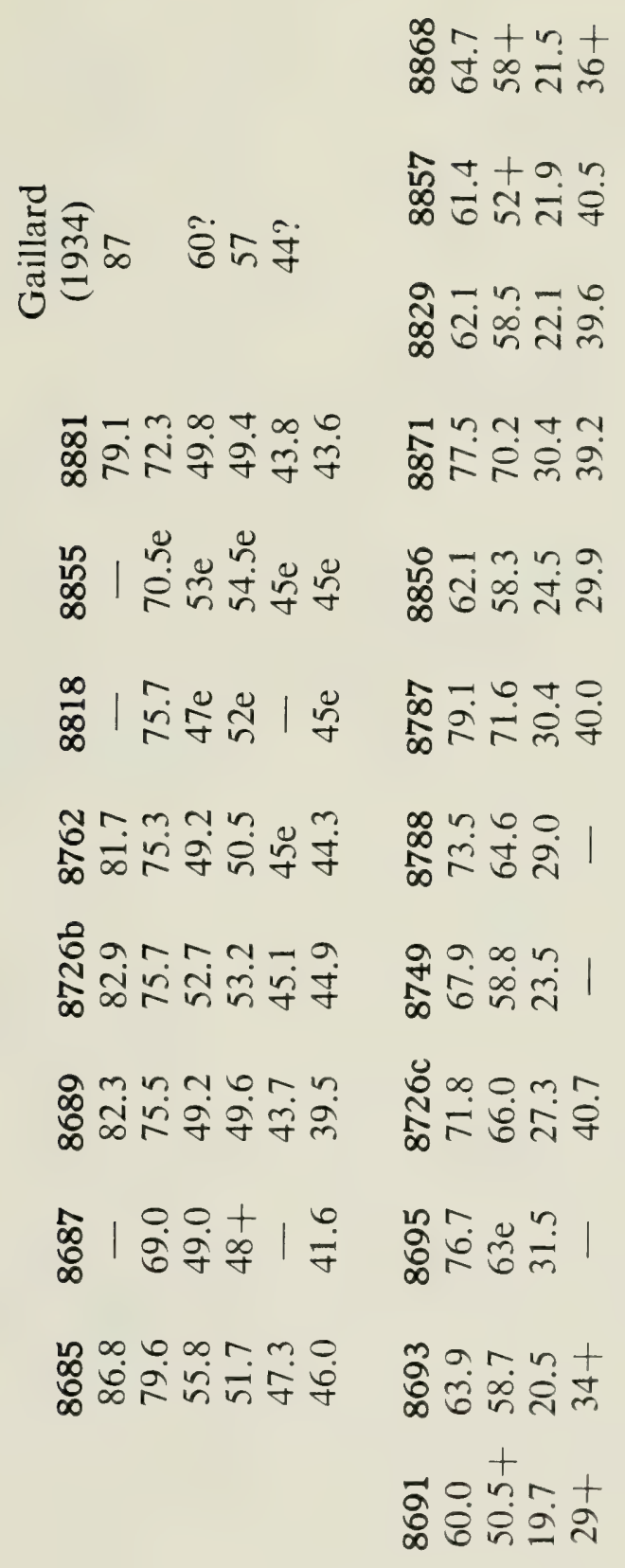

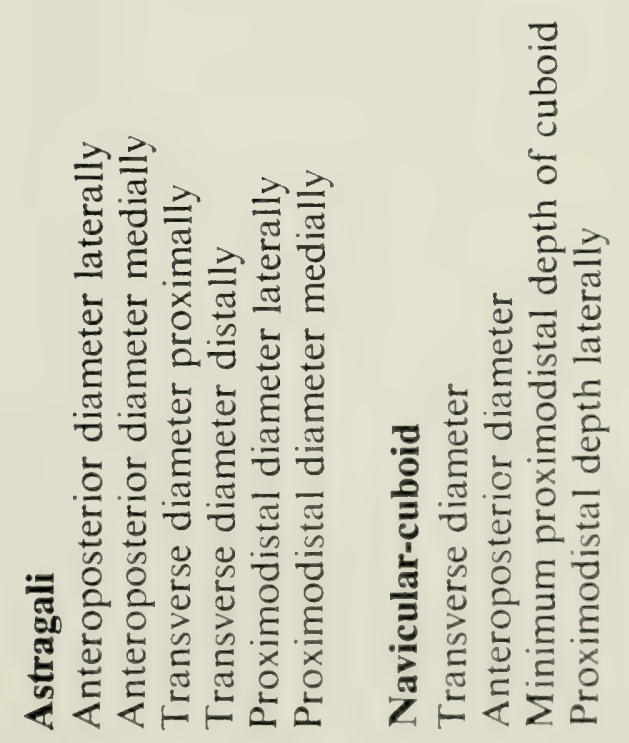




\section{Metacarpals III and IV}

Proximal transverse diameter

Proximal anteroposterior diameter

Midshaft transverse diameter

Midshaft anteroposterior diameter

Distal transverse diameter

Distal anteroposterior diameter

Transverse diameter of metacarpal in

Transverse diameter of metacarpal iv

\section{Tibia}

Distal transverse diameter

Distal anteroposterior diameter

Transverse diameter of astragalar trochlea

\section{Cuneiforms}

Transverse diameter

Anteroposterior diameter

Proximodistal depth

Proximodistal thickness of lamina

\section{Metatarsal II}

Proximal transverse diameter

Proximal anteroposterior diameter

Midshaft length

Metatarsals III and IV
Proximal transverse
diameter
Proximal anteroposterior
diameter
Midshaft transverse
diameter
Midshaft anteroposterior
diameter
Distal transverse
diameter
Distal anteroposterior
diameter
Transverse width of
metatarsal III
Transverse width of
metatarsal IV

8698

8698 8726a
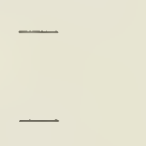

59.9

8727

Mes 8726 d 28.1

45.2

19.3

13.2$$
\text { neiform }
$$$$
8789
$$$$
29.0
$$$$
49.3
$$$$
19.4
$$$$
15.5
$$

8684

8784

8828

74.8

80.6

83.0

56.8

65.5

49.5

57.0

Reynolds

(1939, p. 47)

$52.5-58.5(4)$

$79.0-105.0(4)$

$49.5=$

\section{Entocuneiform}

$86968726 \mathrm{e}$

$24.6 \quad 18.0$

$39.3 \quad 39.9$

$13.6 \quad 14.0$

Reynolds

8726f (1939, p. 48)

$10.9 \quad 7.95-8.15(2)$

17.8

24.3

Reynolds Gaillard (1939, p. 48) (1934)

- $34.9-\quad$ - 49-50

$\begin{array}{lll}-\quad 39.2 & 40 \mathrm{e}-\end{array}$

62.6

80.3

$82-82.5$

78

$37.1-\quad-\quad 40.6$

$44 \mathrm{e}$

28.0

26.8

26.7

29.4

\section{Phalanges I and II}

Overall length

Proximal transverse diameter

Proximal anteroposterior diameter

Midshaft transverse diameter

Least shaft anteroposterior diameter

Distal transverse diameter

Distal anteroposterior diameter

\begin{tabular}{c|cccc} 
Phalanx I & \multicolumn{4}{|c}{ Phalanx II } \\
8700 & 8702 & 8703 & 8793 & 8794 \\
66.6 & 46.5 & 42.0 & 46.7 & 47.3 \\
$31 \mathrm{e}$ & 32.1 & 32.7 & 37.2 & 36.8 \\
$39 \mathrm{e}$ & 31.9 & $33 \mathrm{e}$ & 34.5 & - \\
28.4 & 24.6 & 26.3 & 32.7 & 31.2 \\
20.2 & - & - & 29.0 & 27.6 \\
30.4 & - & - & $35 \mathrm{e}$ & $31.4 \mathrm{e}$ \\
22.5 & - & - & 35.4 & $31 \mathrm{e}$
\end{tabular}


Proximodistal length dorsally

Proximodistal length on volar surface

Height of coronoid above volar plane

Transverse diameter of facet

$91+98 \mathrm{e}$

Anteroposterior diameter of facet

48.6

28.6

$42 \mathrm{e}$

Height of retractor process

$21.2 \quad 22.6$

\section{?Homoioceras vignardi (Fig. 28)}

A single left astragalus (8290, Fig. 28) from a large bovid differs from those previously reported and identified as Bos primigenius. Comparative measurements of this specimen and of the largest entire astragalus of $B$. primigenius ( $8726 \mathrm{~b}$ ) show its larger size and proportionately more massive construction, especially in transverse and tibial-calcanear diameters. It also exhibits well marked muscle and tendon scars.

\section{Dimension}

Anteroposterior diameter on lateral face

?Homoioceras vignardi

Anteroposterior diameter on medial face

8290

$85.5 \mathrm{e}$

78.6

65.5

$55 \mathrm{e}$

Transverse diameter at distal end

48.8

Proximodistal diameter on lateral face

53.3

\begin{tabular}{cc}
\multicolumn{2}{c}{ Bos primigenius } \\
Gaillard \\
$8726 \mathrm{~b}$ & $(1934)$ \\
82.9 & 87 \\
75.7 & \\
52.7 & 60 \\
53.2 & 57 \\
45.1 & $44 ?$ \\
44.9 &
\end{tabular}

The measurements for Gaillard's B. primigenius astragalus are not certainly comparable with those for the Canadian Expedition's materials as his dimensions are not easily identified.

As this astragalus cannot be identified to B. primigenius, and as Homoioceras vignardi has been reported by Gaillard (1934, as Bubalus vignardi) from the same area (Gaillard's specimens came from Sebil II locality in the Sebil Area, pers. comm. E. Vignard to P. E. L. Smith), and as teeth are present in the collection that could derive from Homoioceras, this specimen is therefore tentatively identified as cf. $H$. vignardi.

Gaillard's (1934) report of Bubalus vignardi from the Sebil Area was founded on a broken right hornbase and on left second, third and partial first upper molars (Gaillard, 1934, p. 37 and Pl. v, Figs. 1, 2 and 6; redrawn in Fig. 29). The hornbase is nearly elliptical in section at $5 \mathrm{~cm}$ from the base and measures 101 by 66 in greater and lesser diameters, respectively. These dimensions do not differ significantly from the 100 by 70 reported for a horncore from Oasis Depression (8653) nor from the 104.5 by 75.3 and 108.7 by 77.7 reported for the larger skull from Sebil v (8835). Gaillard remarked "La face antérieure de la corne est creusée de plusieurs gouttières larges et profondes en haut, étroites en bas", but his illustration shows a specimen that has been both weathered and broken, as is typical of some specimens from the Sebil Area in the Canadian Expedition's collections. Gaillard's specimen strongly resembles the relevant parts of the skull assigned to a male Bos primigenius (8835). Gaillard's description of the horn "La cheville se dirige d'abord en dehors et en haut, puis 
elle se recourbe vers le bas, dans le plan du frontal, avec un très légère inflexion en avant rappelant les cornes du Boeuf musqué," recalls the configuration of some of the horncores of $B$. primigenius illustrated by Reynolds (1939), Zeuner (1963) and even possibly Gaillard (1934, Pl. IV, Figs. 2 and 3).

The two teeth of $H$. vignardi (Fig. 29) have moderately bowed buccal surfaces and large, squared lingual surfaces to the paracones and metacones, squared pre- and post-fossettes, small plis hypoloph, interlophar endostyles attached to the distolingual portion of the protocone and, in $\mathbf{M}^{3}$ only, small interfossettes. These teeth are best assigned to a buffalo on these characters although stages of wear produce changes in proportions and pattern of cusps and fossettes.

The presence of $H$. vignardi in the Kom Ombo fauna is unsatisfactorily supported by this evidence, and better materials, such as the skull described by Bate (1951) from Singa in the Sudan for $H$. singae, must be discovered to confirm its presence without question.

\section{Summary of Conclusions on Bos primigenius, B. brachyceros, Syncerus caffer and Homoioceras vignardi}

The large bovid material from the Kom Ombo Plain is only certainly identifiable as Bos primigenius from localities Sebil IV and va. Generally, the dental material resembles in detail the variants that are usual in $B$. primigenius, although some specimens by themselves could be assigned to Syncerus cf. caffer or even Homoioceras vignardi. As diagnostic materials of these latter two species are lacking, and because the range of variation in the minor dental characters of modern B. taurus encompasses variations typical of either Syncerus or Homoioceras, all the large bovid material (except the single astragalus, 8290, Fig. 29) is assigned to B. primigenius. This assignment does not preclude misidentification of partial or variant specimens and it is possible that one or both of the other species may eventually be identified from other Kom Ombo sites, should new material be available in the future.

Gaillard (1934) reported Bos brachyceros and B. primigenius from the Sebil Area in the Kom Ombo Plain. He stated that B. brachyceros shows "au sommet du front, la ligne légèrement sinueuse du chignon (pl. IV, fig. 1), qui charactérise parfaitement Bos brachyceros." A nuchal outline of this conformation is present in B. primigenius (see Gaillard, 1934, Pl. IV, Fig. 3, right hornbase, and Reynolds, 1939). The sinuousness to which Gaillard referred is dependent on the size of the nuchal musculature and its insertions near the inion, and on the size of the horncore, the muscles being larger when there are larger horns, as in large males, when the crests on either side of the midfrontal suture extend laterally to provide the stronger insertions required to support the greater weight of the larger horns. Zeuner (1963) remarked on this change and considered that there is no evidence for domestication of cattle at Kom Ombo during the Late Palaeolithic. 
Measurements of the partial cranium assigned to $B$. brachyceros by Gaillard (1934, p. 31) are similar to those of the smaller skull (8827) collected by the Canadian Expedition from the same area and demonstrated to be probably a female of $B$. primigenius. Other differences considered by Gaillard are sexual or between domesticated and wild or European and African cattle, all of which reflect only size and proportional variation, or the shape of the horns, which is variable in many varieties of cattle (Bohlken, 1962).

Gaillard (1934) referred parts of skulls, lower and upper molars and various limbbones, including the head of a humerus, an astragalus, calcaneum, part of a metatarsal and some tarsal bones from the Sebil Area to $B$. primigenius. Measurements of these specimens are given for comparison in the tables of measurements for the Canadian Expedition's material of $B$. primigenius.

Gaillard distinguished $B$. primigenius by "Les chevilles des cornes se dirigeant en dehors, presque horizontalement, puis elles s'infléchissent en avant et en bas." This conformation is not mutually exclusive from that given by him for B. brachyceros (vide supra), since one is dependent on horncore conformation and one on the configuration of the posterior frontal margin across the inion. The horncores illustrated by Reynolds (1939) and discussed by Bohlken (1962) as B. primigenius include both configurations.

The teeth from the Sebil Area illustrated by Gaillard (1934, Pl. v, Figs. $3,4,5)$ fall within the ranges of variation for the third lower and upper molars of $B$. primigenius. The other cheek teeth Gaillard record as being common but poorly preserved were not illustrated, and he gave only one measurement of $45 \mathrm{~mm}$ for the lingual length of a $\mathrm{M}_{3}$.

The materials of $B o s$ or other large bovids recovered from the Kom Ombo Plain certainly include $B$. primigenius, for which $B$. brachyceros seems to represent the females in which the horns are proportionately smaller, and possibly a buffalo, for which Homoioceras vignardi is the appropriate name. The presence of the latter has not yet to be confirmed as the horn fragment on which it is based could be assigned to $B$. primigenius, and the two upper cheek teeth associated with it are characteristic of buffaloes (e.g., Syncerus or Homoioceras) but not outside the range of variation seen in populations of $B$. primigenius. As the African buffalo, S. caffer, appear to have been absent from Egypt (Zeuner, 1963, p. 245), if a buffalo was present in the Kom Ombo deposits, then the long-horned H. vignardi is more probable (although, if present, it was a scarce member of the fauna). 
Alcelaphus buselaphus-bubal hartebeest (Figs. 30 to 40)

MATERIAL

Obtained from:

Oasis Depression Localities-A; C; E; G; H.

Bayara A.

Gebel Silsila Localities-I; III, Surface and Subsurface, mixed Sebekian and Silsilian-Level 0; III, Sebekian-Level 1; III, mixed Sebekian and Silsilian-Level 2; III, Silsilian-Level 3; V; VII; IX; X; XIII-Sector 2; XIII-Sector 4a; XIV; XV; XVII; Miscellaneous.

Sebil Localities-I; II; III; IV; V; VI; VII.

Khor el-Sil Localities-IIb; III(2); III(3); IV.

\section{CONSIDERATION}

The horncores of the hartebeest are typically lyrate with the midline of each horn diverging from the other at about $90^{\circ}$. The horns spring from a broad, slightly convex frontlet that extends farther behind the orbits than its width, and the occiput lies beneath or anterior to the base of the horns. Ansell (1971, p. 52) cited Ellerman et al. (1953, p. 202) to distinguish between $A$. lichtensteini and $A$. buselaphus. The extinct Kom Ombo hartebeest has the long horn pedicel and forwardly placed occiput characteristic of $A$. buselaphus, and horns that are not "flat and curved inwards towards each other before bending back" but rather inwardly spiralling before pointing posteriorly (Fig. 30). The forehead is flat in A. buselaphus, convex in $A$. lichtensteini, and is flat between the orbits in the fossil. Thus the Kom Ombo hartebeest can be definitely assigned to $A$. buselaphus.

No hartebeest is reported for the living Egyptian fauna (Hoogstraal, 1964), and the nearest living race is the Tora hartebeest (A.b.tora) extant in northern and western Abyssinia and eastern Sudan (Ansell, 1968, p. 137). Lydekker (1926, pp. 84-87, Pl. v) described the horns of Alcelaphus tora as spreading outwards in the form of an inverted bracket from a pedicel of medium height. His illustration of the head (ibid, Pl. v, Fig. 3) suggests wider spreading horns with a basal angle subtending more than a right angle. The Kom Ombo hartebeest more closely resembles the extinct $A$. b. buselaphus although the horns trend towards the conformation typical of $A$. b. tora.

The horncores are usually evenly tapered, smooth or longitudinally grooved, with one or two major grooves on the outer curvature near the base. The bases are flared and bulbous medially, and the tips are usually smooth but occasionally show transverse ridges or thickenings.

The upper cheek teeth are six a side, three premolars and three molars. The anterior second premolar is a small, wedge-shaped tooth, with two buccal styles and a single distolingual fold. The third premolar, larger than the second, comprises a main buccal parastyle and metastyle mesial and distal to the paracone, with a distolingual fold joining the mesiolingual protocone to create a fossette that in unworn specimens is open lingually distal to the protocone and buccally distal to the parastyle, the latter remaining open in some specimens (e.g., 8391). The fourth premolar is 


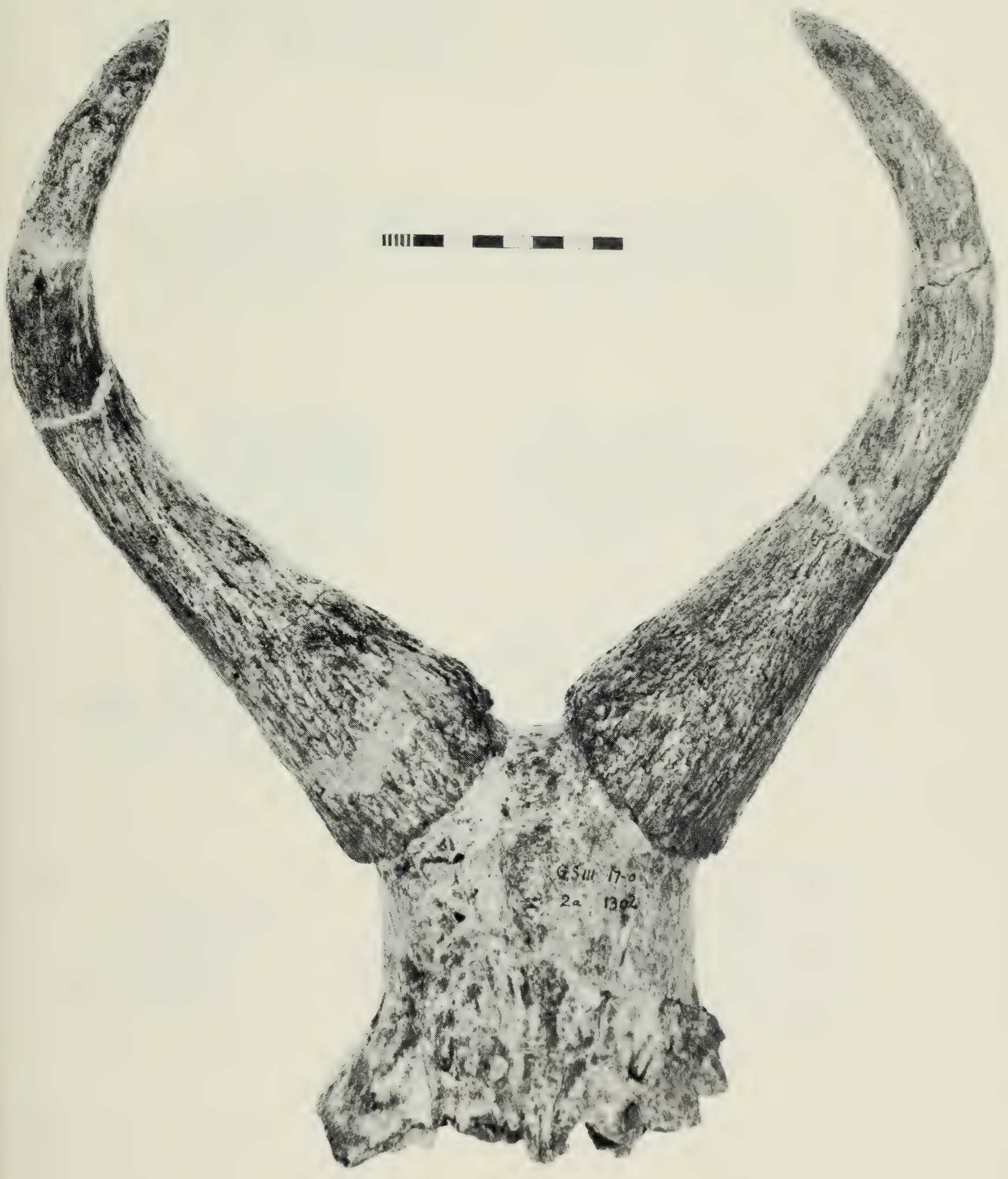

Fig. 30 Alcelaphus buselaphus. Anterior aspect of complete horncores and frontal pedicel 8931 from Gebel Silsila III, Level 1, Sebekian Industry. Scale $=80 \mathrm{~mm}$. 


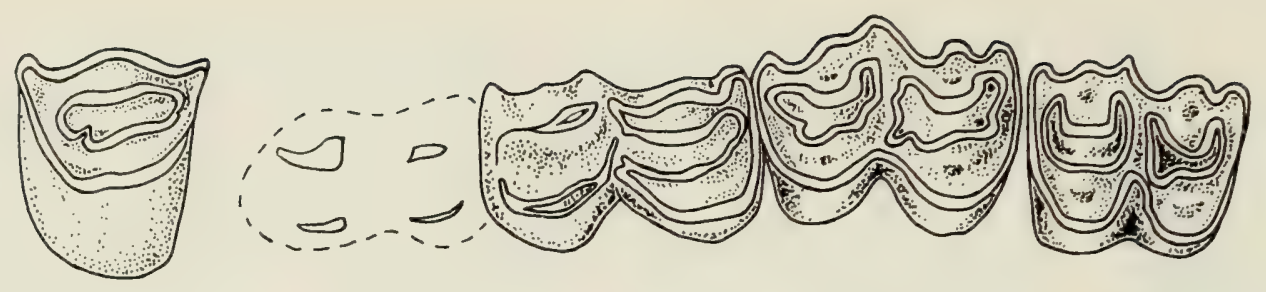

A

B

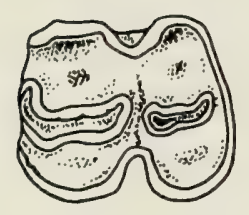

C

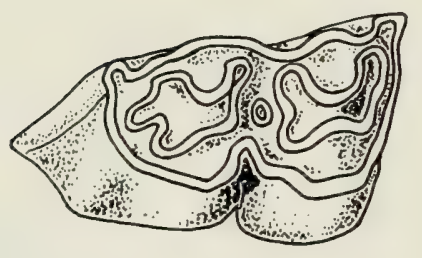

E

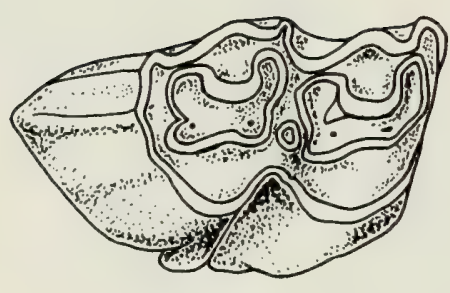

G

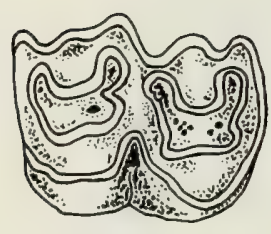

J

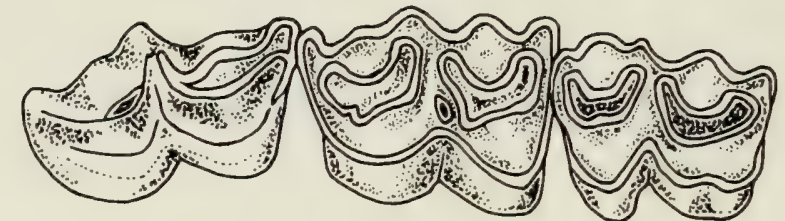

D

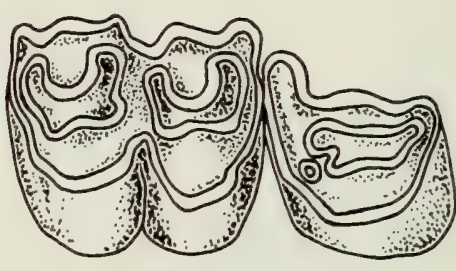

$\mathbf{F}$

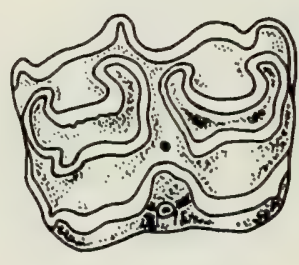

H

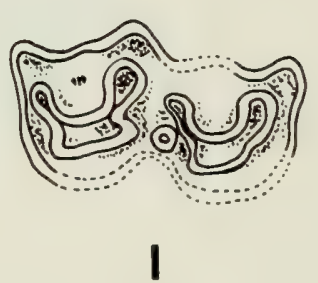

I

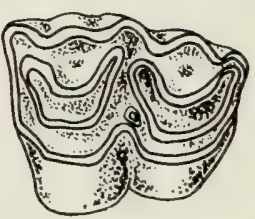

L

Fig. 31 Alcelaphus buselaphus. Occlusal aspects of upper right cheek teeth. A - worn P4 from Gebel Silsila III, Level 1, Sebekian Industry (8942). B - worn milk $\mathrm{p}^{4}$, slightly restored, and newly worn $\mathbf{M}^{1-2}$ and erupting $\mathbf{M}^{3}$ from Gebel Silsila III, Level 1, Sebekian Industry (8940). C - well worn $\mathbf{M}^{1}$ from Gebel Silsila III, Level 1, Sebekian Industry (8943). D - well worn milk p $^{4}$, newly worn $\mathbf{M}^{1}$ and damaged $\mathbf{M}^{2}$, slightly restored, from Gebel Silsila III, Level 1, Sebekian Industry (8939). E - worn $\mathbf{M}^{3}$ from Sebil III (8392). F - worn $\mathrm{P}^{4}-\mathrm{M}^{1}$ from Gebel Silsila III, Level 1, Sebekian Industry (8938). G - worn $M^{3}$ from Gebel Silsila III, Level 0, mixed surface Sebekian and Silsilian industries (8914). H - worn $\mathbf{M}^{2}$ from Gebel Silsila III, Level 1, Sebekian Industry (8946). I - worn and damaged $\mathbf{M}^{2}$ from Khor el-Sil II (9052). J - worn $\mathbf{M}^{1}$, slightly restored, from Sebil II (8383). $\mathrm{K}$ - worn $\mathbf{M}^{1}$ from Gebel Silsila III, Level 2, mixed Sebekian and Silsilian industries (8318). L - worn $\mathrm{p}^{3}$, slightly restored, from Gebel Silsila III, Level 1, Sebekian Industry (8941). Scale $=50 \mathrm{~mm}$. 


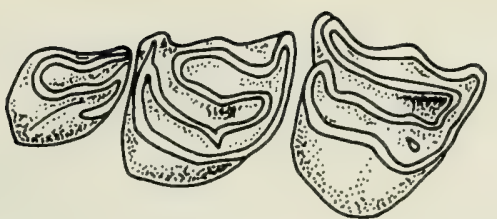

A
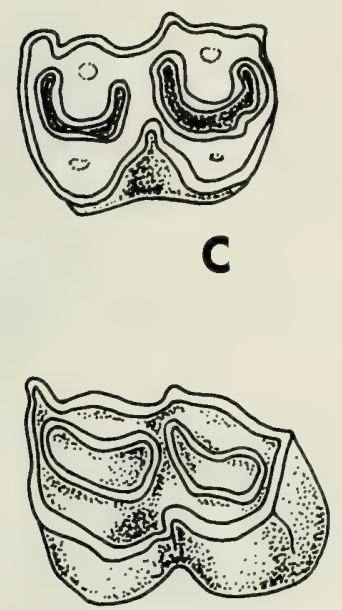

$\mathbf{E}$

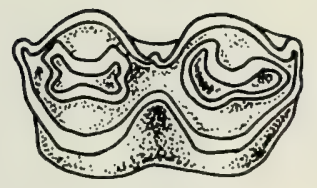

G
B
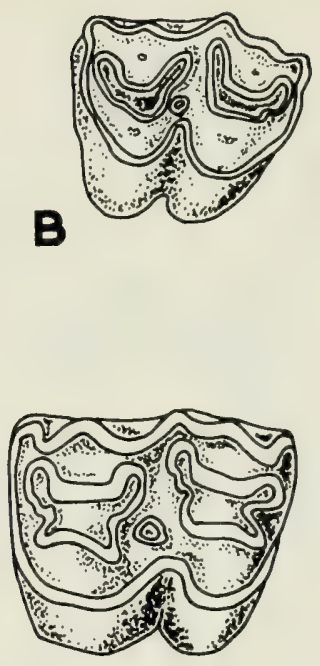

D

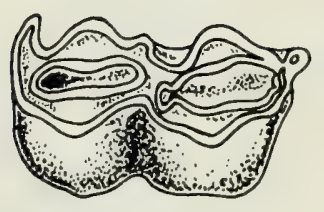

$\mathbf{F}$

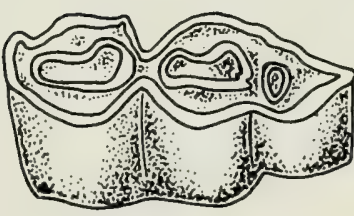

H

Fig. 32 Alcelaphus buselaphus. Occlusal aspects of cheek teeth. A - worn left $\mathrm{P}^{2}-4$, with $\mathrm{P}^{4}$ damaged, from Gebel Silsila III, Level 1, Sebekian Industry (8937). B - worn milk left $\mathrm{p}^{4}$, slightly restored, from Khor el-Sil II (9046). C - left $\mathbf{M}^{1}$, broken section, from Gebel Silsila X (8344). D - worn left $\mathbf{M}^{2}$, stightly restored, from Gebel Silsila III, Level 1, Sebekian Industry (8945). E - worn left $\mathbf{M}^{3}$, slightly restored, from Gebel Silsila III, Level 2, mixed Sebekian and Silsilian industries (8319). F - newly worn right $\mathbf{M}_{2}$ from Sebil I (8366). $\mathrm{G}$ - worn right $\mathbf{M}_{2}$ from Gebel Silsila III, Level 3, Silsilian Industry (8330). $\mathbf{H}$ - worn left $\mathbf{M}_{3}$ from Gebel Silsila III, Level 1, Sebekian Industry (8951). Scale $=50 \mathrm{~mm}$. 

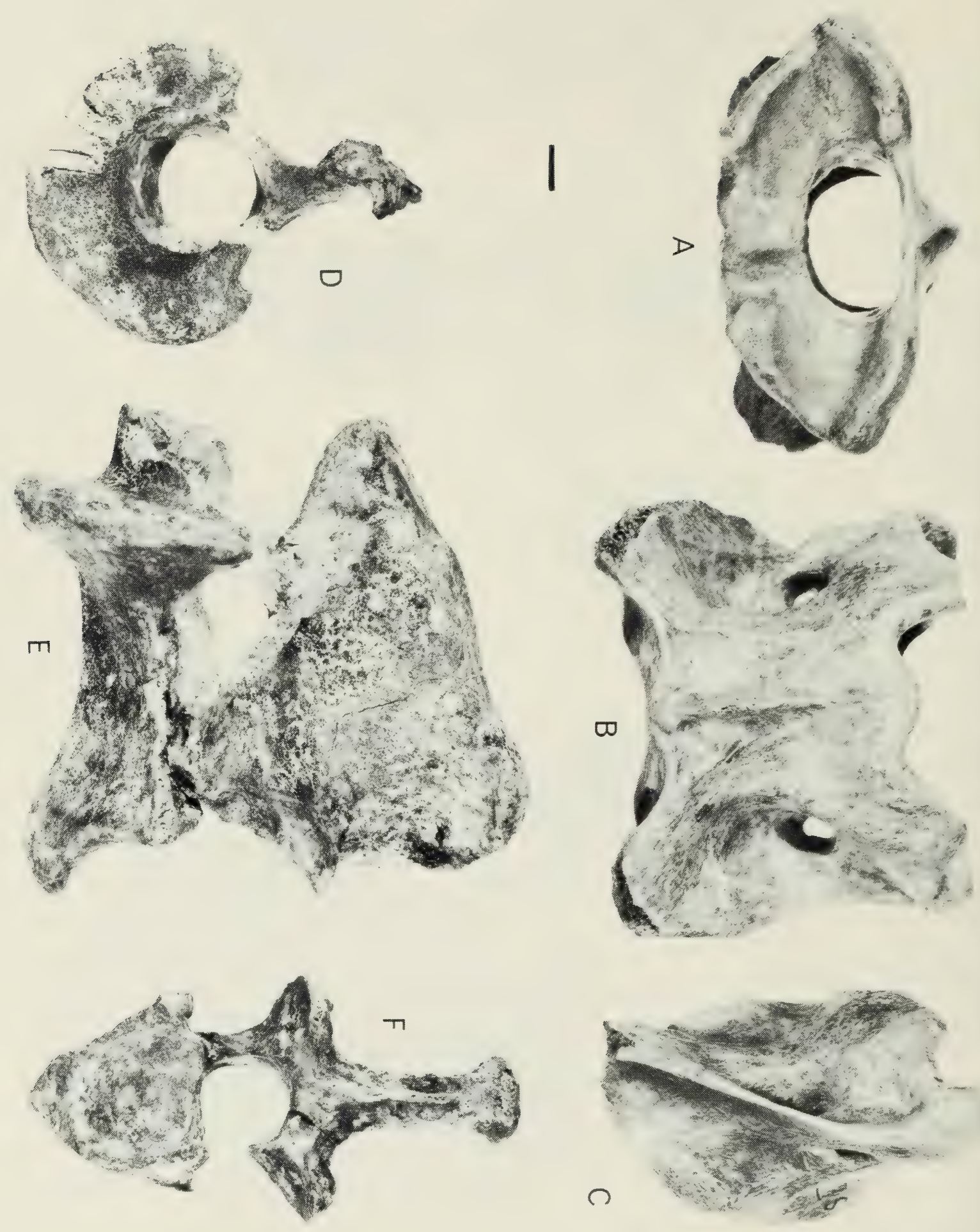

Fig. 33 Alcelaphus buselaphus. Atlas and axis vertebrae.

A-C. Atlas or cervical I vertebra 8539 from Sebil vi. A $=$ condylar or anterior aspect, $\mathrm{B}=$ ventral aspect, $\mathrm{C}=$ left lateral aspect.

D-F. Axis or cervical II vertebra 8953 from Gebel Silsila III, Level 1, Sebekian Industry. $\mathrm{D}=$ atlanteal or anterior aspect, $\mathrm{E}=$ left lateral aspect, $\mathrm{F}=$ posterior aspect.

Bar $=10 \mathrm{~mm}$. 
similar to the third, is larger, has the fossette open only buccally in unworn specimens, and has a distal pli within the fossette. A permanent molar has a well developed parastyle, mesostyle and metastyle, strong crests on the paracone and metacone, squarish fossettes with plis sometimes present mesially and distally in one or both fossettes (8945, Fig. 32D), sometimes an interfossette $(8945,9025)$ that partly occupies the distolingual corner of the prefossette, and an interlophar endostyle or distolingual style may also be present $(8946$, Fig. $31 \mathrm{H})$. The milk molars resemble the permanent in general shape but are less variable in the presence of plis within the fossettes, as only one pli hypoloph with one interfossette (8939, Fig. 31D), and one interfossette (9046, Fig. 32 в) and no endostyles are observable. The enamel on all these teeth is lightly folded or ridged and tends to be covered with a brownish deposit. These teeth resemble those of Alcelaphus in all their characters.

The dentary is lightly built, with a narrow diastema that measures 21.6 by $10.4,23.2$ by 12.5 and 23.5 by 12.2 in dorsoventral and transverse diameters $(8948,8406$, and 9055 , respectively), flares buccally to take the incisive roots and usually has two mental foramina placed anteriorly to the posterior end of the symphysis. The posterior foramen is slightly larger and placed about one-third of the depth of the dentary from the dorsal margin. The anterior foramen lies $10 \mathrm{~mm}$ anterior to the larger, and is in the middle of the ramus, which is 30 deep at that point. The length of the symphysis is about 56 (8948) and that of the diastema about 100 (8406). The condyle measures 14.1 by 30.1 in anteroposterior and transverse diameters (8350), respectively, is strongly hollowed, and stands at least 110 above the ventral margin of the ramus.

The incisors and canines are curved, spatulate and form the procumbent cropping incisive apparatus typical of bovids.

The lower fourth premolar (8345) is laterally compressed, with well developed lingual styles, metaconid and hypoconid, and with small mesial protoconid and paraconid, and an incipient entoconid. The lower molars are also compressed, lack any ectostylid, have strong lingual stylids and conids, and have simple, oval or elongate fossettes. Internal plications are absent in the third molars but may be present in the second or first molars (e.g., 8330, Fig. 32G; 8366, Fig. 32F; and 9053).

The atlas (Figs. 33A to $33 \mathrm{C}$ ) is strong, with a small ventral keel, slightly concave margins to the wings and nearly vertical alar foramina.

The axis (Figs. 33D to 33F) is slightly elongate, with a tall, straight neural crest, a ventral keel leading posteriorly to a strong spur beneath the posterior central articulation. The atlanteal facet is inclined at an angle of about $15^{\circ}$ to the axis of the centrum, and both this facet and the odontoid wrap around the neural canal about $250^{\circ}$. The intervertebral foramina are large and round or oval, and the vertebrarterial canals extend through the posterior half of the centrum, opening posteriorly in the base of the transverse processes on the dorsolateral corners of the posterior centrum and anteriorly through small oval lateral and round medial foramina.

The cervical vertebrae III to VII (Figs. $34 \mathrm{~A}$ to $34 \mathrm{H}$ ) show progressive 
shortening of the body, obliquely inclined central articulations except in VII, increasingly large neural spines, broadening and shortening vertebrarterial canals except in VII where they are absent, transverse processes rising to the level of the top of the body in VII, and increasingly large hyperapophyseal plates directed ventrally in VI and absent in VII. The entire cervical series is arranged so that the seventh leaves the thoracic series almost horizontally, the series VI to III rises upwards to elevate the head, the axis continues this but has a strong neural crest to hold the atlas at an horizontal angle, and the atlas holds the braincase horizontal with the facial region and horn pedicel inclined downwards to give the typical profile of the hartebeest. Specimen 8917 (Figs. 34G to 34H) is typical of cervical VII but has a well developed posterior costal demifacet and a small tubercular facet on the transverse process, thus resembling the thoracic vertebrae. This vertebra may well be an anomalous cervical VIII/thoracic I.

The thoracic vertebrae are lightly built, with keeled centra, oval neural canals, and bridged intervertebral foramina in the central part of the series.

The lumbar vertebrae are similar to the thoracic but wider transversely, with larger neural canals and dorsoventrally compressed centra, open intervertebral notches and the rolled zygapophyseal facets typical of the lumbar region of the spine.

The scapula (Fig. 35A) is small, lightly built, with an elongated neck, small superior area, the spine extending onto the narrowest part of the neck and inclined anteriorly, a prominent coracoid process that is turned slightly inwards and a small posterior process where the vascular groove crosses the anterior surface.

The humerus (Figs. 35B, 36) is lightly built, with an imperforate olecranon fossa, upright medial and slightly rolled lateral distal epicondylar ridges and no auxillary radial facet above the medial condyle.

The radius (Figs. 35c, 36) is lightly built, lacks any fusion with the ulna proximally, and has no prominent rugosities for muscle attachments on the anterior surface and only slightly emphasised insertions on the posterior surface.

The ulna (Figs. 35D, 36) is represented only by olecrana that are flattened medially, with rugose, bulbous ends and set at an angle of about $135^{\circ}$ to the axis of the radius.

The carpals are represented by one complete and a fragmentary scaphoid, a lunar, a normal right and a pathologic left unciform, and seven complete and a half trapezoid. The normal unciform articulates well with the right metacarpals and trapezoids, but the pathological specimen does not because of an external and anterior osteitic growth.

The metacarpals III + IV (Figs. 37A, 38A to 38B) are long and slender, slightly concave posteriorly, without a proximal but with an elongate, narrow, distal intermetacarpal foramen lying in a small groove or on the surface of the bone in the adult. The posterior intermetacarpal foramina are small proximally but larger and round distally. The proximal end has little relief; the trapezoid facet occupies two-thirds of the end and is squared on the anterointernal angle. The unciform facet is small, triangular, and 

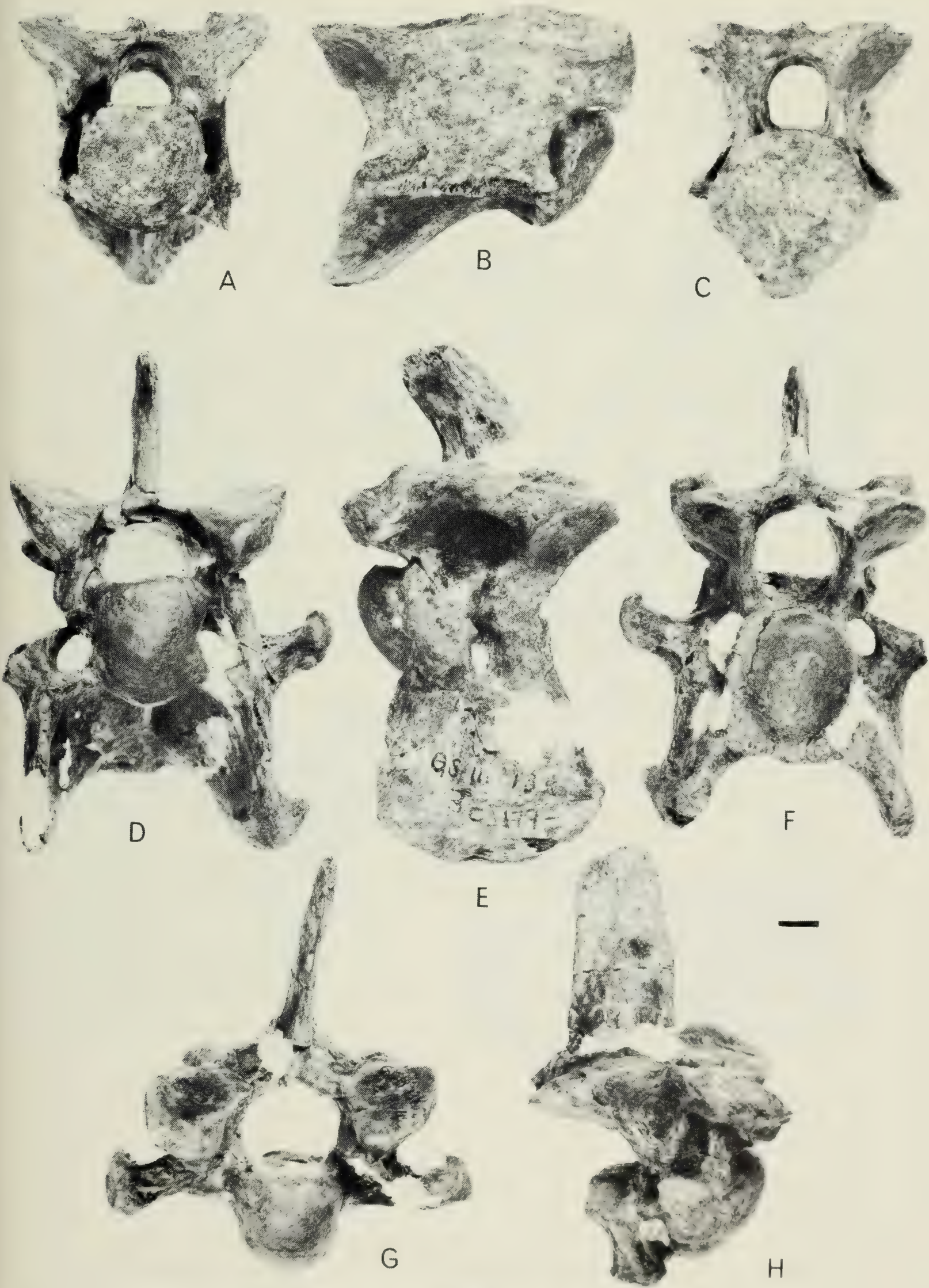

Fig. 34 Alcelaphus buselaphus. Cervical vertebrae ?III, ?VI, and ?VII.

A-C. Cervical vertebra ?III 8956 from Gebel Silsila III, Level 1, Sebekian Industry. $\mathrm{A}=$ anterior aspect, $\mathrm{B}=$ right lateral aspect, $\mathrm{C}=$ posterior aspect. D-F. Cervical vertebra ?VI 8958 from Gebel Silsila III, Level 1, Sebekian Industry. $\mathrm{C}=$ anterior aspect, $\mathrm{E}=$ left lateral aspect, $\mathrm{F}=$ posterior aspect. G, H. Cervical vertebra ?vII 8917 from Gebel Silsila III, Level 0, surface and subsurface mixed Sebekian and Silsilian industries. $G=$ anterior aspect, $\mathbf{H}=$ right lateral aspect.

Bar $=10 \mathrm{~mm}$. 
separated from the trapezoid by a wide, blunt-ended groove that opens posteriorly and at the head of which the proximal intermetacarpal canal opens. The least diameters of the shaft lie about one-third from the distal end for the transverse width and one-quarter for the anteroposterior thickness.

Metacarpal V (8281) is small, awl-like, measuring 4.0 by 7.1 by $40+$ for the transverse, anteroposterior and overall dimensions, respectively.

The pelvic girdle is unrepresented in the Kom Ombo collection.

The femur has an oval caput in outline, with a shallow fovea that has slight dorsal and posterior ridges and the capitular facet extends over the dorsal part of the neck. The distal articulations are typically antelopine, with a wide intercondylar notch and a sharp lateral trochlear eminence. The capites femorium measure 33.8 and 34.0 in diameters for specimens 8397 and 8541 respectively. The patella is triangular and knobby and measures 24.9, 18.1 and 11.4 in proximodistal, transverse and anteroposterior diameters, respectively.

The tibia is strong, with a large and slightly rolled crest, a single large proximal nutrient foramen with small auxillary foramina, and a U-shaped muscular sulcus. The proximal end of the fibula is represented by a short, tear-drop-shaped ossification. The distal end bears small, unequal malleolar facets with an open, wide malleolar canal.

The astragalus (Figs. 39C to 39D, 40) is similar to that of Gazella dorcas, but is slightly longer, broader, and deeper to carry the greater weight of a larger animal. The lateral ridge of the tibial trochlea is proportionately broader, the trochlear pit deeper, and the spurs on the posteroproximal corner of the trochlea larger.

The calcaneum (Figs. 39A, 39B ) is straight, robust, and with a relatively long, parallel-sided calcar. The malleolar facet is prominent but not large, the navicular is lunate and of uniform width, and the sustentaculum is deep and strong. The area for the insertion of the medial ligament can be broad, slightly ridged or prominent. If the latter, the plantar surface of the shaft is increased by the ossification of a shelf on its medial margin and this shelf may extend to within $10 \mathrm{~mm}$ of the level of the sustentaculum. The tuber calcis has a broad groove for the distal part of the Achilles' tendon.

The navicular-cuboid (Figs. 37D, 37E) is similarly robust, with well developed proximal posterointernal and distal posterolateral eminences and a roughened plantar surface. A well marked vascular groove anterolateral to the calcanear facet indicates the passage of the intermetatarsal artery to the cavity between the cuneiforms and the cuboid. This groove appears to be peculiar to the Alcelaphini, as no mention of it can be found in descriptions of cuboids of other bovid genera.

The metatarsal specimens (Figs. 37B, 37C, 38C, 38D) are generally damaged and incomplete, but because of their slender build or lightly developed facets may represent subadult individuals. Those from undoubted adults are strong, with well ossified shafts and marked tarsal facets. There is no proximal anterior intermetatarsal foramen, but the posterior and both distal foramina are present, the distal anterior foramen 


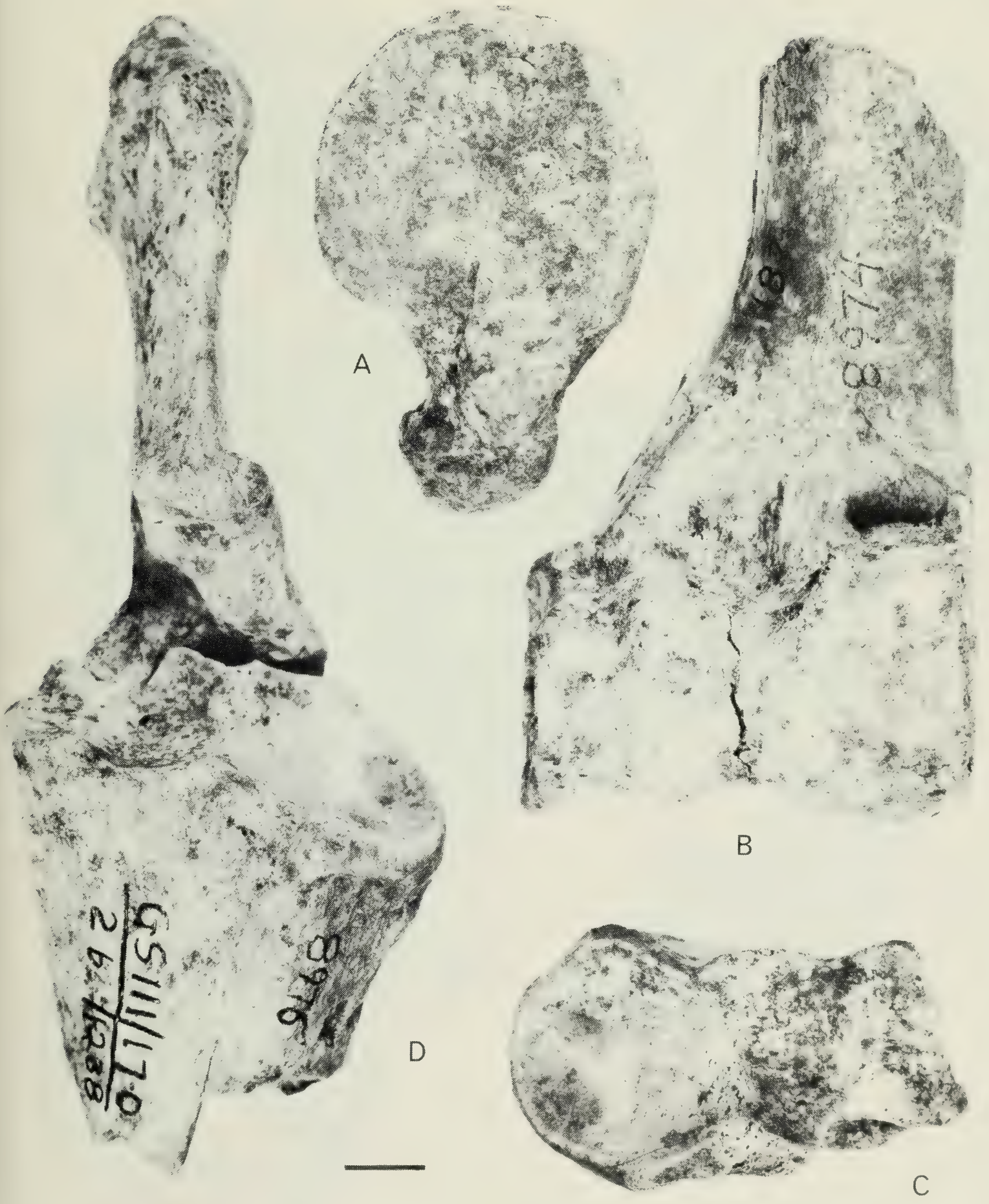

Fig. 35 Alcelaphus buselaphus. Pectoral limb elements.

A. Glenoid aspect of right scapula 8970 from Gebel Silsila III, Level 1, Sebekian Industry.

B. Anterior aspect of distal end of right humerus 8974 from Gebel Silsila III. Level 1, Sebekian Industry.

C. Proximal or humeral articular aspect of right radius 8976 from Gebel Silsila III, Level 1, Sebekian Industry.

D. Articulated proximal ends of right ulna 8980 and radius 8976 to show conformation of humeral articular surfaces, from Gebel Silsila III, Level 1, Sebekian Industry.

Bar $=10 \mathrm{~mm}$. 


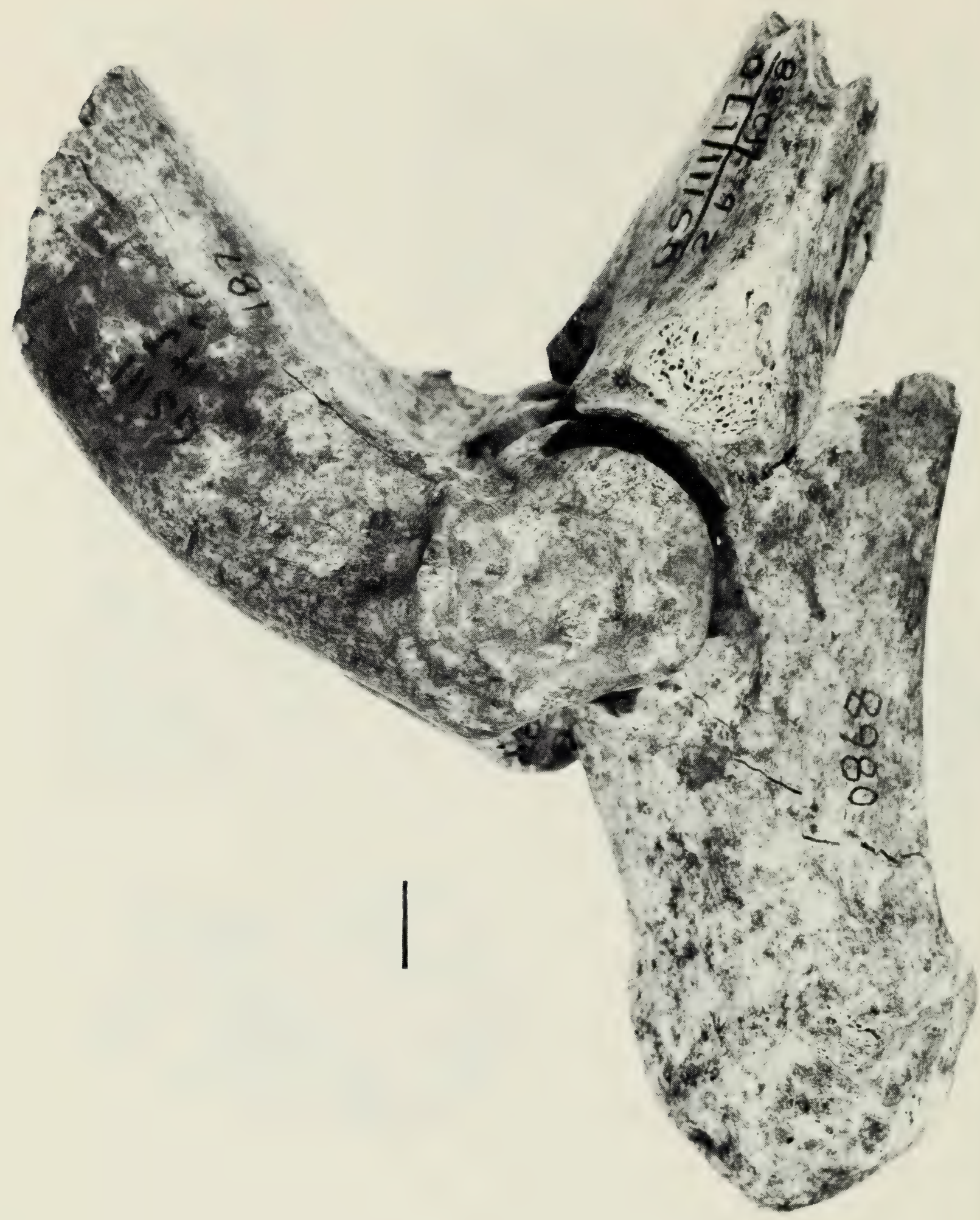

Fig. 36 Alcelaphus buselaphus. Lateral aspect of articulated right elbow joint of distal end of humerus 8974, and proximal ends of ulna 8980 and radius 8976 , from Gebel Silsila III, Level 1, Sebekian Industry. Bar $=10 \mathrm{~mm}$. 


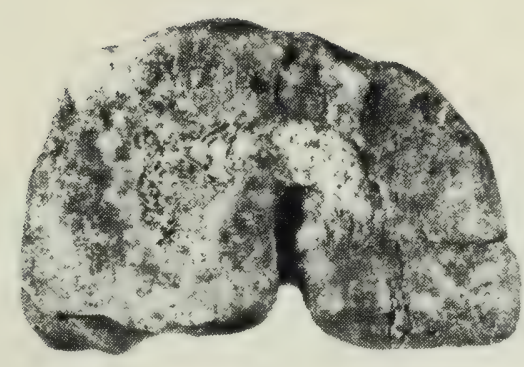

A

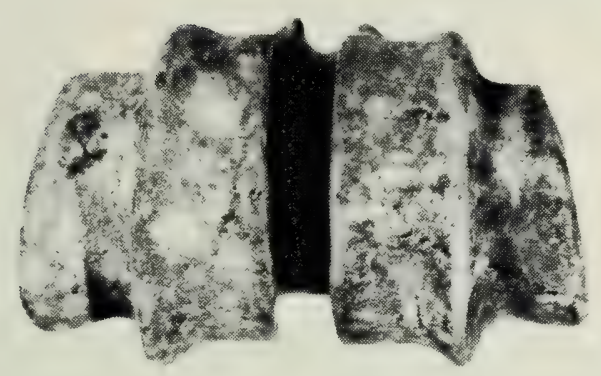

C

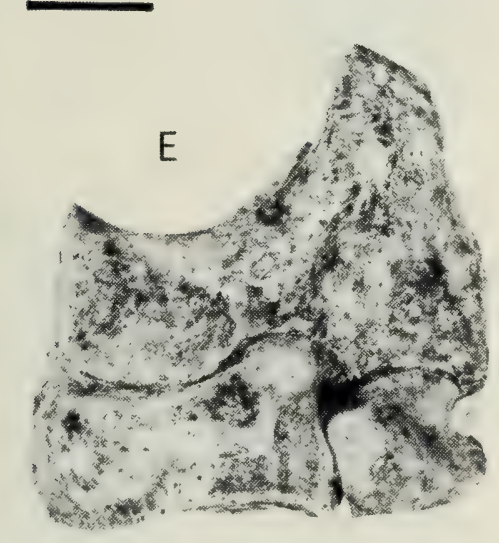

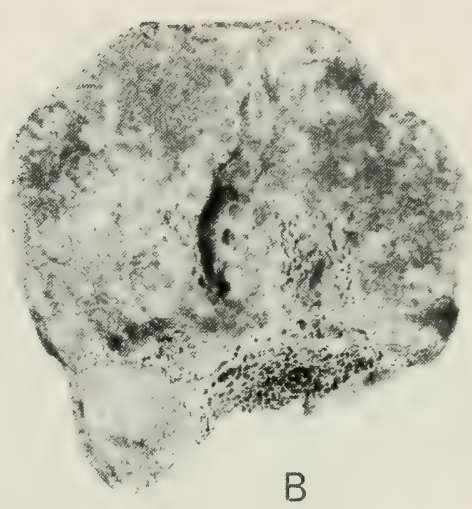
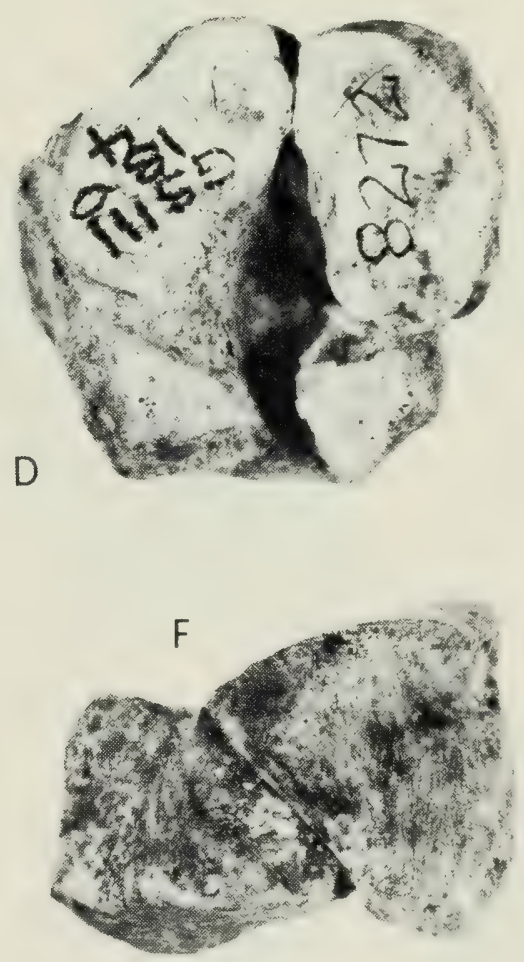

Fig. 37 Alcelaphus buselaphus. Podial elements.

A. Proximal aspect of right metacarpals III + IV 8993 from Gebel Silsila III, Level 1, Sebekian Industry.

B, C. Left metatarsals III + IV 8277 from Gebel Silsila III, Level 1, Sebekian Industry. $\mathrm{B}=$ proximal aspect, $\mathrm{C}=$ distal articulations.

D, E. Right navicular-cuboid with attached mesectocuneiform and entocuneiform 8272 from Gebel Silsila III, Level 1, Sebekian Industry. D = distal aspect showing cuboid (left), mesectocuneiform (top right), and entocuneiform (bottom right), $\mathrm{E}=$ medial aspect showing navicular (above), mesectocuneiform (below left), and entocuneiform (below right).

F. Posterior aspect of left navicular-cuboid 8268 from Gebel Silsila III, Level 1 , Sebekian Industry.

Bar $=10 \mathrm{~mm}$. 

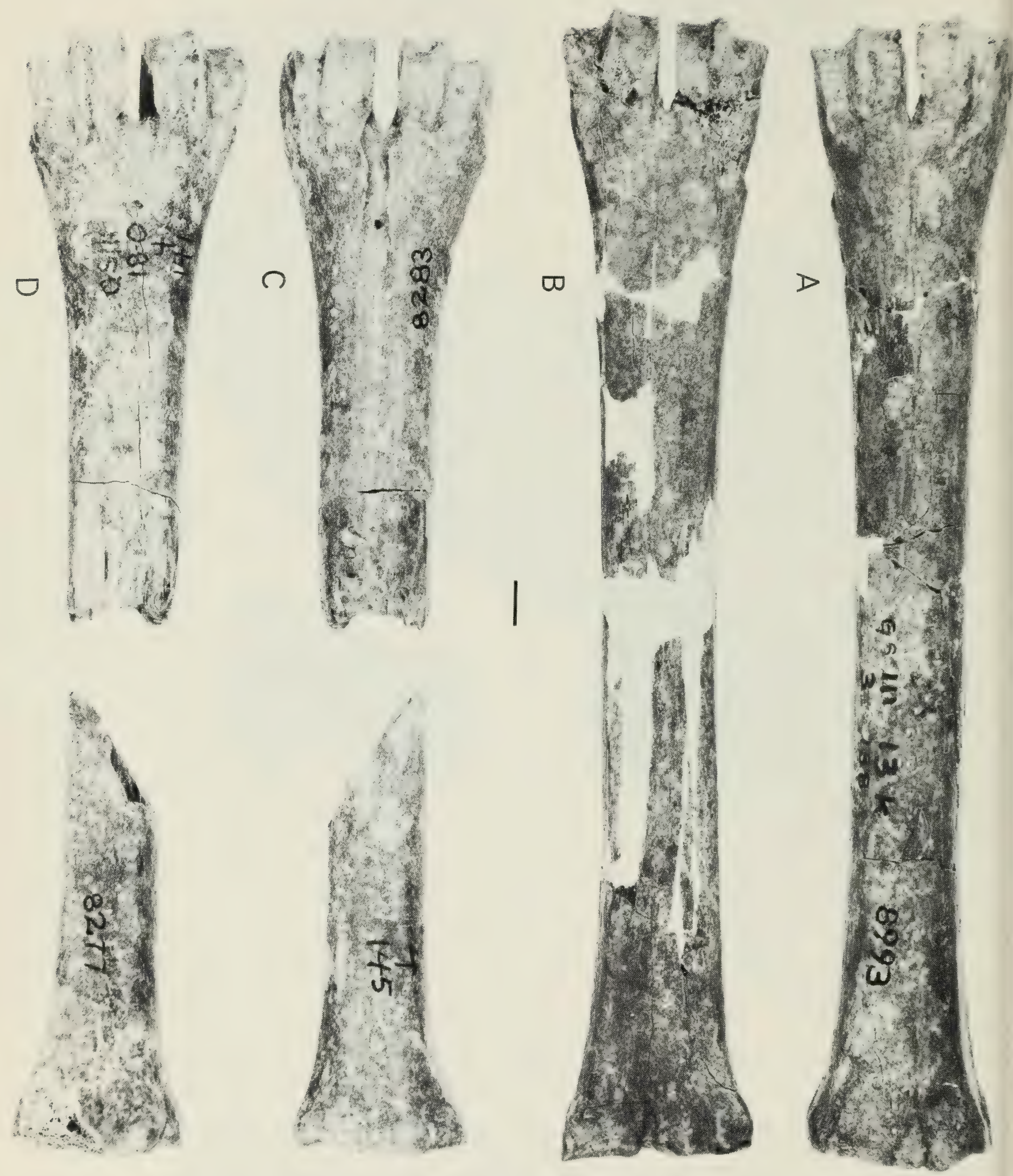

Fig. 38 Alcelaphus buselaphus. Metapodial elements.

A, B. Right metacarpals III + IV 8993 from Gebel Silsila III, Level 1, Sebekian Industry. $\mathrm{A}=$ anterior aspect, $\mathrm{B}=$ posterior aspect.

C, D. Proximal end of left metatarsals III + Iv 8277 and distal end of right metatarsals III + IV 8283 from Gebel Silsila III, Level 1, Sebekian Industry. $\mathrm{C}=$ anterior aspect, $\mathrm{D}=$ posterior aspect.

$\mathrm{Bar}=10 \mathrm{~mm}$. 

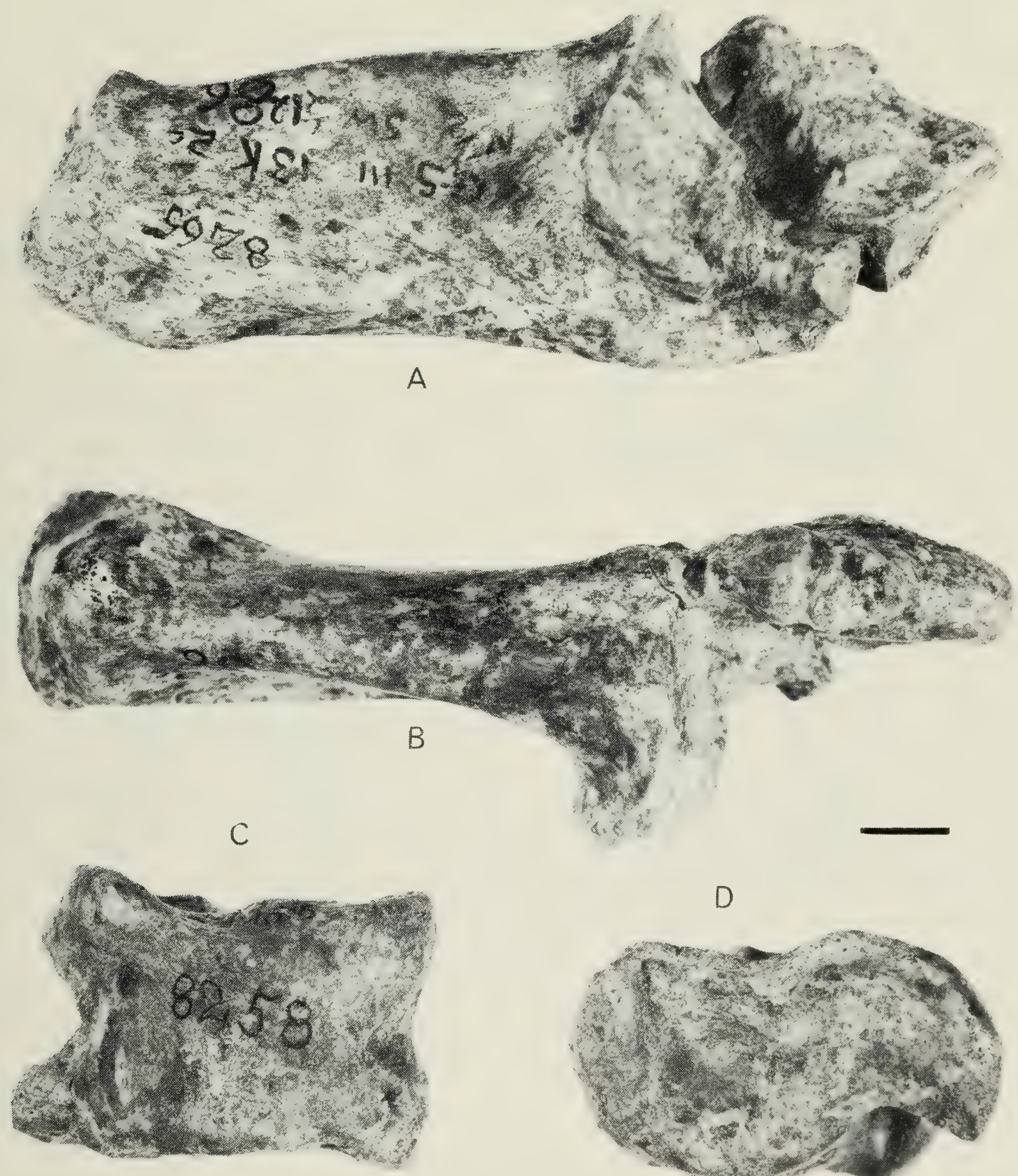

D

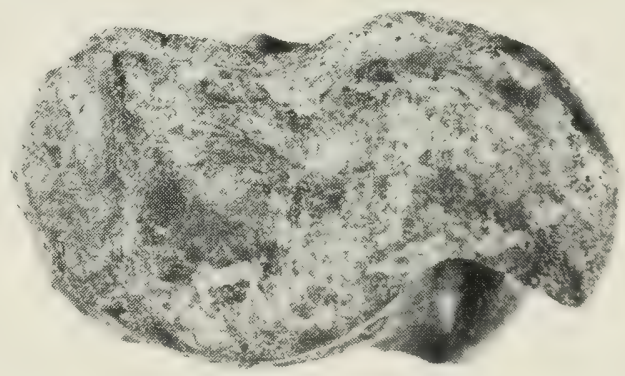

Fig. 39 Alcelaphus buselaphus. Propodial elements

A, B. Left calcaneum 8265 from Gebel Silsila III, Level 1, Sebehian Industry. $\mathrm{A}=$ medial aspect, $\mathrm{B}=$ dorsal or proximal aspect.

C, D. Left astragalus 8258 from Gebel Silsila III, Level 1, Sebekian Industry. $\mathrm{C}=$ calcanear or plantar aspect, $\mathrm{D}=$ lateral aspect.

Bar $=10 \mathrm{~mm}$. 


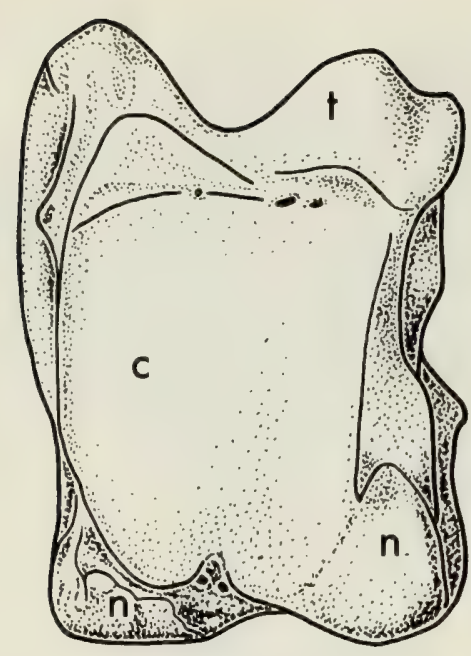

C

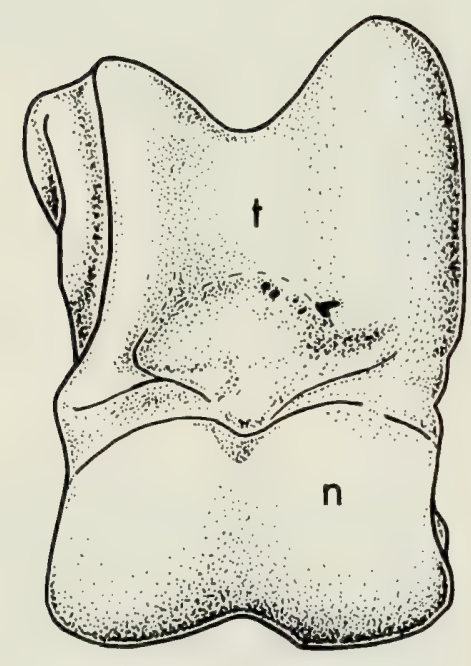

T
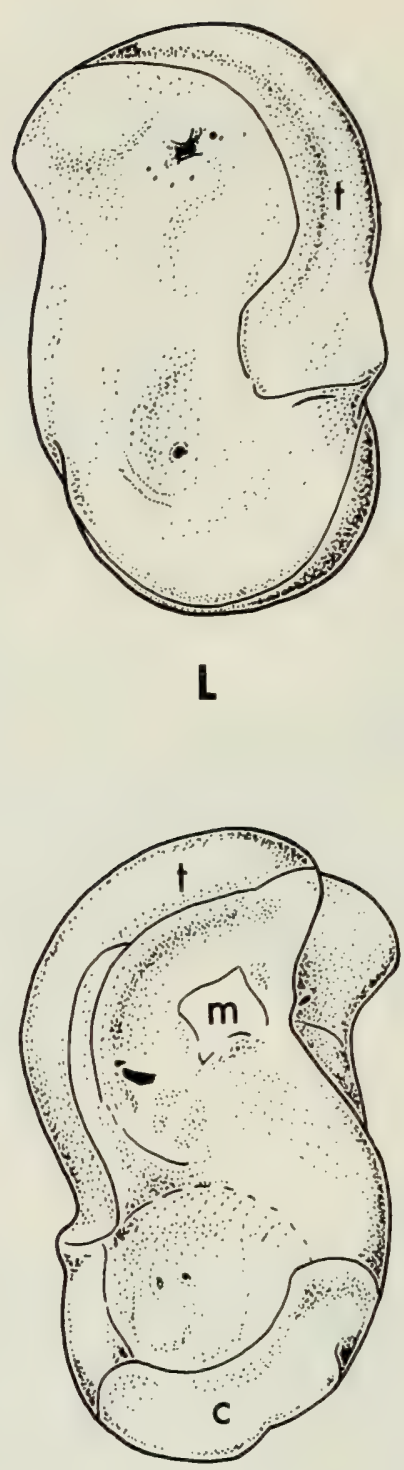

M

Fig. 40 Alcelaphus buselaphus. Aspects of the left astragalus from Sebil v (8533). $\mathrm{C}$ - calcanear aspect. L - lateral aspect. T - tibial aspect. M - medial aspect. Facets are indicated on the astragalus by small letters: $\mathrm{c}=$ calcanear. $\mathrm{t}=$ tibial, $\mathrm{n}=$ navicular, and $\mathrm{m}=$ malleolar facets. Scale $=50 \mathrm{~mm}$.

lying within a wide groove that extends the length of the anterior surface of the bone and forms a nearly tubular canal distal to the foramen. The shaft is oval in cross-section just proximal to the distal articulations, with a ridge and groove on the anterior surface, and subrectangular at the proximal end with both anterior and posterior grooves. The distal articulations are broad and massive, with their facets oriented slightly laterad.

The proximal phalanges are fragmentary, and only one presumed manual and one presumed pedal are sufficiently complete for comparison. The manual phalanx I (8293) is somewhat shorter than the pedal (8295) but similar in proximal cross-section. 
The middle phalanges cannot be allocated to the manus or pes, because they are either too fragmentary or represent specimens that are relatively larger than could be expected for the manual phalanges II and articulate better with the presumed pedal phalanx I (8295), but cannot be identified as pedal phalanges II.

The ungual phalanges are elongate, with small angles, prominent foramina, and mammilate extensor processes. The volar surface is smooth, with sharp external and rounded internal margins, and the dorsal margin is sharp and slightly internally rolled.

The volar sesamoid (8311) measures 11.7, 16.3 and 19.3 in transverse, anteroposterior and proximodistal diameters, respectively.

Gaillard (1934, p. 40) identified Alcelaphus buselaphus as Bubalis buselaphus from the Sebil Area of the Kom Ombo Plain and listed a right lower molar, atlas and axis vertebrae, astragalus, the distal end of a right metatarsal, part of a femur, and pieces of horncores. The latter were not illustrated or described because of their poor states of preservation.

The lower molar (Gaillard, 1934, Pl. VI, Fig. 1) agrees with those recovered by the Canadian Expedition but is slightly smaller and possesses a small ectostylid between the protoconid and hypoconid, which is not present in the Canadian Expedition's specimens.

The atlas and axis illustrated by Gaillard (1934, PI. VI, Figs. 2 and 3) appear identical with those in the Canadian Expedition's collection, even to size, although absence of some reference points does not allow for exact comparisons. The astragalus (Gaillard, 1934, Pl. VI, Fig. 4) is likewise similar in conformation and size to the Canadian Expedition's material. The distal end of right metatarsals III+IV (Gaillard, 1934, Pl. VI, Fig. 5) is similar but smaller, perhaps because of the removal of its prominences by erosion while exposed on the surface, and the unequal distal articulations noted by Gaillard are not obvious.

Unfortunately, Gaillard's material did not include any complete frontlets or horncores and so no determination to subspecies was possible. It is likely, however, that his material derived from the same species as that identified in the Canadian Expedition's material, as identifiable horncore fragments of $A$. buselaphus were obtained from several Sebil Area sites.

Measurements of some of the better preserved specimens of Alcelaphus buselaphus with some comparative measurements of $A$. lichtensteini are as follows:

\section{Dimensions}

\section{Upper Cheek Teeth}

Milk

$\mathrm{p}^{3}$ mesiodistal diameter

buccolingual diameter, mesially buccolingual diameter, distally 


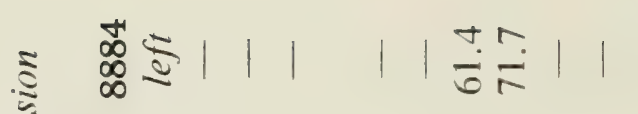

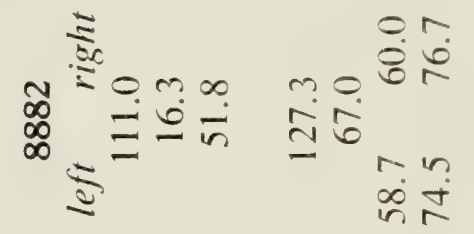

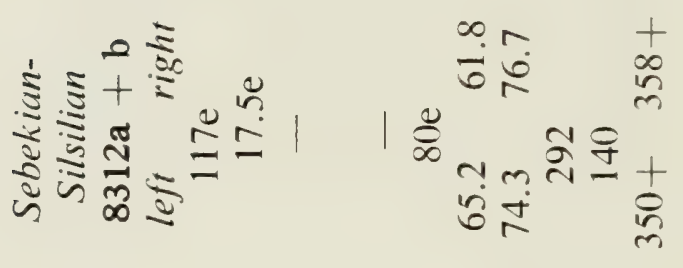

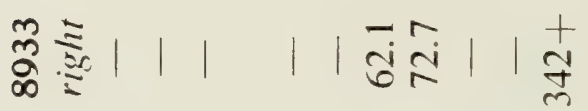

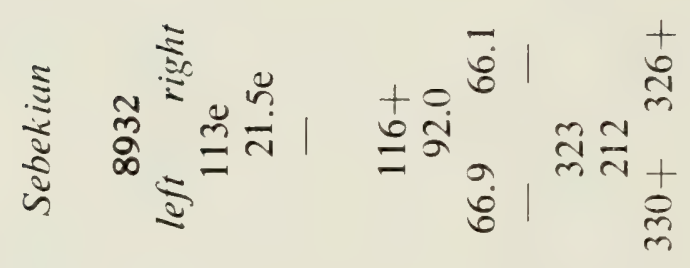

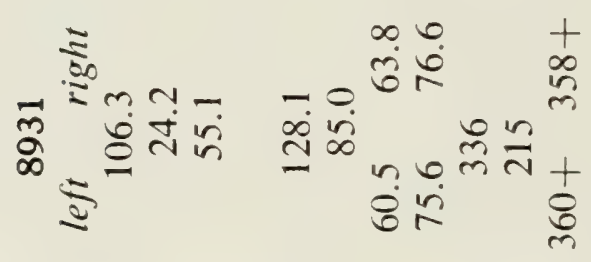

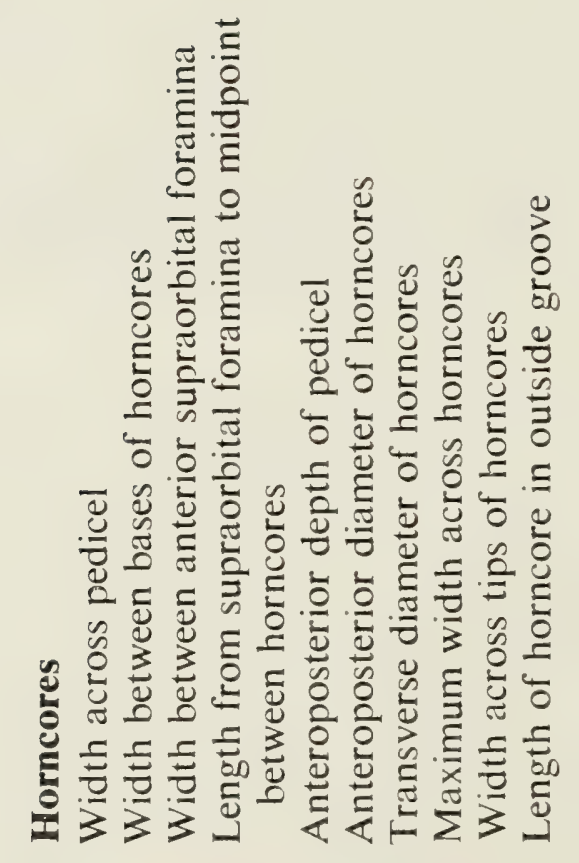




\section{Permanent}

P2 mesiodistal diameter buccolingual diameter

$\mathrm{P}^{3}$ mesiodistal diameter buccolingual diameter

$\mathrm{P}^{4}$ mesiodistal diameter buccolingual diameter

$M^{1}$ mesiodistal diameter buccolingual diameter, mesially buccolingual diameter, distally

$\mathbf{M}^{2}$ mesiodistal diameter buccolingual diameter, mesially buccolingual diameter, distally

$\mathbf{M}^{3}$ mesiodistal diameter buccolingual diameter, mesially buccolingual diameter, distally

\section{Lower Cheek Teeth}

Permanent

$\mathbf{P}_{4}$ mesiodistal diameter buccolingual diameter

$\mathbf{M}_{1}$ mesiodistal diameter buccolingual diameter, mesially buccolingual diameter, distally

$\mathbf{M}_{2}$ mesiodistal diameter buccolingual diameter, mesially buccolingual diameter, distally

$\mathrm{M}_{3}$ mesiodistal diameter buccolingual diameter, mesially buccolingual diameter, distally buccolingual diameter, talonoid

\section{Atlas}

Transverse diameter over condylar facets Transverse diameter over axial facets

Minimum transverse diameter across alae Dorsoventral depth in middle

Dorsoventral height over condylar facets Length in midventral line

Diameter of neural canal posteriorly

Axis

Length odontoid to dorsal margin of posterior centrum

Length atlanteal facet to posteroventral keel in midline

Length of neural crest

$\begin{array}{rrrrrr}8391 & 8937 & 8938 & 8942 & \text { left } & \text { right } \\ - & 8.5 & - & - & - & 8.3 \\ - & 6.7 & - & - & - & 7.1 \\ 12.3 & 12.6 & - & - & 12.0 & 11.5 \\ 9.6 & 10.4 & - & - & 13.9 & 13.5 \\ - & 13.9 & 14.4 & 14.4 & 12.3 & 12.5 \\ - & 11.3 & 13.0 & 12.4 & 14.9 & 14.7 \\ & 8940 & & & & \\ & 20.3 & 19.9 & & 14.9 & 15.0 \\ 13.2 & 14.2 & & 14.2 & 14.2 \\ 12.3 & 14.2 & & 15.8 & 15.0 \\ & 8946 & 8945 & & \\ 22.0 & 23.0 & 23.2 & 21.7 & 22.2 \\ 13.1 & 15.0 & 14.8 & 16.7 & 16.8 \\ & - & 15.6 & 16.2 & 16.1 & 15.9 \\ 8392 & 8914 & 8947 & & \\ 22.7 & 24.1 & 24.0 & 26.0 & 27.7 \\ 14.8 & 15.0 & 14.7 & 17.0 & 16.2 \\ 13.6 & 14.6 & 13.8 & 14.9 & 15.5\end{array}$

\section{5}

16.0

10.2

8949

21.2

11.4

11.7

8366

23.4

10.1

11.1

Alcelaphus

lichtensteini

ROM 26.12.174

left right

7.1

11.5

2.5

5.0

\section{2}

2.2

5.9

27.7

5.2
5.5 
Length neural crest to postzygapophyses

Length of neural arch over lamina to postzygapophyses

Transverse diameter of odontoid

Transverse diameter of atlanteal facets

Transverse diameter of posterior centrum

Minimum transverse diameter of centrum

Transverse diameter of postzygapophyses

Transverse diameter of posterior extremity of neural crest

Transverse diameter of neural canal anteriorly

Transverse diameter of neural canal posteriorly

$\begin{array}{rrrr}99.5 & - & - & - \\ 88.0 & - & 74.0 & - \\ 31.3 & 33.8 & 32.8 & 32.4 \\ 71.3 & 71.0 & 72.5 & 73.9 \\ 40.7 & 42.8 & 41.5 & 42.4 \\ 34.3 & 35.9 & 21.9 & 34.3 \\ 54.5 & - & 45.5 \mathrm{e} & - \\ 20.3 & - & - & - \\ 21.8 & 24.5 & - & - \\ 20.7 & - & 23 \mathrm{e} & 24.0 \\ 51.7 & 49 \mathrm{e} & 50.4 & 53.7 \\ 81.2 & - & - & - \\ 117.3 & - & - & - \\ 38.5 & 38.8 & 33.0 & 39.2\end{array}$

Dorsoventral height of atlanteal facets

Dorsoventral height of neural crest above atlanteal facets

Dorsoventral height of neural crest above posterior ventrum

Dorsoventral height of posterior centrum

Dorsoventral height of posterior neural canal

\section{Thoracic and Lumbar Vertebrae}

Length of centrum

Length of lamina

Length pre- to post-zygapophyses

Transverse diameter of anterior centrum and demifacets

Transverse diameter of posterior centrum and demifacets

Transverse diameter of posterior centrum without demifacets

Transverse diameter of transverse processes

Transverse diameter of prezygapophyses

Transverse diameter of postzygapophyses

Dorsoventral height of anterior centrum

Dorsoventral height of posterior centrum

Transverse diameter of neural canal anteriorly

Transverse diameter of neural canal posteriorly

Dorsoventral diameter of neural canal anteriorly

Dorsoventral diameter of neural canal posteriorly

\section{Scapula}

Transverse diameter of glenoid

Anteroposterior diameter of glenoid

Minimum transverse diameter of neck

Minimum anteroposterior diameter of neck

Anteroposterior diameter over coracoid

\section{Humerus}

Transverse diameter of distal condyle

Minimum diameter of distal condyle

Anteroposterior height of medial condyle

Anteroposterior height of distal condyle

Transverse diameter of shaft

Anteroposterior diameter of shaft

$\begin{array}{ccc}- & - & \\ & - & \text { Thoracic } \\ & 8370 & \text { Lumbar } \\ & 42.2 & 8371 \\ & 26.7 & 44.2 \\ \text { mifacets } & 49.5 & 50.2 \\ \text { emifacets } & 34.7 & 41 \mathrm{e} \\ \text { ut demifacets } & 50.4 & \\ & 26.8 & 45 \mathrm{e} \\ & 69.8 & - \\ & 25.0 & 39 \mathrm{e} \\ & 24 \mathrm{e} & 50 \mathrm{e} \\ & 26.2 & 23.0 \\ & 26 \mathrm{e} & 23.2 \\ & 17.2 & 24.2 \\ & 20.5 & - \\ & 12.6 & 15.8 \\ & 14.2 & -\end{array}$




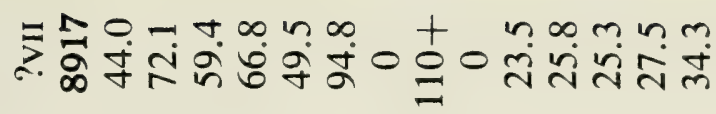

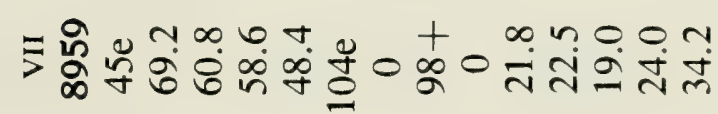

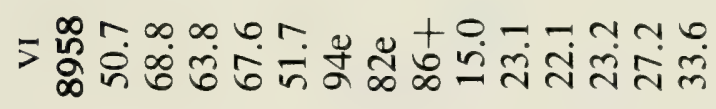

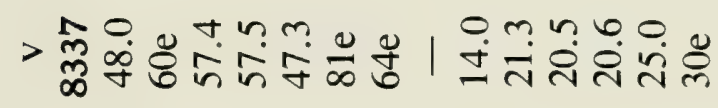

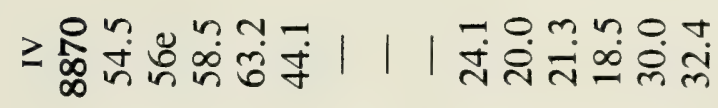

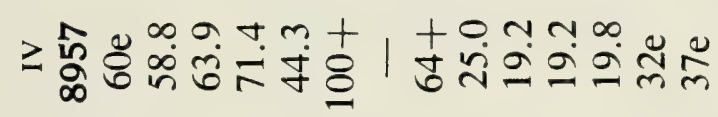

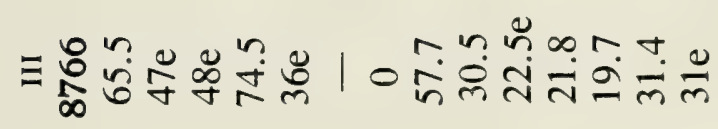

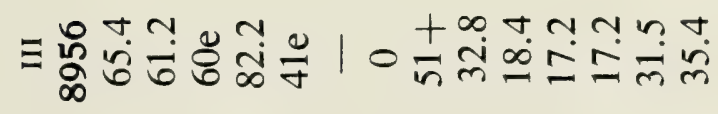

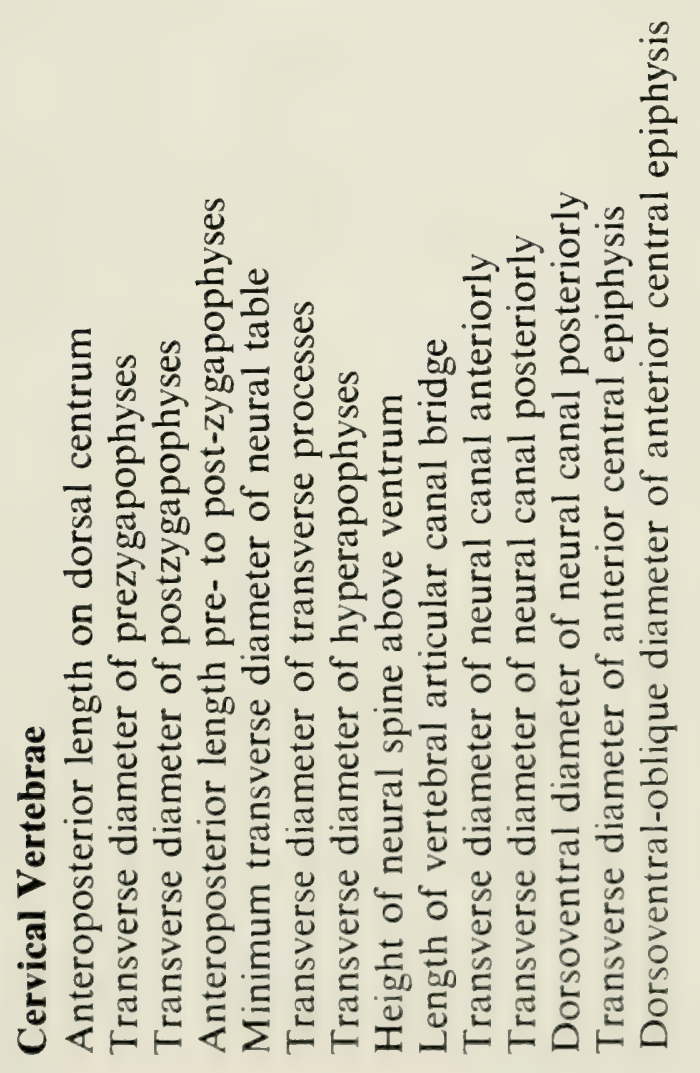




\section{Radius}

Transverse diameter of proximal end

Anteroposterior diameter of proximal end

Ulna

Length from processus anconaeus to end of olecranon

Transverse diameter in semilunar notch

Transverse diameter of processus anconaeus

Transverse diameter of olecranon shaft

12.9

17.3

Transverse diameter of olecranon tuberosity

Anteroposterior diameter in semilunar notch

Anteroposterior diameter over processus anconaeus

Anteroposterior diameter of olecranon shaft

20.8

11.5

30.4

20.8

49.9

Anteroposterior diameter of olecranon tuberosity

$39.3 \quad 38.0$

\section{Trapezoid}

Anteroposterior diameter

Proximodistal diameter

Transverse diameter

\section{Unciform}

Anteroposterior diameter

Proximodistal diameter

Transverse diameter

\section{Lunar}

$\begin{array}{lll}24.9 & 24.1 & 24.5\end{array}$

$\begin{array}{lll}14.5 & 16.1 & 17.0\end{array}$

25.6

43.2

$43.5 \mathrm{e}$

Anteroposterior diameter

Proximodistal diameter

Transverse diameter

\section{Scaphoid}

Anteroposterior diameter

Proximodistal diameter

Transverse diameter

\section{Metacarpals III + IV}

Total length

Proximal transverse diameter

Proximal anteroposterior diameter

Midshaft transverse width

Midshaft anteroposterior thickness

Least transverse width

Least anteroposterior thickness

Distal transverse diameter

Distal anteroposterior diameter

$\begin{array}{lccccc}8993 & 8996 & 8994 & 8896 & 8374 & 8530 \\ 253 & - & - & - & - & - \\ 41.9 & 41.4 & 44.7 & 42.2 & 39.4 & 41.5 \\ 28.6 & 28.4 & 28.0 & 28.9 & 27.9 & 28.5 \\ 24.9 & 25.4 & - & 23.9 & 23 \mathrm{e} & - \\ 22.2 & 21 \mathrm{e} & - & 21.2 & 17 \mathrm{e} & - \\ 24.5 & - & - & - & - & - \\ 18.9 & - & - & - & - & - \\ & & & & & \\ 45.2 & 4697 & 8332 & 8898 & 8900 & 8531 \\ 28.0 & 29.0 & 26.9 & 44.8 & 47.2 & 42.9 \\ 21 \mathrm{e} & 21.2 & 21.2 & 21.7 & 28.3 & 27.7 \\ 21.0 & 21.7 & 21.5 & 21.0 & 21.0 & 19.3 \\ & & & & & 19.9\end{array}$

Distal transverse diameter of metacarpal III

Distal transverse diameter of metacarpal IV

Tibia

Proximal transverse diameter

Proximal anteroposterior diameter

Distal transverse diameter

Distal anteroposterior diameter

Diameter across astragalar facets 


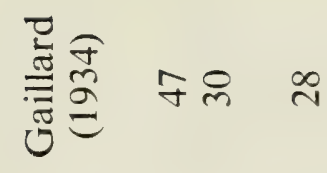

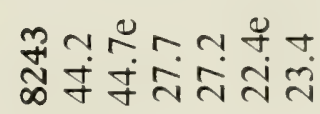

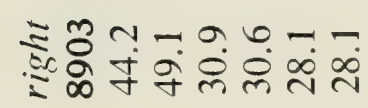

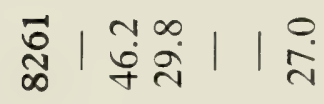

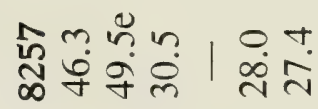

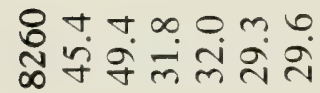

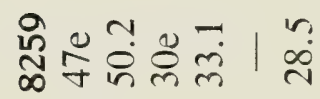

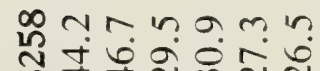

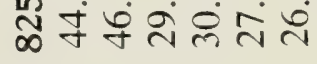

ह

m $0 .+\infty \sim 0$

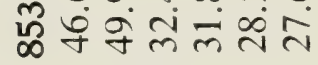

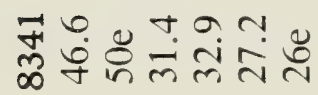

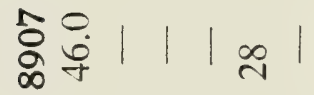

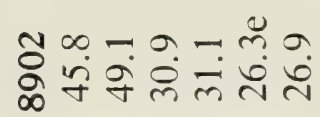

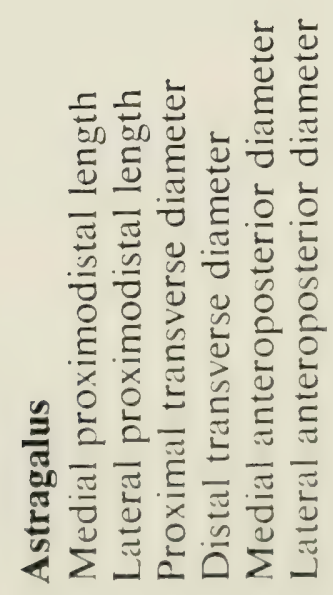


Total length

Transverse diameter of navicular process

Transverse diameter over sustentaculum

Transverse diameter of shaft of calcar

Transverse diameter of tuber calcis

Dorsoventral diameter over malleolar facet

Dorsoventral diameter over coronoid process

Least dorsoventral diameter of shaft of calcar

Dorsoventral diameter of tuber calcis

Maximum length of navicular facet

Width of middle of navicular facet

Depth of sustentaculum

\section{Navicular-cuboid \\ Proximodistal diameter over cuboid \\ Proximodistal diameter over navicular \\ Oblique proximodistal diameter on posterior surface \\ Anteroposterior diameter \\ Transverse diameter \\ Transverse diameter of cuboid only}

\section{Cuneiform}

Total proximodistal diameter

Least proximodistal diameter

Transverse diameter

Anteroposterior diameter

\section{Metatarsals III and IV \\ Proximal transverse diameter \\ Proximal anteroposterior diameter}

Shaft transverse diameter

Least shaft anteroposterior diameter

Distal transverse diameter

Distal anteroposterior diameter

Transverse diameter of distal metatarsal III facet

Transverse diameter of distal metatarsal IV facet

\section{Phalanges I and II}

Total length

Proximal transverse diameter

Proximal anteroposterior diameter

Midshaft transverse diameter

Least anteroposterior diameter of shaft

\begin{tabular}{lllll||rc} 
& \multicolumn{3}{c}{ right } & \multicolumn{2}{c}{ left } \\
8272 & 8270 & 8271 & 8378 & 8255 & 8377 & 8268 \\
20.0 & 17.1 & 16.7 & 19.0 & 19.0 & 18.5 & 18.0 \\
& & & & & & \\
$12.5 \mathrm{e}$ & 11.6 & 12.0 & 13.9 & 23.8 & 11.3 & 12.3 \\
& & & & & & \\
27.7 & 25.1 & 25.2 & 28.8 & 27.2 & 28.7 & 26.3 \\
38.2 & 41.0 & 39.8 & 40.5 & 33.6 & 39.4 & 38.7 \\
42.2 & 40.5 & 41.1 & 44.1 & - & 42.8 & 41.6 \\
20.5 & 20.1 & 20.9 & 21.6 & - & $17+$ & 18.2
\end{tabular}

right

8272

\begin{tabular}{cc|}
$\begin{array}{c}\text { Mesecto- } \\
\text { cuneiform }\end{array}$ & $\begin{array}{c}\text { Ento- } \\
\text { cuneiform }\end{array}$ \\
$15 \mathrm{e}$ & 12.1 \\
10.2 & - \\
17.5 & 13.4 \\
26.8 & 14.0
\end{tabular}

8273

Mesecto-

cuneiform cuneiform

12.2

$10.2 \quad 10.7$

$18.0 \quad 9.0$

$24.8 \quad 13.5$

right

$8272 \quad 8273$

$37.2 \quad 37 \mathrm{e}$

$36.6 \quad 37.6$

$\mathbf{8 2 7 8} \quad \mathbf{8 2 7 6} \quad \mathbf{8 9 2 6}$

$\begin{array}{lll}38.0 & 36.9 & 35.2\end{array}$

$\begin{array}{lll}37.3 & 36.5 & 35.4\end{array}$

8283

Gaillard

(1934)

\begin{tabular}{ll|r}
20.7 & 24.4 & 25.2
\end{tabular}

21.7

45.5

21.9

20

42

29.6

28.5

20.2

21.5

19

20.7

21.9

18

$8302 \quad 8303 \quad 8380$

?Pedal II

$\begin{array}{lll}41.0 & 42.0 & 40.9\end{array}$

$\begin{array}{lll}19.8 & 22.4 & 20.7\end{array}$

$25.2-25.5$

$\begin{array}{lll}14.9 & 16.0 & 16.4\end{array}$

$\begin{array}{lll}16.4 & 18.8 & 17.4\end{array}$ 
Distal transverse diameter

Distal anteroposterior diameter

\section{Phalanges III}

Length on anterior surface

Length on volar surface

Proximal transverse diameter

Proximal anteroposterior diameter over facet

Height of extensor process above volar surface

Transverse width of middle of volar surface

\begin{tabular}{|c|c|c|c|c|}
\hline e & 21.1 & 16.7 & 18.0 & 18.1 \\
\hline & 19.9 & 21.6 & 24.9 & 22.1 \\
\hline & 8306 & 8307 & 8309 & 8310 \\
\hline & 46.9 & $41 \mathrm{e}$ & - & \\
\hline & 54.7 & $50 \mathrm{e}$ & - & - \\
\hline & 17.5 & 17.2 & 17.5 & 18.0 \\
\hline & 26.3 & 26.0 & 29.3 & 27.2 \\
\hline & 26.4 & - & 31.3 & 32.1 \\
\hline & 9.8 & 9.4 & 12.2 & 13.3 \\
\hline
\end{tabular}

Gazella dorcas-Dorcas gazelle (Figs. 41 to 43 )

The gazelline materials fall naturally into two groups by size, one large and one small. As male horncores fall within the group of larger specimens and the female horncores within the group of smaller specimens, it is assumed that these size differences represent sexual dimorphism. Lydekker (1926) stated that the African Dorcas gazelle stands about 21-24 inches $(=52.5-60 \mathrm{~cm})$ at the shoulder, and that the horns of males are larger than those of females, in which they are more variable in length and usually straighter. Rode (1943, pp. 83, 84) stated that Dorcas gazelles from French West Africa stand from 54 to $60 \mathrm{~cm}$ at the shoulder, which agrees with Lydekker's data, that the horns "sont beaucoup plus fines chez la femelle que chez le mâle" and that "Celles de la femelle ont la forme de minces tiges presque droites." He gave a range of size for the length of the horns as 25 to $30 \mathrm{~cm}$ with a record length of $38 \mathrm{~cm}$ for a specimen from Touggourt collected in 1931. Harrison (1968) considered the Arabian subspecies, Gazella dorcas saudiya, and stated that it usually stands less than $60 \mathrm{~cm}$ at the shoulder, with horns in the males ranging from 244.5 to $304 \mathrm{~mm}$ and in the females from 175 to $244 \mathrm{~mm}$. But Harrison's ranges were derived from only six males and eight females and are not representative of the Egyptian race of the Dorcas gazelle, G. d. dorcas.

\section{MATERIAL}

Obtained from:

Gebel Silsila Localities-II; III, Surface and Subsurface, mixed Sebekian and Silsilian-Level 0; III, Sebekian-Level 1; III, Silsilian-Level 3; IX; X; XIV; XVIII; Miscellaneous.

\section{Sebil Localities-I; v.}

Khor el-Sil Localities-IIa; IIb; Miscellaneous (II/III).

\section{CONSIDERATION}

\section{Male Cranial Material}

The skull with the right horncore (8237, Fig. 41) is diagnostic to Gazella. The horn is curved in this specimen, although variably so in other specimens, and agrees with Ellerman and Morrison-Scott's (1951), Hoogstraal's (1964) and Harrison's (1968) definitions for this element in male G. dorcas. Gentry (1966, p. 49) stated that the genus has sub-circular or elliptical cross-sections to the horncores, with the lateral surfaces often flattened and 
no torsion of the axes. The Kom Ombo materials show similar crosssections but slight torsion is apparent in $8236,8246,8247$ and $8248+$ 8249. The horns diverge in anterior view and curve gently backward in lateral view (Fig. 41). The supraorbital foramina or pits are placed in triangular fossae on the anteromedial angle of the base of the horn pedicels. The frontal region between the bases of the horns is not elevated above the level of the supraorbital margins. The auditory bullae are moderately large. In these characters the cranial material from Kom Ombo agrees with typical Gazella.

The transverse diameter of the base of the horn, expressed as a percentage of the longitudinal diameter, ranges between 62 and $80 \%$ for G. dorcas (Gentry, 1966, p. 65, Fig. 8) and between 65.8 and $75.9 \%$ for the Kom Ombo males. The width across the supraorbital foramina, expressed as a percentage of the orbital width, ranges between 34 and $47 \%$ for G. dorcas (Gentry, 1966, p. 90, Fig. 13) and $35.7 \%$ for the Kom Ombo specimen. In both these ratios the Kom Ombo material agrees with those derived by Gentry from recent material.

\section{Female Cranial Material}

The female's horncores are smaller and straighter (Fig. 42A) than those of males, although possessing a slightly recurved axis, the cross-sections are more nearly circular with slightly flattened posterior faces. The horns are placed on the skull at a smaller angle to the frontal plane so that the distance from the base of the horn sheath to the frontal pit is relatively and absolutely greater and is an almost straight continuation of the superior lateral line of the core rather than forming an angle to it as in males. The frontal pit is smaller in females and, being farther from the base of the horn, is not as often preserved as in males. The female's horns are set as far apart on their centres as in the males but, as they are smaller in section, appear to be set further apart. The horns are slightly divergent or nearly parallel but straight in frontal view.

The disparity in the lengths of the horncores reflects the variation in development of horns in females. The more nearly corresponding diameters and proportions of the basal areas are consequently more reliable for diagnosis of sex and species of fossil specimens.

\section{Dentition and Postcranial Material}

The two isolated teeth, the left second and right third upper molars (8252, Fig. 43B; 8253, Fig. 43A, respectively) are hypsodont, with parastyle, metastyle and mesostyle, of which the central metastyle is the most prominent. The columns of the paracone and metacone are not prominent, and no vestiges of endostyles are visible. The second molar resembles that illustrated by Gentry (1966, p. 53, Fig. 2) for Gazella granti, and those in the ROM (skull 91.11.1.197a) but has a minute pli or fold on the distal surface of the protocone where it joins the metacone. The metastyle of the third molar is not well developed, although the parastyle and mesostyle are more massive than in $\mathrm{M}^{2}$ but otherwise resemble those in the ROM specimen. However, both fossil teeth are larger than those in the recent 
TABLE 3. Comparative measurements of crania of the Pleistocene Kom Ombo and Recent Gazella dorcas.

\begin{tabular}{|c|c|c|c|c|c|}
\hline \multirow[b]{2}{*}{ Dimension } & \multicolumn{3}{|c|}{ males } & & \multirow{2}{*}{$\begin{array}{c}\text { G. dorcas } \\
\text { ROM } \\
91.11 .1 .197 ?\end{array}$} \\
\hline & 8232 & 8236 & 8237 & 8250 & \\
\hline Width across orbits & $70 \mathrm{e}$ & $71 \mathrm{e}$ & $72 \mathrm{e}$ & - & 79.5 \\
\hline Transverse diameter of horn base & 21.0 & 20.2 & 22.0 & 25.0 & 20.1 \\
\hline Anteroposterior diameter of horn base & 31.9 & 30.5 & 29.0 & 36.0 & 29.3 \\
\hline $\begin{array}{l}\text { Percentage of transverse diameter to } \\
\text { anteroposterior diameter of horn base }\end{array}$ & 65.8 & 66.2 & 75.9 & 69.4 & 68.6 \\
\hline $\begin{array}{l}\text { Diameter of postorbital construction } \\
\text { Length from nuchal eminence to }\end{array}$ & - & - & $57 \mathrm{e}$ & - & 52.6 \\
\hline anterior surface of horn pedicels & - & - & 92.1 & - & 85.5 \\
\hline Diameter across condyles & $44 \mathrm{e}$ & - & 46.9 & - & 37.7 \\
\hline Depth of condyles & 13.3 & - & 15.0 & - & 14.6 \\
\hline Height from basioccipital to sagittal crest & - & - & 56.7 & - & 49.0 \\
\hline magnum to nuchal eminence & 一 & 一 & 40.5 & - & 34.1 \\
\hline Width across mastoids & - & - & $62 \mathrm{e}$ & - & 55.2 \\
\hline Width of foramen magnum & $15 \mathrm{e}$ & - & $20 \mathrm{e}$ & - & 15.6 \\
\hline Height of foramen magnum & - & - & 13.4 & - & 12.6 \\
\hline Diameter across tympanic bullae & - & - & 51.0 & - & 52.3 \\
\hline Width across supraorbital pits & 20.1 & $26 \mathrm{e}$ & 25.7 & $30 \mathrm{e}$ & 24.4 \\
\hline $\begin{array}{l}\text { Percentage of width across supraorbital } \\
\text { pits to width across orbits }\end{array}$ & - & - & 35.7 & - & 30.7 \\
\hline $\begin{array}{l}\text { Minimum diameter of basioccipital } \\
\text { Length from tip of horncore to }\end{array}$ & 17.7 & - & 15.2 & - & 15.0 \\
\hline supraorbital pit & - & - & $150 \mathrm{e}$ & - & - \\
\hline
\end{tabular}

specimen, whose sex is unknown, and in which the teeth are not as well worn.

The two associated teeth, $\mathrm{rP}^{+}-\mathrm{M}^{1}$ (8230, Fig. 43C) are small, well worn, and slightly damaged. The enamel is not ridged, there is no endostyle on $\mathrm{M}^{1}$ or plications of the fossette in the enamel; the premolar is squared with low ectostyles and ridges; the molar has a protocone smaller than the metaconule, the former angular and the latter squared, and the fossettes are small, crescentic and placed mesially within their halves of the tooth. The left lower incisor (9063) measures 9.0 by $4.2 \mathrm{~mm}$ for the maximum transverse and buccolingual diameters of the crown, respectively, and comes from a fully mature or older animal as the enamel over the distal twothirds of the lingual surface is worn away. The condyle (9060) measures 14.1 by 6.2 for the transverse and anteroposterior diameters, respectively.

The axis (8223) is too badly damaged to be diagnostic, and measures 29e and 31.5 for the width across the atlanteal facets and for the length from the anterior opening of the neural canal to the postzygapophyses, respectively.

The centrum and left lamina (8254) of an elongated cervical vertebra, possibly IV, measure 39 for the length of the body and 16.5 by 11.7 for the depth and width of the anterior central epiphysis, respectively. The 


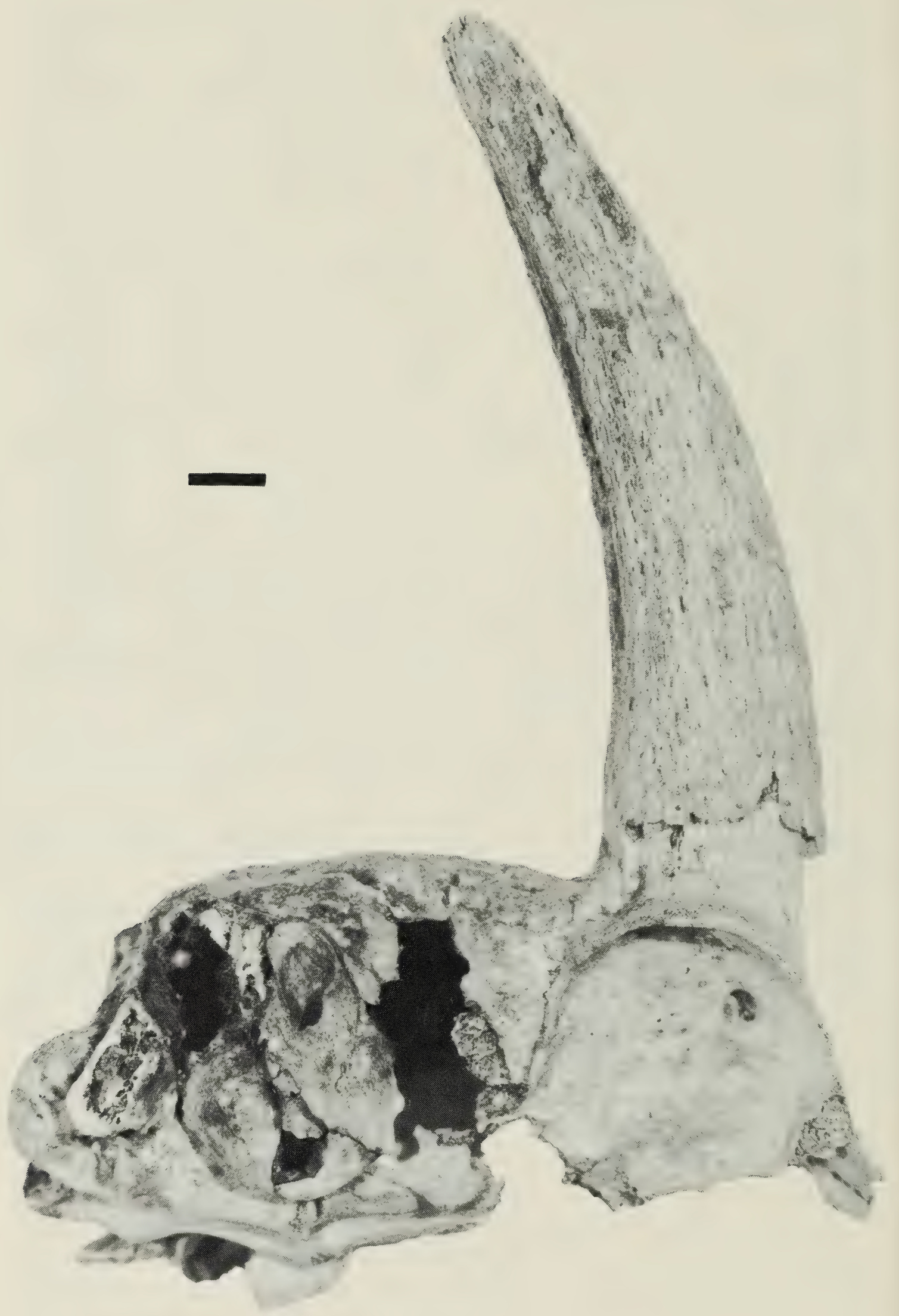

Fig. 41 Gazella dorcas. Right lateral aspect of damaged male cranium with right horncore 8237 from Sebil I. Bar $=10 \mathrm{~mm}$. 

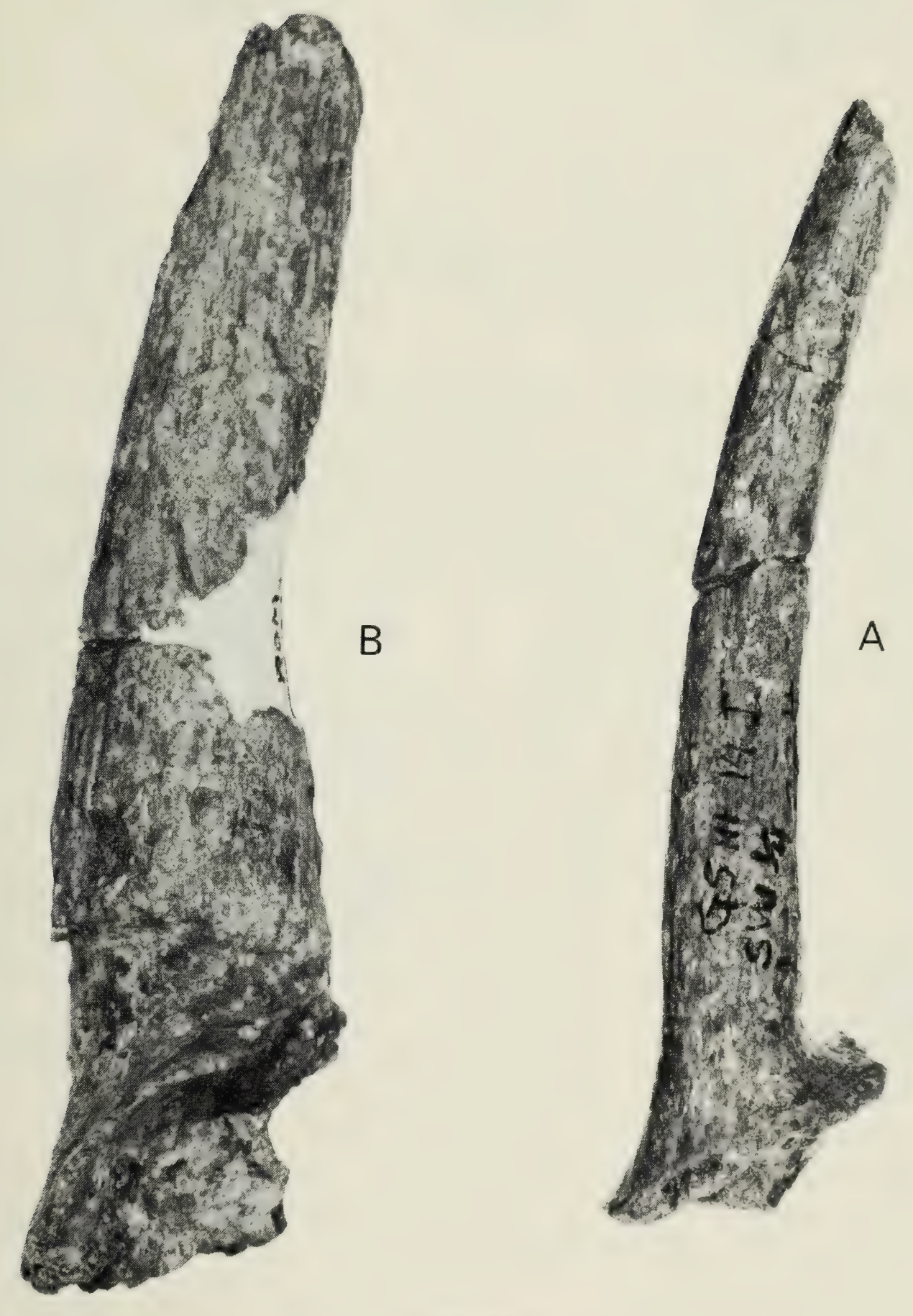

Fig. 42 Gazella dorcas and Gazella? ?eptoceros.

A. Gazella dorcas. Medial aspect of female right horncore 8221 from Gebel Silsila III, Level 1, Sebekian Industry.

B. Gazella ?leptoceros. Lateral aspect of male left horncore 8233 from Gebel Silsila III, Level 0 , surface and subsurface mixed Silsilian and Sebehian industries.

Bar $=10 \mathrm{~mm}$. 

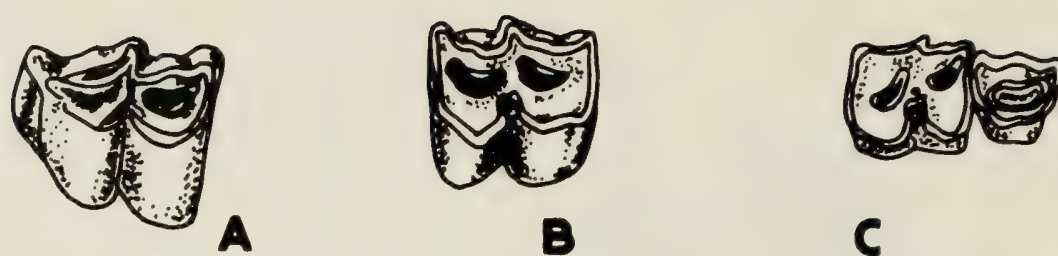

B

C

Fig. 43 Gazella dorcas. Occlusal aspects of cheek teeth. A - newly worn right M:" from Sebil v (8253). B - worn left $\mathrm{M}^{2}$ from Sebil v (8252). C - well worn right $\mathbf{P}^{4}-\mathbf{M}^{1}$, partially restored, from Gebel Silsila IX $(8230)$. Scale $=$ $50 \mathrm{~mm}$

vertebrarterial canal lies just ventral to the level of the top of the centrum and extends three-quarters of the length of the body.

The damaged scapulae $(8231,9064)$ are lightly built, have long necks, spines, and reduced anterior areas, and measure $24 \mathrm{e}$ and $21 \mathrm{e}$ by 17.2 and 13.6 for the greater and lesser diameters of the glenoid and coracoid areas, and 14.4 and 11.7 by 8.5 and 6.7 in least anteroposterior and transverse diameters of the neck, respectively.

Scapular glenoid (8218) appears to be juvenile as the coracoid process is absent. The neck is slim, apparently the anterior areas were small, and the spine projects beyond the narrowest part of the blade. This specimen measures $32 \mathrm{e}$ by 20.5 in anteroposterior length and transverse diameter of the coracoid and glenoid and 17.0 by 10.7 in least anteroposterior and transverse diameters of the neck, respectively.

The distal end of the humerus (8240) shows a perforated olecranon fossa and measures $24.2,12.8$ and $22 \mathrm{e}$ in transverse diameter of the condyle, least diameter of the condyle and anteroposterior height of the lateral epicondyle, respectively.

The distal epiphysis of the radius (8241) exhibits the oblique carpal facets typical of small, advanced artiodactyls.

The medial condyle of the femur (8227) measures 12.7 by $24 \mathrm{e}$ in transverse and anteroposterior diameters, respectively.

The distal ends of the tibia 8242 measure 17.0 by 22.0 in anteroposterior and transverse diameters, respectively, and specimen 9062 is 16.6 in anteroposterior diameter.

The metacarpal (8224) and metatarsal specimens $(8219,8220)$ are lightly built with large ends. The intermetacarpal groove is small and narrow, and the intermetatarsal groove is wider and more extensive. A posterior nutrient intermetacarpal foramen is present.

The proximal phalanges (8225a and b, 8244) are lightly built, slender, and elongate, and $8225 \mathrm{a}$ and b articulate with metacarpal 8224 .

The ischial fragment (9065) differs from specimens from the Khor el-Sil localities or elsewhere in the Kom Ombo Plain deposits in being black, well waterworn and rounded on the edges, denser, and apparently more heavily mineralised. This specimen may therefore have been secondarily derived from an older deposit and may have derived from an horizon such as that reported by Sandford (1934) at El Hibbah and Qâu (Kau el-Kebir), 
where black and highly mineralised bones of Hippopotamus, Bos sp., and Crocodilus sp. were recovered from consolidated gravels.

Measurements of selected specimens are:

\section{Dimension}

Horncores

Length of horncore

Anteroposterior diameter of base of horncore

Transverse diameter of base of horncore

Width between bases of horncores

Length of horns

$\begin{array}{ccc}8221 & 8222 & 8251 \\ 130 \mathrm{e} & 105 \mathrm{e} & - \\ 16.7 & 14.0 & 15.4 \\ 15.6 & 11.9 & 13.6 \\ 32 \mathrm{e} & 34 \mathrm{e} & 26 \mathrm{e} \\ 165 \mathrm{e} & 130 \mathrm{e} & -\end{array}$

\section{Dentition}

$\mathrm{P}^{4}$ mesiodistal length buccolingual diameter

M1 mesiodistal length buccolingual diameter, mesially buccolingual diameter, distally

$\mathbf{M}^{2}$ mesiodistal length buccolingual diameter, mesially buccolingual diameter, distally

$\mathbf{M}^{3}$ mesiodistal length maximum mesiodistal diameter buccolingual diameter, mesially buccolingual diameter, distally

\section{Metapodials}

Proximal transverse diameter

Proximal anteroposterior diameter

Midshaft transverse diameter

Midshaft anteroposterior diameter

Least anteroposterior shaft diameter

Distal transverse diameter

Distal anteroposterior diameter

Transverse diameter of metacarpal/metatarsal III distally

Transverse diameter of metacarpal/metatarsal IV distally

\section{Proximal Phalanges}

Total length

Proximal transverse diameter

Proximal anteroposterior diameter

Midshaft transverse diameter

Midshaft anteroposterior diameter

Distal transverse diameter

Distal anteroposterior diameter

$\begin{array}{cccc} & & 8219 & 8228 \\ & & 20.5 & - \\ & & 21.7 & - \\ 8224 & 8226 & 8220 & \\ 14 \mathrm{e} & - & 11.5 & 12.3 \\ - & - & 15.8 & 14+ \\ 8.5 & - & 10.8 & - \\ 20.7 & 20.7 & 23.4 & - \\ 15.9 & 15.9 & 16.8 & - \\ & & & \\ 9.7 & 9.8 & 10.1 & - \\ & & & \\ 9.5 & 9.5 & 10.3 & - \\ 8225 \mathrm{a} & \text { and b } & & 8244 \\ I I I & I V & & \\ - & - & & 39.2 \\ 11.1 & 10.8 & & 10.7 \\ 14.7 & 14.5 & & 14.2 \\ - & 8.7 & & 8.1 \\ - & - & & 9.4 \\ - & - & & 9.4 \\ - & - & & 9.1 \\ & & & 119\end{array}$

Metacarpals Metatarsals III and IV III and IV

82198228

$20.5-$

21.7

$823091.11 .1 .197 \mathrm{a}$

$6.9 \quad 6.6$

6.3

$10.1 \quad 10.3$

$\begin{array}{ll}7.9 & 7.7\end{array}$

$11.9 \quad 11.5$

$10.2 \quad 8.3$

$13.3 \quad 12.4$

$16.5 \quad-$

$10.2 \quad 6.7$ 
Gazella leptoceros-rhim or white gazelle (Fig. 42B)

MATERIAL

Obtained from:

Gebel Silsila Locality III, Surface and Subsurface, mixed Sebekian and Silsilian-Level 0.

\section{CONSIDERATION}

Gazella leptoceros differs from $G$. dorcas only by having straight as opposed to variably recurved horns. Moreover, $G$. leptoceros is a slightly larger animal that inhabits the desert areas west of the Nile (Ellerman and Morrison-Scott, 1951; Hoogstraal, 1964).

The horncore, 8233 (Fig. 42B), is typical of Gazella sp. and measures 26.8 by 19.7 in anteroposterior and transverse diameters, respectively, of the pedicel. The intact horn is estimated to have been $17 \mathrm{~cm}$ long, which is small in comparison to the range of 28 to $30 \mathrm{~cm}$ for G. leptoceros from French West Africa given by Rode (1943, p. 88). The Kom Ombo specimen may therefore represent a small $G$. leptoceros or, alternatively, the least curved condition of the horncore in the $G$. dorcas population, or a straighter variety as illustrated by Gentry (1966, Pl. 2, C, Species Group B) for a straight variant of $G$. wellsi.

This specimen is tentatively assigned to G. leptoceros.

\section{Discussion of Gazella dorcas and G. leptoceros}

Gaillard (1934, p. 44 and P1. VI, Figs. 6, 7, and 8) report Gazella Isabella (=G. dorcas isabella) from the Sebil Area in the Kom Ombo Plain on the evidence of an astragalus, the distal end of a metacarpal, and many fragmentary horncores. He gave no measurements of any specimens, but his illustrations agree well with the specimens recovered by the Canadian Expedition in the Kom Ombo Plain.

Gaillard's material confirms the presence of $G$. dorcas, probably $G$. $d$. dorcas, the present Egyptian subspecies, in the Kom Ombo area but, unfortunately, gives no information on the presence or absence of $G$. leptoceros in the area during the Late Palaeolithic. 
MATERIAL

Obtained from:

Oasis Depression A.

\section{CONSIDERATION}

Specimen 8234 (Fig. 44) comprises the bases of the horns, the frontal region including the left supraorbital margin, the detached dorsal surface of the brain pan, and isolated fragments.

The horncores measure about 69 by 65 in transverse and anteroposterior diameters, respectively, and diverge at about $90^{\circ}$. The transverse diameters at the base of the horns and across the anterior supraorbital eminence are about 113 and 177 respectively. The minimum anterior intraorbital width is about $100 \mathrm{~mm}$.

Reed and Turnbull (MS 1967) reported A. lervia from the Gebel Silsila Formation at Gebel Silsila 2. The specimen from Oasis Depression is badly preserved, fragmentary, and partly mineralised, and appears to be fossil rather than recent. 


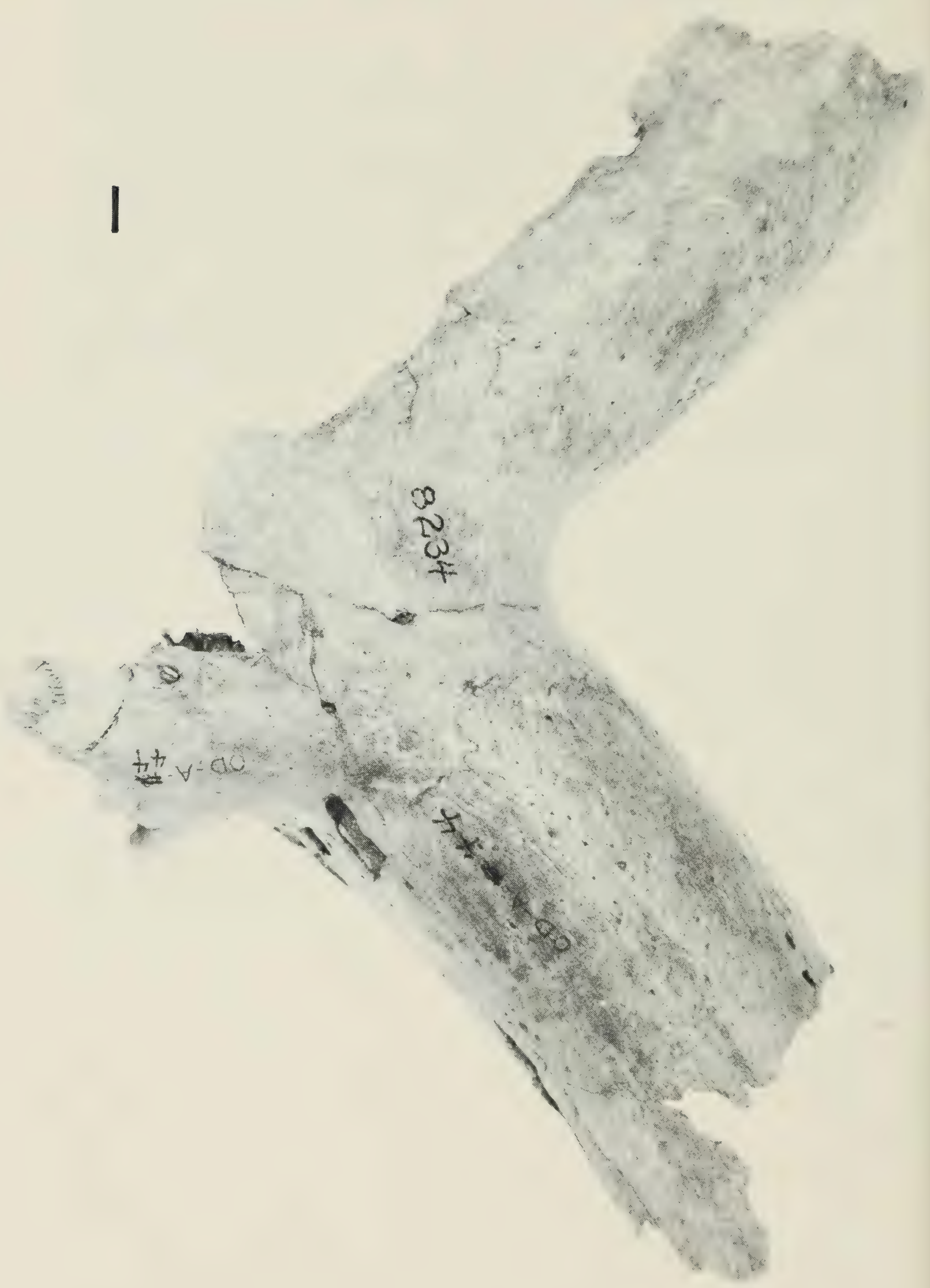

Fig. 44 Ammotragus lervia. Frontal aspect of base of horncores 8234 from Oasis Depression. Bar $=10 \mathrm{~mm}$. 



\section{Discussion of the Kom Ombo Faunas}

The Gebel Silsila Formation (Younger Channel Silts) of Late Pleistocene age has yielded many organic traces (Butzer and Hansen, 1968). The botanical remains consist of root-drip tubules or concretions, occasional root fragments from small woody plants, usually found in old levée deposits, and hollow rootlet casts, at times with some carbonised matter, covered in bedded silts.

The molluscan fauna consists of the clam Unio willcocksi, usually found in association with the bivalve Corbicula fluminalis or the gasteropod Cleopatra bulimoides, or with both. Planorbis, Valvata and Bulinus are absent (Leigh and Butzer, 1968). The matrix enclosing the vertebrate fossils included parts of shells of these taxa as well as of the Nile oyster (Etheria elliptica), which was tentatively identified only at Gebel Silsila 2B and Khor el-Sil.

Vertebrate remains from the Kom Ombo localities were reported previously by Gaillard (1934, p. 57), Sandford (1934, p. 86), Reed (1965), Reed and Turnbull (1969, MS 1967) with isolated taxa noted by Oakley (1965), and Smith $(1967,1968)$. These authors will be referred to in the discussion as appropriate.

\section{New Observations}

The vertebrates in the fauna recorded from the Kom Ombo sites represent two main ecological types, those that are directly associated with permanent water and those able to go for some time without drinking. Of those that are directly associated with water, some are permanently restricted to it, some can move away from it for short periods but return to the same pool or part of a river, and some are migrants that may at other times of their lives pass through less well-watered areas.

TABLE 4. Distribution of the vertebrate taxa recognized in the Late Palaeolithic Pleistocene Sites of the Kom Ombo Plain, Upper Egypt, arranged by locality and archaeological site, subsite or horizon. All data are original to this paper except those reported by Gaillard (1934) and those that are fide Reed and Turnbull (1969, MS 1967) for Gebel Silsila 2A and $2 \mathrm{~B}$, and those for taxa in the presently extant Nubian faunas, which are from Boulenger $(1909,1911)$ for Pisces, Loveridge and Williams (1957) for Reptilia, Etchécopar and Hue (1964) and Nicol (1919) for Aves, and Hoogstraal $(1963,1964)$ and Lydekker (1926) for Mammalia. Symbols: + indicates the presence of the taxon, as supported by material examined, recognizable illustrations, or generally documented occurrences; $+\cdots+=$ presence of taxon at both sites and in area between sites; $*=$ unpublished reports; ? = unidentified fragments of bone assignable only to Class or undiagnostic material most likely derived from the taxon indicated; + ? = certain identification of taxon but locality less certain; $\mathrm{n}=$ specimen from near the site Gebel Silsila VII; and $1816=$ date of death of last recorded wild hippopotamus in Egypt. 
All three fish identified (Clarias anguillaris-Nile catfish, Lates niloticus -Nile perch, and Barbus sp.-African barbel) indicate abundant and permanent water throughout the year. There may have been strong seasonal fluctuations in the availability of water in localised areas or channels off the main course of the Nile, and these may have forced the fish to migrate to deeper and permanent waters to avoid the stagnant pools and the possibility of desiccation. The occurrence of $L$. niloticus from only Fatira Site E suggests that this species was more abundant in the larger channels and that $C$. anguillaris and Barbus sp. may have been more common in the stiller waters of the side channels.

The presence of the Nile soft-shelled turtle (Trionyx triunguis) gives little additional evidence of the climate or aquatic conditions, as it easily migrates over land or in water in search of a suitable habitat. It is a generalised carnivore without being restricted to certain sizes or conditions of its food, and prefers to inhabit the deeper water where there is abundant aquatic vegetation. Such environments undoubtedly existed in many of the side channels where the Nile catfish also lived.

The avifauna includes shore, wading and diving water birds. The region therefore included both shallow and deeper waters with suitable prey. The heron (Ardea cinerea) would stalk its fish or frogs in the shallows, the flamingo (Phoenicopterus antiquorum) would stand in the shallows, straining its food from the water, and the spoonbill (Platalea leucorodia) would sift the muds for frogs, larvae and arthropods. In the deeper water the cormorant (Phalacrocorax carbo), pochard (Aythya ferina), goosander (Mergus merganser), red-breasted merganser ( $M$. serrator) and smew ( $M$. albellus) would swim under water after their fish, while the rafts of mallard (Anas platyrhynchos), pintail (A. acuta), teal $(A$. crecca) and widgeon $(A$. penelope) would dabble and dive after their smaller food. During the day the ruddy sheld duck (Tadorna ferruginea), the bean goose (Anser fabalis), white-fronted goose ( $A$. albifrons) and brent goose (Branta bernicla) or red-breasted goose ( $B$. ruficollis) would be sitting or standing on the shores or in the shallows, pulling up waterweeds, and at night or dusk the geese would fly away from the water to the savannas to feed on any ripened grasses or insects. An occasional spur-winged goose (Plectropterus gambensis) might also be seen among the other geese. The crane (Grus grus) would be found away from the water on the savannas, where it would be seeking insects and small lizards or frogs in moist places. At the edge of the water or on open land might be found curlew (Numenius arquatus) searching for small invertebrates on which to feed. Overhead an osprey (Pandion haliaetus), golden eagle (Aquila chrysaëtos) or a black kite (Milvus migrans) might silently pass as they hunted their prey.

The seasonal variation in populations of these birds would have been great, only the golden eagle, black kite, cormorant, grey heron, and possibly the flamingo being resident throughout the year, and even among these species, many of the flamingo and cormorant would depart during the summer for more northern habitats. Most of the birds would have wintered along the Nile from September to April, during the northern 
Eurasian winter, although the spoonbill and crane might only be seen as they passed from the tropics to the north or returned south. Some of the winterers are less commonly represented than the others, as the smew, goosander, bean goose, brent or red-breasted goose are known from only a few records, and the flamingo may have wintered in the Nile delta, as at the present time. The spur-winged goose is known probably only as an escaped captive in Egypt in the present century but may have extended its range northwards from the Sudan during the Late Pleistocene when the area was better watered. The red-breasted goose was common in Egypt in Pharaonic times and therefore was probably more common at the close of the Pleistocene.

The remains of the avifauna are from scattered sites in the Gebel Silsila and Sebil series of Localities, but are more numerous in Gebel Silsila Locality III. At this site the remains are restricted to the upper three levels or those associated with the present-day, the Sebekian industry, and that mixed with probable Sebekian and Silsilian cultural debris. Only the Silsilian level of Gebel Silsila IX produce avian remains, i.e., spoonbill (Platalea leucorodia), which suggests that between the Silsilian and Sebekian cultures about $12,500-12,000$ years B.C. there was a change in the habits of the inhabitants of the Kom Ombo Plain that allowed or produced the need to take waterfowl. No charred avian bones were observed, although both fish and mammalian remains often were.

The mammalian remains show the same spectrum of water- and dryland ecological divisions, with the dry-land forms predominant. The only truly amphibious mammal was the hippopotamus (Hippopotamus amphibius), which spends its days in the water, usually submerged and only occasionally coming up to breathe, and which comes out at night to browse on vegetation. Large bovines often like to wallow in the water or mud, especially during hot and dry periods, and this presumably was the habit of the wild cattle (Bos primigenius) and the long-horned buffalo (Homoioceras vignardi). Modern Cape buffalo (Syncerus caffer) retreat into either dense bush or swamp in the heat of the day and venture onto the grasslands during the cool of the day or at night. The hartebeest (Alcelaphus buselaphus), Dorcas and white gazelles (Gazella dorcas and G. leptoceros), Nubian wild ass (Equus asinus) and Cape hare (Lepus capensis) are creatures of the veldt or savanna grasslands and live mainly away from water, only approaching the river when there is no water available elsewhere. The bandicoot or pest rat (Nesokia indica) would have been resident along the banks of the seasonally flooded channels and marshy areas, burrowing into the banks and feeding on the fleshy stems and roots of marginally aquatic or marsh plants such as the bulrush or cattail (Typha latifolia). The Barbary sheep (Ammotragus lervia) and perhaps the gazelle and ass might have inhabited the broken hills east of the Kom Ombo Plain rather than the flatter grasslands, and the sheep would seldom have approached the river. The single record of the Barbary sheep, from the Oasis Depression at Gebel Silsila, suggests that it was an uncommon element. The wolf-jackal (Canis lupaster), striped hyaena (Hyaena hyaena), and spotted hyaena 
(Crocuta crocuta) probably ranged freely in all environments, as they do today when unmolested by man (Homo sapiens).

The Egyptian bandicoot or pest rat could well have provided food for the jackal or hyaena or other lesser carnivores, or for the osprey, kite, or golden eagle among the birds. Similarly, the Cape hare, Dorcas gazelle, and even jackal might have provided prey for the golden eagle or the hyaena when caught in the open on the grassveldt.

Wild cattle and the hartebeest were the main sources of mammalian protein for the Palaeolithic residents and, as hartebeest is most numerous, the early inhabitants of the Kom Ombo Plain c. 15,000-10,000 B.C. probably did not have domesticated cattle or, if they did, did not have sufficient to provide them with a constant supply of meat. These men hunted widely, as they obtained gazelle and possibly sheep from the hills, hartebeeste from the savannas, wild cattle from near the river flats and hippopotamus from the river itself. However, none of the bones recovered from the archaeological sites show signs of butchering or breakage that could be certainly attributed to man, although many of the green breaks that exposed the marrow cavities in the longbones may well have been caused by him. The presence of young animals of many of the taxa suggests that the sites were occupied during the spring or early summer and, with the evidence for winter occupation of the sites from the avian remains, supports the conclusion that the plain was probably occupied throughout the year.

The distribution of the taxa by site reflects the more extensive sampling at Gebel Silsila Locality III which yielded the smaller bird bones and the recovery elsewhere of generally large specimens from the deflated or surface collected sites. Unfortunately, remains of the bandicoot or pest rat, Cape hare and Barbary sheep are scant and other rodents and carnivores are unrepresented.

The faunal list indicates that the Kom Ombo Plain was well-watered, probably covered with grassland and trees as in the orchard savanna or bushveldt of Africa today, that the hills had grass and acacia trees and that the Nile was bordered by gallery riverine forest with swamps, with quiet meanders and pools in the side channels. None of these deductions differ from those of Butzer (1959) who listed many plants for the Neolithic of the Nile Valley that are still members of the present flora. The archaeological sites all lie along the banks of or near channels of the ancient Nile, presumably so placed that the inhabitants could obtain water and wood with ease, could take fish throughout the year and hunt the resident herds of mammals when they came to water or moved closer to the water in the dry season, and take birds mainly during the winter season when they had migrated south from Europe. The situation of Gebel Silsila III and its recovered faunal remains suggests that this Sebekian site, and therefore probably those at other sites, was permanently occupied by a resident hunting and gathering population that specialised in taking birds or mammals at different seasons. The area was subject to winter rainfall and probably periodic summer flooding, as shown by the stratified nature of the Gebel Silsila Formation with its contained silts and fine clays (Butzer, 1959; Butzer and Hansen, 1968). 
The fauna from Gebel Silsila XIII associated with the Menchian and Sebilian industries of $c .11,000-10,000$ B.C. is not extensive. The presence of Nile catfish at most subdivisions of the site suggests that fishing was a common occupation. The record of the pintail, one of the most common ducks hunted by the Sebekians at Gebel Silsila III, shows that wildfowling was practised. The mammals obtained are the commonly hunted wild cattle, hartebeest and hippopotamus, species that are present at most of the other sites. Unfortunately, the probability that the fauna reflects the selection of larger or better preserved elements is high, and careful collecting should reveal a fauna similar to that from the upper levels at Gebel Silsila III or the Sebil Localities. The absence of Gazella from Gebel Silsila XIII is puzzling, as this species is well represented by remains at other sites.

The presence of avian remains in the Sebekian at Gebel Silsila III and the lack of any burnt avian bones from any site, together with the presence of burnt fish and mammalian remains from other levels at Gebel Silsila III and other sites, suggest that, although the Sebekian peoples hunted birds, they did not bake or roast them.

\section{Comparison of the Kom Ombo Fauna with Others Reported within the Nile Valley}

Three faunas, composed of mammals and fish, have been reported from the Wadi Halfa region in the northern Sudan (Robinson, 1966; Gautier, 1968; Greenwood, 1968), Khartoum (Bate, in Arkell, 1949), Singa and Abu Hugar (Abu Higar) ( Bate, 1951) from south of Khartoum, and from $13 \mathrm{~km}$ southeast of Edfu (Idfu) (Sandford and Arkell, 1933, pp. 33-36), just north of Kom Ombo, and Qâu (Qâu el-Kebir) (Sandford, 1934, p. 86) some 200 miles to the north. These faunas, except for that from Khartoum, are compared with those from Kom Ombo (Table 4).

Robinson (1966) identified the bandicoot or pest rat (Nesokia indica) from near Wadi Halfa, and Perkins (1965) recorded wart hog (Phacochoerus aethiopicus) together with catfish (Clarias lazera), Nile perch, crocodile (Crocodilus niloticus), probably Dorcas gazelle, wild cattle, hartebeest, hippopotamus and ass from levels dated by radiocarbon analysis at $14,950 \pm 300$ B.P. The presence of Nesokia indica suggests a wetter climate in which there were soft, thoroughly wet, clayey or muddy banks to the Nile as this animal is today confined to the delta of the Nile and nearby areas (Flower, 1934; Hoogstraal, 1963; Robinson, 1966).

The vertebrate faunas reported by Gautier (1968) and Greenwood (1968) from the Wadi Halfan Nubian sites excavated by the Combined Prehistoric Expedition are comparable with those from Kom Ombo. The fish fauna differs only in the presence of Tilapia and possibly ? Chrysichthys at Wadi Halfa for which materials are not numerous nor are these genera identified from the Sebilian levels at Kom Ombo. The mammalian fauna is more divergent as black-backed jackal (Canis mesomelas), kob (.4denota kob), red-fronted gazelle (Gazella rufifrons), a large gazelle (Gazella [Nanger] sp.), and goat (Capra hircus) are present at Wadi Halfa but not at Kom Ombo. 
Neither Wendorf (1968), Gautier (1968) nor Greenwood (1968) summarised the levels or localites that have yielded the various vertebrate faunal elements but by selecting data from their papers and that of Marks (1968) on the Sebilian, it was possible to produce a list of the vertebrates whose remains were recovered from the Wadi Halfa sites comparable to those of Kom Ombo between 15,000 and 10,000 B.C. The industries involved are the Sebilian, Qadan and Ballanan. The Sebilian is considered to have existed between 15,000 and 9,000 B.C. (Wendorf, 1968), involved seven or nine major and five minor sites, and contained one major site (1024) and one minor site (8899) that yielded faunal remains. The Qadan ranged from 12,550 to ?4,480 B.C. (Wendorf, 1968), involved 17 sites, some of which were subdivided, and contained three early sites (34c, 8905 A-H and ANE-1) that yielded vertebrate remains. The Ballanan industry lasted from 14,000 to 12,000 B.C. (Wendorf, 1968), involved five sites, and included three sites $(8856,8859$ and 8957$)$ that produced vertebrates. These sites may be listed to give their ages, $C_{14}$ dates, and recovered vertebrate remains, as given by Wendorf (1968), Gautier (1968) and Greenwood (1968).

Sebilian

Time Range $\quad 15,000-9,000$ B.C.

Sites

$\left.\begin{array}{l}1024 \mathrm{~A} \\ 1024 \mathrm{C}\end{array}\right\} \quad \begin{aligned} & \text { Equus asinus } \\ & \text { Bos primigenius } \\ & \text { Alcelaphus buselaphus } \\ & 8899 \quad \begin{array}{l}\text { Clarias sp. } \\ \text { Bos primigenius } \\ \text { Gazella rufifrons }\end{array}\end{aligned}$

Qadan

Time Range

$12,550-? 4,480$ в.С.

Sites

34C Clarias sp.

Canis aureus

Hippopotamus amphibius

Bos primigenius

Alcelaphus buselaphus

Gazella rufifrons

Dated at 9,460 \pm 270 B.C. (wsU-189)

$9,250 \pm 150$ в.C. (WSU-106)

8905 A-H Clarias sp.

Canis mesomelas

Hippopotamus amphibius

Bos primigenius

Alcelaphus buselaphus

Gazella rufifrons

Dated at 12,550 \pm 490 B.C. (wsu-315)

ANE-1 Clarias sp.

Barbus sp.

Equus asinus

Hippopotamus amphibius

Bos primigenius

Alcelaphus buselaphus

Gazella rufifrons

Large antelope indet.

Dated at c. 10,000 B.C. 


\begin{tabular}{|c|c|}
\hline \multirow[t]{3}{*}{$\begin{array}{l}\text { Time Range } \\
\text { Sites }\end{array}$} & $\begin{array}{l}14,000-12,000 \text { в.С. } \\
8856 \quad \text { Clarias sp. } \\
\text { Dated between } 16,000-12,000 \text { в.с. }\end{array}$ \\
\hline & $\begin{array}{l}8859 \quad \text { Clarias sp. } \\
\text { Barbus } \mathrm{cf} \text {. bynni } \\
\text { Tilapia sp. } \\
\text { Lates sp. } \\
\text { Small rodent (?Nesokia indica; } \\
\text { see Robinson, 1966) } \\
\text { Bos primigenius } \\
\text { Dated at } c .16,700 \text { B.C. }\end{array}$ \\
\hline & $\begin{array}{l}\text { Alcelaphus buselaphus } \\
\text { Gazella rufifrons }\end{array}$ \\
\hline
\end{tabular}

The composite fauna obtained from these faunal samples is comparable with that from Kom Ombo and contains the same mammals except the black-backed jackal (Canis mesomelas) and the red-fronted gazelle ( $G a$ zella rufifrons), that represent two genera present at Kom Ombo but more southern species. The Kom Ombo fish fauna is similar to that from Ballanan site 8859 , which also included Tilapia sp., but which was not identified to species.

The record of a small rodent from Ballanan site 8859, lying within the Nile Valley, may represent Nesokia indica, identified by Robinson (1966) from the Upper Palaeolithic of Dabarosa West, site 6B28, some $50 \mathrm{~km}$ to the southwest. This rodent occurred also in the Kom Ombo Plain during the same times.

Gautier (1968, p. 97) suggested that wild cattle (Bos primigenius), hartebeest (Alcelaphus buselaphus) and red-fronted gazelle (Gazella rufifrons) were abundant and that hartebeest was normally found in dry, luxuriant grassland or savanna, that wild cattle preferred open, arid grassland, dry bushland or even light woodland, and that kob and gazelle preferred savanna. He suggested that these conditions prevailed away from the Nile and that the banks and flats along the river would have been more heavily wooded. Gautier's interpretation agrees with that for the Kom Ombo Plain, although $G$. rufifrons is characteristic of wetter and $G$. dorcas of drier conditions. Thus the Kom Ombo habitats may have always been somewhat drier than those in the southern Sudan. Gautier reported no remains of buffalo (either Syncerus or Homoioceras), or Barbary sheep (Ammotragus lervia). He remarked that the advent of the domestic goat may have brought about at least the partial degradation of the woodlandsavanna ecosystem towards a more xerophytic or desert condition, and that a contributing factor may have been a simultaneous progressive change towards a drier ecosystem. Certainly, the area was becoming drier towards the end of the Würm glaciation, but the goat was not present until predynastic times. The pre-dynastic peoples have left crude pictures of giraffe. elephant and ostrich (Sandford and Arkell, 1933) and it is reasonable to suspect that these vertebrates were present as members of the fauna, a sample of which was recovered from Wadi Halfa. 
Wendorf (1968, p. 1055, Fig. 8) showed the Sebilian as contemporaneous with the Qadan and slightly later than the Ballanan industries. He stated that there is no record of Qadan at Kom Ombo, although the Ballanan industry may be there. Wendorf's range for the Sebilian includes all three Sebilian subphases distinguished by Vignard $(1923,1934)$ the Silsilian and Sebekian industries of Smith (1966a, 1966b, 1967).

Wendorf (1968, p. 1048) remarked that the Sebilian remains show "Hunting of large savanna animals; no evidence for fishing, small animal hunting, or other utilization of the Nilotic microenvironment." The Ballanan peoples practised "Mixed hunting and fishing, with large savannatype animals most important", and the Qadan showed "Hunting of large savanna-type animals, emphasis on fishing, and at some localities, gathering and grinding of grain."

The lack of any record of avian or reptilian remains from the Wadi Halfa sites is peculiar, especially as avian remains were relatively common in the Sebekian level of Gebel Silsila III at Kom Ombo and were probably not absent from the other sites. The absence or near absence of evidence for wildfowling or fishing from the Wadi Halfa Sebilian levels suggests that the Sebilian sites were primarily occupied by hunters. They were "Very small camps with dense concentrations of artifacts. Little or no primary work-shop debris present" (Wendorf, 1968, p. 1048). These sites may have been inhabited only in the summer, when wildfowl would have been scarce but the mammals perhaps concentrated nearer the river. Permanent encampments may have been either on the hills or nearer the winter wildfowling areas. The interpretation of the Ballanan sites corresponds to that of the Silsilian and of the Qadan to that of the Sebekian at Kom Ombo, although the palaeontological evidence gives no hint as to the possible grain-gathering or grinding activities of the Sebekian people.

Bate (in Arkell, 1949) reported on the fauna associated with Late Pleistocene human remains from a site situated northeast of the Khartoum Central railway station. The remains were "covered with a thin, hard, and strongly adherent calcareous deposit", similar to that which encrusted many of the fragments from the sites in the Kom Ombo Plain, and many were broken into small pieces, presumably evidence of the use of the animals as sources of food. Bate (in Arkell, 1949, pp. 16-28) listed nine taxa of fish, five reptiles, one bird, and 22 mammals. The fish include Clarias sp. "including C. lazera", Lates cf. niloticus; the reptiles Crocodilus sp. and Trionyx sp.; the bird may have been Plectropterus gambensis, and the mammals include Hyaena cf. hyaena, the ?Egyptian wolf-jackal Canis ?lupaster, Hystrix sp., Hippopotamus cf. amphibius, Equus sp., and antelope, all of which are or may have been present in the deposits at Wadi Halfa, Kom Ombo, or farther north. The Khartoum fauna is typically Ethiopian and apparently lacks Bos primigenius, Homoioceras sp., Alcelaphus buselaphus and Gazella sp., although a gazelle "about the size of Gazella soemmeringi" may have been present, and Equus is scarce, represented by a single molar that cannot be identified to either ass or zebra. Purely Ethiopian elements not known from northeastern Africa are ?lechwe 
(Onotragus cf. megaceros), ?kob (?Adenota leucotis), ?oribi (?Ourebia sp.), buffalo (Syncerus cf. aequinoctialis), ?black rhinoceros (Diceros cf. bicornis) and ?African elephant (Loxodonta ?africanus). The age of the Khartoum site is approximately the same as that of the deposits from the Kom Ombo Plain and Bate (in Arkell, 1949) drew attention to Gaillard's (1934) account of the Sebilian fauna. However, the Khartoum fauna is too distinctly Ethiopian and does not contain examples of Bos primigenius, Gazella dorcas, Equus asinus africanus, etc., for direct comparison with those from farther north and is therefore omitted from Table 5.

The Singa and Abu Hugar faunas include a long-horned African buffalo (Homoioceras singae), porcupine (Hystrix astasobae), oryx (Oryx sp.) and an antelope (Bate, 1951). The presence of Oryx at Kom Ombo would not be surprising, as Oryx is found in Arabia today, must have occupied a continuous distribution from the Sudan through Lower Egypt and Sinai to Arabia during Pleistocene times, and has been tentatively reported from the early Middle Pleistocene of Israel at 'Ubeidiya by Haas (1966, p. 33) as an "Ory $x$-like antelope", which "corresponds fairly well in size with Palaeoryx, but in shape more with the much smaller recent genus Oryx."

The sites south of Edfu (Sandford and Arkell, 1933) and at Qâu (Sandford, 1934, Qau el-Kabir) contain faunal elements that are present at Kom Ombo, and a pig, Sus sp., and do not suggest different climatic conditions or habitat. Dr. D. M. S. Watson's faunal list for the Qâu deposit (Sandford, 1934, p. 86) agrees well with that provided by Gaillard (1934) for Kom Ombo, allowing for taxonomic variants. However, Sandford (1934) added Crocodilus niloticus to the fauna as he had "observed specimens on the Kom Ombo Plain." He did not state where or at what level, and his record must be considered unconfirmed by the present palaeontological evidence. A record of ostrich, Struthio camelus, was added by Gaillard (in Vignard, 1934, p. 99, footnote 1) but is unsupported by described material or later records. Gaillard (in Vignard, 1934) included Nodularia coelatura as a fish, but this binomial refers to the species Nodularia (Coelatura) nilotica, a unionid lamellibranch mollusc (Gaillard, 1934, pp. 54-56). Nonetheless, the genus Nodularia is now considered to be a subgenus of Unio and may refer to Gaillard's (1934) Unio willcocksi, which is present in these deposits (Butzer and Hansen, 1968) and considered a junior synonym of $U$. abyssinicus by Martin (1968).

Sandford (1934, p. 88) reported bones and teeth of Hippopotamus amphibius, Bos sp., and Crocodilus sp. from El Hibbah, on the opposite bank of the Nile near El Fashin, and the same vertebrates and also siluroid fish from near esh-Sheikh Timai, near Geziret Shaibah. These specimens are all blackened, highly mineralised and hard set in gravels, and Sindford considered them possibly contemporary with those from Qâu.

Perkins (1965) reported scattered fossil materials of Clarias lazera, Lates niloticus, Crocodilus niloticus, Gazella ?dorcas, Bos sp. (cither B. primigenius or B. brachyceros), Alcelaphus buselaphus, Phacochoerus aethiopicus, Hippopotamus amphibius, and Equus asinus africamus from the middle layers of the Nile's Upper Pleistocene silts in Sudanese Nubia. 


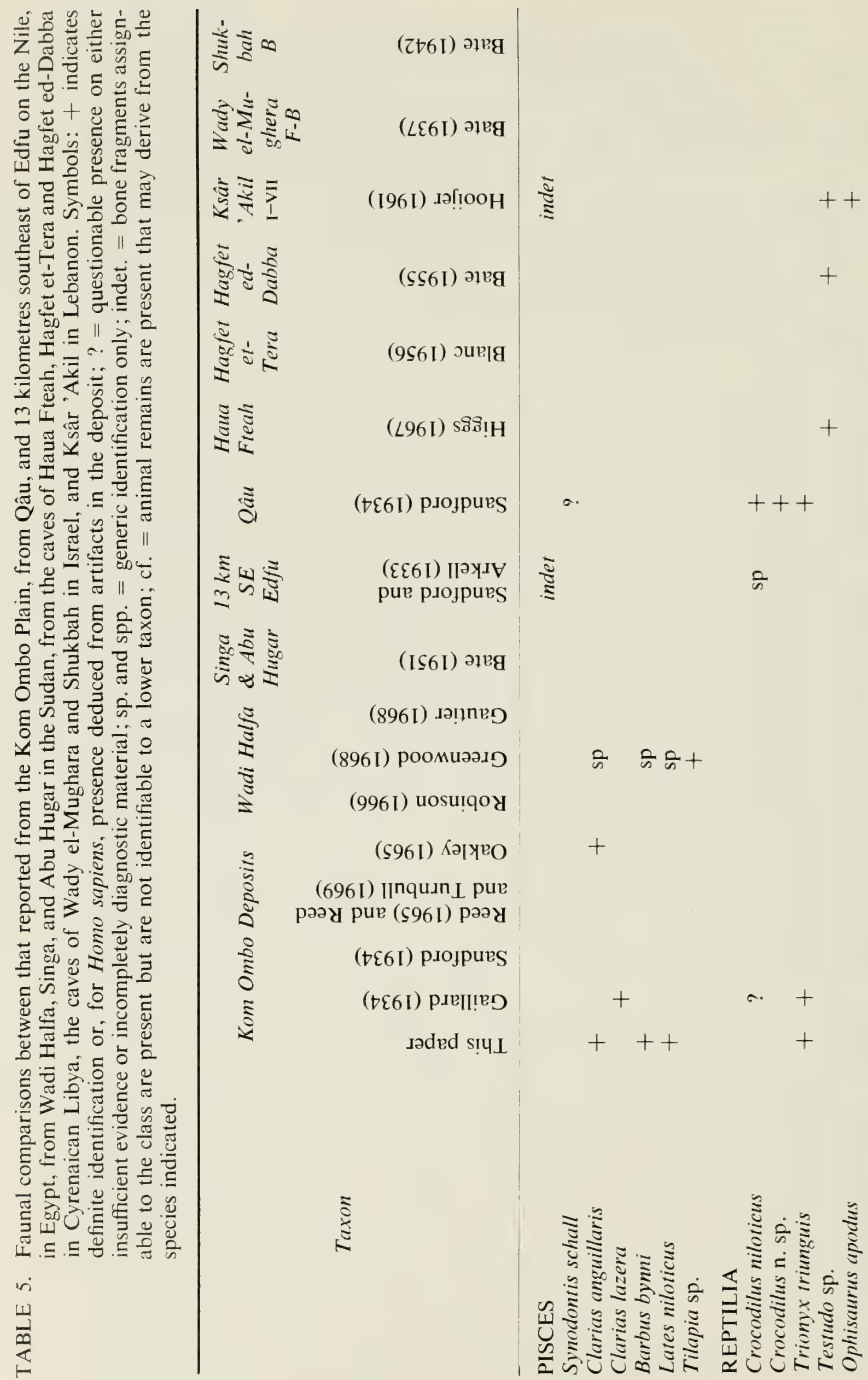




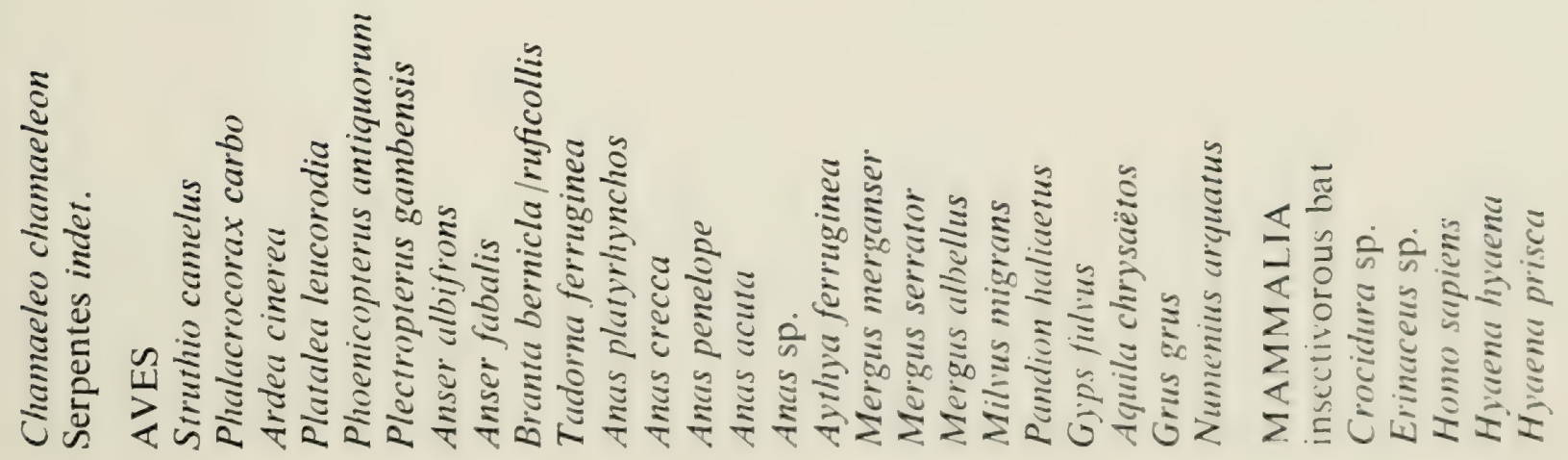




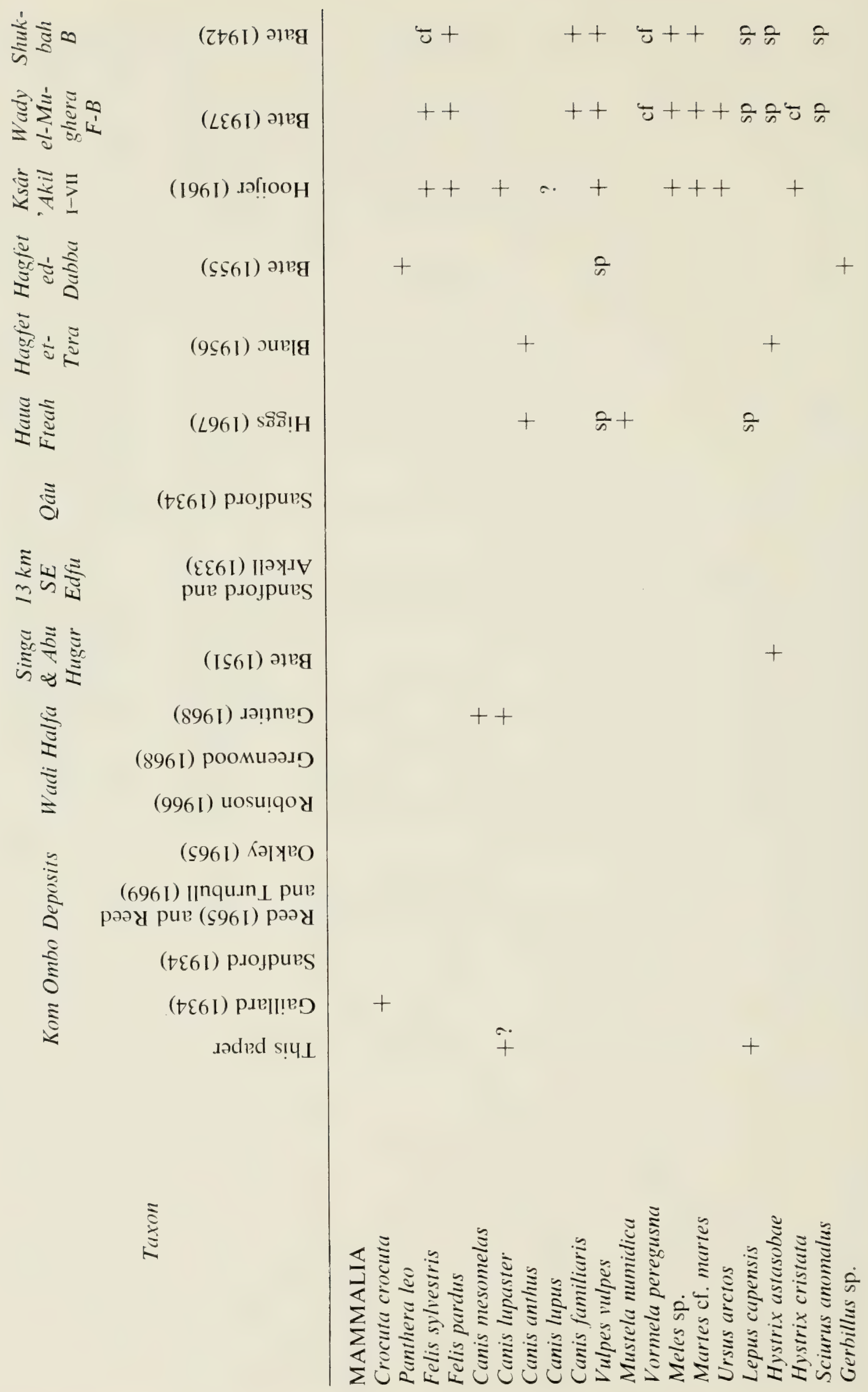




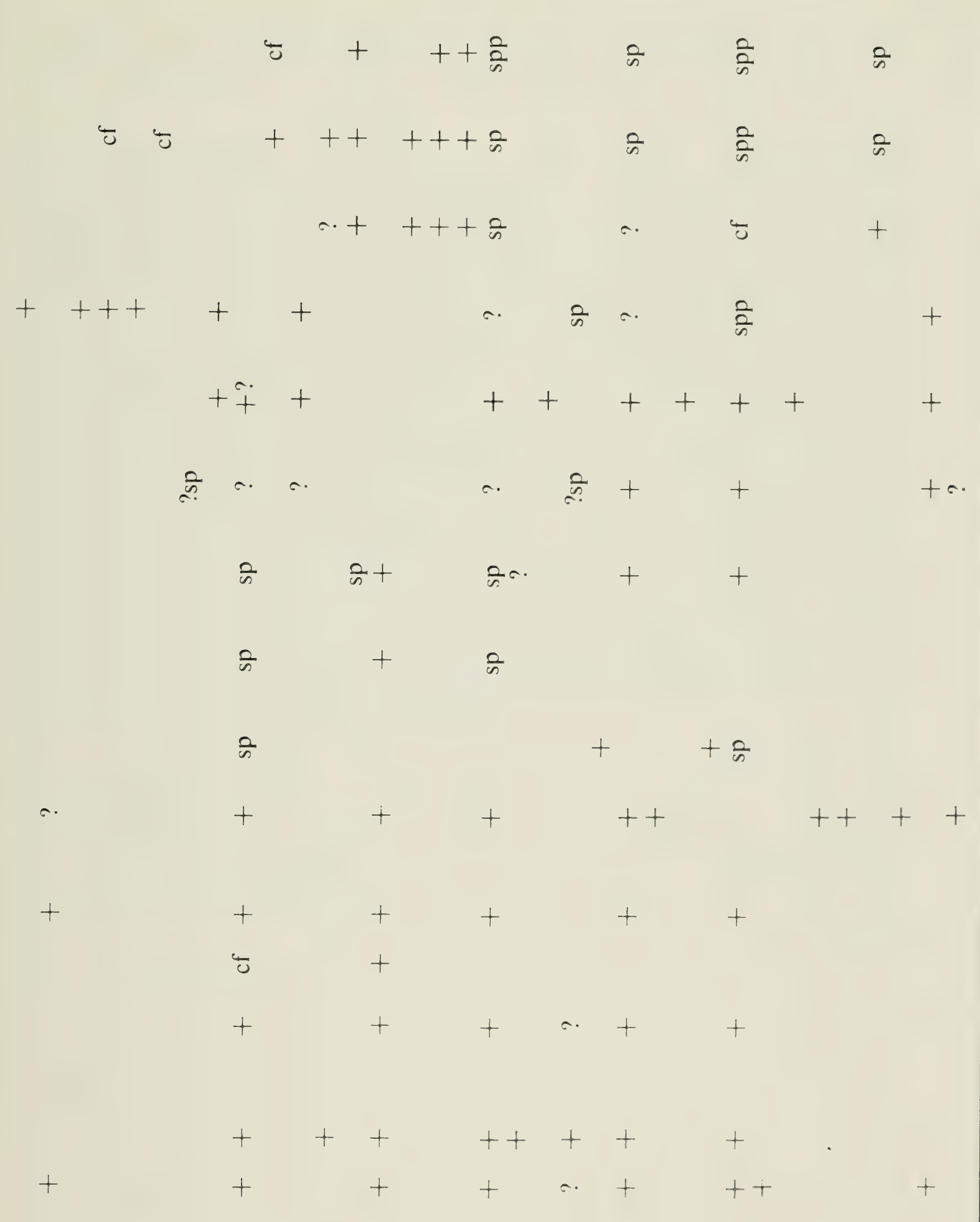


These silts "are all characterised by the presence of Unio willcocksi, a large edible clam." He cited Fairbridge's (1962, p. 5) $\mathrm{C}_{14}$ date of 14,950 \pm 300 years BP $(12,988 \pm 300$ B.C. $)$ for these beds. This fauna is similar to that recorded from the Kom Ombo deposits and elsewhere within the Nile Valley, but Perkins (1965) stated that "The presence of Wart Hog and the Hartebeest, both of which are forest dwellers, indicate[s] that the climate in the Middle Nile Valley was moister during the Upper Pleistocene." This statement is incorrect, as although undoubtedly the climate was moister at that time, both these animals are characteristic of savannabushland or bushveld and do not inhabit closed forest or dense woodland.

Caton-Thompson (1952, pp. 72 and 79) reported tooth fragments from a bovine and an equine not a horse from Mound-Springs $\mathrm{KO} 10 \mathrm{C}$ and $\mathrm{KO}$ $8 \mathrm{~A}$, respectively, from eight kilometers east of Kharga Oasis. These specimens were considered to be of Levalloisian age. She also reported (1952, p. 168) teeth of Hyaena cf. striata and a mandibular fragment of a gazelle from the Neolithic of Hearth 3 at Mound-Spring KO 8A. Stone shelters in the vicinity of Kharga Oasis contained spines of Lates niloticus and a broken horncore of Gazella dorcas and these may date from Twentysecond to Twenty-seventh Dynastic times (Caton-Thompson, 1952, p. 193).

When the recovered taxa from Kom Ombo and other Nile Valley sites are compared with the present day Egyptian fauna, relatively few differences are noted. All the fish and reptiles are present at both levels. Among the birds, there have been changes in abundance and breeding colonies, some birds having been more common (e.g., red-breasted goose, Branta ruficollis) or breeding in Pharaonic times (flamingo, Phoenicopterus antiquorum). Others, now only an occasional visitor, were likely more common under more pluvial conditions (e.g., spur-winged goose, Plectropterus gambensis).

The Kom Ombo mammalian fauna has lost its largest components. The hippopotamus became extinct in 1816 (Flower, 1932), the Egyptian bandicoot or pest rat has had its range restricted by climatic changes, and the population of gazelles (Gazella dorcas and $G$. leptoceros), Nubian ass (Equus asinus), Barbary sheep (Ammotragus lervia), and probably striped hyaena (Hyaena hyaena) limited by man's activities and hunting pressure. Some are known from remains recovered from tombs, e.g. hartebeest (Alcelaphus buselaphus) (Flower, 1932, p. 437), some are entirely extinct, e.g., the long-horned buffaloes (Homoioceras spp.), and some are now limited to the Sudan, e.g. hartebeest, and spotted hyaena (Crocuta crocuta) (Setzer, 1956). The wild cattle (Bos primigenius) have been replaced by the domesticated form (B. taurus). 


\section{Comparison with the Cyrenaican Faunas from Wadi Derna and the Synchronous Levels at the Caves of Haua Fteah, Hagfet et-Tera and Hagfet ed-Dabba}

\section{HAUA FTEAH}

Higgs' (1967) report on the fauna from the Eastern Oranian levels at Haua Fteah, dated c. 14,000 to 9,000 years ago, includes jackal (Canis anthus), fox (Vulpes sp.), and spotted hyaena (Crocuta crocuta). While the identified species of hyaena, jackal, and fox, may be different, the material from Kom Ombo is such that errors of identification of these fragments could have occurred, and the assumption is that the Haua Fteah fauna in the Eastern Oranian levels is similar to if not identical with that recorded from Kom Ombo. Higgs (1967, p. 19, 20, Pl. II.1,1) remarked that an equid pelvic fragment from the Levalloiso-Mousterian layers "is similar to specimens attributed to Equus mauritanicus in the Muséum National d'Histoire Naturelle in Paris" and that other specimens identified only to Equus sp. include teeth that agree with Boule's (1899) criteria for Equus mauritanicus ( $=$ E. burchelli mauritanicus; Romer, 1928, 1935) which is a zebra similar to the living Burchell's zebra. Higgs (1968, Pl. VII.1,17) illustrated the proximal end of a humerus of a bird of medium size obtained from the Late Palaeolithic levels at Haua Fteah but no mention of this specimen was located in the text.

\section{WADI DERNA}

Bate (1955) discussed the Quaternary vertebrate faunas of Cyrenaica, and reported Homoioceras sp., Ammotragus sp., Hippotigris sp. [= Equus (Hippotigris) sp.], Testudo sp., possibly a large antelope and perhaps hippopotamus or rhinoceros from Wadi Derna. This deposit is considered to be of Lower Levalloiso-Mousterian age and therefore older than the other faunas considered here. However, the presence of Homoioceras sp. and Equus (Hippotigris) sp. correlates with the presence of $H$. vignardi from Kom Ombo and other species elsewhere and to the presence of zebras identified to Equus burchelli (sensu latu) from Haua Fteah and Hagfet et-Tera.

\section{HAGFET ET-TERA}

Bate (1955, p. 276) considered the faunas from Hagfet et-Tera, first reported by Petrocchi in 1940 and originally identified by Baron G. A. Blanc. The fauna as presented by Petrocchi (1940) is given in the first table, page 138.

Blanc (1956) presented a revised list of identified species from this cave and consolidated the two earlier layers into a single fauna that he referred to as "Paleolitico medio", characterised by "alcuni strumenti litici di tecnica musteriana." The middle layer is ascribed to the "Paleolitico superiore" and characterised by "una industria di tipo musteriano". The fauna of the uppermost layer was associated with an abundant industry that showed "affinità con quelle ibero-maurusiana od oraniana dell'Africa settentrionale." Blanc's (1956) revision of the fauna is presented without alteration in the second table, page 138 . 


$\begin{array}{cccc}\text { "Mousterian } & \text { Layer G } & \text { Layers } \\ \text { breccia" } & \text { Middle } & \text { Layer D } & \text { Band C } \\ & \text { Upper } \\ & \text { Palaeolithic } & & \text { Palaeolithic }\end{array}$

hyaena indet.

Hystrex cristata

Rinoceros (Mercki?)

Equus asinus hidruntinus

Equus caballus

Cervus sp.

Bos primigenius

Bos sp.

Antilope sp.

Capra sp.

Ovide?

\begin{tabular}{cccc} 
& \multicolumn{3}{c}{ coprolite } \\
& $\mathrm{X}$ & $\mathrm{X}$ & \\
$\mathrm{X}$ & & $\mathrm{X}$ & $\mathrm{X}$ \\
$\mathrm{X}$ & $\mathrm{X}$ & $\mathrm{X}$ & $\mathrm{X}$ \\
& & $\mathrm{X}$ & large size? \\
$\mathrm{X}$ & & $\mathrm{X}$ & primigenius? \\
& & Kobus? & large size \\
$\mathrm{X}$ & & $\mathrm{X}$ & \\
$\mathrm{X}$ & $\mathrm{X}$ & & \\
& $\mathrm{X}$ & & \\
\hline
\end{tabular}

Bate (1955) remarked on the presence of Equus caballus, E. asinus hydruntinus, and Capra in Petrocchi's (1940) list and stated that she doubted the presence of a true horse in the deposits as this species is considered to be present only in Neolithic or later horizons in North Africa (Romer, 1928, 1935; Arambourg, 1938). Bate suggested that because zebras can attain large size, perhaps the specimens represented a zebra. Blanc (1956) confirmed this supposition by listing Equus burchelli and omitting $E$. caballus.

Bate (1955) also doubted the identification of E. asinus hydruntinus in Petrocchi's (1940) list. As E. a. hydruntinus is a name for a small equine from various levels of the central and southern European Pleistocene (Stehlin and Graziosi, 1935) and since E. burchelli coexisted with it and $E$. a. africanus was extant in the area until recently, it is more likely that the ass present was $E$. a. africanus. The dimensions given by Blanc (1956) for the upper teeth of his $E$. (Asinus) hydruntinus resemble those for $E$. asinus africanus from Kom Ombo, and comparison of Blanc's descriptions

\begin{tabular}{lccc}
\hline & $\begin{array}{c}\text { Lower Level } \\
\text { Middle } \\
\text { Palaeolithic }\end{array}$ & $\begin{array}{c}\text { Middle Level } \\
\text { Upper } \\
\text { Palaeolithic }\end{array}$ & $\begin{array}{c}\text { Upper Level } \\
\text { Latest } \\
\text { Palaeolithic }\end{array}$ \\
\hline $\begin{array}{l}\text { Canis anthus F. Cuvier } \\
\text { Hyaena } \text { sp. }\end{array}$ & & $\mathrm{X}$ & $\mathrm{X}$ \\
$\begin{array}{l}\text { Hystrix cristata } \text { L. } \\
\text { Rhinoceros sp. }\end{array}$ & $\mathrm{X}$ & $\mathrm{X}$ & \\
$\begin{array}{l}\text { Equus } \text { Asinus) hydruntinus } \text { Regàlia } \\
\text { Equus burchelli Gray }\end{array}$ & $\mathrm{X}$ & $\mathrm{X}$ & $\mathrm{X}$ \\
$\begin{array}{l}\text { Bos primigenius } \text { Boj. } \\
\text { Bos ibericus } \text { Sanson } \\
\text { Bubalis boselaphus } \text { Pallas }\end{array}$ & & $\mathrm{X}$ & $\mathrm{X}$ \\
$\begin{array}{l}\text { Kobus } \text { sp. } \\
\text { Gazella dorcas } \text { L. }\end{array}$ & & $\mathrm{X}$ & $\mathrm{X}$ \\
$\begin{array}{l}\text { Gazella setifensis Pom. } \\
\text { Ammotragus lervia } \text { Pallas }\end{array}$ & & $\mathrm{X}$ & \\
\hline
\end{tabular}


and illustrations (Blanc, 1956, Tav. 1, Figs. 1-12) where possible do not definitely preclude his $E$. (A.) hydruntinus specimens from being considered as $E$. $a$. africanus. The ass in the deposits at Hagfet et-Tera is therefore considered to be E. a. africanus.

Bate also remarked on the presence of Capra sp., and suggested that Ammotragus would be a more likely genus, and Blanc (1956) made this substitution. Bate (1955) also reported Homoioceras or Bos, Ammotragus sp., Gazella dorcas, and ?Hippotigris sp. in the material at her disposal.

The zebra is either Equus (Quagga) burchelli or E. (Hippotigris) zebra (Hoffstetter, 1950, p. 689) and, as the quaggas are more caballiform, the former is more likely. Bate's (1955) inclusion of "?Hippotigris sp." in the Wadi Derna and the Hagfet et-Tera faunas suggests that she was using the subgeneric name for $E$. burchelli, as did Mendrez (1966). Moreover, she (1955, p. 286) later referred to Arambourg's (Arambourg et al., 1934; Arambourg, 1938) reports of a small equid by the same name, whereas Romer $(1928,1935)$ referred to all the zebra material recovered from Mauritania as E. burchelli mauritanicus. The records of $E$. burchelli from Haua Fteah, Hagfet et-Tera, and Hagfet ed-Dabba constitute the first records for zebra from the Middle or Upper Palaeolithic of Cyrenaica and extend its distribution at that time from Mauritania eastwards, but not as far as the Nile valley or the hills of the eastern desert.

Blank (1956) also reported Bos primigenius and B. ibericus; the latter is a smaller form sometimes considered to be a variety of $B$. primigenius, as is $B$. brachyceros (Zeuner, 1963). Romer (1935, p. 171) stated that "The only criterion for a distinction between $B$. primigenius and $B$. ibericus outside of size differences (which I have shown to be apparently invalid in the present material) lies in the structure of the horns. ... It is quite possible that no such type existed there [in Mauritania] in reality before the introduction of domestic cattle in Neolithic times." Jarman (1970, p. 241) said of B. ibericus, "A small form of wild Bos was distinguished in the Palaeolithic sites of North Africa by Pomel (1894) and most other authors have followed him in treating it as a separate species from the larger $B$. primigenius. The small form is now usually known as Bos ibericus, and is recorded by Arambourg (1934) and Vaufrey (1955) throughout the Palaeolithic succession of the area." Arambourg also claimed that the North African population of $B$. primigenius is distinguishable from the European forms. The specific status of $B$. ibericus, although recognised in many works, is probably no more valid than that of $B$. brachyceros.

The fauna from Hagfet et-Tera is thus as given by Blanc (1956) with the probable change of $E$. (A.) hydruntinus to $E$. ( $A$.) asinus africanus and the inclusion of $B$. ibericus within $B$. primigenius.

\section{HAGFET ED-DABBA}

Bate (1955) reported no faunal changes in the layers that yielded bone in this cave and treated all the vertebrate remains as a single assemblage. The identifiable taxa from within the Upper Layers I-III and Lower Layers IVvII are as follows: 


\begin{tabular}{lcc}
\hline & $\begin{array}{c}\text { Lower Levels } \\
\text { IV-VII }\end{array}$ & $\begin{array}{c}\text { Upper Levels } \\
\text { I-III }\end{array}$ \\
\hline $\begin{array}{l}\text { insectivorous bat } \\
\text { Crocidura sp. - white-tailed shrew }\end{array}$ & $\mathrm{X}$ & $\mathrm{X}$ \\
Panthera leo Linnaeus - lion & $\mathrm{X}$ & $\mathrm{X}$ \\
Vulpes sp. - fox & & $\mathrm{X}$ \\
Gerbillus sp. - gerbil & & $\mathrm{X}$ \\
Apodemus sp. - field mouse & $\mathrm{X}$ & $\mathrm{X}$ \\
Eliomys sp. - garden dormouse & $\mathrm{X}$ & $\mathrm{X}$ \\
Microtus cyrenae Bate - Cyrenaican fossil vole & $\mathrm{X}$ & $\mathrm{X}$ \\
Homoioceras sp. - extinct African buffalo & $\mathrm{X}$ & $\mathrm{X}$ \\
Bos or Homoioceras - wild ox or extinct African buffalo & $\mathrm{X}$ & $\mathrm{X}$ \\
Ammotragus sp. - Barbary sheep & $\mathrm{X}$ & $\mathrm{X}$ \\
?Antilope sp. - ?antelope & $\mathrm{X}$ & $\mathrm{X}$ \\
Gazella sp. - gazelles & $\mathrm{X}$ & $\mathrm{X}$ \\
Hippotigris sp. - zebra & & $\mathrm{X}$ \\
Rhinoceros sp. - rhinoceros & $\mathrm{X}$ & \\
?Gyps sp. - vulture & $\mathrm{X}$ & $\mathrm{X}$ \\
Testudo sp. - small land tortoise & & \\
\hline
\end{tabular}

The fauna recognised by Bate (1955) agrees with others thus far reviewed. The ?Antilope remains are from "perhaps ... a large antelope" and may therefore represent Alcelaphus buselaphus, the hartebeest, which would otherwise constitute a marked absence. Hippotigris probably represents Equus burchelli.

\section{Comparison with the Fauna from the Synchronous Levels from the Caves of Ksâr 'Akil, Lebanon, and Wady el-Mughara and Shukbah, Palestine}

The Cave of Ksâr 'Akil contains Palaeolithic remains, with a radiocarbon date of $28,000 \pm 380$ B.C. at $6.75 \mathrm{~m}$ below the surface, and are associated with "Aurignacian" remains (Higgs, 1967, p. 39). As the Kom Ombo fauna approximately extends from 15,000 to 10,000 B.C. and as the 6.75 m level at Ksâr 'Akil may be considered equivalent to Level viII, only the upper layers at Ksâr 'Akil are comparable with the Kom Ombo sites. Comparison is therefore made with the fauna from Levels I to VII or VIII.

The most striking difference is in the presence of three deer, red deer (Cervus elaphus), roe deer (Capreolus capreolus), and Iranian deer (Dama mesopotamica), the wild goat (Capra aegragus), wolf (Canis lupus), badger (Meles sp.), marten (Martes cf. martes), brown bear (Ursus arctos) and wild cat (Felis sylvestris). Hyaena is not known from this level, although the spotted hyaena (Crocuta crocuta) occurs from levels XIX to XXXIII (Hooijer, 1961).

The presence of the carnivores can be attributed to their habits of denning in caves and thus being present to leave remains should one die in the cave, whereas in Kom Ombo and other Nilotic sites the chance of a carnivore dying and not being either scavenged or otherwise disposed of would be small. The deer occupy open woodland or open country with 
small wooded areas and do not indicate wet or generally moist conditions throughout the year (Higgs, 1967). The goat and roe deer are capable of inhabiting semi-arid broken country, and feeding on a variety of shoots and leaves of trees and bushes, wild berries, and grasses (Harrison, 1968). The fauna from the upper levels of Ksâr 'Akil may therefore reflect only a more Eurasian aspect, in marked contrast to the Ethiopian aspect of the sites previously considered.

Lydekker (1887, p. 163) mentioned antler fragments and other specimens of a deer (Cervus sp.) from Wadi Halfa. This collection was not fully described and appears to have been lost. Because no cervids are reported from the Nile's Pleistocene deposits by any author except Lydekker, I consider his report unsubstantiated.

An interesting record is that of a possible hartebeest (?Alcelaphus) from Level viII, E4. Hooijer (1961, p. 45) identified a left $\mathbf{M}_{3}$ that measures 33 by 11 in length and breadth, respectively, measurements that agree with those of 8916 from the surface at Gebel Silsila III, Kom Ombo.

Bate (1937) reported the fauna from the caves at Wady el-Mughara and later (1942) that from Shukbah. Only the mammals reported from Level B and F-C at el Wad, Wady el-Mughara and from the Natufian "Mesolithic" Level B at Shukbah will be considered here. The fauna of the two horizons at Wady el-Mughara are similar to that at Ksâr 'Akil in the presence of roe, red and Iranian deer, wild goat and the scant remains of hartebeest, and to that from Shukbah in roe and Iranian deer, wild goat and hartebeest. But not only is a caballine horse present at Wady el-Mughara, but also an onager or hemione (Equus hemionus). The carnivores are again more common at both sites than at Kom Ombo, with spotted hyaena (Crocuta crocuta) also present at Shukba. The spotted hyaena and hartebeest were therefore still inhabiting the coastal regions of Palestine and Lebanon some 30,000 to 20,000 years ago.

It is notable that the spotted hyaena (Crocuta crocuta) appeared early in the record and the striped (Hyaena hyaena) later, but the spotted hyaena disappeared in the Neolithic in Mauritania (Romer, 1928, p. 96) and in the Near East, whereas the striped hyaena persists to the present day. The right $\mathbf{M}_{3}$ of a hartebeest (Bate, 1937, Fig. $7 \mathrm{~g}$ ) from Wady el-Mughara measured 30.5 by 10.5 in length and breadth (Hooijer, 1961, p. 45) which again agrees with those from Kom Ombo. Hartebeest are also known from Egyptian tombs (Flower, 1932, p. 437), from Haua Fteah, Cyrenaica (Higgs, 1967), Kom Ombo, Upper Egypt, and probably Wady el-Mughara and Shukbah, Palestine (Bate, 1937, 1942, respectively), and possibly from Ksâr 'Akil (Hooijer, 1961) between 30,000 and 10,000 B.C. There is discussion (Lydekker, 1926, p. 81) that hartebeest was present on the borders of Palestine until recent times. These records of remains support at least the presence of Alcelaphus sp. in Palestine during the Late Pleistocene and it may have persisted well into the Holocene and even to recent historical times. Moreover, there is no record of hartebeest from the Lower Pleistocene of Bethlehem (Hooijer, 1958) or the early Middle Pleistocene of 'Ubeidiya (Haas, 1966; Stekelis et al., 1969). 
The presence of Equus in the Palestinian deposits poses another problem. Bate $(1937,1942)$ reported $E$. hemionus and $E$. cf. hemionus from Wady el-Mughara levels F-B and Shukbah level B, respectively. Ducos (1970) compared the equid remains from Mureybit, Syria, and concluded that they represent not $E$. hemionus hemippus but $E$. (Asinus) sp., which he referred to $E$. (A.) palestinae Ducos 1968 but also admitting that it might be $E$. (A.) hamar Hamilton Smith 1841. Moreover, Ducos (1970) commented on the presence of an African rather than an Asiatic mediumsized equid in the Neolithic deposits of Palestine and Syria. His observation supports the occurrence of other African taxa (Alcelaphus sp. and Oryx sp.) in the region in Late Pleistocene times and also suggests that there has been replacement in the Arabian peninsula of taxa now considered African rather than Asiatic by taxa from Central Asia, and that this replacement has continued into northeastern Africa, where Equus burchelli has been replaced by $E$. asinus (Churcher, In press).

\section{Summary}

The vertebrate faunas of the archaeological sites excavated by the Canadian Prehistoric Expedition to Egypt in 1962-63 in the Plain of Kom Ombo, Upper Egypt, comprise 40 taxa: three fish, one reptile, 22 birds and 14 mammals, as well as indeterminate material.

The faunal elements reflect and confirm the interpretation that the Kom Ombo Plain was better watered between 15,000 and 10,000 B.C. than at present, that riverine forest or woodland existed along the banks of the channels of the River Nile, that there were swamps and savannas or bushveldt between the river and the adjacent hills, which were covered with orchard savanna.

The recovered faunal elements record the hunting activities of the Sebilian, Sebekian, Silsilian, Halfan, Menchian and other prehistoric peoples, who all took larger game animals such as hippopotamus, bubal hartebeest, wild cattle, as well as smaller antelope and hares. The Nile catfish was also a common source of food. Waterfowl provided a major source of protein for the Sebekian and probably also the Sebilian peoples, but was apparently neglected by the Silsilian.

Comparison of the Kom Ombo faunal sample with other Nilotic sites of similar age and that from Haua Fteah, Cyrenaica, gives similar faunal spectra, when allowances are made for present distributional patterns. Comparison with faunas from the caves at Ksâr 'Akil and Mount Carmel (Shukbah and Wady el-Mughara) show obvious differences that indicate the relatively greater Eurasian component in these faunas. 


\section{Acknowledgments}

I thank Dr. P. E. L. Smith, Director of the Canadian Expedition, for his patience in explaining the circumstances surrounding many aspects of the collection of the vertebrate specimens and for allowing me the extended time necessary to complete this report, and Dr. Loris S. Russell, then Chief Biologist, Royal Ontario Museum, for bringing the project to my attention. I owe grateful thanks also to Dr. C. A. Reed, Director of the Yale Expedition, for providing me with his and Mrs. P. F. Turnbull's unpublished results, and to Dr. R. J. Fulton, of the Canadian Expedition and the Geological Survey of Canada, for reading the section on the geology of the various sites to ensure its general accuracy.

Dr. R. L. Peterson and Miss Judith L. Eger of the Department of Mammalogy, Dr. E. J. Crossman, Department of Ichthyology and Herpetology, and Dr. H. G. Savage, Research Associate in the Department of Ornithology, ROM, all assisted me in my researches by allowing me to examine comparative material and assisting me with the identifications. Dr. A. G. Edmund, Department of Vertebrate Palaeontology, Rom, also allowed me to examine comparative material in his care and allocated the catalogue numbers for the specimens.

Mr. Gordon Gyrmov, Chief Technician, Department of Vertebrate Palaeontology, prepared some of the larger specimens, and Mr. John E. Cameron, my assistant during June, July, and August 1969, and Mr. Wesley J. White, my assistant from October 1969 onwards, sorted, prepared, and catalogued the remainder. Miss Sheila V. Freeman typed the manuscript, and Miss E. Anne Holland assisted in drawing the maps and line diagrams. Mr. Leighton Warren, Department of Photography, Rом carried out the photography necessary for the line diagrams and halftone plates. Mr. Peter Buerschaper prepared a cranial and pectoral skeleton of Clarias anguillaris, which had been provided at short notice by Dr. Samy Gorgy, Director of the Institute of Oceanography and Fisheries, Kayed-Bey, Alexandria, Egypt. The various large and small tasks that these persons performed have all contributed to the compilation of this report.

Last, I sincerely thank Dr. T. S. Parsons, Department of Zoology, University of Toronto, Dr. L. S. Russell of the RoM, and Dr. P. E. L. Smith of the Université de Montréal for reading the manuscript in its entirety and for offering their criticisms and suggestions. Dr. Alan W. Gentry of the Department of Mammals, British Museum (Natural History), London, and Dr. Karl W. Butzer of the Department of Anthropology and Geography, University of Chicago, also read and commented on aspects of the work.

To all these persons and to the members of both the Canadian and Yale Expeditions, I offer my thanks for their help.

Dr. Loris S. Russell deserves my special thanks and appreciation for suggesting the work, for maintaining an interest in it during the many vicissitudes that plagued it, and for assisting in its final publication. 


\section{Literature Cited}

ANSELL, W. F. H.

1971 Order Artiodactyla pp. 1-84. In Meester, J. and H. W. Setzer, eds. The mammals of Africa; an identification manual, pt. 15. City of Washington, Smithsonian Institution Press.

ARAMBOURG, C.

1938 Mammifères fossiles du Maroc. Mém. Soc. Sci. Nat. Maroc, vol. 46, pp. $1-74$.

ARAMBOURG, C., M. BOULE, H. VALlois and R. VERNEAU

1934 Les grottes paléolithiques de Béni-Ségòual (Algérie). Archs. Inst. Paléont. Hum., mém. 13, pp. 1-242.

ARKELL, A. J.

1949 Early Khartoum; an account of the excavation of an early occupation site carried out by the Sudan Government Antiquities Service in 1944-5. London, Oxford University Press. 145 pp.

BATE, D. M. A.

1937 Palaeontology; the fossil fauna of the Wady el-Mughara Caves, pp. 137-233. In Garrod, D. A. E., and D. M. A. Bate. The Stone Age of Mount Carmel; excavations at Wady el-Mughara. Report Joint Expedition British School Archaeology Jerusalem and American School Prehistoric Research 1929-1934, vol. 1, pt. 2. Oxford, Clarendon Press. 240 pp.

1942 The fossil mammals of Shukbah, app. 1, pp. 15-20. In Garrod, D. A. E., and D. M. A. Bate. Excavations at the cave of Shukbah, Palestine, 1928. Proc. Prehist. Soc., n.s., vol. 8, pp. 1-20.

1949 A new African fossil long-horned buffalo. Ann. Mag. Nat. Hist. London, ser. 12, vol. 2, pp. 396-398.

1951 The mammals from Singa and Abu Hugar, pp. 1-28. In The Pleistocene fauna of two Blue Nile sites. Fossil Mammals of Africa, no. 2. London. Printed by Order of the Trustees of the British Museum. 50 pp.

1955 Vertebrate faunas of Quaternary deposits in Cyrenaica, app. A, pp. 274-291. In McBurney, C. B. M., and R. W. Hey. Prehistory and Pleistocene geology in Cyrenaican Libya. Cambridge, Cambridge University Press. 315 pp.

BLANC, G. A.

1956 Sulla esistenza di Equus (Asinus) hydruntinus Regàlia nel Pleistocene del Nord Africa. Boll. Soc. Geol. Ital., vol. 75, pp. 176-187.

BOHLKEN, H.

1962 Probleme der Merkmalsbewertung am Säugetiersschädel, dargestellt am Beispiel des Bos primigenius Bojanus 1827. Gegenbaurs Morph. Jb., vol. 103, pp. 509-661.

BOULE, M.

1899 Observations sur quelques équidés fossiles. Bull. Soc. Géol. Fr., ser. 3, vol. 27, pp. 531-542.

BOULENGER, G. A.

1909 Catalogue of the freshwater fishes of Africa in the British Museum (Natural History). I. London. Printed by Order of the Trustees of the British Museum. 373 pp. 
BOULENGER, G. A.

1911 Catalogue of the freshwater fishes of Africa in the British Museum (Natural History). II. London. Printed by Order of the Trustees of the British Museum. 529 pp.

BUTZER, K. W.

1959 Studien zum vor- und früheschichtlichen Landschaftswandel der Sahara. III. Die Naturlandschaft Agyptens während der Vorgeschichte und der Dynastischen Zeit. Abh. Math.-Naturw. Kl. Acad. Wiss. Mainz, no. 2, pp. 46-122.

BUTZER, K. W. and C. L. HANSEN

1965 On Pleistocene evolution of the Nile Valley in southern Egypt. Can. Geogr., vol. 9, pp. 74-83.

1968 Desert and River in Nubia; geomorphology and prehistoric environments at the Aswan Reservoir. Madison, University of Wisconsin Press. 562 pp.

CATON-THOMPSON, G.

1952 Kharga Oasis in prehistory. London, University of London, Athlone Press. 213 pp.

CHURCHER, C. S.

1972 Preliminary report on the fauna of Late Palaeolithic sites in Upper Egypt. Science, vol. 177, no. 4045, pp. 259-261.

In press

The relationships of the late Pleistocene vertebrate fauna from Kom Ombo, Upper Egypt. In Rushdi Said and B. H. Slaughter, eds. Contributions to the paleontology of Africa. Proc. 75th Anniv. Geol. Surv. Egypt, Ann. Geol. Surv. Egypt.

COOKE, H. B. S.

1943 Cranial and dental characters of the recent South African Equidae. S. Afr. J. Sci., vol. 40, pp. 254-257.

CRANE, H. R. and $J$. B. GRIFFIN

1965 Gebel Silsilah site, Egypt. M-1551; University of Michigan radiocarbon dates X. Radiocarbon, vol. 7, pp. 123-152.

1966 Gebel Silsilah series, Egypt. M-1641, Gebel Silsilah, Locality III, Square 14J, Level 1. M-1642, Gebel Silsilah, Locality III, Squares 17-0 and 18-0; University of Michigan radiocarbon dates XI. Radiocarbon, vol. 8, pp. 256-285.

DUCOS, P.

1968 L'origine des animaux domestiques en Palestine. Publ. Inst. Préhist. Univ. Bordeaux, mém. 6, pp. 1-191.

1970 The Oriental Institute excavations at Mureybit, Syria: Preliminary report on the 1965 campaign, Part IV: Les restes d'Equidés. Journal of Near Eastern Studies, vol. 29, no. 4, pp. 273-289.

ELLERMAN, J. R. and T. C. S. MORRISON-SCOTT

1951 Checklist of Palaearctic and Indian mammals, 1758-1946. London. Printed by Order of the Trustees of the British Museum. 810 pp.

ELLERMAN, J. R., T. C. S. MORRISON-SCOTT and R. W. HAYMAN

1953 South African mammals, 1758-1951: a reclassification. London. Printed by Order of the Trustees of the British Museum. $363 \mathrm{pp}$.

ETCHECOPAR, R. D. and F. HUE

1964 Les oiseaux du nord de l'Afrique de la Mer Rouge aux Canaries. Paris, Editions N. Boubée. 606 pp. 
FAIRBRIDGE, R. W.

1962 New radiocarbon dates of Nile sediments. Nature, vol. 196, no. 4850 , pp. $108-110$.

FLOWER, S. S.

1932 Notes on the Recent mammals of Egypt, with a list of the species recorded from that kingdom. Proc. Zool. Soc. Lond., vol. 2, pp. $369-450$.

FULTON, R. J.

Ms 1964 Quaternary geology of the Kom Ombo Plain. Unpublished manuscript.

GAILlARD, C.

1934 Contributions à l'étude de la faune préhistorique de l'Égypte. Archs. Mus. Hist. Nat. Lyon, vol. 14, mém. 3, pp. 1-125.

GAUTIER, A.

1968 Mammalian remains of the northern Sudan and southern Egypt, pp. 80-99. In Wendorf, F., ed. The prehistory of Nubia. Vol. 1. Fort Burgwin Research Center, Publication no. 5 and Southern Methodist University Contributions in Anthropology no. 2. Taos, N.M., Fort Burgwin Research Center and Southern Methodist University Press. 531 pp.

GENTRY, A. W.

1966 Fossil Antilopini of East Africa. Fossil Mammals of Africa, no. 20. Bull. Br. Mus. Nat. Hist., Geol., vol. 12, no. 2, pp. 45-106.

1967 Pelorovis oldowayensis Reck, an extinct bovid from East Africa. Fossil Mammals of Africa, no. 22. Bull. Br. Mus. Nat. Hist., Geol., vol. 14 , no. 7, pp. 245-311.

GREENWOOD, P. H.

1968 Fish remains, pp. 100-109. In Wendorf, F., ed. The prehistory of Nubia. Vol. 1. Fort Burgwin Research Center, Publication no. 5 and Southern Methodist University Contributions in Anthropology no. 2. Taos, N.M., Fort Burgwin Research Center and Southern Methodist University Press. $531 \mathrm{pp}$.

GREENWOOD, P. H., D. E. ROSEN, S. H. WEITZMAN and G. S. MYERS

1966 Phyletic studies of teleostean fishes, with a provisional classification of living forms. Bull. Am. Mus. Nat. Hist., vol. 131, art. 4, pp.1-455.

HAAS, G.

1966 On the vertebrate fauna of the Lower Pleistocene site 'Ubeidiya. The Lower Pleistocene of the central Jordan valley. The excavations at 'Ubeidiya, 1960-1963. Jerusalem, Israel Academy of Sciences and Humanities. $68 \mathrm{pp}$.

HAMILTON SMITH, C. L.

1841 The natural history of horses. The Equidae or genus Equus of Authors. Mammalia, Vol. 12. Jardine, W., ed. The Naturalist's Library, Vol. 21. Edinburgh, W. H. Kizars, 352 pp.

HARRISON, D. L.

1968 The mammals of Arabia. Vol. 2. Carnivora. Hyracoidea. Artiodactyla. London, E. Benn, pp. 193-381.

HIGGS, E. S.

1967 Environment and chronology-the evidence from mammalian fauna, pp. 16-44. In McBurney, C. B. M., The Haua Fteah (Cyrenaica) and the Stone Age of the south-east Mediterranean. Cambridge, Cambridge University Press. 387 pp. 
HOFFSTETTER, R.

1950 La structure des incisives inférieures chez les Équidés modernes. Importance dans la classification des Zèbres-Couaggas. Bull. Mus. Hist. Nat., ser. 2, vol. 22, pp. 684-692.

HOOGSTRAAL, $\mathrm{H}$.

1963 A brief review of the contemporary land mammals of Egypt (including Sinai). 2. Lagomorpha and Rodentia. J. Egypt. Publ. Hlth. Ass., vol. 38 , pp. $1-35$.

1964 A brief review of the contemporary land mammals of Egypt (including Sinai). 3. Carnivora, Hyracoidea, Perissodactyla, and Artiodactyla. J. Egypt. Publ. Hlth. Ass., vol. 39, pp. 205-239.

HOOIJER, D. A.

1950 The fossil Hippopotamidae of Asia, with notes on the recent species. Zool. Verh. Leiden, no. 8, pp. 1-124.

1958 An early Pleistocene mammalian fauna from Bethlehem. Bull. Br. Mus. Nat. Hist., Geol., vol. 3, no. 8, pp. 265-292.

1961 The fossil vertebrates of Ksâr 'Akil, a Palaeolithic shelter in the Lebanon. Zool. Verh. Leiden, no. 49, pp. 1-68.

JARMAN, M. R.

1970 The prehistory of Upper Pleistocene and Recent cattle. Part 1: East Mediterranean with reference to north-west Europe. Proc. Prehist. Soc., 1969, n.s., vol. 35, no. 11, pp. 236-266.

LEIGH, E. G., JR., and K. W. BUTZER

1968 Fossil Mollusca from the Kom Ombo Plain, app. G, pp. 509-511. In Butzer, K. W., and C. L. Hansen. Desert and River in Nubia; geomorphology and prehistoric environments at the Aswan Reservoir. Madison, University of Wisconsin Press. 562 pp.

LOVERIDGE, A. and E. E. WILLIAMS

1957 Revision of the African tortoises and turtles of the suborder Cryptodira. Bull. Mus. Comp. Zool. Harv., vol. 115, no. 6, pp. 163-557.

LYDEKKER, R.

1887 On a molar of a Pliocene type of Equus from Nubia. Q. J. Geol. Soc. Lond., vol. 43, pp. 161-164.

1926 The game animals of Africa. 2d. ed. Rev. by J. G. Dollman. London, Rowland Ward. 483 pp.

MARKS, A. E.

1968 The Sebillian Industry of the Second Cataract, pp. 461-531. In Wendorf, F., ed. The prehistory of Nubia. Vol. 1. Fort Burgwin Research Center, Publication no. 5 and Southern Methodist University Contributions in Anthropology no. 2. Taos, N.M., Fort Burgwin Research Center and Southern Methodist University Press. 531 pp.

MARTIN, F.

1968 Pleistocene mollusks from Sudanese Nubia, pp. 56-79. In Wendorf, F., ed. The prehistory of Nubia. Vol. 1. Fort Burgwin Research Center, Publication no. 5 and Southern Methodist University Contributions in Anthropology no. 2. Taos, N.M., Fort Burgwin Research Center and Southern Methodist University Press. 531 pp.

MENDREZ, C.

1966 On Equus (Hippotigris) cf. burchelli (Gray) from 'Sterkfontein Extension'. Transvaal. South Africa. Ann. Transv. Mus., vol. 25, no. 5 , pp. $91-97$. 
NAVILLE, E. and H. R. HALL

1913 The xith Dynasty temple at Deir el-Bahari. Part 3. Egypt Explor. Fund, mem. 32, pp. 1-36.

NICOLL, M. J.

1919 Handlist of the birds of Egypt. Minister of Public Works, Egypt. Zoological Service Publication, no. 29. Cairo, Government Press. $119 \mathrm{pp}$.

OAKLEY, K. P.

1965 The antiquity of the new Kom Ombo skull. Man, vol. 65, art. 96, p. 104.

PERKINS, D.

1965 Three faunal assemblages from Sudanese Nubia. Kush, vol. 13, pp. 56-61.

PETIT, M.

1939 Anatomie des molaires des equidés. Thèse de Docteur ès Sciences Naturelles, Université de Paris. Toulouse, Imprimerie Toulousaine Lion. 328 pp.

PETROCCHI, G.

1940 Ricerche preistoriche in Cirenaica. Africa Ital., vol. 7, no. 1-2, pp. $1-34$.

PEYER, B.

1928 Ergebnisse der Forschungsreisen Prof E. Stromers in den Wüsten Ägyptens. v. Tertiäre Wirbeltiere. 2. Die Welse des ägyptischen Alttertiärs nebst einer kritischen Übersicht über alle fossilen Welse. Abh. Bayer. Akad. Wiss., Math.-Naturw. Abt., vol. 32, abh. 3, pp. $1-61$.

POMEL, A.

1894 Boefs-taureaux. Mon. Carte. Géol. Algérie (Pal.), no. 3, pp. 1-106. QUINN, J. H.

1957 Pleistocene Equidae of Texas. Rep. Invest. Bur. Econ. Geol. Univ. Texas, no. 33, pp. 1-51.

REED, C. A.

1961 Osteological evidence for prehistoric domestication in southwestern Asia. Z. Tierzücht. ZüchtBiol., vol. 76, pp. 31-38.

1965 A human frontal bone from the Late Pleistocene of the Kom Ombo Plain, Upper Egypt. Man, vol. 65, art. 95, pp. 101-104.

1969 The pattern of animal domestication in the prehistoric Near East, pp. 361-380. In Ucko, P. J., and G. W. Dimbleby, eds. The domestication and exploitation of plants and animals. London, Duckworth. $581 \mathrm{pp}$.

REED, C. A. and P. F. TURNBULL

1969 Late Pleistocene mammals from Nubia, pp. 55-56. In van Zinderen Bakker, E. M., ed. Palaeoecology of Africa and of the surrounding islands and Antarctica. Vol. IV, covering the years 1966-1968. Cape Town, A. A. Balkema. 274 pp.

MS 1967 Fossil mammals from the Late Pleistocene of Nubia. Unpublished manuscript.

REYNOLDS, S. H.

1922 A monograph on the British Pleistocene Mammalia. Vol. III, Part I. 
Hippopotamus. Palaeontogr. Soc. 1920, Monogr. 74, pp. 1-38.

1939 A monograph on the British Pleistocene Mammalia. Vol. III, Part VI.

The Bovidae. Palaeontogr. Soc. 1938, Monogr. 92, pp. 1-65.

ROBINSON, P.

1966 Fossil occurrence of murine rodent (Nesokia indica) in the Sudan. Science, vol. 154, no. 3746, p. 264.

RODE, P.

1943 Mammifères ongulés de l'Afrique Noire, Première Partie. Famille des Bovidés (Buffles, Antilopes, Gazelles). Faune de l'Empire Français, vol. 2. Paris, Librairie Larose. 123 pp.

ROMER, A. S.

1928 Pleistocene mammals of Algeria; fauna of the Paleolithic station of Mechta-el-Arbi, pp. 79-163. In Pond, A. W. A contribution to the study of prehistoric man in Algeria, North Africa. Bull. Logan Mus., vol. 1, no. 2, pp. 1-189.

1935 Part II. Mammalian remains from some Paleolithic stations in $\mathrm{Al}-$ geria, pp. 165-184. In Pond, A. W., L. Chapuis, A. S. Romer, and F. C. Baker. Prehistoric habitation sites in the Sahara and North Africa. Bull. Logan Mus., no. 5, pp. 1-244.

SANDFORD, K. S.

1934 Paleolithic man and the Nile valley in Upper and Middle Egypt; a study of the region during Pliocene and Pleistocene times. University of Chicago Oriental Institute Publication, vol. 18 and Prehistoric Survey of Egypt and West Asia, vol. 3. Chicago, University of Chicago Press. $131 \mathrm{pp}$.

SANDFORD, K. S. and W. J. ARKELL

1933 Paleolithic man and the Nile Valley in Nubia and Upper Egypt; a study of the region during Pliocene and Pleistocene times. University of Chicago Oriental Institute Publication, vol. 17 and Prehistoric Survey of Egypt and West Asia, vol. 2. Chicago, University of Chicago Press. 92 pp.

SETZER, H. W.

1956 Mammals of the Anglo-Egyptian Sudan. Proc. U.S. Natn. Mus., vol. 106 , no. 3367 , pp. $447-587$.

SMITH, P. E. L.

1964 Radiocarbon dating of a Late Paleolithic culture from Egypt. Science, vol. 145 , no. 3634 , p. 811.

1966a New prehistoric investigations at Kom Ombo (Upper Egypt). Zephyrus, vol. 17, pp. 33-45.

1966b The Late Paleolithic of Northeast Africa in the light of recent research. In Clark, J. D. and F. C. Howell, eds. Recent Studies in Paleoanthropology. Am. Anthrop., vol. 68, no. 2, pt. 2, pp. 326-355.

1967 New investigations in the Late Pleistocene archaeology of the Kom Ombo Plain (Upper Egypt). Quaternaria, vol. 9, pp. 141-152.

1968 A revised view of the later Palaeolithic of Egypt, pp. 391-399. In La préhistoire; problèmes et tendances. Paris, Editions du Centre National de la Recherche Scientifique. 529 pp.

STEHLIN, H. G. and P. GRAZIOSI

1935 Ricerche sugli asinidi fossili d'Europa. Abh. Schweiz. Pal. Ges., vol. 56, mém. 3, pp. 1-73. 
STEKELIS, M., O. BAR-YOSEF and T. SCHICK

1969 Archaeological excavations at Ubeidiya, 1964-1966. The Pleistocene of the central Jordan valley. The excavations at 'Ubeidiya. Jerusalem, Israel Acadamy of Sciences and Humanities. 29 pp.

STROMER, E.

1904 Nematognathi aus dem Fajûm und dem Natronthale in Aegypten. Neues Jb. Miner. Geol. Paläont., vol. 1, pp. 1-7.

VAUFREY, R.

1955 Préhistoire de l'Afrique. I. Le Maghreb. Publications de l'Institut des Études de Tunis, Iv. Paris, Masson. 458 pp.

VIGNARD, E.

1923 Une nouvelle industrie lithique, le Sébilien. Bull. Inst. Fr. Arch. Orient., vol. 22, pp. 1-76.

1934 Les microburins tardenoisiens du Sébilien. Congr. Préhist. France, Xe Sess., pp. 66-106.

1955 Un kjoekkenmödding sur la rive droite du Wadi-Shaït dans le nord de la plaine de Kom-Ombo (Haute-Egypte). Bull. Soc. Préhist. Fr., vol. 52, pp. 703-708.

VILLIERS, A.

1958 Tortues et crocodiles de l'Afrique noire française. Institut Français d'Afrique Noire, Initiations Africaines 15. Dakar, Institut Français d'Afrique Noire. 354 pp.

WENDORF, F.

1968 Summary of Nubian prehistory, pp. 1041-1069. In Wendorf, F., ed. The Prehistory of Nubia. Vol. II. Fort Burgwin Research Center Publication no. 5 and Southern Methodist University Contributions in Anthropology no. 2. Taos, N.M., Fort Burgwin Research Center ZEUNER, F. E. and Southern Methodist University Press, pp. 535-1084.

1963 A history of domesticated animals. London, Hutchinson. 560 pp. 


\section{Appendix}

Catalogue of specimens obtained from the archaeological deposits in the Kom Ombo Plain arranged by zoological taxon. Each site is named and its abbreviation given in parentheses. Figures in square brackets following each site or subdivision of each site give the estimated minimum number of individuals from which the sample recovered could have been derived; for example, "[22-167]" indicates that 167 specimens are identified and could have been derived from a minimum of 22 individuals. The true number of individuals represented probably lies between these two figures.

Each specimen or set of specimens is briefly described, followed within parentheses by its catalogue number or numbers in the Collection of Fossil Vertebrates, ROM, and its site designation. Lower case letters following immediately after the catalogue numbers indicate similar specimens possessing the same number but identified individually by the letter. Lower case letters or numbers separated from each other by commas and followed by a dash indicate similar specimens from the archaeological square or level indicated by the designation following the dash. Colons separate specimens that do not derive from the same archaeological provenance but may be catalogued under the same number. Semicolons separate specimens that are recognisably distinct by their descriptions and have different catalogue numbers. For example, " $8000 \mathrm{a}, \mathrm{b}-12 \mathrm{~J} / 2 \mathrm{a}$ : c and d-14K/3f" indicates that there are four specimens $\mathrm{a}, \mathrm{b}, \mathrm{c}$, and $\mathrm{d}$ catalogued under number 8000 , that specimens $\mathrm{a}$ and $\mathrm{b}$ derived from square $12 \mathrm{~J}$ and from level $2 \mathrm{a}$ within that square, while specimens $\mathrm{c}$ and derived from square $14 \mathrm{~K}$ and its level $3 \mathrm{f}$.

\section{PISCES}

\section{Clarias anguillaris - Nile catfish}

Oasis Depression (OD) [2-2]

Nearly complete skull (8001-A) lacking nasals, supraorbitals and dermal sphenoids; fragment comprising dermal ethmoids and parts of prefrontals (8002-A).

\section{Bayara (B)}

\section{Area $A[1-1]$}

Frontal, prefrontal and part of dermal ethmoid (8003).

\section{Gebel Silsila (GS)}

II [1-2]

Two fragments of skull roof (9066: and 9067).

III Surface and Subsurface, Mixed Sebilian and Sebekian - Level o [19-114]

Partial skull, lacking margins $(8004-14 \mathrm{~K} / 1 \mathrm{f})$; two braincase fragments (8005a, b-14K/1e); three partial juvenile skulls (8006-13K/1c: $8007-14 \mathrm{~J} /$ 2a: $8008-17 \mathrm{H}) ; 12$ dermethmoid or maxillary fragments $(8009 \mathrm{a}, \mathrm{b}-12 \mathrm{~L} / 1$ : c-13K/1a-1b: d, e-13K/1c: f-14J/1a: g, h, i, j \& k-14K/1f: 1-33?); three maxillary tooth row fragments $(8010 \mathrm{a}-12 \mathrm{~L} / 1: \mathrm{b}, \mathrm{c}-14 \mathrm{~J} / 2 \mathrm{a})$; two braincase fragments ( $8011 \mathrm{a}, \mathrm{b}-14 \mathrm{~K} / 1 \mathrm{f})$; skull roof fragment (8012); supraoccipital (8013); right palatine and palatine fragment $(8014 \mathrm{a}-12 \mathrm{~L} / 1 \mathrm{l}$ b-13K/1c); 
basisphenoid fragments (8015a, b-13K/1c: c-14J/2a: d-14K/1e: e-20K); two basioccipital fragments $(8016 \mathrm{a}-13 \mathrm{~J} / 2 \mathrm{a}: \mathrm{b}-14 \mathrm{~J} / 2 \mathrm{a})$; eight left articulars 8017-12L/1: 8018-13J/1b: 8019, 8020-13K/1a-1b: 8021, 8022-14J/2a: 8023-14K/1e: 8024-21K); twelve right articulars (8025: 8026: 8027, $8028-12 \mathrm{~L} / 1$ : $8029-13 \mathrm{~K} / 1 \mathrm{a}-1 \mathrm{~b}: 8030,8031,8032-13 \mathrm{~K} / 1 \mathrm{c}: 8033-14 \mathrm{~J} / 2 \mathrm{a}$ : 8034-17H: 8035-20F: 8036-20M); three left and one right dentary fragments $(8037 \mathrm{a}-13 \mathrm{~K} / 1 \mathrm{a}-1 \mathrm{~b}: \mathrm{b}-13 \mathrm{~K} / 1 \mathrm{c}: \mathrm{c}-20 \mathrm{M}$ : d-14J/2a, respectively); left and right quadrate $(8038-12 \mathrm{~L} / 1: 8039-14 \mathrm{~J} / 2 \mathrm{a})$; three left and six right cleithra $(8040-13 \mathrm{~K} / 1 \mathrm{e}: 8041-14 \mathrm{~J} / 2 \mathrm{a}: 8042-14 \mathrm{~K} / 1 \mathrm{f}$ : 8043: 8044: 80459L/1c: $8046-13 \mathrm{~K} / 1 \mathrm{c}: 8047,8048-14 \mathrm{~J} / 2 \mathrm{a}$ respectively); one right coracocleithrum (8049-20M); one left cleithral pectoral fossa $(8050-14 \mathrm{~J} / 2 \mathrm{a})$; one left and two right coracoids (8051-12L/1: 8052, 8053-13K/1c); two right precoracoids (8054: 8055-12L/1); left clavicle (8056-13K/1a-1b); one right pectoral spine, lacking tip (8057); three left and three right pectoral spine proximal ends (8058a: b-12L/1c: c-18O/2b: d-12L/1: e-14J/2a: f-18G); two postcranial vertebrae (8059a: b-14J/1); two pairs of associated dorsal vertebrae $(8060 \mathrm{a}-12 \mathrm{~L} / 1: \mathrm{b}-14 \mathrm{~J} / 1) ; 22$ assorted dorsal vertebrae (8061a, b, c, d, e, f, g, h: i-12K/1: j, k, 1-12L/1: m, n, o, p, q-13K/1c: r-14J/1: s, t-14J/2a: u-17G: v-18O/2b); six caudal vertebrae (8062a, b, c, d, e, f).

III Sebekian-Level 1 [22-167]

Partial skull, lacking margins $(8063-14 \mathrm{~J} / 3 \mathrm{a})$; posterior half of skull, lacking basicranial region $(8064-9 \mathrm{O} / 1 \mathrm{~b})$; three damaged skulls, lacking margins and posterior portions $(8065-14 \mathrm{~J} / 3 \mathrm{a}: 8066-14 \mathrm{JK}: 8067-14 \mathrm{~K} / 2)$; posterior part of skull $(8068-14 \mathrm{~J} / 3 \mathrm{a})$; two crushed small skulls $(8069-13 \mathrm{~J} / 2 \mathrm{a}: 8070$ $13 \mathrm{~J} / 2 \mathrm{~b}) ; 15$ anterior dermethmoid, vomerine and associated areas $(8071 \mathrm{a}-$ 9N/2b: b-10M/1c: c-10M/1e: d-10M/1f: e-13K/2b: f-13K/2g: g-13K/ 14a: h-14I: i-14J/2b: j-14J/3a: k-14J/3b: $1-14 \mathrm{~K}-17 \mathrm{O} / 2 \mathrm{~b}: \mathrm{m}, \mathrm{n}-15 \mathrm{~J} / 2$ : $0-17 \mathrm{O} / 2 \mathrm{~b})$; nine frontal and braincase fragments $(8072-14 \mathrm{~J} / 3 \mathrm{a}: \mathrm{b}-14 \mathrm{~J} / 3 \mathrm{~b}$ : c-14K: d, e-14K-17O/1a-1b: f, g, h-14K/2b: i-18O/4); ventral surface of a braincase $(8073-14 \mathrm{~J} / \mathrm{SW} 1 / 4) ; 13$ fragments of braincase $(8074 \mathrm{a}, \mathrm{b}-10 \mathrm{M} /$ 1e: c-13K/27O: d, e-13K/2: f, g, h-13K/2b: i-13K/2e: j-13K/2i: k, 1$13 \mathrm{~K} / 14 \mathrm{a}: \mathrm{m}-15 \mathrm{~J} / 2)$; four supraoccipital fragments $(8442 \mathrm{a}-10 \mathrm{M} / 1 \mathrm{~b}$ : b$14 \mathrm{~K}-17 \mathrm{O} / 2 \mathrm{~b}$ : c-17L/2f: d-180/4); 13 skull roof fragments $(8075 \mathrm{a}, \mathrm{b}, \mathrm{c}-10 \mathrm{M}$ /1e: d, e-11L/1b: f-13K: g, h, i-13K/2a: j-13K/3: k, l, m-14J/3a); two dermsphenoid fragments (8076a-11L/1b: b-14K-170/2b); two left clavicle fragments $(8077 \mathrm{a}-11 \mathrm{~L} / 1 \mathrm{~b}: \mathrm{b}-14 \mathrm{~K}-17 \mathrm{O} / 2 \mathrm{~b}) ; 12$ left angulars $(8078-9 \mathrm{~N} /$ 2bcde: $8079-10 \mathrm{M} / 1 \mathrm{c}: 8080-13 \mathrm{~J} / 2 \mathrm{~b}: 8081-13 \mathrm{~J} / 2 \mathrm{~d}: 8082-13 \mathrm{~K} / 2 \mathrm{a}: 8083$, 8084-13K/2b: 8085-14K-17O/2b: 8086-180/4: 8087, 8088-180: 8089$20 \mathrm{M}) ; 14$ right angulars $(8090-9 \mathrm{~N} / 2 \mathrm{bcde}: 8091-10 \mathrm{~N} / 1 \mathrm{~b}: 8092-10 \mathrm{M} / 1 \mathrm{c}$ : 8093, 8094-13J/2d: 8095-13K/2c: 8096-13K/3: 8097-13K/14a: 8098 14J/3a: $8099-14 \mathrm{~K}-17 \mathrm{O} / 2 \mathrm{~b}: 8100-15 \mathrm{~J} / 2$ : $8101-16 \mathrm{M}: 8102,8103-17 \mathrm{O} /$ $2 \mathrm{~b})$; two right and three left dentary fragments with tooth plates (8104a13J/2e: b-14K-17O/2b: c, d-9N/2bcde: e-10M/1c); one juvenile right mandible $(8105-11 \mathrm{~L} / 1 \mathrm{~b})$; four posterior fragments of dentary $(8106 \mathrm{a}-$ $10 \mathrm{~N} / 1 \mathrm{~b}: \mathrm{b}-11 \mathrm{~L} / 1 \mathrm{~b}: \mathrm{c}-13 \mathrm{~K} / 2 \mathrm{i}: \mathrm{d}-17 \mathrm{~L} / 2 \mathrm{f})$; four left and three right quadrates $(8107,8108-13 \mathrm{~J} / 2 \mathrm{~b}: 8109-14 \mathrm{~K}-17 \mathrm{O} / 2 \mathrm{~b}: 8110-17 \mathrm{~L} / 2 \mathrm{f}: 8111-10 \mathrm{M} / 1 \mathrm{c}$ : $8112-13 \mathrm{~J} / 2 \mathrm{e}: 8113-17 \mathrm{~L} / 2 \mathrm{f}$ respectively); one left side pectoral girdle (8114-14K/2); four left and two right cleithra (8115-10M/1c: $8116-14 \mathrm{~J} /$ 3a: $8117-14 \mathrm{~K} / 2$ : $8118-14 \mathrm{~K} / 2 \mathrm{~b}: 8119-13 \mathrm{~K}: 8120-13 \mathrm{~K} / 2 \mathrm{i}$ respectively); one cleithral fragment $(8121-11 \mathrm{~L} / 1 \mathrm{~b})$; two left and one right coracocleithra 
(8122-14J/3a: 8123-14J/SW 1/4: 8124-14K/2b); four right coracoids $(8125-13 \mathrm{~K} / 2 \mathrm{i}: 8126,8127-15 \mathrm{~J} / 2: 8128-16 \mathrm{M} / 2 \mathrm{~b})$; one left and two right coracoprecoracoids $(8129,8130-13 \mathrm{~K} / 14 \mathrm{a}: 8131-14 \mathrm{~K}-17 \mathrm{O} / 2 \mathrm{~b})$; two left and two right pectoral spine proximal ends $(8132 \mathrm{a}-10 \mathrm{M} / 1 \mathrm{j}: \mathrm{b}-18 \mathrm{O}: \mathrm{c}-13 \mathrm{~J} /$ 2e: d-170/2b); spine tip $(8133-10 \mathrm{M} / 1 \mathrm{c})$; one postcranial vertebra $(8134$ $12 \mathrm{~L} / 2)$; two sets of three and one pair of associated dorsal vertebrae $8135 \mathrm{a}-13 \mathrm{~K} / 2 \mathrm{~b}$ : b-14J/3b: c-9O/1b, respectively); 19 assorted dorsal vertebrae $(8136 \mathrm{a}-10 \mathrm{~N} / 1 \mathrm{~b}: \mathrm{b}, \mathrm{c}, \mathrm{d}-12 \mathrm{~L} / 2$ : e-13J/2b: f, g, h-13J/2d: i-13K: j-13K/2a: k-13K/2b: 1, m, n, o-13K/2c: p-14J/3b: q-14K/3a: r, s-18O); four caudal vertebrae $(8137 \mathrm{a}-10 \mathrm{~N} / 1 \mathrm{~b}: \mathrm{b}-13 \mathrm{~J} / 2 \mathrm{e}: \mathrm{c}-14 \mathrm{~J} / 3 \mathrm{~b}: \mathrm{d}-17 \mathrm{P} / 1 \mathrm{~b})$.

III Mixed Sebekian and Silsilian - Level 2 [7-65]

Seven maxillary-dermethmoid areas $(8138 \mathrm{a}-13 \mathrm{I} / 1 \mathrm{:}$ b, c, d-13J/2b: e, f, g-14I/2a); skull roof fragment (8139-13I/1); supraoccipital (8140-13J/ $2 \mathrm{~b})$; two basicranial fragments ( $8141 \mathrm{a}-13 \mathrm{~J} / 2 \mathrm{~b}$ : b-14I/2a); two basioccipital areas (8142a-11J/1b: b-14J/2a); six left angulars (8143-12J/2b: 8144$12 \mathrm{~K} / 1 \mathrm{a}: 8145-12 \mathrm{~K} / 1 \mathrm{~b}: 8146-13 \mathrm{I} / 1: 8147,8148-13 \mathrm{~J} / 2 \mathrm{~b})$; six right angulars $(8149-9 \mathrm{~N} / 1 \mathrm{~b}: 8150-12 \mathrm{~K} / 1 \mathrm{a}: 8151-13 \mathrm{~J} / 2: 8152,8153,8154-13 \mathrm{~J} / 2 \mathrm{~b})$; left palatine (8155-12J); one left and two right dentary fragments $(8156 \mathrm{a}$ $12 \mathrm{~K} / 1 \mathrm{~b}: \mathrm{b}, \mathrm{c}-13 \mathrm{~J} / 2 \mathrm{~b}$ respectively); one left and one right quadrate (8157-11L/1a: 8158-13J/2b respectively); left opercular (8159-13I/1); three left and one right cleithrum $(8160,8161,8162,8163-13 \mathrm{~J} / 2 \mathrm{~b}$, respectively); one right coracoid $(8164-14 \mathrm{~J} / 2 \mathrm{a})$; one right pectoral spine, lacking tip (8165-13J/2b); four left and one right proximal ends of pectoral spines (8166a-9O/1a: b-12L/1b: c, d, e-13J/2b respectively); one left and one right pectoral spine shaft fragment $(8167 \mathrm{a}, \mathrm{b}-13 \mathrm{~J} / 2 \mathrm{~b}$ respectively); one spine tip (8168-12I/1a); three postcranial vertebrae (8169a$12 \mathrm{~K} / 1 \mathrm{~b}: \mathrm{b}, \mathrm{c}-13 \mathrm{~J} / 2 \mathrm{~b})$; four and two associated dorsal vertebrae $(8170 \mathrm{a}$, b-14I/2a); six dorsal vertebrae ( $8171 \mathrm{a}-11 \mathrm{~L} / 1 \mathrm{a}: \mathrm{b}, \mathrm{c}-12 \mathrm{~K} / 1 \mathrm{a}: \mathrm{d}, \mathrm{e}-13 \mathrm{~J} / 2 \mathrm{~b}$ : f-14I/2a); four caudal vertebrae (8172a, b, c, d-13J/2b).

III Silsilian - Level 3 [1-6]

Left supraorbital $(8173-9 \mathrm{~L} / 1 \mathrm{~d})$; two skull roof fragments $(8174 \mathrm{a}-9 \mathrm{~L} / 1 \mathrm{~d}$ : b-11J/1c); left opercular (8175-9L/1d); left cleithrum (8176-12J/1c); right pectoral spine shaft $(8177-11 \mathrm{~J} / 1 \mathrm{~d})$.

IX [1-2]

Fragment of right prefrontal (8178-5g); pharyngeal bar and tooth (8179-3).

$\mathrm{x}[2-8]$

Dermethmoid, right prefrontal and frontal fragments (8180); left frontal and sphenotic areas of skull (8181); skull fragments (8182a, b, c-5a); right articular (8183-5a); bases of two right pectoral spines (8184a, b-5a).

XI $[1-1]$

Part of shaft of ? pectoral spine (8185-2),

XIII - Sector 2 [2-2]

Dermethmoid and right prefrontal (8186) and other fragments; dermethmoid and left prefrontal fragment (8187).

XIII - Sector $2 a[1-1]$

Dermethmoid, left prefrontal and right frontal and vomer (8188).

XIII - Sector $3[1-1]$

Dermethmoid, prefrontal, frontal, and left sphenotic areas (8189).

XIII - Mound E [1-2]

Dermethmoid and prefrontal fragment of skull $(8190,8191)$. 
XIII - Mound $G$ [1-1]

Tip of pectoral spine (8192).

XIII - Mound K [1-1]

Vertebra lacking processes $(8193)$.

XIV [2-2]

One whole and one fragmentary left dentary (8194a, b respectively).

Xv [1-2]

Dermethmoid fragment (8195); skull fragment (8196).

Miscellaneous, near Localities III - VIIA [3-10]

Dermethmoid, prefrontal, and vomerine fragment (8197-5); dermethmoid

and vomerine fragment (8198-3); posterior frontal and braincase fragment (8199-3); dermethmoid fragment (8200-3); left articular (8201-3); hyoid fragments (8202a, b-3); unidentified (8203a, b, c-3).

Sebil Localities (S)

I [2-2]

Two left pectoral spines $(8204,8205-\mathrm{a})$.

III [3-3]

Damaged skull, lacking supraorbital, dermsphenoid, pteromastoid and basicranial regions (8206-e); two dermethmoid regions (8207a-a: b-e).

v [11-23]

Dermethmoid and frontal regions (8208-b); nine incomplete dermethmoid and vomerine regions $(8209 \mathrm{a}, \mathrm{b}, \mathrm{c}, \mathrm{d}, \mathrm{e}, \mathrm{f}, \mathrm{g}, \mathrm{h}, \mathrm{i})$; two right vomerine regions $(8210 \mathrm{a}, \mathrm{b})$; five braincase regions $(8211 \mathrm{a}, \mathrm{b}, \mathrm{c}, \mathrm{d}, \mathrm{e})$; two basisphenoid regions $(8212 \mathrm{a}, \mathrm{b})$; two supraoccipitals $(8213 \mathrm{a}, \mathrm{b})$; left articular (8214-a); and base of left pectoral spine (8215).

\section{Khor el-Sil Localities (KS)}

Ia [2-6]

Right posterior supraoccipital-pterotic region (9001, 9002); dermethmoid and vomerine region (9003); fronto-supraoccipital region (9004); two basioccipital-exoccipital portions $(9005,9006)$; base of right pectoral spine (9007).

II $a$ [1-3]

Right postorbital (9008); fragmentary right pterotic (9009a, b, c, d); left coracocleithral part of glenoid fossa of pectoral girdle (9010).

II $b$ [2-5]

Two partial braincases, frontal regions only $(9011,9012)$; vomerine plates (9013), basioccipital area (9014); base of ? right pectoral spine (9015).

III $(2)$ [1-3]

Hyoid fragment, anterior end (9016); bases of left and right pectoral spines (9017: 9018$)$.

III(3) [1-3]

Left hyoid (9019); right articular (9020); base of left pectoral spine (9021). IV $[1-4]$

Fragments of skull roof $(9022,9023,9024,9025)$.

Miscellaneous (II/III) [1-2]

Dermethmoid fragment (9026); right pectoral spine (9027).

Barbus bynni - African barbel

\section{Gebel Silsila (GS)}

III Surface and Subsurface, Mixed Sebekian and Silsilian - Level 0 [1-1]

Left anterior pharyngeal tooth and lower bony support (8410-14J/2a). 


\section{Lates niloticus - Nile perch}

Fatira Localities (F)

E [1-1]

Slightly damaged vertebral centrum (8411).

\section{Gebel Silsila (GS)}

III Sebekian-Level 1 [2-2]

Ceratohyal of large individual (8412-14J/3b); small hyoid fragment (8413).

\section{REPTILIA}

Trionyx triunguis - Nile soft-shelled turtle

Oasis Depression (OD) [1-2]

Middle portion of right ? second costal (8414); middle part of posterior surface of left hypoplastron (8415).

\section{Gebel Silsila (GS)}

III Surface and Subsurface, Mixed Sebekian and Silsilian - Level 0 [1-2]

Three associated cervical vertebrae $(8416-14 \mathrm{~K} / 1 \mathrm{f})$; isolated cervical vertebra (8417-17G).

III Sebekian-Level 1 [1-5]

Left squamosal fragment $(8418-13 \mathrm{~K} / 2 \mathrm{e})$; two isolated cervical vertebrae (8419-13K/2a: 8420-17P/1b); last cervical vertebra (8421-12L/2); end of a longbone, ? radius, ulna or metapodial $(8422-14 \mathrm{~K} / 2)$.

III Mixed Sebekian and Silsilian-Level 2 [1-1]

? First cervical vertebra (8423-13J/2b).

Sebil (S)

IV $[1-1]$

Lateral portion of a costal ( 8424$)$.

\section{AVES}

Phalacrocorax carbo - cormorant or shag

\section{Gebel Silsila (GS)}

III Surface and Subsurface, Mixed Sebekian and Silsilian - Level 0 [1-2]

Left humerus, distal end $(8425-22 \mathrm{I} / 1)$; right carpometacarpus, proximal end $(8426-13 \mathrm{~K} / 1 \mathrm{c})$.

III Sebekian-Level 1 [2-8]

Right coracoid, humeral end (8427-14J/3a); left coracoids, humeral and sternal ends (8428-14J/3a: $8429-10 \mathrm{M} / 1 \mathrm{e}$ respectively); left carpometacarpus, proximal end ( $8430-9 \mathrm{~N})$; left femur, distal end ( $8431-9 \mathrm{~N} / 2 \mathrm{bcde})$; left tarsometatarsus, proximal and distal ends $(8432-17 \mathrm{P} / 1 \mathrm{~b}: 8433-13 \mathrm{~J} / 2 \mathrm{~d}$ respectively); left tarsometatarsus, partial distal end (8434-180/4).

Ardea cinerea - grey heron

\section{Gebel Silsila (GS)}

III Surface and Subsurface - Level 0 [1-1]

Right tarsometatarsus, distal end ( $8440-180 / 2 b)$, probably from a subadult. III Sebekian-Level 1 [1-3]

Two tibial shaft fragments $(8441 \mathrm{a}-10 \mathrm{~N} / 1 \mathrm{~b}: \mathrm{b}-14 \mathrm{~J} / 3 \mathrm{~b})$; tarsometatarsal shaft fragment $(8443-13 \mathrm{~K} / 2 \mathrm{c})$. 
III Mixed Sebekian and Silsilian - Level 2 [1-1]

Left tarsometatarsus, distal end (8444-13J/2b).

x [1-1]

Right ulna, proximomedial surface of shaft (8445-5a).

Platalea leucorodia - spoonbill

Gebel Silsila (GS)

III Sebekian-Level 1 [1-1]

Ulna shaft fragment (8437-180/4).

IX Sebilian [1-1]

Right ulna, damaged distal end and part of shaft (8438-5)

Sebil (S)

I [1-1]

Sternum, anterior cardinal margin and coracoidal sulci (8439).

Phoenicopterus antiquorum - greater flamingo

Gebel Silsila (GS)

III Surface and Subsurface, Mixed Sebekian and Silsilian - Level 0 [1-2]

Fragmentary right ulna (8435-170/1b); ulna shaft fragment (8436-180).

Anser albifrons - white-fronted goose

Gebel Silsila (GS)

III Sebekian-Level 1 [1-1]

Left humerus, proximal end ( $8446-14 \mathrm{~J} / 3 \mathrm{~b})$.

Sebil (S)

$\mathrm{v}[1-2]$

Right humerus, proximal and distal ends only ( $8447 \mathrm{a}, \mathrm{b}$, respectively).

Anser fabalis - bean goose

Gebel Silsila (GS)

III Mixed Sebekian and Silsilian - Level 2 [1-1]

Left humerus, proximal end (8449-14K/2).

Branta sp. - brent or red-breasted goose

Gebel Silsila (GS)

III Sebekian-Level 1 [1-1]

Left scapula, glenoid portion (8450-14J/3b).

Tadorna ferruginea - ruddy sheld duck

Gebel Silsila (GS)

III Sebekian - Level 1 [1-1]

Femoral shaft fragment (8451-14J/3a).

III Mixed Sebekian and Silsilian - Level 2 [1-1]

Right humerus, damaged, distal end (8452-13J/2b).

Anas platyrhynchos-mallard

Gebel Silsila (GS)

III Surface and Subsurface, Mixed Sebekian and Silsilian - Level 0 [1-2]

Two femoral shaft fragments $(8453 \mathrm{a}: \mathrm{b}-13 \mathrm{~K} / 1 \mathrm{c})$.

III Sebekian-Level 1 [2-7]

Left coracoids, humeral ends $(8455-13 \mathrm{~J} / 2 \mathrm{e}: 8456-14 \mathrm{~J} / 3 \mathrm{~b})$; right coracoid,

humeral articulation $(8457-13 \mathrm{~K} / 2 \mathrm{c})$; right coracoid, sternal end $(8458$ - 
$17 \mathrm{O} / 2 \mathrm{~b})$; left and right carpometacarpi, proximal ends $(8459-13 \mathrm{~K} / 2 \mathrm{c}$ : 8460-12L/2) ; carpometacarpal, metacarpal III shaft fragment (8461-9N/ 2bcde).

III Mixed Sebekian and Silsilian - Level 2 [1-2]

Humeral shaft fragment (8462-13J/2b); femoral shaft fragment (8463$13 \mathrm{~J} / 2 \mathrm{~b}$ ).

Sebil (S)

III $[1-1]$

Left coracoid, slightly water-worn (8464).

Anas crecca-teal

Gebel Silsila (GS)

III Surface and Subsurface, Mixed Sebekian and Silsilian - Level 0 [1-4]

Right and left coracoids, sternal ends $(8465,8466-14 \mathrm{~J} / 2 \mathrm{a}$, respectively); left humerus, caput only (8467-14J/2a); right humerus, distal end only (8468-13K/1a-1b).

III Sebekian-Level 1 [1-7]

Right and left coracoids, humeral ends (8469-18O/4: 8470-14J/3a respectively); one left humerus, distal end only (8471-9N/2b); left carpometacarpus, proximal half $(8472-9 \mathrm{~N} / 2 \mathrm{~b})$; right carpometacarpus, distal half $(8473-12 \mathrm{~L} / 2)$; one humeral and one ulnar shaft fragment $(8474-12 \mathrm{~K} / 1 \mathrm{~b}$ : 8475-18P/1, respectively).

III Mixed Sebekian and Silsilian - Level 2 [3-4]

Left humerus, distal portion of shaft and end (8476-13J/2b); right humerus, distal end only ( $8477-12 \mathrm{~K} / 1 \mathrm{a})$; right humerus, distal end fragment (8478$11 \mathrm{~L} / 1 \mathrm{a})$; right ulna, distal end $(8479-12 \mathrm{~K} / 1 \mathrm{~b})$.

$\mathrm{x}[1-1]$

Right humerus, shaft only (8480-5a).

Anas penelope - widgeon

\section{Gebel Silsila (GS)}

III Surface and Subsurface, Mixed Sebekian and Silsilian - Level 0 [1-2]

Left humerus, proximal half of shaft $(8481-170 / 2 b)$; humeral shaft fragment $(8482-9 \mathrm{~N}-1213)$.

III Sebekian-Level 1 [1-1]

Humeral shaft fragment (8483-180/4).

III Mixed Sebekian and Silsilian - Level 2 [1-2]

Left humerus, proximal end $(8484-13 \mathrm{~J} / 2 \mathrm{~b})$; humeral shaft fragment $(8485$ $13 \mathrm{~J} / 2 \mathrm{~b})$.

Anas acuta - pintail

\section{Gebel Silsila (GS)}

III Surface and Subsurface, Mixed Sebekian and Silsilian - Level 0 [2-9]

Ulnar shaft fragment $(8486-13 \mathrm{~K} / 1 \mathrm{a})$; one left and one right coracoid, humeral ends $(8487-13 \mathrm{~K} / 1 \mathrm{c}$ : $8488-18 / 2$ respectively); right scapula, glenoid end $(8489-17 \mathrm{P} / 1 \mathrm{~b})$; one left and two right humeri, proximal ends (8490-13K/1a-1b: 8491-12L/1: 8492-13J/2b, respectively); two right humeri, distal ends only (8493-14J/1:8494-180/4).

III Sebekian-Level 1 [2-10]

Humeral shaft fragment $(8495-9 \mathrm{~N} / 3 \mathrm{c})$; femoral shaft fragment (8496$13 \mathrm{~J} / 2 \mathrm{~d})$; ulnar shaft fragment $(8497-10 \mathrm{M} / 1 \mathrm{c})$; left coracoid, sternal fragment (8498-9N); left scapula, glenoid end (8499-13J/2e); one left and 
one right humerus, proximal ends $(8500-180 / 4: 8501-10 \mathrm{M} / 1 \mathrm{~d}$ respectively); left humerus, caput only (8502-13J/2e); two right humeri, distal ends only $(8503-10 \mathrm{~N} / 1 \mathrm{bc}: 8504-13 \mathrm{~J} / 2 \mathrm{~b})$.

III Mixed Sebekian and Silsilian-Level 2 [1-2]

Left coracoid, sternal fragment $(8505-9 \mathrm{~N} / 1 \mathrm{~b})$; right coracoid, humeral end $(8506-12 \mathrm{~K} / 1 \mathrm{a})$.

XIII - Sector 2 [1-1]

? Ulnar shaft (8507-2a).

Anas sp. - unidentified duck

\section{Gebel Silsila (GS)}

III Surface and Subsurface, Mixed Sebekian and Silsilian - Level 0 [1-1]

Humeral shaft fragment (8508-180).

III Mixed Sebekian and Silsilian - Level 2 [2-2]

Left humerus, crushed proximal end (8509-15J/1); left caput humeri fragment $(8510-13 \mathrm{~J} / 2 \mathrm{~b})$.

Aythya ferina-pochard

Gebel Silsila (GS)

III Sebekian-Level 1 [1-1]

Right humerus, proximal end $(8511-14 \mathrm{~J} / 3 \mathrm{a})$.

III Mixed Sebekian and Silsilian - Level 2 [1-1]

Right humerus, proximal end (8512-13J/2b).

Plectropterus gambensis - spur-winged goose

Gebel Silsila (GS)

III Surface and Subsurface, Mixed Sebekian and Silsilian - Level 0 [1-1]

Left scapula, glenoid end (8513).

Mergus merganser - goosander

Gebel Silsila (GS)

III Sebekian-Level 1 [1-3]

Left and right coracoids, humeral ends $(8514-14 \mathrm{~K} / 2: 8515-17 \mathrm{O} / 2 \mathrm{~b}$, re-

spectively); left humerus, distal half of shaft (8516-170/2b).

III Mixed Sebekian and Silsilian - Level 2 [1-1]

Right humerus, distal articulation (8517-13J/2b).

Mergus serrator - red-breasted merganser

Gebel Silsila (GS)

III Surface and Subsurface, Mixed Sebekian and Silsilian - Level 0 [1-1]

Right humerus, distal end (8518-12L/1).

III Sebekian-Level 1 [1-2]

Left humerus, distal part of shaft and end (8519-9N).

Mergus albellus - smew

Gebel Silsila (GS)

III Surface and Subsurface, Mixed Sebekian and Silsilian - Level 0 [1-1]

Right coracoid, shaft and sternal end (8520-13K).

III Sebekian-Level 1 [1-2]

Right radius, proximal end $(8521-11 \mathrm{~L} / \mathrm{lb})$; left carpometacarpus, proximal end $(8523-12 \mathrm{~L} / 2)$. 


\section{Milvus migrans - black kite}

\section{Gebel Silsila (GS)}

III Surface and Subsurface, Mixed Sebekian and Silsilian - Level 0 [1-1]

Left humerus, proximal end of shaft (8254-14J/1).

$$
\text { Pandion haliaetus - osprey }
$$

\section{Gebel Silsila (GS)}

\section{Mixed Sebekian and Silsilian - Level 2 [1-1]}

Left pes, digit III, ungual phalanx (8525-13J/2a).

Aquila chrysaëtos - golden eagle

\section{Khor el-Sil (KS)}

III(3) Hearth area [1-1]

Articular end of right sixth rib. costa VI, lacking capitular process (9028).

$$
\text { Grus grus - crane }
$$

Sebil (S)

IV $[1-1]$

Left coracoid, coracoid foraminal region (8526).

Numenius ? arquatus - curlew

\section{Gebel Silsila (GS)}

III Sebekian-Level 1 [1-1]

Left ulna, distal end (8527-9N/2b).

Aves indet. - unidentified birds

\section{Gebel Silsila (GS)}

III Surface and Subsurface, Mixed Sebekian and Silsilian - Level 0 [?-8]

Seven longbone shaft fragments (8528a, b, c, d, e, f, g); one pedal proximal phalanx, proximal end $(8535-14 \mathrm{~J} / 2 \mathrm{a})$.

\section{Sebekian-Level 1 [?-12]}

Eight longbone shaft fragments ( $8636 \mathrm{a}, \mathrm{b}, \mathrm{c}, \mathrm{d}, \mathrm{e}, \mathrm{f}, \mathrm{g}, \mathrm{h})$; three possible radial fragments $(8546 \mathrm{a}, \mathrm{b}, \mathrm{c})$; one possible carpometacarpal II shaft fragment (8547).

\section{Mixed Sebekian and Silsilian - Level 2 [?-10]}

Five longbone shaft fragments $(8548,8549,8550,8551,8552)$; one furcular fragment $(8553-13 \mathrm{~J} / 2 \mathrm{~b})$; one distal half of a pedal proximal phalanx $(8554-13 \mathrm{~J} / 2 \mathrm{~b})$; three vertebral or synsacral fragments $(8555-12 \mathrm{~K} /$ 1a: $8556,8557-13 \mathrm{~J} / 2 \mathrm{~b})$.

\section{XIV [1-1]}

Longbone shaft fragment ( 8558 ).

$\mathrm{XV}[1-1]$

Longbone shaft fragment (8559).

\section{MAMMALIA}

Homo sapiens - man

Oasis Depression (OD) [1-1]

Upper first milk incisor (disintegrated).

\section{Gebel Silsila (GS)}

III Silsilian - Level 3 [1-1]

Left upper first milk incisor, $\mathrm{li}^{1}$ ( $8560-13 \mathrm{~J} / 2 \mathrm{c}$ ). 
Canis sp., either Canis lupaster or C. familiaris -

Egyptian wolf-jackal or domestic dog

Gebel Silsila (GS)

$\mathrm{x}$ [1-1]

Damaged condyle of a right dentary (8561) of a medium-sized canid.

Hyaena hyaena-striped hyaena

Sebil (S)

III $[1-1]$

Isolated nuchal fragment with the lambdoid margin of the sagittal crest (8562).

Lepus capensis - Cape hare

Gebel Silsila (GS)

viI [1-1]

Symphysis and parts of horizontal rami with left $\mathrm{P}_{3}-\mathrm{M}_{3}$ and right $\mathrm{P}_{3}-\mathrm{M}_{1}$ of a mandible (8563).

Sebil (S)

III [1-1]

Horizontal ramus with $\mathrm{P}_{3}-\mathrm{M}_{2}$ of left dentary (8564).

?Nesokia indica - Egyptian bandicoot or pest rat

Khor el-Sil (KS)

II $b$ [1-3]

Right lower incisor (9029): fragment of lower incisor (9030); fragment of ascending ramus of left dentary with base of coronoid (9031).

III $[1-1]$

Fragment of lower incisor (9032).

Equus asinus cf. africanus - Nubian wild ass

Oasis Depression (OD) [1-1]

Right metacarpal II, proximal end (8566).

Gebel Silsila (GS)

I [1-7]

Badly wind-eroded and shattered materials from surface: sacrum, proximal vertebral centrum (8567); right calcaneum (8568); right metatarsal III, posterior surface of proximal portion (8569); distal articulation of metapodial $(8570,8571)$; two ungual phalanges $(8572,8573)$.

$\mathrm{x}[1-1]$

Damaged distal end of right femur (8574).

XI [1-3]

Right upper $\mathrm{M}^{1}$, buccal surface only (8575-2); fragment of buccal surface of $\mathrm{M}^{3}$ (8576-1); wind-eroded half ungual phalanx (8577-5b).

XVII [1-5]

Weathered and shattered specimens: lower incisive and symphysial region of mare (8578-a); deflated axis (8579-a); thoracic vertebra ? x, lacking spine (8580-a); partial distal articulation of right tibia (8581-a); right ectocuneiform (8582-a) that associates with the proximal ends of left metatarsals II and III (8583-a).

Sebil (S)

I [1-1]

Damaged phalanx II (8584-c). 
II [1-3]

Fragment of ectoloph of upper molar (8585-a); distal articulation of right tibia (8586-a); right metatarsal II, lacking distal point (8587-a).

III [1-2]

Buccal surface of right lower ? second premolar (8588-e); distal end of ?metacarpal (8589-c).

VII [1-7]

Right lower or left upper second milk incisor, i 2 (8590-c); left upper second milk premolar, $1 \mathrm{p}^{2}$ (8591-c); right upper third milk premolar, $\mathrm{rp}^{3}$ (8592-c); right upper first molar, $\mathrm{rM}^{1}(8593-\mathrm{c})$; fragment of crown of right lower third molar, $\mathrm{rM}_{3}$ (8594-c); left tibia, medio-distal fragment (8542-b); left astragalus $(8454-\mathrm{a})$.

\title{
Miscellaneous [1-3]
}

Surface collected or of uncertain provenance: right upper third molar, $\mathrm{rM}^{3}$ (8595); left astragalus, deflated (8596); right metatarsal (8597).

\section{Hippopotamus amphibius - hippopotamus}

\section{Oasis Depression (OD) [2-6]}

Partial skull, lacking palatal portions (8598-A); damaged mandible, lacking articular processes and some teeth (8599); juvenile cervical vi vertebra (8600-B); lumbar vertebra, fragment of centrum (8601-C); rib (8602); part of right acetabulum and ischial radius $(8603-\mathrm{C})$.

\section{Bayara (B)}

\section{Area $A$ [1-3]}

Fragment of nasal (8604); weathered left side of centrum of axis (8605); fragment of pubis near symphysis (8606).

\section{Gebel Silsila (GS)}

\author{
III Surface and Subsurface, Mixed Sebekian and Silsilian - Level 0 [1-1] \\ Fragment of tooth $(8522-170 / 1 \mathrm{~b})$. \\ III Sebekian-Level 1 [2-6]
}

Head and shaft fragments of rib (8607-14J/3a: 8608-170/2b); right metacarpals II and IV (8609-170/2b: $8610-18 \mathrm{O} / 4$, respectively); left femur, proximal end (8611-14K/SW 1/4.2); juvenile partial right calcaneum (8612-15J/2).

\section{Mixed Sebekian and Silsilian - Level 2 [1-2]}

Facial region of left maxilla $(8613-16 \mathrm{M})$, separate from but probably associated with the posterior part of the left maxillary shelf and base of the jugal suture with damaged first and second molars, $1 \mathrm{M}^{1-2}$, and alveolus for the fourth premolar, $1 \mathrm{P}^{4}(8614-16 \mathrm{M} / 1 \mathrm{a}-1 \mathrm{~b})$.

$\mathrm{x}[2-4]$

Cranial fragment (8615); juvenile thoracic vertebra ? IV or v, lacking ends of processes (8616); left side of phalanx I, atypical (8565); worn ? juvenile phalanx III (8617).

$\mathrm{XIII}-$ Sector 2 [1-3]

Fragmentary lower left third molar, $\mathrm{IM}_{33}$ (8618); maxillary fragment with alveoli (8619); medial condyle of left femur (8620). XIII - Sector $2 a$ [1-1]

Buccal half of right lower first or second molar, $\mathrm{rM}_{1}$ or $\mathrm{rM}_{2}$ (8621).

XIII - Mound $H$ [1-1]

Fragments of pathological tusk $(8622,8623-\mathrm{H})$. 
$\mathrm{XIV}-\mathrm{XV}[1-1]$

Anterior half of centrum of axis, lacking neural arch and deflated (8624-4). Sebil (S)

I [1-2]

Proximal end of left metatarsal $v(8625-\mathrm{c})$; phalanx I, right manual digit II (8626-c).

III $[1-3]$

Fragments of molar enamel ( $8627,8628-a)$; isolated odontoid peg of axis (8629-a).

IV [2-3]

Cervical vertebra III, neural arch and left prezygapophysis only (8630); juvenile right calcaneum (8631); worn phalanx II (8632).

$\mathrm{v}[2-5]$

Palatal fragment with alveoli (8633-b); distal ends of two left tibiae (8634, 8635 -b) ; right navicula (8636-b); manual phalanx II from digits III or IV (8637).

VI [2-2]

Right lower milk fourth premolar, $\mathrm{rp}_{4}$ (8638); right lower third molar, $\mathrm{rM}_{3}(8639)$.

Miscellaneous, between III and IV [1-2]

Left squamosal region of skull (8640); deflated partial atlas (8641).

Khor el-Sil (KS)

I $a$ [1-1]

Proximoventral fragment of right metacarpal II (9033).

IV $[1-1]$

Fragment of molar enamel (9034).

Miscellaneous (II/III) [2-2]

Fragment of left astragalus (9035); juvenile left tibial diaphysis (9036).

Bos primigenius - wild cattle

Oasis Depression (OD) [4-58]

Partial first molar (8642-C); left upper second molar, 1M² (8643-B); right upper second molar, $\mathrm{rM}^{2}$ (8644-B): damaged right upper second molar, $\mathrm{rM}^{2}$ (8645-A); damaged right upper first molar, $\mathrm{rM}^{1}$, and roots of milk third and fourth premolars, $\mathrm{rp}^{3-4}(8646-\mathrm{G})$, with associated fragments of second molar (8647: 8648-G); left lower second and third molars, $1 \mathbf{M}_{2-3}$ (8649-C); damaged left lower third molar, $1 \mathrm{M}_{3}$, and parts of dentary including condyle ( $8650 \mathrm{a}, \mathrm{b}, \mathrm{c}-\mathrm{C})$; right diastematic fragment (8653-C); horncore fragments (8652-G); occipital condyles and foramen magnum (8655-A); ventral arch of atlas (8656-A); damaged and deflated axis (8657-B); axis lacking neural arch and posterior part of body (8658-B); odontoid and atlanteal facets of axis only (8659-E); separated facets of odontoid and atlanteal facets (8660a, b-C); damaged cervical vertebra III (8662-G); ? juvenile cervical IV, lacking ends of processes (8663-A); cervical III, lacking ends of processes (8664-A); damaged cervical $\mathrm{v}$, lacking processes and most of centrum (8665-A); fragmentary cervical ? III (8666-G); two damaged thoracic vertebrae $(8667,8668$-A); juvenile thoracic ? IV, lacking posterior half (8669-B); lumbar vertebral centrum (8670-A); two right scapular glenoids and necks (8671-A: 8672-C); distal articulation of left humerus (8673-C); medial condylar fragment of right humerus (8674-A); olecranon of right ulna (8675); proximal end of left radius (8676-B); 
proximomedial angle of right radius $(8677-\mathrm{H})$; distal end of left cubitus (8678-A); water-worn partial distal end of left radius (8679-A); distal ends of two metacarpals III and IV (8680-A: 8681-E); greater trochanter of left femur (8682-A); water-worn proximal end of left tibia (8683-A); waterworn distal end of left tibia (8684-C); four left and two right damaged astragali (8685-A: 8686-B: 8687-F: 8688-H: 8689-A: 8690-F, respectively); water-worn left and two right and partial right navicular-cuboids (8691-F: 8692-B: 8693-F: 8694-C, respectively); weathered left navicularcuboid (8695-A); weathered left ectocunieform (8696-F); water-worn distal ends of two metatarsals $(8697,8698-\mathrm{F})$; distal articulation of ? metacarpal (8699-C); entire right side and proximal end of left side phalanges I (8700, 8701-F, respectively); worn left and right side phalanges II (8702, 8703-F, respectively); proximal end of left side and lateral surface of right side phalanges III (8704, 8705-F, respectively).

\section{Bayara (B)}

\section{Area $A$ [1-2]}

A fragment from the middle of a right horncore (8706); lateral half of a right scapular glenoid (8707).

\section{Gebel Silsila (GS)}

I [1-4]

Upper molar tooth fossette (8708); juvenile cervical vertebra vi (8709); juvenile thoracic vertebra? VII (8710); juvenile calcaneum (8711).

II $[1-1]$

An isolated distal fragment of a left lower molar, comprising the hypoconid and part of the metaconid cusps only (9037).

\section{Sebekian - Level 1 [2-15]}

Left upper fourth premolar, $1 \mathrm{P}^{4}(8712-17 \mathrm{O} / 2 \mathrm{~b})$; left upper first molar $1 \mathrm{M}^{1}$ (8713-170/2b), associated with 8712; left upper second molar, $1 \mathrm{M}^{2}$ (8715$9 \mathrm{~A} / 1 \mathrm{~b})$; right upper milk second, third and fourth premolars and first molar, $\mathrm{rp}^{2-4}, \mathrm{M}^{1}(8716-17 \mathrm{O} / 2 \mathrm{~b})$; juvenile horncore fragment $(8717-14 \mathrm{~J} /$ $3 \mathrm{~b})$; condyle, damaged coronoid and angle of right dentary (8718-16J/2); detached coronoid of left dentary $(8719-18 \mathrm{O} / 4)$; damaged thoracic vertebral centrum $(8720-17 \mathrm{O} / 2 \mathrm{~b})$; distal ends of left and right humeri (8721$13 \mathrm{~K} / 2 \mathrm{~d}$ : $8722-14 \mathrm{~K} / 2$, respectively); right unciform $(8723-14 \mathrm{~J} / 3 \mathrm{~b})$; damaged proximal end of right metacarpal $(8724-13 \mathrm{~K} / 2 \mathrm{a})$; fragmentary right ischium (8725-170/Diagonal trench); associated right astragalus, navicular-cuboid, mesectocuneiform, entocuneiform, metatarsal II and proximal end of metatarsals III and IV (8726b, c, d, e, f, a-14K/2); proximal end of left metatarsals III and IV (8727-170/2b); damaged ungual phalanx III (8728-14J/3b).

III Silsilian - Level 3 [1-3]

Right upper second molar, $\mathrm{rM}^{2}$ (8729-12J/1c); left upper third molar, 1M $^{3}$ (8730-9L/1d); right lower third molar, $\mathrm{rM}_{3}$, distal margin of entoconid (8731-11J/1d).

VII [1-3]

Fragments from frontal region of a skull (8732-3); horncore fragment (8733-3); damaged glenoid of right scapula (8734-A3).

IX $[1-1]$

Fragmentary lower left molar (8735-5). 
$\mathrm{x}[1-6]$

Right upper first and second molars, rM ${ }^{1-2}$, newly erupted $(8736,8737$, respectively); damaged right upper third molar, $\mathrm{rM}^{3}$ (8738-3); lower molar fragment (8739-4); left manual cuneiform (8740); phalanx III, proximal fragment (8741).

XIII - Sector 1 [1-2]

Left trapezoid (8742-1); weathered left astragalus (8743-1).

XIII - Sector 2 [1-2]

Juvenile left dentary with $\mathrm{P}_{4}$ and $\mathrm{M}_{1}$, and roots of $\mathrm{P}_{2-3}$, badly weathered (8744-2); two isolated upper molar fossettes and part of a para- or metacone (8745-2).

XIII - Sector 3 [1-1]

The medial condyle of the distal end of a left humerus (8746-3).

XIII - Sector 4 [1-1]

An unworn left upper second molar, $1 \mathrm{M}^{2}$ (8747-4).

XIII - Mound $H$ [1-2]

Cement lakes and lingual surface from a lower left molar $(8748-\mathrm{H})$; left navicular-cuboid, weathered $(8749-\mathrm{H})$.

XIV [2-13]

Right upper third premolar, $\mathrm{rP}^{3}$, mesiobuccal fragment (8751); fragments of worn molar $(8752,8753,8754)$; juvenile cervical vertebral centrum, worn (8755); thoracic or lumbar half central epiphysis (8756); fragment of right scapular glenoid (8757); left humerus, medial condyle (8758); proximomedial corner of right radius (8759); left trapezoid (8760); right manual cuneiform, worn (8761); right astragalus (8762); phalanx II, proximal end (8763).

XIV - XV [1-1]

Lower left third molar, $1 \mathrm{M}_{3}$, lacking the hypoconulid and some of the cementum (8764).

$\mathrm{XV}[1-1]$

Condyle of left dentary (8448).

XVII $[1-3]$

Left dentary with fragmentary $P_{2}-P_{4}$ and damaged $M_{2}$ (8765-a); tooth fragment, probably from 8765 (8767-a); detached caput femoris (8768-a). Miscellaneous [1-3]

Right lower second incisor, $\mathrm{rI}_{2}$ (8981); isolated right upper second molar, $\mathrm{rM}^{2}$ (8750); sacrum, slightly damaged (8769).

\section{Sebil (S)}

I [2-27]

Left upper permanent fourth premolar, $1 \mathrm{P}^{4}$ (8770-c); right upper third molar, $\mathrm{rM}^{3}$, mesial portion (8771-c); right lower third molar, $\mathrm{rM}_{3}$, mesial twothirds (8772-d); upper molar fossette (8773-c); fragment of horncore (8774-d); right humerus medial condyle (8775-d); part of trochlea of left humerus (8776-a); left ulna of olecranon (8777-d); left scaphoid (8778-c); right trapezoid, water-worn (8779-c); metacarpal distal articulations (8780-b: 8781d); left coxa, part of the acetabulum (8782-d); left caput humeri (8783-c); right tibia, distal end (8784-c); damaged right and left astragali (8785: 8786-c); complete and partial right navicular-cuboids (8787-c: 8788-b, respectively); left mesectocunieform (8789-c); left metatarsals III and IV, distal ends (8790-b); metatarsal distal articulations 
(8791-b: 8792-d); phalanges II, right side (8793: 8794-c); ungual phalanges III (8795-b: 8796-d).

II $[2-12]$

Lower right molar fragments, rM? (8797-a); horncore fragment (8799-a); left condyle of dentary (8800-a); thoracic vertebral centrum (8801-a); left scapular glenoid (8802-a); fragment of left scapular glenoid (8803-a); left humerus, proximal end, damaged (8804-a); right humerus, distal articulation (8805-a); right radius, medial angle of distal articulation (8806-a); metapodial distal articulations $(8807,8808-\mathrm{a})$; damaged left astragalus (8809-a).

III $[1-10]$

Left upper fourth premolar, $1 \mathrm{P}^{4}$, damaged (8810-c); left upper second molar, $1 \mathrm{M}^{2}$, damaged, and associated left upper third molar, $1 \mathrm{M}^{3}$, buccal half only (8811: 8812-e, respectively); upper molar fragments (8813-a: 8814-e); lower molar fragments (8815-e); mental foramen and part of symphysis of left dentary $(8816-\mathrm{c})$; right trapezoid, anterior portion (8817-e) ; right astragalus, medial half (8818-e); metapodial distal articulations $(8819,8820-\mathrm{a})$.

IV [1-9]

Upper molar fragments $(8821,8822,8823,8824)$; lower molar fragments $(8825,8826)$; braincase with base of horns (8827); distal end of right tibia (8828); worn left navicular-cuboid (8829).

v [4-30]

Right upper first molar, $\mathrm{rM}^{1}$, damaged (8830); left upper second molar, $\mathrm{IM}^{2}$, distal half only (8831); left lower third and fourth premolars, $\mathbf{I P}_{3-4}$, distal and mesial halves, respectively, left lower first molar, $\mathbf{l M}_{1}$, damaged, and second molar, $1 \mathrm{M}_{2}$, all probably parts of the same mandible (8832, 8833,8834 , respectively); fronto-parietal table and horn bases of a skull (8835-a); partial left horncore (8836-b); right supraorbital region and part of skull roof (8837: 8838); left tympanic bulla (8839-b); nuchal fragment of a skull (8840-b); three symphysial and diastematic fragments of right dentaries (8841: 8842: 8843-b); premolar alveolar region of a left dentary (8844-b); two right mandibular condyles (8845: 8846-b); left mandibular condyle (8847-b); condyle with coronoid (8848-b); cervical vertebra IV, juvenile and weathered (8849-b), and vI, lacking neural arch (8850-b), both lacking neural transverse and ventral processes; left scapular glenoid (8851-b); right metacarpal, distal end (8852-b); ' right trapezoid (8853-b); calcar of right calcaneum (8854-b); left astragalus, damaged (8855-b); left and right navicular-cuboids, weathered (8856: 8857-b, respectively); right metatarsal, distal end (8858-b); juvenile metapodial shaft (8859-b); two ungual phalanges III, left side, damaged (8860: 8861-b).

VI $[1-1]$

Left dentary fragment with second and fourth premolars, first molar and roots of third premolar (8862).

vII $[1-7]$

Left upper second premolar, $1 \mathrm{P}^{2}$ (8863-b); metacone and distal fossette of an upper left molar (8864-a); buccal surface of protoconid of left lower third molar, $1 \mathrm{M}_{2}$ (8865-a); right lower second incisor, $\mathrm{rI}_{2}$ (8866-c); right lunar (8867-c); left and right navicular-cuboids (8868, 8869-a, respectively). 


\section{Miscellaneous [1-10]}

Includes material collected from the surface between localities Sebil III.c and IV but not included in either samples. Right upper first molar, $\mathrm{rM}^{1}$ (8872); upper molar fossettes (8873); three horncore fragments (8874, $8875,8876)$; coronoid and condyle of left dentary (8877); axis, lacking neural crest and transverse processes $(8878)$; body of cervical vertebra (8879); scapular glenoid, ? juvenile (8880); right astragalus, weathered (8881).

Khor el-Sil (KS)

II $a$ [1-1]

Fragment of horncore (9038).

II $b[1-1]$

Fragment of crown of right lower molar with protoconid and paraconid (9039).

III(2) $[1-1]$

Enamel fragment, buccal surface of upper molar (9040-2).

IV $[1-2]$

Two molar fragments $(9041,9042)$.

Miscellaneous (II/III) [1-3]

Cement lake of upper molar (9043) ; right astragalus, distomedial fragment (9044); fragment of trapezoid (9045).

? Homoioceras vignardi - long-horned African buffalo

Oasis Depression (OD)

Area $A$ [1-1]

Left astragalus (8290).

\section{Alcelaphus buselaphus - bubal hartebeest}

Oasis Depression (OD) [2-27]

Water-worn frontlet (8882-A); damaged left horncore (8883-C); base of left horncore (8884-A); water-worn fragments of horncore $(8885,8886-\mathrm{C}$ : $8887-G)$ : incisive region and symphysis of mandible with all incisors and canines damaged and newly erupting (8888-G); lower jaw and tooth fragment (8889-A); right side and ventral arch of damaged atlas (8890-A); water-worn cervical III lacking right proximal part of arch $(8766-\mathrm{H})$; damaged cervical vertebra IV $(8870-\mathrm{C})$; damaged cervical ?v, posterior parts only (8871); damaged thoracic vertebra (8891-E); right side of thoracic vertebra (8892-A); left scapular glenoid and neck fragment (8893-A); right humerus, damaged distal end (8894-C); right radius, proximal end (8895-A); right metacarpals III and IV, shaft and proximal end (8896-G) ; right metacarpals III and IV, damaged proximal end (8897C); two right and one left distal ends of metacarpals III and IV (8898, 8899-A : 8900-G respectively); deflated distal end of left femur (8901-A); one left and two right astragali (8902-E: 8903-A: 8216-C, respectively); ? left metatarsals III and IV, damaged distal end (8904-A).

Bayara (B)

Area $A$ [2-3]

Fragment of left horncore (8905); juvenile left dentary with erupting third molar, $1 \mathbf{M}_{3}$ (8906); left astragalus, medial half (8907). 
I [1-3]

Damaged right side of basioccipital-basisphenoid and condyle (8908); left scapular glenoid and neck (8909); metatarsals III and IV, proximo-posterior angle (8910).

III Surface and Subsurface, Mixed Sebekian and Silsilian - Level 0 [2-20]

Distal part of left horncore (8911-14J/SW 1/4.2b); horncore tip (8912$14 \mathrm{~J} / 2 \mathrm{a})$; right occipital condyle (8913-13K); right upper third molar, $\mathrm{rM}^{3}$ (8914-13K/1c); damaged symphysial region (8915-21L); damaged unworn left lower third molar, $1 \mathrm{M}_{3}(8916-14 \mathrm{~K} / 1 \mathrm{f})$; cervical vertebra ? VII, damaged $(8917-13 \mathrm{~K} / 1 \mathrm{c})$; thoracic vertebral centrum $(8918-14 \mathrm{~K} / 1 \mathrm{e})$; two partial thoracic vertebral centra $(8919-14 \mathrm{~K} / 1 \mathrm{e}: 8920)$; left trapezoid $(8921$ $16 \mathrm{O})$; proximal end fragment of right metacarpals III and IV (8922-14J/2a); distal end fragment of right metacarpals III and IV (8923-23J; left femur, juvenile, distal end of diaphysis $(8924-14 \mathrm{~K} / 1 \mathrm{e})$; left calcaneum, maleolar and navicular process $(8925-21 \mathrm{~L})$; right metatarsals III and IV, proximal end (8926-14J/3b); proximal and distal fragments of phalanges I (8927-21 K: $8928-14 \mathrm{~J} / 2 \mathrm{a})$; juvenile right side phalanx II, lacking the proximal epiphysis (8929-14K/1f); distal articulation left side phalanx II (8930-19M).

III Sebekian-Level 1 [7-122]

Pair of horncores and frontal regions posterior to orbits (8931-17O/2a); damaged pair of horncores and frontal region (8932-16M/1a-1b); right horncore (8933-180/4); crushed right horncore (8934-14J/1); left horncore base (8935-14J/3a.1); left horncore tip (8936-16J/2); left upper second, third and fourth premolars, $1 \mathrm{P}^{2-4}$, in maxillary fragment (8937$9 \mathrm{~N} / 2 \mathrm{~b}$ ) ; right upper fourth premolar and first molar in maxillary fragment $(8938-170 / 2 b)$; right upper milk third and fourth premolars and partial first molar, $\mathrm{rp}^{3-4}, \mathrm{M}^{1}$, in maxillary fragment (8939-14O/3a); right upper milk fourth premolar and first, second and erupting third molars, $\mathrm{rp}^{4}, \mathrm{M}^{1-3}$, in maxillary fragment $(8940-14 \mathrm{~K} / 2)$; damaged right upper milk third premolar, $\mathrm{rp}^{3}$ (8941-14J/3a); right upper fourth premolar, $\mathrm{rP}^{4}$ (8942-10M/ $1 \mathrm{j})$; right upper first molar, $\mathrm{rM}^{1}(8943-13 \mathrm{~K} / 2 \mathrm{~g})$; damaged right upper first molar, $\mathrm{rM}^{1}$ (8944-13K/3); left upper second molar, $1 \mathrm{M}^{2}$ (8945-14J/ $3 \mathrm{c})$; right upper second molar, $\mathrm{rM}^{2}(8946-13 \mathrm{~K} / 2 \mathrm{a})$; unworn right upper third molar, $\mathrm{rM}^{3}$ (8947-140); associated incisive region, part of ventral margin of right dentary and remains of second and third molars, $\mathrm{rM}_{2-3}$ (8948-14K-17O/2b); damaged right lower first molar $\mathrm{rM}_{1}(8949-11 \mathrm{~L} / 1 \mathrm{~b})$; left lower second molar, $1 \mathrm{M}_{2}$, newly worn $(8950-13 \mathrm{~J} / 2 \mathrm{a})$; left lower third molar, $1 \mathbf{M}_{3}$ (8951); lower molar fragment, possibly part of 8948 (8952$14 \mathrm{~K}-17 \mathrm{O} / 2 \mathrm{~b})$; restored axis $(8953-16 \mathrm{M} / 2 \mathrm{~b})$; body of axis $(8954-13 \mathrm{~K} / 2 \mathrm{~b})$; damaged juvenile axis, lacking posterior central epiphysis (8955-14J/3b); cervical ? III, lacking transverse processes (8956-14J/3a); cervical ? IV, subadult $(8957-13 \mathrm{~K} / 3)$; cervical ? vI, damaged $(8958-13 \mathrm{~K} / 3 \mathrm{c})$; cervical ? VII, juvenile (8959-13K/3); damaged body of cervical ? III (8960-9N/2b); six partial thoracic vertebral centra (8961-14I.J: $8962-14 \mathrm{~J} / 3 \mathrm{~b}: 8963-9 \mathrm{~N} /$ 3a: 8964-13J/2d: 8965-13K/2b: 8966-14K); lumbar vertebral spine (896714I.J); damaged caudal vertebra (8968-13K/2b); rib shaft (8969-14J); right scapular glenoid and neck $(8970-170 / 2 b)$; juvenile left scapular glenoid $(8971-14 \mathrm{~K} / 2 \mathrm{~b})$; distal ends of two left and two right humeri ( 8972 , 8973-14J/3a: 8974-14J/3a: 8975-180/4, respectively); right radius, proximal end (8976-170/2b); right radius, juvenile, distal end (8977-14J/3a); left radius, juvenile, distal end of diaphysis $(8978-170 / 2 b)$; left and right 
ulnar olecrana (8979-14K/2: 8980-170/2b), latter articulates with 8976 ; right scaphoid (8982-15J/2); medial face of left scaphoid (8983-14K-17O/ $2 \mathrm{~b})$; left lunar (8984-14J/3b); two entire and lateral half of a third trapezoid $(8985-13 \mathrm{~K} / 2 \mathrm{a}: 8986-14 \mathrm{I}: 8987-14 \mathrm{~J} / 3 \mathrm{a}$, respectively); two right trapezoids $(8988-13 \mathrm{~K} / 2 \mathrm{~b}: 8989-13 \mathrm{~K} / 3)$; right and pathologic left unciforms (8990-17O/2b: 8991-13K/1c); juvenile right metacarpals III and IV, proximal end only, and associated trapezoid $(8992-14 \mathrm{~K} / 2)$; right metacarpals III, IV and v (8993-13K/3); two left metacarpals III and IV, proximal ends (8994-11 M/2.3: 8995-17O/2b); right metacarpals III and IV, proximal half and associated right metacarpal $\mathrm{v}(8996,8281-17 \mathrm{O} / 2 \mathrm{~b})$; right metacarpals III and IV, distal end (8997-10N/1b.c); metacarpals III and IV, waterworn distal end (8998-14K-170/2b); half distal end of metacarpal (8999$13 \mathrm{~K} / 2 \mathrm{e})$; right metacarpals III and IV, juvenile, distal ends of diaphyses (9000-180/4); medial condyle of left femur (8256-15J/2); four damaged left astragali (8257-13J/2d: 8258-14J/3a: 8259-14K/2: 8260-17O/2b); one damaged and one partial right astragalus $(8261-13 \mathrm{~K} / 2 \mathrm{a}: 8262-13 \mathrm{~K} /$ $2 \mathrm{~h}$, respectively); right calcaneum $(8263-18 \mathrm{O} / 4)$; sustentacular process of right calcaneum (8264-170/1b); one adult, one subadult, without an ossified tuber calcis, and one juvenile left calcaneum $(8265-13 \mathrm{~K} / 2 \mathrm{c}: 8266$ 170/2b: $8267-14 \mathrm{~J} / 3 \mathrm{~b}$, respectively); one adult and one juvenile left navicular-cuboid $(8268-14 \mathrm{~K} / 2: 8269-14 \mathrm{~J} / 3 \mathrm{ab}$, respectively); two right navicular-cuboids $(8270,8271-170 / 2 b)$; one right navicular-cuboid with attached mesectocuneiform and entocuneiform (8272-18O/4); left mesectocuneiform and entocuneiform (8273-170/2b), associated with 8271; right metatarsal III and IV, three damaged proximal ends and one proximomedial fragment $(8543-14 \mathrm{~J} / 3 \mathrm{~b}: 8544-14 \mathrm{~K}: 8274-17 \mathrm{O} / 2 \mathrm{~b}: 8275-14 \mathrm{~K}$, respectively); left metatarsals III and IV, three proximal ends and one proximoanterior fragment $(8276-17 \mathrm{O} / 2 \mathrm{~b}: 8277,8278,8279-18 \mathrm{O} / 4$, respectively); proximal end of left metatarsals III and IV $(8280-17 \mathrm{O} / 2 \mathrm{~b})$; distal ends of one left and one right metatarsal III and IV $(8282-14 \mathrm{~K} / 2: 8283-18 \mathrm{O} / 4$, respectively); two juvenile right shafts with associated, but unfused, distal articulations $(8284-11 \mathrm{M} / 2-3: 8285-13 \mathrm{~K} / 2 \mathrm{a})$; one juvenile distal end of diaphyses III and IV (8286-14K); three left side and two right side detached distal epiphyses of metatarsals (8287-11M/2-3: 8288-14I: 8289-14J/1: 8291-13K/2a: 8292-14J/3a); left side ? manual phalanx I (8293-9N/3a); and distal end of left side phalanx I $(8294-170 / 2 b)$; restored and volar surface of right and left ? pedal phalanges I (8295-14J/3a: 8296-18O/2b, respectively); proximal ends of four right side phalanges I $(8297-14 \mathrm{~K} / 2$ : 8298-14K: 8299-15J/2: 8300-17O/2b); distal end of phalanx I (8301$17 \mathrm{O} / 2 \mathrm{~b})$; two entire and proximal end of right side phalanges II $(8302-12 \mathrm{~L} /$ 2: 8303-15J/2: 8304-14J/3a, respectively); juvenile left side phalanx II, lacking proximal epiphysis $(8305-14 \mathrm{~J} / 3 \mathrm{a})$; one adult and one juvenile right side phalanx III (8306-14K: 8307-13K, respectively); one juvenile and the proximal ends of two left side phalanges III $(8308-14 \mathrm{~J} / 3 \mathrm{a}: 8309-17 \mathrm{O} / 2 \mathrm{~b}$ : 8310-14K-17O, respectively); proximal volar sesamoid (8311-13J/2d). 
III Mixed Sebekian and Silsilian - Level 2 [3-19]

Detached left and right horncores and damaged frontal areas $(8312 \mathrm{a}, \mathrm{b}-$ $16 \mathrm{M})$; right horncore base and two parietal fragments (8313a, b, c-16M/ $1 \mathrm{a}-1 \mathrm{~b})$; damaged juvenile right horncore $(8314-16 \mathrm{M})$; right horncore tip (8315-16M/ Diagonal trench); two horncore fragments (8316a, b-16M); parietal fragments $(8317-16 \mathrm{M} / 1 \mathrm{a}-1 \mathrm{~b})$; damaged left upper first molar, $1 \mathrm{M}^{1}$ (8318-9N/1b); damaged right upper third molar, $\mathrm{rM}^{3}$ (8319-12I/1a); lower molar fragment $(8320-12 \mathrm{~K} / 1 \mathrm{~b})$; two fragments of atlanteal facets of atlas (8321-18P/1); right scapular neck fragment (8322-14I/2a); patella (8323-14I/2a); tibia, juvenile, water-worn proximal epiphysis (8324-15J/ 1 ); juvenile left side phalanx I, lacking proximal epiphysis (8325-13J/2a); proximal end of fusing diaphysis and proximal epiphysis of left side phalanx I ( $8326-13 \mathrm{~J} / 2 \mathrm{~b})$; diaphysis and free proximal epiphysis of left side ? manual phalanx I (8327-13J/2b); juvenile right side phalanx II (8327-13J/2b); juvenile right side phalanx II, lacking proximal epiphysis $(8328-13 \mathrm{~J} / 2 \mathrm{~b})$.

III Silsilian-Level 3 [1-4]

Damaged ? right upper molar (8329-13J/3a); left lower second molar, $1 \mathbf{M}_{2}$ (8330-12J/1c); fragment of lower third molar, $\mathrm{M}_{3}$ (8331-12J/1c); right metacarpals III and IV, distal end (8332-12I/1d).

$\mathrm{v}[1-2]$

Right tibia, medial malleolar fragment (8333-2); deflated distal end of metatarsal (8334-2).

VII $[1-6]$

Right lower molar, mesial fragment (8335-A3); cervical vertebra ? III, right lamina only (8336); cervical vertebra ? v, lacking neural spine and left process (8337); damaged right scapular glenoid (8338-A3); femoral shaft fragment ( 8339 ); proximal end of right side phalanx I ( 8340 ).

IX $[1-2]$

Damaged left astragalus (8341-3); metapodial distal articulation (8342-E). $\mathrm{x}$ [2-7]

Right upper second molar, $\mathrm{rM}^{2}$, distal half (8343-5a); right upper first or second molar, $\mathrm{rM}^{1}$ or $\mathrm{M}^{2}$, base only (8344-5a); unworn left lower fourth premolar, $1 \mathbf{P}_{4}$ (8345-3); left lower third molar, $1 \mathbf{M}_{3}$, fragment (8346-5a); cervical vertebral body (8347); juvenile metapodial diaphysis (8348); phalanx I fragment (8349).

XIII - Sector 2 [1-1]

Posterior margin of right dentary (8350).

XIII - Sector $4 a[1-1]$

Left scapula fragment, anterior glenoid margin (8351).

XIV $[1-2]$

Isolated upper molar lakes $(8352,8353)$.

$\mathrm{XV}[1-3]$

Upper molar fragments $(8354,8355)$; distal shaft and articulations of right

? metacarpal (8356); left pubic acetabular fragment (8357).

XVII [1-2]

Right scapular glenoid fragment (8358-a); metapodial distal articulation (8359a, b-a) .

Miscellaneous [1-3]

Two horncore fragments $(8360,8361)$; left humerus, damaged distal articulation (8362-3). 
I [2-23]

Right horncore fragment (8363-c); water-worn left maxillary fragment with remains of second and third molars, $1 \mathrm{M}^{2-3}$ (8364-b); damaged right upper first or second molar, $\mathrm{rM}^{1}$ or $\mathrm{M}^{2}$ (8365-a) ; right lower second molar, $\mathrm{rM}_{2}$ (8366-c) ; lower molar fossette (8545-c); atlas, nearly complete (8367c); axis, worn body only (8368-b); cervical vertebra, ? VI, arch and anterior centrum only (8369-c); thoracic vertebra ? VI (8370-c); damaged lumbar vertebral arch and centrum $(8371-c)$; proximal and distal ends of subadult left humerus (8372a, b-b, respectively); distal articulation of right humerus (8373-c); proximal end of left metacarpals III and IV (8374-b); distal end of metacarpals III and IV (8375-c); damaged left calcaneum (8376-c); deflated right astragalus (8243-c); left and right navicular-cuboids (8377, 8378-c, respectively); proximal end of right side phalanx I (8379-c); right side phalanX II (8380-a); two damaged left side phalanges III $(8381,8382-\mathrm{c})$.

II $[2-8]$

Right upper first molar, rM$^{1}$ (8383-a); damaged atlas (8384-a); two left scapular glenoids $(8385,8386-a)$; distal articulation of left humerus (8387-a); distal ends of left and right metacarpals III and IV $(8388,8389-a$, respectively); distal end of left tibia (8390-a).

III $[1-14]$

Right upper third premolar, $\mathrm{rP}^{3}$ (8391-e); left upper third molar, $1 \mathrm{M}^{3}$ (8392-e) ; upper molar fragment (8393-e) ; lower molar fragment (8394-e); odontoid and atlanteal facets of left humerus (8395-c); distal articulation of left humerus (8396-e); right caput femoris (8397-e); left navicularcuboid, lacking proximo-posterior areas $(8245-\mathrm{a})$; tooth fragments $(8398$, 8399, 8400, 8401, 8402: 8403-e).

IV [1-1]

Left tibia, proximal end (8404).

v [3-13]

Horncore fragment (8405-b); diastematic region of left dentary (8406-b); distal half of upper molar (8407); damaged axis (8408-b); odontoid and atlanteal facets of axis (8409-b); right trapezoid (8529); right metacarpals III and IV, proximal end (8530-b); distal ends of left and right metacarpals III and IV (8531, 8532-b, respectively); left astragalus (8533-b); right side phalanx I, proximal end (8534); ? juvenile left ilium (8537); juvenile femur, distal end (8538).

VI $[1-2]$

Atlas (8539); right navicular-cuboid (8255).

vII $[1-2]$

Axis, lacking neural arch (8540-a); right caput femoris (8541-a).

Khor el-Sil (KS)

II $b[1-1]$

Left upper fourth milk prémolar, $\mathrm{lp}^{4}$, damaged on lingual surface (9046) III $(2)[1-2]$

Two molar fragments $(9047,9048)$.

III(3) [1-1]

Fragment of scapular blade (9049).

IV [1-2]

Right ulna, olecranon and processus anconaeus (9050); left radius, proximomedial fragment (9051). 
Miscellaneous (II/III) [1-7]

Right upper second molar, $\mathrm{rM}^{2}$, damaged (9052a, b); lower right first molar, $\mathrm{rM}_{1}$, in jaw fragment (9053); lower right second or third molar, $\mathrm{rM}_{2}$ or $\mathbf{M}_{3}$, mesial half only (9054); left dentary, diastematic region (9055); left and right scapular glenoids (9056: 9057, respectively); waterworn condyle of right dentary (9058).

\section{Gazella dorcas - Dorcas gazelle}

\section{Gebel Silsila (GS)}

II [1-1]

Fragment of cervical vertebra v or VI, right posterior part of centrum and lamella only (9059).

III Surface and Subsurface, Mixed Sebekian and Silsilian - Level 0 [1-4]

Head of rib and part of a shaft $(8217-13 \mathrm{~K} / 1 \mathrm{a}-1 \mathrm{~b})$; ?juvenile left scapular glenoid and neck $(8218-13 \mathrm{~K} / 1 \mathrm{a}-1 \mathrm{~b})$; right metatarsals, proximal end (8219-12L/1); left metatarsals III and IV, shaft and distal end (8220-14K/ $1 \mathrm{e})$.

III Sebekian - Level 1 [1-7]

Female right horncore, lacking tip (8221-14J/SW 1/4); female left horncore, lacking tip (8222-11M/2-3); axis vertebra, neural arch and left atlanteal facet (8223-14K-17O/2b); associated left metacarpals III and IV, distal end only, and both phalanges I, proximal ends only $(8224,8225$ $18 \mathrm{O} / 4$, respectively); right metacarpals III and IV, distal end (8226-17O/2b); left femur, medial condyle (8227-13J/2d); right metatarsal, shaft fragment (8228-170/2b).

III Silsilian - Level 3 [1-1]

Male right horncore, basal fragment $(8229-9 \mathrm{~L} / 1 \mathrm{~d})$.

IX [1-1]

Right upper fourth premolar and first molar, $\mathrm{rP}^{4}-\mathrm{M}^{1}$, in maxillary fragment (8230-5).

$\mathrm{x}[1-1]$

Right scapula, lacking vertebral areas (8231).

XIV [1-3]

Parts of a single male skull: horncore bases and basal fragment of right horncore (8232a); basioccipital-basisphenoid (8232b); left occipital condyle $(8232 \mathrm{c})$.

XVIII $[1-1]$

Left metatarsals III and IV, proximoposterior portion (8235).

Miscellaneous [1-1]

Male left horn base and supraorbital region (8236-2).

Sebil (S)

I [2-7]

Damaged male cranium and right horncore $(8237-a)$; weathered male left horncore (8238-c); left occipital condyle and nuchal area (8239-c); left humerus, distal end (8240-a); detached juvenile left radial epiphysis (8241-c); right tibia, distal end (8242-c); left side phalanx I (8244-b).

$\mathrm{v}[3-9]$

Male left horncore (8246-b); male left horn base $(8247-b)$; male right horncore, base and tip $(8248,8249-b$, respectively $)$; fragmentary male frontlet with horn bases $(8250-b)$; female parietal and right frontal areas with right horn base (8251-b); left upper second molar, $1 \mathrm{M}^{2}$ (8252); right upper third 
molar, $\mathrm{rM}^{3}$ (8253); cervical vertebra ? IV, centrum and left side of lamina (8254-b).

Khor el-Sil (KS)

II $a$ [1-3]

Right dentary, fragments of coronoid, condyle and angle (9060); proximal fragment of metacarpals III and IV (9061); left tibia, distal malleolar fragment (9062).

II $b[1-1]$

Left first lower incisor, $1 \mathrm{II}_{1}$ (9063).

Miscellaneous (II/III) [1-2]

Left scapular, lacking inferior and vertebral areas (9064); right acetabular fragment of ischium (9065).

? Gazella leptoceros - white gazelle or rhim

Gebel Silsila (GS)

III Surface and Subsurface, Mixed Sebekian and Silsilian - Level 0 [1-1]

A single left horncore, lacking tip and with an almost straight axis (8233$16 \mathrm{M} /$ Diagonal trench).

Ammotragus lervia - Barbary sheep

Oasis Depression (OD) [1-1]

Damaged frontlet with the base of both horncores (8234-A). 



